




\section{L'Égypte d'aujourd'hui}





\section{L'Égypte}

\section{d'aujourd'hui}

SON AGRICULTURE

SON ÉTAT ÉCONOMIQUE ET POLITIQUE

SES RESSOURCES FINANCIĖRES

SA FORTUNE IMMOBILIÉRE

ET SA DETTE HYPOTHÉCAIRE

P A R

le Comte CRESSATY

PARIS

LIBRAIRIE DES SGIENGES POLITIQUES ET SOGIALES

MARCEL RIVIËRE ET Cie

31, RUE JACOB, ET 1, RUE SAINT-BENOIT

1912 


$$
\text { P. }
$$$$
\rightarrow, i,
$$

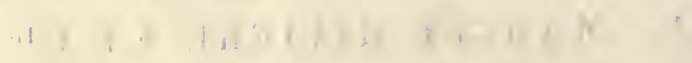$$
+4, \cdots, \cdots, \cdots
$$$$
-1114
$$ 


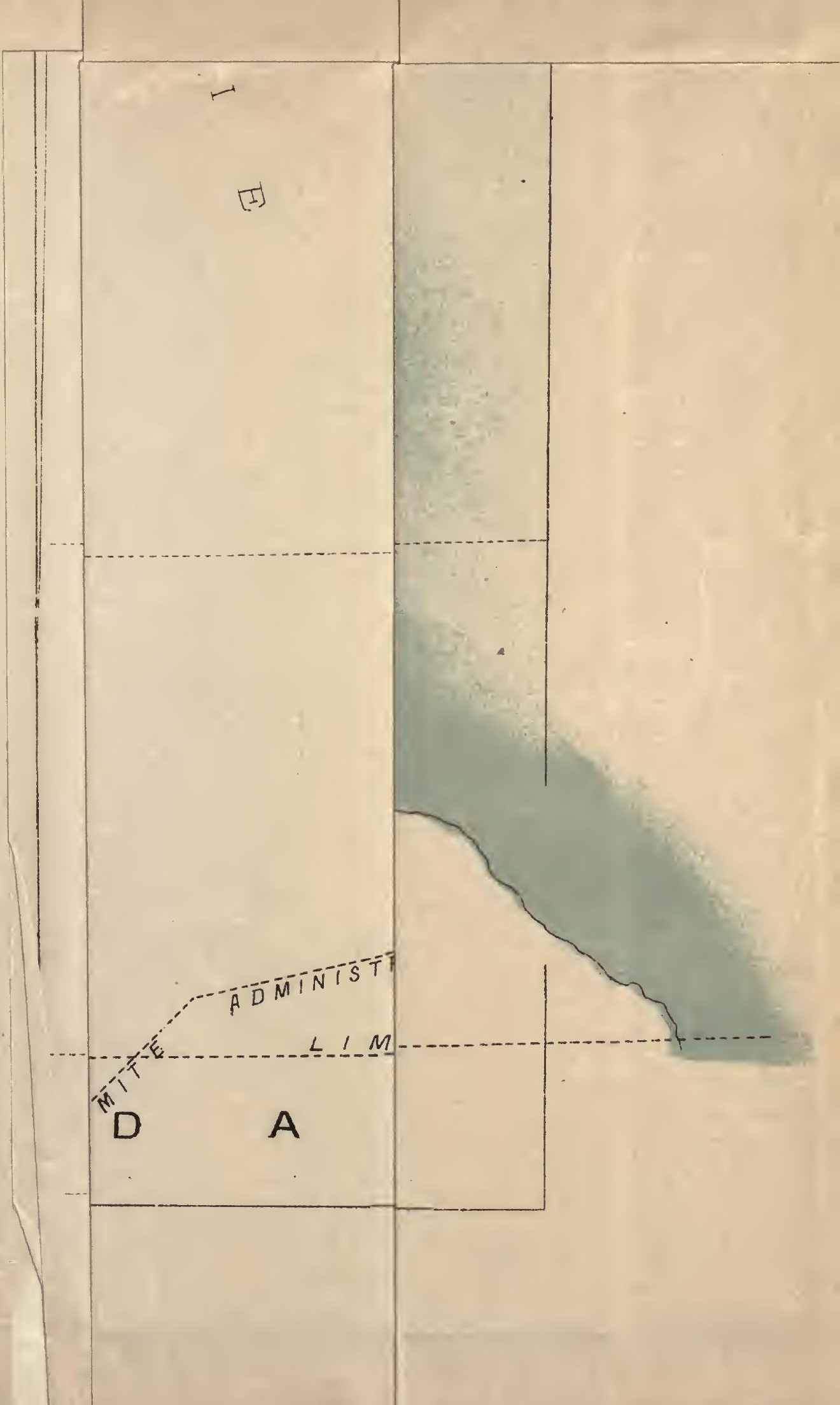





\section{INTRODUCTION}

L'importance considérable des capitaux français qui, depuis quelques années, ont afflué en Egypte ${ }^{1}$, le vaste mouvement d'affaires qui s'est manifesté dans cet admirable pays, les discussions passionnées que la récente crise égyptienne a provoquées et dont on peut, aujourd'hui encore, percevoir les échos d'ailleurs bien affaiblis, les bruits tendancieux dus à des calculs intéressés ou aux suggestions de l'ignorance, les inévitables déformations que subissent trop souvent, dans les esprits, les choses lointaines, tout cela nous a engagé à publier cette Etude, qui, sous une forme très succincte mais aussi complète que possible, est destinée à faire apparaître sous son véritable jour, dans son entière réalité, la situation économique et financière de l'Égypte.

Dans ce travail, nous nous sommes attaché à ne rien

1. L'Égypte occupe le second rang, après la Russie, parmi les débiteurs de notre épargne nationale; toutefois, il est bon de faire observer qu'en Russie les capitaux français sont allés, en majeure partie, à des emprunts d'État, tandis qu'en Egypte ils ont apporté principalement leur concours au développement du commerce et de l'agriculture. A ce point de vue, l'Égypte occupe le premier rang. 
laisser à la fantaisie; nos renseignements, nous les avons puisés à des sources d'une autorité indiscutable; nos chiffres, dont il est facile de contrôler l'exactitude, nous les avons demandés aux statistiques officielles. A défaut d'autres mérites, ces quelques pages ont du moins celui d'une parfaite sincérité.

Nous serions heureux si elles pouvaient contribuer à mieux faire connaître ce beau pays d'Égypte, à mettre en pleine lumière ses ressources, sa prospérité présente et celle qu'il est permis d'attendre d'un avenir prochain, et à servir ainsi, dans une mesure appréciable, les intérêts de l'influence et de l'épargne françaises sur la terre des Pharaons. 
Planche II

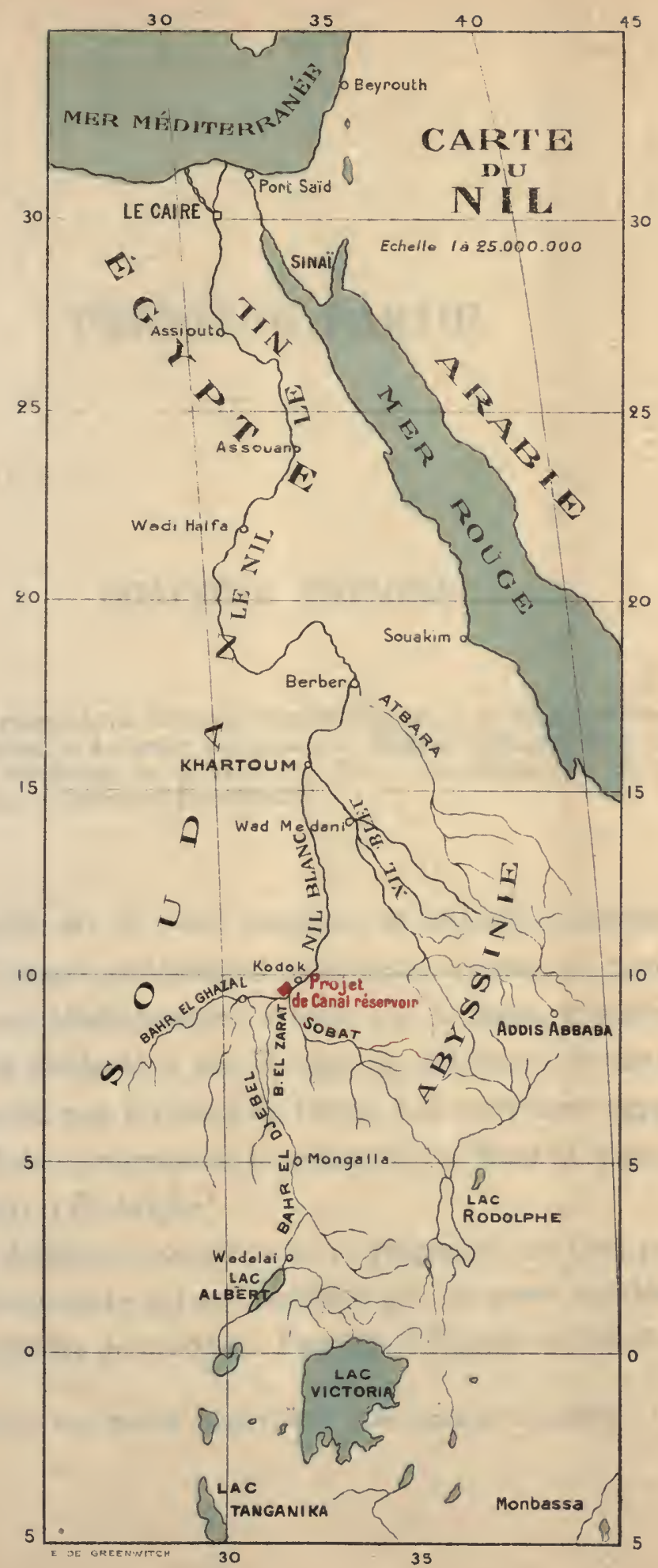




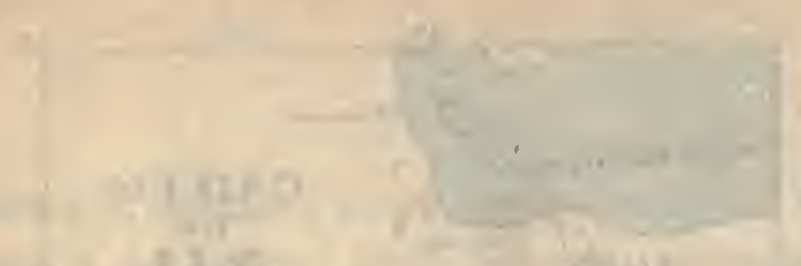

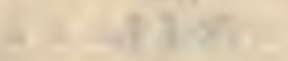

A 415 1

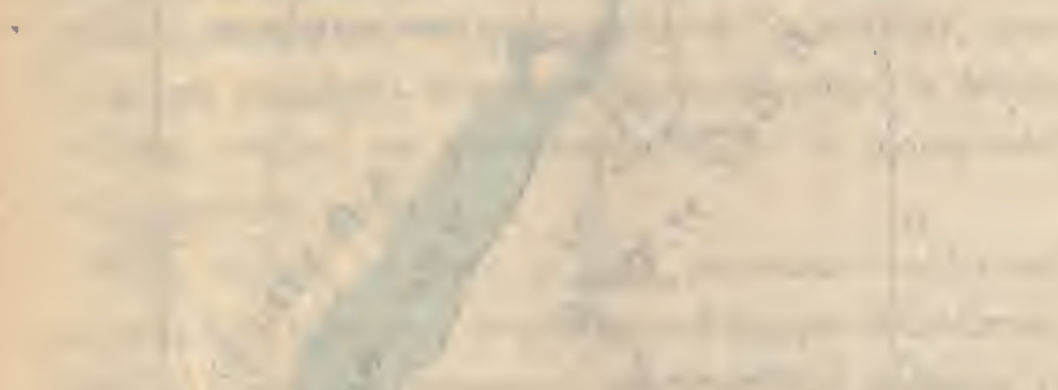

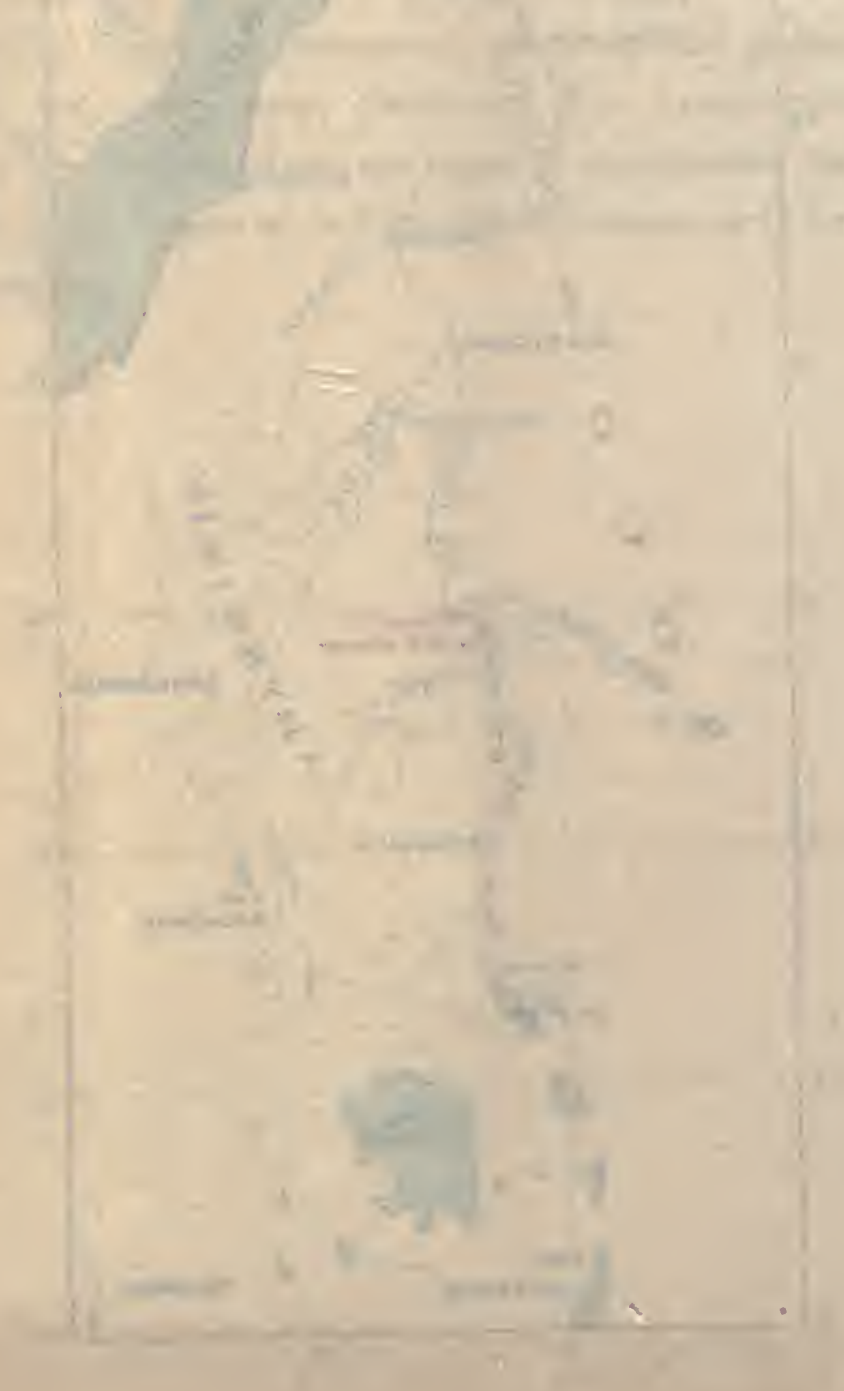




\section{PREMIÈRE PARTIE}

\section{CHAPITRE PREMIER}

Définition géographique et économique de l'Égypte. - Le Nil, ses origines, sa formation. - La crue; ses causes. - Régime hydrographique du Nil. - Formation de la vallée du Nil. - Constitution du sol; sa fécondité. - Travaux hydrauliques.

L'Égypte est un vaste territoire de 930.000 kilomètres carrés presque entièrement désertique, borné, au nord, par la mer Méditerranée; à l'est, par la Syrie, l'Arabie, le golfe d'Akaba et la mer Rouge; au sud, par le Soudan, et à l'ouest, par le désert de Lybie. Les territoires égyptiens d'Asie comprennent la péninsule du Sinaĩ et le gouvernement d'El-Ariche ${ }^{1}$.

Cette définition, exacte pour le géographe, ne l'est pas pour l'économiste qui ne considère que les terres habitées et susceptibles de produire. Pour lui, l'Égypte se réduit à 
la vallée du Nil et compte seulement 33.595 kilomètres carrés; "étroite bande de terre d'alluvion, longue comme la tige filiforme d'une plante que couronnerait la fleur à demi épanouie du Delta, elle n'est que le lit et l'estuaire $\mathrm{du} \mathrm{Nil}{ }^{1}$ ».

"L'Égypte moderne mesure environ 1.000 milles d'Alexandrie à Ouadi-Halfa. Sa largeur, de Port-Saïd à Alexandrie, est d'environ 200 milles. Le sommet du Delta du Nil se trouve un peu au nord du Caire. Au sud de ce point, le pays habitable se rétrécit rapidement et se trouve par endroits réduit à quelques mètres sur chaque rive du fleuve ${ }^{2}$ ).

On sait le rôle du Nil en Egypte et, depuis longtemps, il est devenu banal d'en vanter les bienfaits. Il est difficile, cependant, de n'en point parler si l'on veut mettre en lumière les ressources exceptionnelles de cette merveilleuse contrée qui doit tout au fleuve qui la vivifie.

Jusqu'en ces derniers temps, les sources du Nil étaient entourées d'un impénétrable mystère. Les anciens Égyptiens ne pouvant concevoir, à la fois, la sécheresse presque absolue de leur climat et le débit formidable du fleuve en temps de crue, lui avaient assigné le ciel pour origine. Cette opinion nous est révélée par leurs bas-reliefs et leurs papyrus.

Aujjourd'hui, ce mystère est presque entièrement

1. P. Arminjon, La Situation économique de l'Égypte (1911), p. 2.

2. Lord Cromer, Modern Egypt, II, p. 126. 
dissipé, et, sauf une région restreinte mal connue encore, tout le bassin du Nil a été exploré. Sa surface est évaluée à 2 millions 803.000 kilomètres carrés, la longueur du fleuve à 5.592 kilomètres, depuis la chute du Ripou, au sortir du lac Victoria-Nyanza, jusqu'à la Méditerranée, à l'embouchure de la branche de Rosette (planche II). Avant les hardis voyageurs Livingstone et Stanley, on savait qu'à la hauteur de Khartoum, capitale du Soudan égyptien, le Nil se partage en deux branches : le Nil Blanc, venu des régions équatoriales, et le Nil Bleu, descendu des hauteurs d'Abyssinie et apportant les crues habituelles. On savait aussi qu'à 365 kilomètres, en aval de Khartoum, se jette une rivière, l'Atbara, qui descend également des monts abyssins.

Depuis, de nombreux explorateurs ont parcouru en tous sens les pays traversés par le Nil ou par ses affluents ; les résultats de leurs recherches ont été réunis par le capitaine Lyons, ex-directeur du Département égyptien de l'Arpentage, dans un livre, The Physiography of the river $\mathrm{Nil}$ and its basin, qui constitue une étude approfondie du régime hydrographique, géologique et climatologique de la région du Nil.

D'après cette étude, quatre régions, d'inégales altitudes, fournissent le Nil d'eaux pluviales :

$1^{\circ} \mathrm{La}$ région des lacs équatoriaux (situés à une altitude de 1.300 à 1.500 mètres) ;

$2^{\circ} \mathrm{La}$ crête séparative du bassin du Congo d'avec celui du Bahr-el-Ghazal (d'une altitude de 800 à 900 mètres); 
$3^{\circ}$ Le plateau d'Abyssinie, dont l'altitude dépasse 2.000 mètres ;

$4^{0}$ Le vaste territoire (d'une altitude inférieure à 500 mètres) qui s'étend de Gondokoro à la Méditerranée.

La cause efficiente de la crue du Nil, c'est, en réalité, l'Atbara et surtout le Nil Bleu, qui, venus des hauts plateaux d'Abyssinie, se changent, au moment des pluies, en torrents redoutables, apportant alors au Nil Blanc, qu'ils rencontrent à Khartoum, des flots tumultueux chargés de limon fertilisant et provoquant ainsi ses débordements.

Si le volume d'eau fourni par les affluents de la région équatoriale est très régulier et peut être évalué à 500 mètres cubes par seconde pour l'année entière, il n'en va pas de même pour le débit des affluents abyssins qui est extrêmement variable et passe de 50 mètres cubes, en étiage, de décembre à mai, à 15.000 mètres cubes, au plus fort de la crue, entre juillet et octobre.

Tous ces éléments sont nettement définis et exactement contrôlés: 41 nilomètres, posés par l'administration, le long du fleuve, mesurent son débit ; et les 223 stations météorologiques de la région $d u$ Nil et des régions avoisinantes donnent de précieux renseignements sur l'importance des pluies. D'ici peu, grâce à ces données, le service de l'arpentage sera en mesure de prévoir, d'une saison à l'autre, les principales circonstances des crues à venir.

Tout cela montre que l'administration, justement 
préoccupée de suivre les mouvements quotidiens du régime hydrographique du fleuve, ne néglige aucun moyen pour atteindre ce but.

Comment le Nil s'est-il frayé un chemin jusqu'à la mer? Les principaux géologues sont aujourd'hui d'accord pour reconnaitre que la vallée et le Delta sont l'œuvre du fleuve lui-même qui, au temps où il traçait son cours, creusa le bas plateau désertique qui constitue le sol général de l'Égypte et fit de la vallée actuelle son lit, et du Delta son estuaire. A ce sujet, l'introduction du Statistical Year Book of Egypt (1910), rédigée par la section de l'arpentage, s'exprime ainsi : contrairement à l'opinion qui attribue l'origine de la vallée à une dépression du sol, de nombreux éléments permettent d'affirmer qu'il faut y voir le résultat d'un travail d'érosion produit par le cours du Nil.

Ce travail achevé, le fleuve, passant au régime de reconstitution, s'est livré à un travail de comblement qui se continue encore, mais sur une moins grande échelle que par le passé.

Chaque année, notamment pendant la période de la crue, ses eaux, chargées des débris provenant de la trituration !des roches, arrachées aux sommets et aux versants nord et ouest du plateau abyssin et broyées par le courant, viennent recouvrir le sol de la vallée et du Delta d'une couche uniforme de limon épaisse d'un millimètre et dont le volume, d'après la surface des terres qu'elle recouvre, représente 33 millions de mètres cubes. 
Comme la plupart des grands fleuves, le Nil contient dans ses eaux, soit en dissolution, soit en suspension, tous les éléments fertilisants du sol ${ }^{1}$, dont la composition ne diffère de celle du limon du fleuve que dans les proportions des matières qui les constituent. Cette composition varie suivant les régions, d'après la position que celles-ci occupent par rapport aux canaux d'alimentation, les plus voisines recevant les matières plus denses, tandis que les plus éloignées recueillent le surplus par ordre de densité et en proportion inverse de leur éloignement de ces canaux.

La composition du sol et de l'eau du Nil étant connue, on comprend de quelles puissantes ressources alimentaires, sans cesse renouvelées, disposent les plantes cultivées dans le pays. Mais voici ce qui en fera mieux encore apprécier

1. Voici, à ce sujet, un tableau comparatif de la composition des eaux du Nil et de celle du sol que nous extrayons de The Egyptian Agriculture, ouvrage en deux volumes publié par le Ministère égyptien de l'Instruction publique (t. I, p. 15) :

\begin{tabular}{|c|c|c|c|}
\hline Eléments. & $\begin{array}{c}\text { Matieres en } \\
\text { suspension dans } \\
\text { les eaux du Nil } \\
\text { pendant la crue. }\end{array}$ & $\begin{array}{c}\text { Bon sol } \\
\text { a Tantah } \\
\text { (Basse- } \\
\text { Egypte). }\end{array}$ & $\begin{array}{l}\text { Bon sol } \\
\text { à Matai } \\
\text { (Haute- } \\
\text { Fgypte). }\end{array}$ \\
\hline Potasse................ & 0,53 & 0,55 & 0,76 \\
\hline Soude ................ & 0,57 & 0,58 & 0,74 \\
\hline 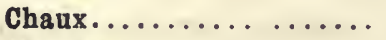 & 3,07 & 3,38 & 4,47 \\
\hline Magnésie...$\ldots \ldots \ldots \ldots$ & 2,68 & 2,88 & 2,89 \\
\hline Oxyde de manganèse.... & 0,25 & 0,22 & 0,26 \\
\hline Oxyde de fer et d'alumine.. & 25,56 & 23,36 & 24,39 \\
\hline Acide phosphorique...... & 0,25 & 0,20 & 0,28 \\
\hline Acide carbonique........ & 0,73 & 0,67 & 1,10 \\
\hline Chlore................. & 0,00 & 0,09 & 0,10 \\
\hline Matières organiques ...... & 8,82 & 7,79 & 7,78 \\
\hline Matières insolubles et sables. & 57,54 & 60,28 & 57,23 \\
\hline \multirow{2}{*}{ Azote...$\cdots \ldots \ldots \ldots$} & 0,145 & 0,07 & 0,095 \\
\hline & $\overline{100}$ & 100 & 100 \\
\hline
\end{tabular}


l'importance. Depuis que le Nil est entré dans son stade de réédification, - et cela remonte à plusieurs milliers d'années, - ses apports annuels de limon ont fini par former une couche dont l'épaisseur varie, en moyenne, entre 15 et 25 mètres.

Enfin, pour comprendre comment cette couche couvre la totalité du territoire habité, il faut se rappeler que, dans la saison de la crue, les eaux débordant de leur lil s'étendaient des deux côtés en une nappe immense allant d'Assouan (extrême-sud) jusqu'à la Méditerranée sur une longueur de 1.050 kilomètres. Il est vrai qu'avec la conversion à l'irrigation pérenne des quatre cinquièmes de cette étendue, - travail entrepris dans la première moitiédu siècle dernier et achevé tout récemment, - le régime de l'inondation ne s'observe plus que dans les quatre provinces du Sud. Malgré cette conversion, le sol n'en con. tinue pas moins à recevoir, dans sa totalité, la couche habituelle qui, maintenant, lui est apportée par les canaux d'irrigation.

De tout ce qui précède ressort avec évidence la confirmation decette vérité que l'Égypte doit tout au Nil, ou, comme l'a dit avec tant d'élégance le père des historiens : l'Égypte est un don $d u$ Nil. Après l'avoir arrachée au désert en sapant graduellement sa surface jusqu'au niveau naturel de la vallée, il l'a reconstituée des matériaux d'origine volcanique qu'il enlève chaque année au plateau d'Abyssinie, ainsi que des débris organiques qu'il recueille sur sa route, et l'a dotée de tous les éléments de la vie. Nul 
autre facteur ne collabore avec lui à son entretien. Ce n'est pas la pluie, rare en certaines régions, presque totalement inconnue dans les autres, qui y contribue. Le Nil supplée à tout, et dans quelle mesure! Et avec quel avantage! De même que c'est à lui qu'est due la formation de la vallée et du Delta, c'est encore à lui qu'incombe le soin de pourvoir à leur existence.

Il faut tenir compte aussi, en dehors de la fertilisation du sol par le Nil, d'un phénomène unique au monde qui assure à la terre d'Egypte son extraordinaire fécondité.

Un des étonnements qu'éprouve un nouveau venu en Egypte, c'est d'y voir des récoltes obtenues sans labour et sans engrais, récoltes dont les résultats ne le cèdent ni en quantité ni en qualité à celles qui, dans les autres parties du pays, sont l'objet des soins les plus attentifs. Dans toute la partie de la Haute-Egypte encore soumise au régime de l'irrigation par bassin, le labourage est inconnu. Sitôt le retrait des eaux de crue qui y ont séjourné trois mois et demi, les semailles sont faites sans le moindre labour.

L'explication de ce fait a été donnée dans de nombreuses publications. Voici ce qu'en dit M. J. Barois ${ }^{1}$ :

"Après que les eaux se sont retirées, la terre se dessèche " peu à peu; au bout de quelque temps, comme elle est " très argileuse, elle se rétracte, se fend, est bientôt " coupée par des crevasses nombreuses et profondes qui 
" s'enfoncent dans le sol et se subdivisent en fissures de " plus en plus minces; pendant toute la saison du repos " de la terre, le sol est ainsi préparé pour une aération " parfaite; l'oxygène et l'azote de l'air pénètrent dans " les ramifications des crevasses et entrent en contact " intime avec les particules terreuses dans toute l'épais" seur de la couche active du sol. Les eaux d'inondation, " arrivant ensuite, emprisonnent cet air qui, se trouvant " très divisé, est évidemment plus apte à être dissous " facilement et à être transformé en produits qui seront " ensuite assimilés par les racines des plantes. Cette " aération si complète de la terre pendant la période de " sécheresse des bassins permet de supprimer tout labou" rage avant l'ensemencement qui suit immédiatement "le retrait des eaux."

"Le sol de l'Egypte, écrit de son côté Chélu bey" " peut ainsi réaliser deux récoltes sans qu'il soit besoin de "faire intervenir la charrue, condenser dans ses pores " le maximum d'acide carbonique, d'oxygène, d'ozone " et d'azote prêts à se transformer et à se combiner de "façon à former des bicarbonates, de l'acide azotique, " des sels ammoniacaux, etc... Notons aussi que l'action " capillaire, parfaite dans les conditions qui viennent " d'être indiquées, intervient pour concentrer, à la por" tée des plantes, les matériaux nourrissants élaborés " et lentement aspirés." 
Nous avons ainsi en présence les éléments que voici : dans l'atmosphère: de l'azote, de l'oxygène, de l'ozone, de l'acide carbonique; dans la terre, de l'argile divisée, des sels alcalins et de l'oxyde de fer, c'est-à-dire tous les éléments d'une nitrière artificielle intensive.

Toutefois, pour que le Nil accomplisse au mieux sa fonction, l'aide des hommes est indispensable, sinon ses débordements causeraient parfois des désastres. Il a fallu élever des digues, creuser des canaux, établir des réservoirs artificiels et combiner des systèmes d'irrigation. Pour répondre aux besoins sans cesse grandissants du pays, le fleuve a été aménagé selon les procédés les plus perfectionnés de l'hydraulique. Ses eaux, toujours chargées des mêmes éléments et à peu près dans les mêmes proportions, vont répandre la fécondité sur la totalité du territoire habité qu'elles desservent. Un réservoir, le plus vaste du genre, qui emmagasine un milliard de mètres cubes d'eau et doit prochainement être en état d'en recevoir 1 milliard 300 millions de plus, ce qui por. tera sa capacité à 2 milliard 300 millions de mètres cubes, pare aux insuffisances de son débit en temps d'étiage. Quatre grands barrages (planche I), deux dans la HauteEgypte, à Assiout et à Esneh, et deux dans la BasseEgypte, ceux de Galioub et de Zifteh. régularisent le niveau des distributions d'eau; une multitude de canaux de toutes sections et de toutes longueurs, depuis le canal Ibrahimieh, long de 314 kilomètres, large de 40 mètres au plafond, qui dessert, à la fois, trois provinces de la Haute- 
Egypte, jusqu'à ceux qui ne font qu'un service local, sillonnent le pays en tous sens.

Tout cet ensemble constitue un immense réseau qui couvre le pays, lui fournissant toutes les ressources nécessaires aux irrigations, à l'alimentation et aux transports. A ce dernier point de vue, nous pouvons ajouter que le développement des canaux navigables est actuellement de 3.540 kilomètres, ce qui est considérable par rapport à la surface restreinte du territoire habité. Terminons en disant qu'un réseau de drains, qui se développe de plus en plus, assure l'assainissement du sol en recevant le trop-plein des eaux d'arrosage. 


\section{GHAPITRE II}

\section{CLIMAT}

Conditions climatériques. - Les saisons; leur régulari té. — La température ; ses moyennes. - Le Khamsin. - Les trois facteurs essentiels de la prospérité agricole.

Mais si, au point de vue de la richesse du sol et du régime des 'eaux, l'Égypte est le pays le plus favorisé, elle ne l'est pas moins au point de vue du climat.

Par sa situation géographique, l'Égypte appartient à la zone chaude; toutefois, par sa configuration générale, elle jouit d'un climat qui n'a, croyons-nous, d'analogue nulle part ailleurs. Bornée, au nord, par la Méditerranée, à l'est, par la mer Rouge et le canal de Suez qui relie ces deux mers, enfermée, d'autre part, entre les deux grands déserts qui la bordent à l'est et à l'ouest, elle est, grâce à cette situation, l'une des contrées qui offrent le moins de variations climatériques. Non seulement les saisons y 
sont d'une régularité presque absolue, mais il s'y rencontre un état particulier qui en rend le séjour très supportable même au mois de juillet, le plus chaud de l'année. Placée, d'un côté, à la limite nord de la région parcourue par les vents alizés ${ }^{1}$, dont la bande, dans sa course au nord, s'arrête à la hauteur d'Assiout, et, de l'autre, enfermée, comme nous l'avons dit, entre deux immenses déserts qui, la nuit, rayonnent avec intensité la chaleur reçue pendant le jour, il s'établit, de ce double fait, à Assiout, une zone de haute pression continue ayant pour effet de refouler vers les régions équatoriales l'air sec et chaud du désert, et de remplacer celui-ci par un apport d'air frais venant de la Méditerranée.

Ainsi, malgré la chaleur parfois écrasante du jour, et sauf dans les rares journées de Khamsin, où le phénomène se produit à une heure plus avancée de la nuit, aussitôt que le soleil est arrivé au bout de sa course, l'air se rafraîchit par l'arrivée d'un courant continu de la mer. Ce phénomène est tout l'opposé de celui qui se produit partout au voisinage de celle-ci. Le jour, moins échauffée que la terre sèche, la mer envoie une brise rafraîchissante, tandis que, la nuit, c'est de la terre sèche que souffle la brise. Grâce à cette particularité qui caractérise le climat de l'Égypte, il s'y produit, entre la tempé-

1. On sait que la bande des alizés, dontla largeur est d'environ 200 kilomètres, suit le mouvement apparent du soleil d'un côté à l'autre de l'équateur, passant avec lui au sud en hiver et remontant au nord en été. Dans sa course au nord, la bande arrive jusqu'à Assiout, qui est à $27^{\circ}, 11$ de l'équateur, puis, de là, retourne vers le sud avec le soleil. 
rature la plus chaude et la température la plus froide, un écart dépassant $15^{\circ}$ et, dans certaines régions même, $20^{\circ}$ en vingt-quatre heures. A un autre point de vue, ainsi que le fait remarquer fort justement l'Annuaire statistique de l'Égypte (1910), déjà cité, la prédominance du vent du Nord constitue un facteur économique très important, en permettant aux voiliers de remonter le fleuve pour aller au Sud, tandis que son courant leur fait suivre le chemin opposé pour revenir au Nord.

D'après les publications officielles ${ }^{1}$, les moyennes de la température sont de $10^{\circ}$ en hiver et de $30^{\circ}$ en été, sauf de faibles variations correspondant à la situation des diverses régions. Au point de vue général, il est bien rare que le thermomètre descende à $0^{\circ}$ ou s'élève au-dessus de $35^{\circ}$.

D'autre part, le vent brûlant du désert, qui souffle depuis le commencement du printemps jusqu'à la fin de l'été sur les autres parties de l'Afrique du Nord et dont les effets sont souvent désastreux pour l'agriculture de ces contrées, est absolument inoffensif en Egypte ${ }^{2}$; outre qu'il y est beaucoup moins chaud, il ne se fait sentir que durant une très courte période, de la seconde quinzaine d'avril à la première quinzaine de juin, soit pen-

1. Statistical Year Book of Egypt (1909), p. 7.

2. Suivant une communication faite, le 11 avril dernier, à la Cairo Scientific Society, par M. L. Balls, botaniste attaché au service de la Société khédiviale d'Agriculture, le Khamsin exercerait une influence heurcuse sur le développement du cotonnier, dont la croissance est beaucoup plus rapide lorsque l'air est chaud et le solcil voilé. (Journal du Caire, 12 avril 1911). 
dant une cinquantaine de jours, d'où son nom de Kham$\sin$.

Son apparition n'a lieu, du reste, qu'à l'époque où, comme l'indiquent nos tableaux, les cultures d'hiver sont entrées dans la période de maturité, tandis quele cotonnier, nouvellement semé, est encore dans la période de germination, ce qui, de part et d'autre, est sans conséquence sur leur développement.

Ainsi donc, grâce à ces trois facteurs essentiels de la prospérité agricole : la nature du sol, l'eau et la température, l'Égypte occupe incontestablement le premier rang dans le monde.

"Dans aucun autre pays, écrit lord Cromer", l'agri" culteur n'a moins à redouter les hasards et les troubles " des saisons. Il est vrai que, si le Nil est extraordinaire" ment haut ou bas, le cultivateur est plus ou moins " exposé aux dangers de l'inondation ou de la sécheresse.

"Mais il y a une énorme différence entre les risques de " ce genre et ceux que court la culture dans les pays " dépendant, pour leur approvisionnement d'eau, de la " chute des pluies; car, si aucune force humaine ne peut " augmenter ou diminuer la quantité de pluie qui tombe " des nuages, il est au pouvoir de l'homme de régler l'eau " du Nil, comme de restreindre, sinon de conjurer, les " dangers de l'insuffisance ou de l'excès d'eau. Dans ce " pays extrêmement favorisé, la nature semble avoir

1. Modern Egypt, II, p. 456. 
" dit à l'homme: "Je t'accorde les conditions les plus " favorables pour cultiver le sol: un climat vivifiant, un " approvisionnement d'eau assuré et un élément ferti" lisant naturel, qui, avec très peu d'effort de ta part, " renouvelleront chaque année les puissances productives " du sol ; c'est à toi de perfectionner à ton avantage les "dons que je t'ai prodigués." 


\section{PRODUITS DU SOL}

Les saisons agricoles. - Terres soumises au régime de l'irrigation pérenne. - État de leur exploitation et résultats de cette exploitation par termes de deux ans. - Combinaisons culturales; leurs revenus comparatifs.

Maintenant que nous avons exposé brièvement les conditions physiques du milieu, passons à l'examen de sa production agricole.

Dans les deux tableaux (I et II) ci-après nous avons résumé, d'un côté, en mesures égyptiennes et, de l'autre, en mesures françaises, les résultats de l'exploitation agricole du pays ${ }^{1}$. (Voir planches III et IV.)

1. Nous n'y avons fait figurer que quelques-uns des principaux produits de la grande culture. Pour compléter nos renseignements, nous croyons utile de donner tout au moins l'indication des autres produits de cette catégorie et des régions d'où ils proviennent. En voici la liste telle qu'on peut la constituer d'après les ouvrages consacrés à l'agriculture égyptienne :

Sésame, cultivé dans la Basse-Égypte et dans le Fayoum;

Indigo, cultivé au Fayoum;

Arachide, dans les sols sablonneux; 
Le premier tableau fait connaitre la répartition des saisons agricoles, qui sont au nombre de trois: Nili (de l'époque de la crue), Chetoui (d'hiver), Saifi (d'été), ainsi que les résultats moyens des cultures de chacune d'elles. Il a été composé, ainsi que le suivant, avec des éléments recueillis, soit sur place, soit dans quelques publications spéciales au nombre desquelles nous citerons l'Almanach officiel du Service de l'Arpentage et les rapports annuels de l'Administration des Domaines de l'Etat Égyptien. Nous y avons condensé toutes les indications pouvant rendre compte de l'état de l'exploitation du sol.

Dans le second tableau, et en nous aidant des éléments contenus dans le premier, nous avons montré les résultats généraux de cette exploitation.

Ce tableau montre notamment qu' on peut obtenir deux récoltes par an. Les statistiques agricoles l'établissent par ailleurs et nous apprennent que, pour une superficie de terre cultivée, ayant, en 1908-1909, atteint 5.373.982 feddans, il y a eu 7.670.544 feddans de cultures; ce qui prouve que, sur les 5.373.982 feddans ci-dessus, 2.296.562, ou les $42,730 / 0$ ont reçu plus d'une culture ${ }^{1}$.

Nos deux tableaux donnent une idée très nette de la fertilité du sol ; remarquons toutefois que les rendements

Pois chiches, dans les terres à bassins et autour des villes;

Fenugrec, dans la province de Queneh (Haute-Égypte);

Lupin, dans les terres sablonneuses;

Henné, dans la province de Charkyeh (Basse-Égypte);

Carthame, dans les provinces de Queneh et de Guirgué (Haute-Egyple);

Chanvre et lin, sur tout le territoire cultivé.

1. Annuaire slatistique de l'Égypte (1910), p. 238. 
qui y sont indiqués ne se rapportent qu'à la grande propriété. Pour la petite propriété, en raison surtout de la densité de la population agricole, les rendements sont supérieurs à ceux de la grande propriété, grâce aux soins plus minutieux qu'elle peut recevoir. En outre, aux deux récoltes de la grande culture, elle ajoute les produits de l'exploitation maraîchère, qui trouvent un large débouché dans les nombreux centres du pays.

Examinons maintenant la qualité et la richesse des produits. Le premier rang parmi ces derniers appartient incontestablement au coton; aussi croyons-nous devoir lui consacrer une courte notice. 


\section{TABLEAU I}

\section{Agriculture Égyptienne}

Terres soumises au régime de l'irrigation pérenne État d'exploitation des terres

(EN FEDDANS ET EN LIVRES EGYPTIENNES)

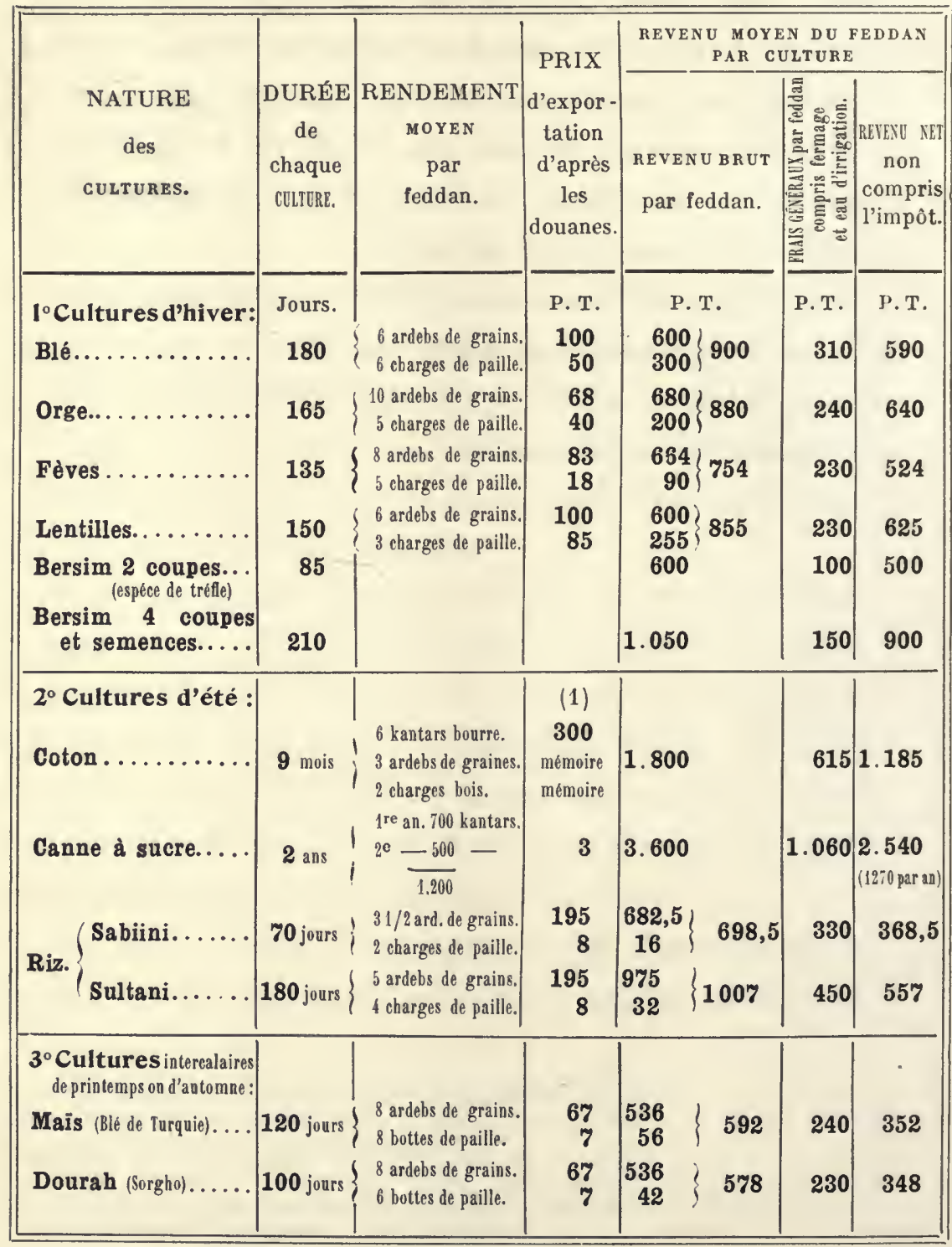

(1) L'usage s'est établi, en matière d'estimation, de compter le coton avec ses sousproduits à raison de P. T. 300 le kantar; nous nous y conformons, quoique dans ces dernières années les cours aient de beaucoup dépassé ce chifire. Si nous avions procédé d'après la moyenne de ces cours, le revenu net de la culture se fût élevé à près 


\section{TABLEAU |}

\section{Agriculture Égyptienne}

Terres soumises au régime de l'irrigation pérenne

État d'exploitation des terres

(EN HECTARES ET EN FRANCS)

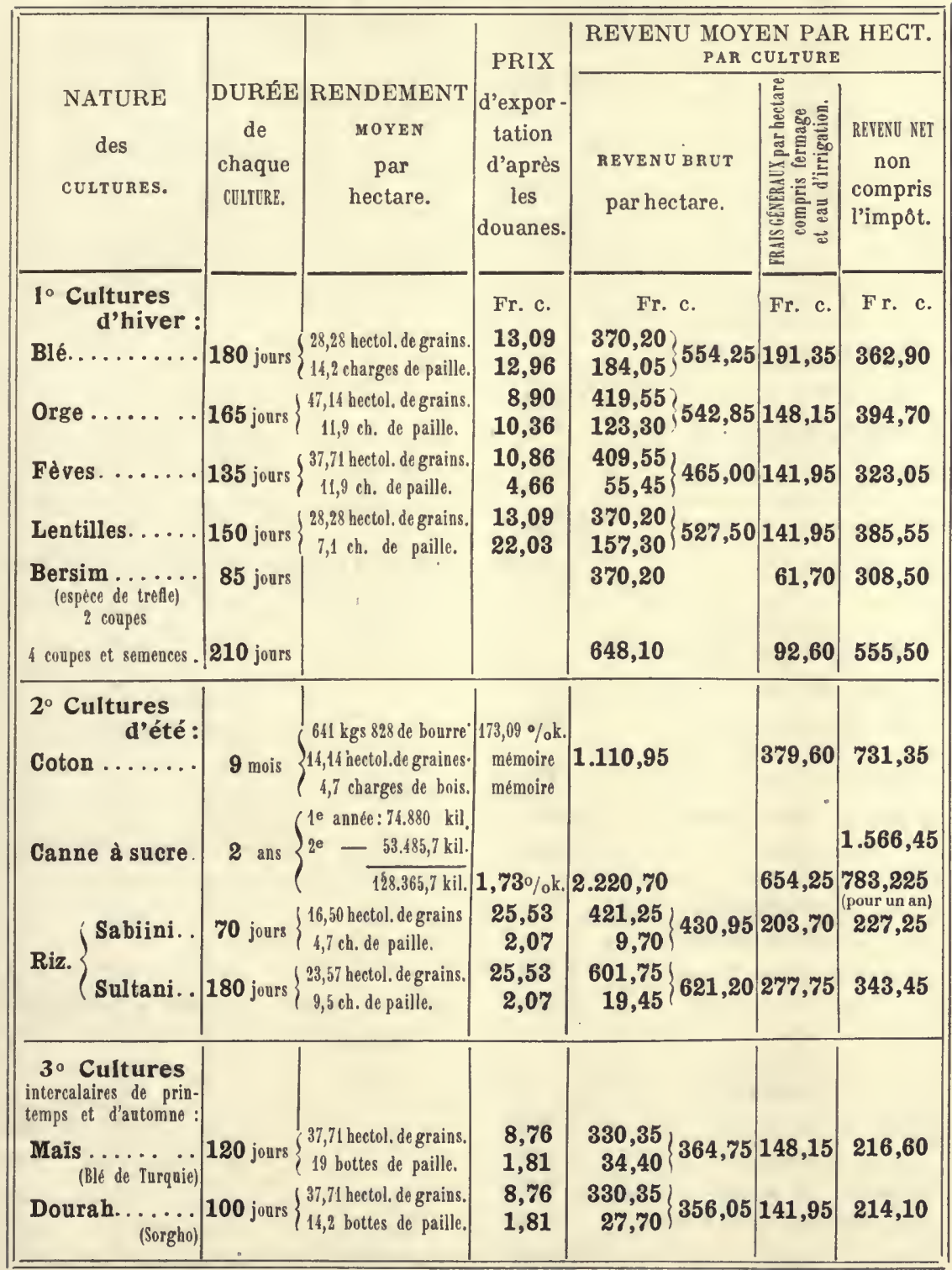

de P. T. 1.400 au lieu de 1.185 que nous a données le calcul au prix global de P. T. 300 .

Valeur de la livre égyptienne $=$ P.T. $100=25 \mathrm{fr} .9235 .-$ Valeur du franc $=$ P. T. 3,8575. Valeur dufeddan $=4.200 \mathrm{mq}$. - Valeur del'ardeb $=198$ litres. - Valeur du kan tar $=44 \mathrm{~kg} .928$. 


\section{TABLEAU II}

\section{Agriculture Égyptienne}

Résultats de l'exploitation des terres par terme de deux ans

Revenus comparatifs du sol suivant les cultures exploitées dans la période considérée

(EN FEDDANS ET EN LIVRES EGYPTIENNES)

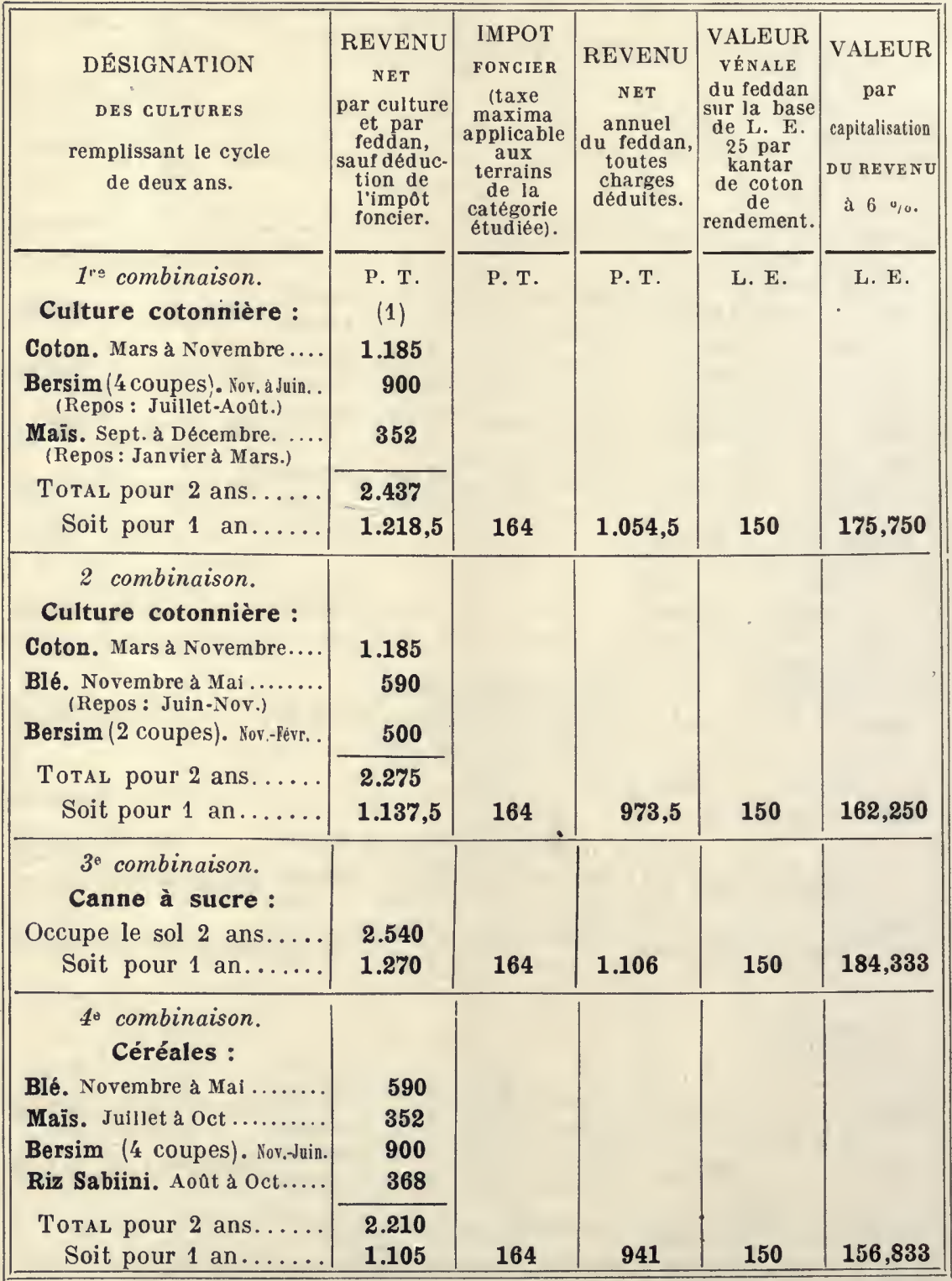

(1) Comme il a été exposé en note, au bas du tableau précédent, si l'on s'était basé sur la moyenne des cours du coton dans les dernières années, l'écart de profit entre les deux premières combinaisons et les deux dernières ent été plus considérable. 


\section{TABLEAU II}

\section{Agriculture Égyptienne}

Résultats de l'exploitation des terres par terme de deux ans

Revenus comparatifs du sol

suivant les cultures exploitées dans la période considérée

(EN HECTARES ET EN FRANCS)

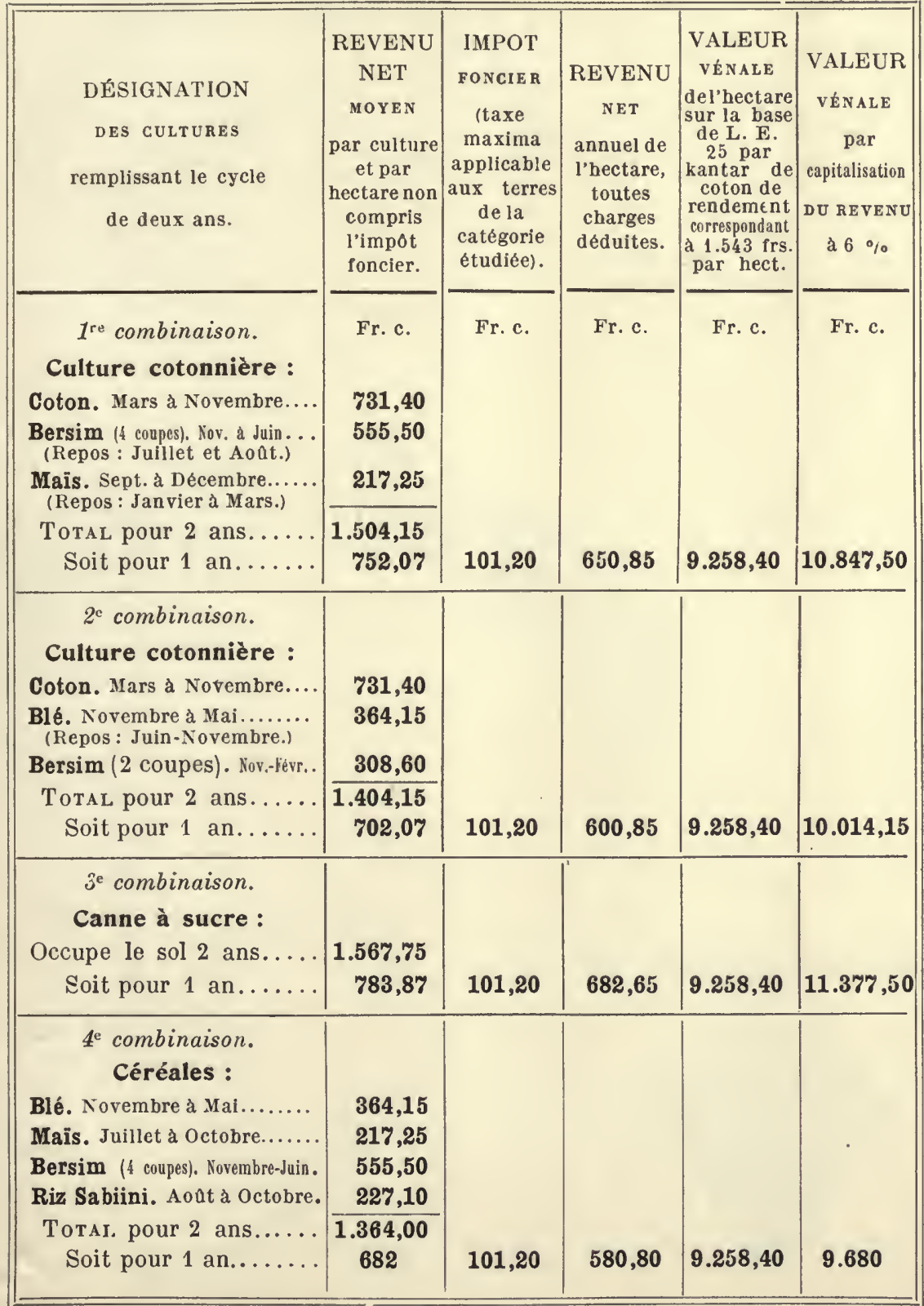





\section{Agriculture Egyptienne}

- Etat d'Exploitation des terres 1

\section{CULTURES D'HIVER}

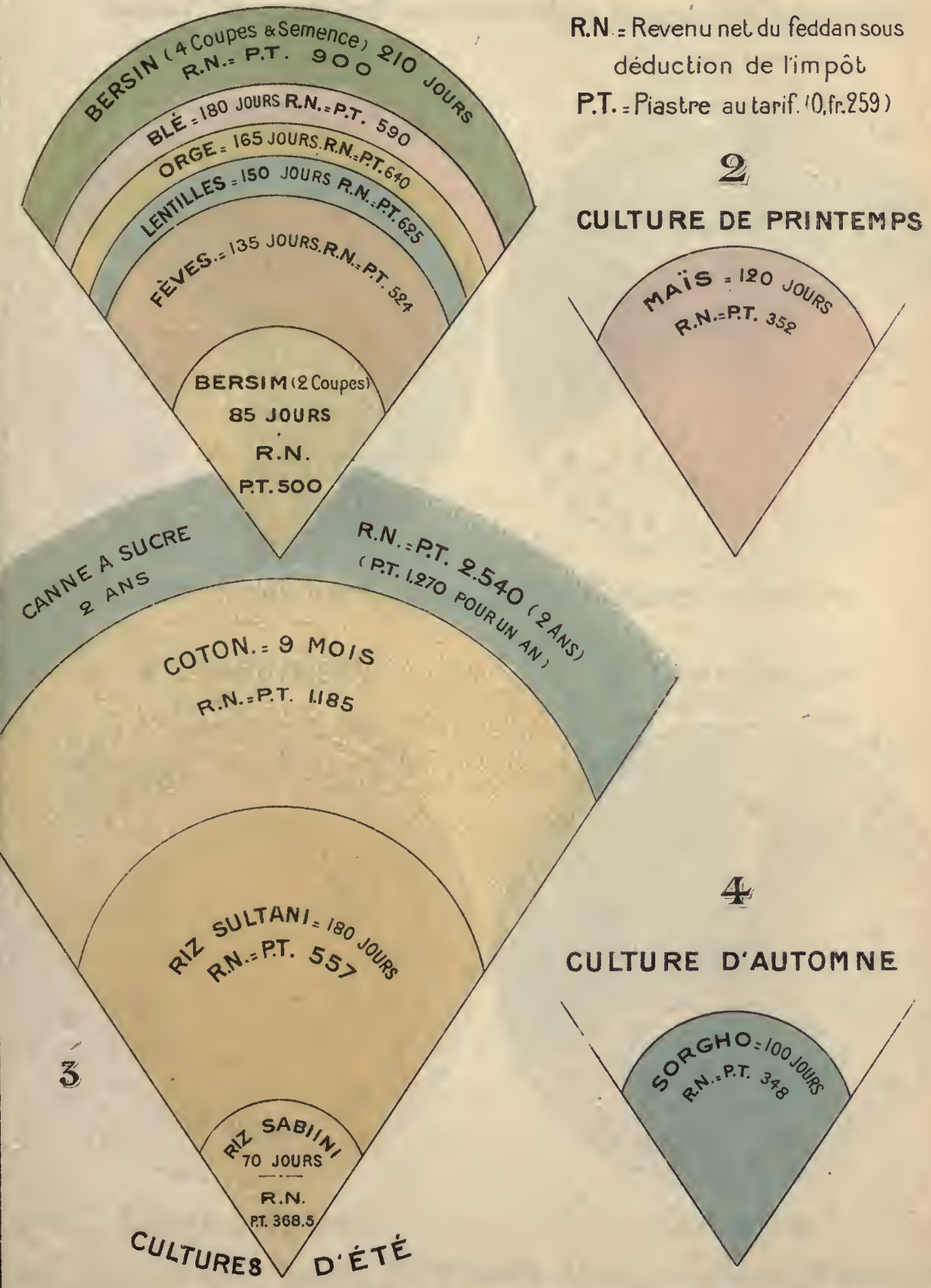

\section{Abréviations}

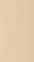

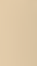

= Revenu nel du feddansous 


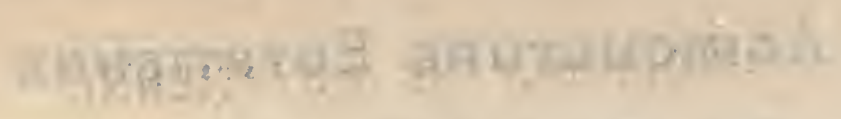

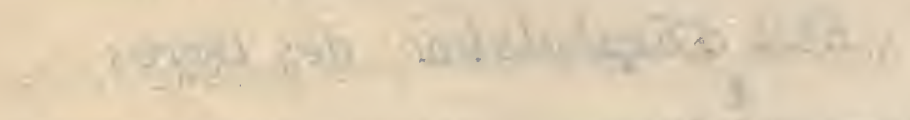

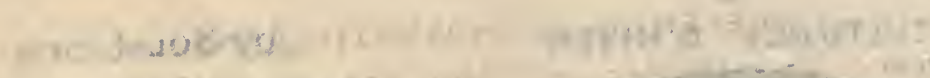

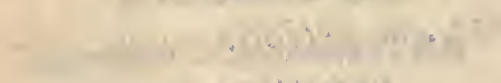

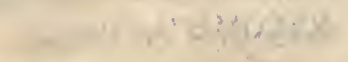

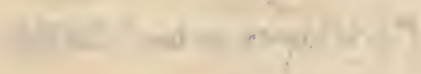

5.

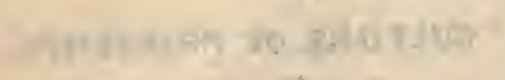

$2+2+4+45 x$
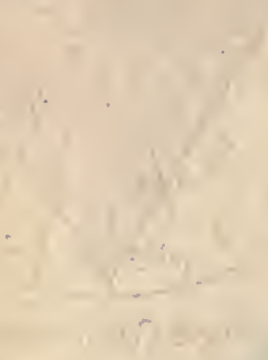

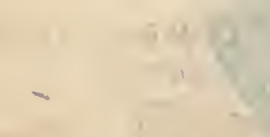
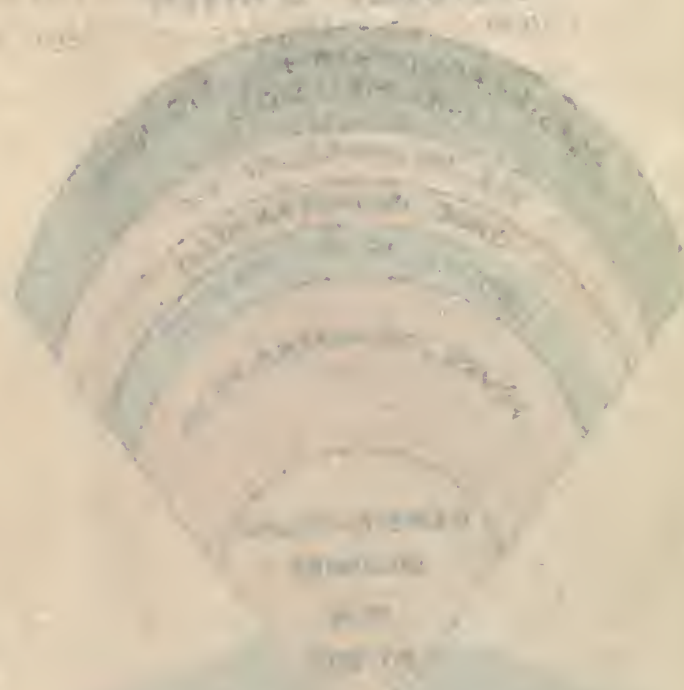

a

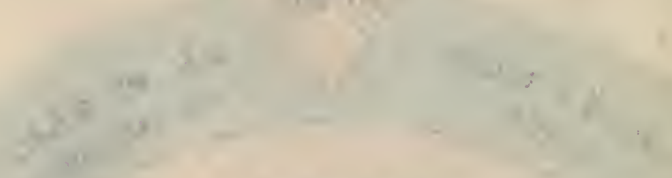

$$
\begin{aligned}
& 2.2+290
\end{aligned}
$$

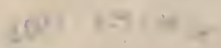

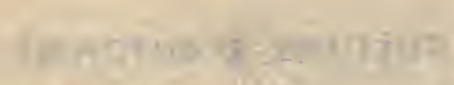

$2+\cos 746$

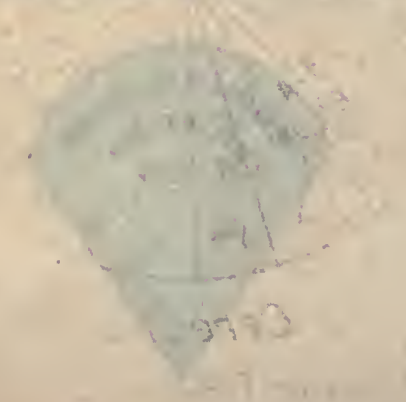

$y=7 *+48 ?$ 


\section{Agriculture Egyptienne}

Résultats de lexploitation des terres par périodes de? ans Revenus Comparatifs du Sol suivant les cultures exploilées dans la période considérée

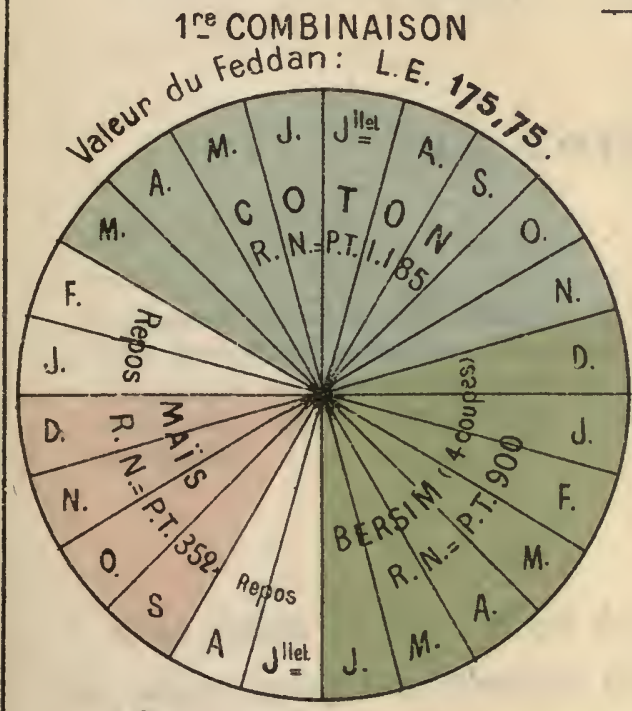

Culture Cotonnière

3. COMBINAISON

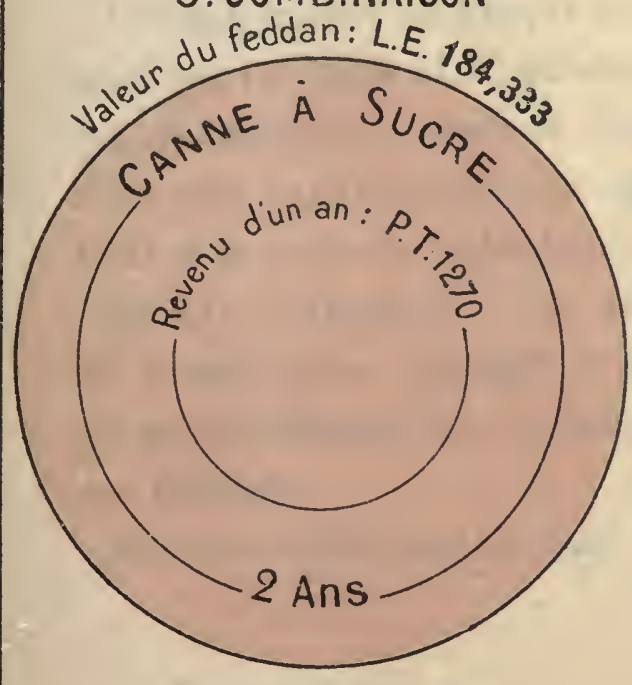

Canne à Sucre

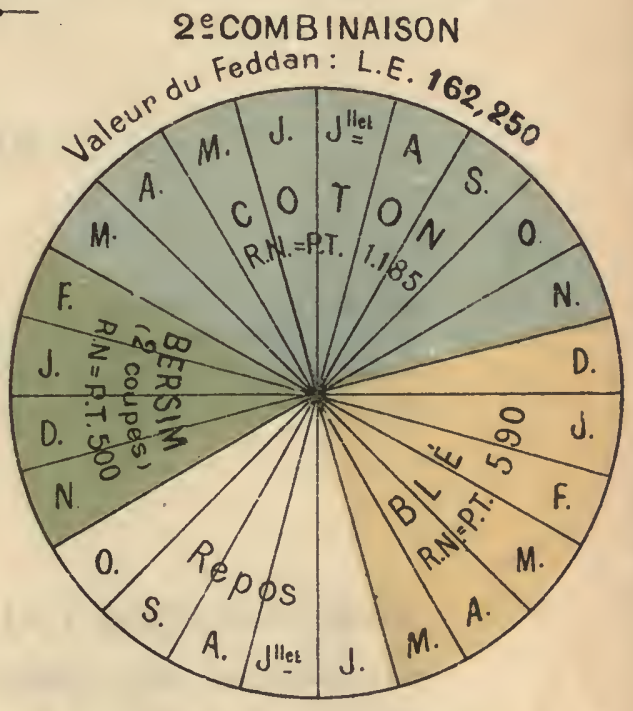

Culture Cotonnière

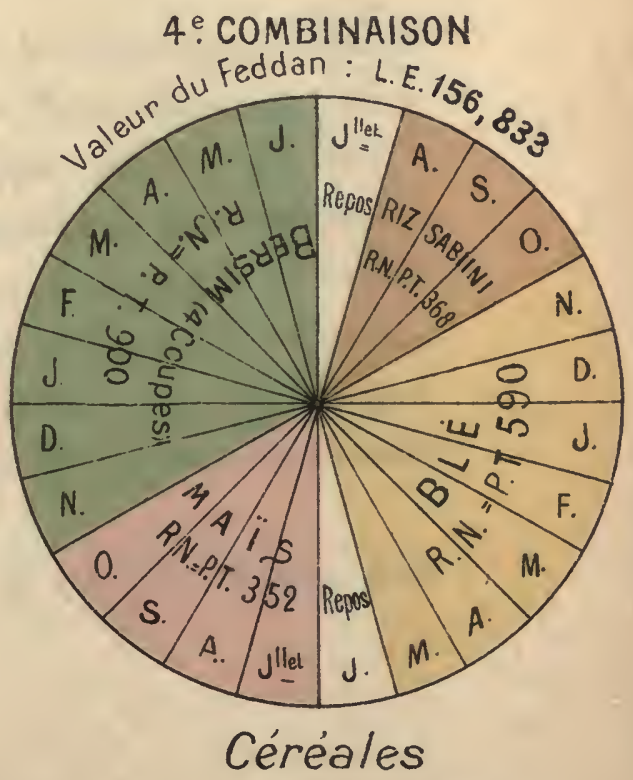

Abréviations: J.Janvier. F. Février,.M. Mars, etc..... R.N.: Revenu net-P.T.. Piastre tarif ( ) fr. 259) 


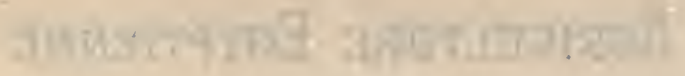

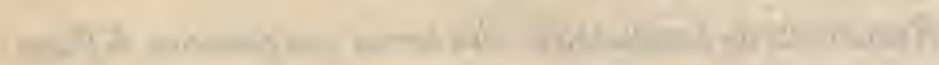

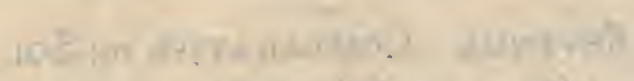

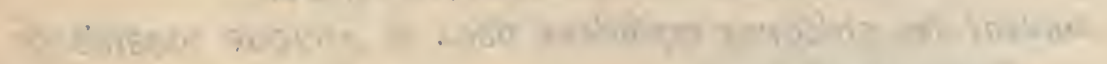

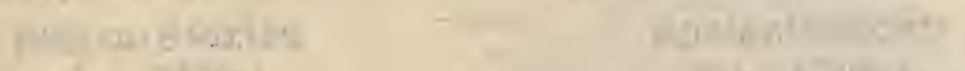

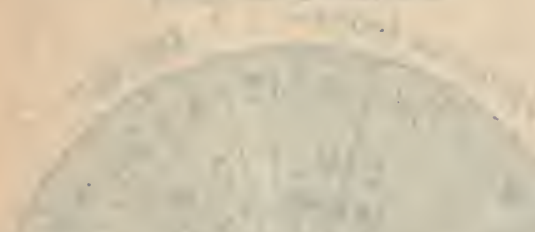

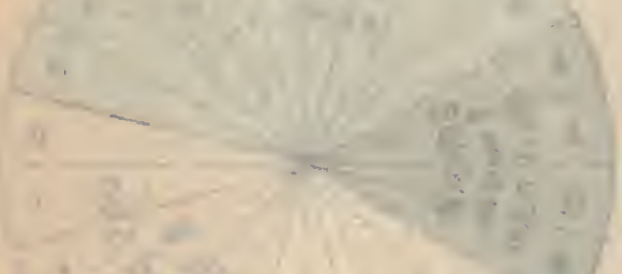

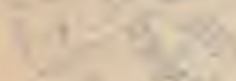

$4=$

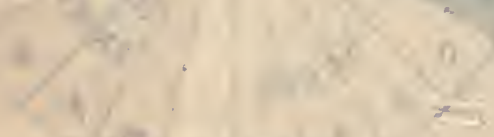

$$
2+1-1-6+3
$$

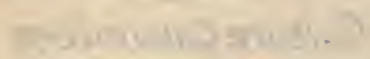
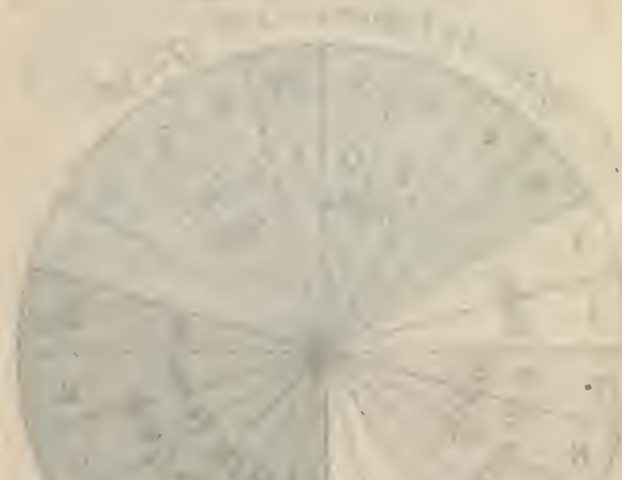

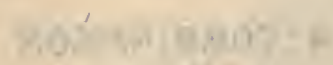

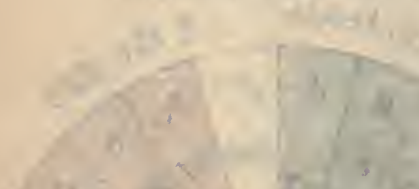

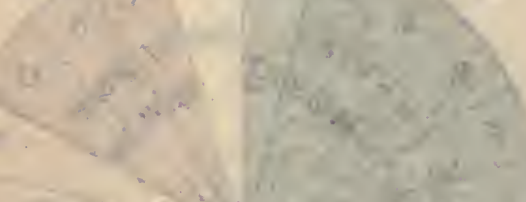

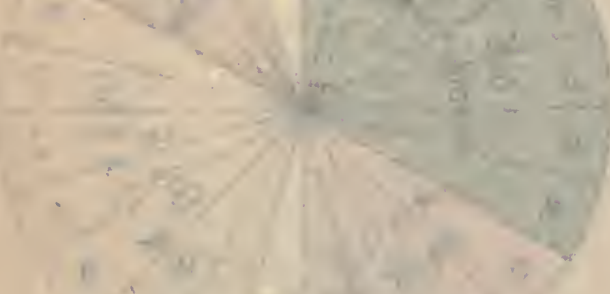

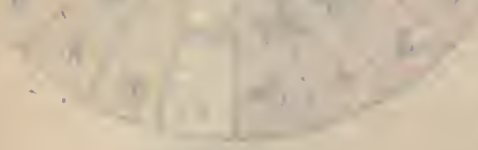

$$
34+4,-174
$$

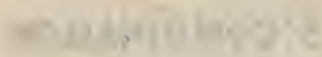
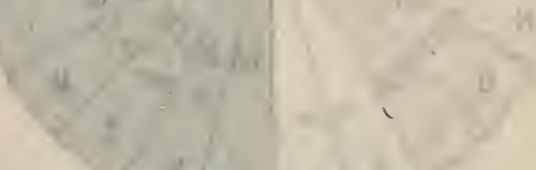


\section{CHAPITRE IV}

\section{LE COTON}

Son introduction en Égypte (1820). - Son acclimatation. - Il est le premier produit du genre. - Rendements comparés de l'Égypte et de l'Amérique. - Qualités spéciales du coton égyptien; sa prime sur le coton américain. - Ses emplois. - Son concurrent (Sea Island) très négligeable.

"La vallée du Nil a offert de tout temps au cotonnier un milieu exceptionnellement favorable par la nature de son sol, le degré de sa température, l'abondance et la régularité de ses eaux."

Quoique cultivé en Égypte dès la plus haute antiquité, ainsi que l'a établi M. F.-Chaŕles Roux, dans son remarquable ouvrage le Coton en Égypte, ce précieux textile n'est entré dans l'exploitation agricole du pays que depuis 1820 , à la suite de l'introduction d'une nouvelle variété originaire d'Abyssinie, faite par un botaniste français, M. Jumel, qui en entreprit la culture, sous les auspices du grand Méhémet-Ali, fondateur de la dynastie actuelle des Khédives.

Cet événement, qui, au point de vue économique, a eu 
une portée énorme, se signale aussi par une autre particularité digne d'être notée. Le nouveau venu, quoique d'origine étrangère, s'est si bien comporté sur le sol égyptien qu'il $\mathrm{y}$ a acquis tous les caractères d'une plante autochtone.

Semé en d'autres pays, il n'a pas répondu généralement aux espérances que son succès en Egypte avait fait concevoir. Ce succès y est tel que, malgré les efforts tentés ailleurs pour lui susciter un rival, il reste toujours le premier produit du genre, distançant considérablement tous les autres, et par l'importance de son rendement et par la qualité de sa bourre. En effet, tandis que la récolte moyenne est en Amérique de 200 livres (90 k. 6) par acre (4.047 m. carrés), celle d'Egypte est encore aujourd'hui, malgré la période de diminution que nous traversons et dont nous parlons plus loin, de 4 kantars 20 (188 k. 697) par feddan (4.200 m. carrés), soit plus du double. En ce qui concerne la qualité, il suffit de dire que, sur tous les marchés cotonniers, l'égyptien est coté avec une prime qui, dans ces dernières années, a varié de 50 à $690 / 0$ sur l'américain. Telle est la supériorité du coton égyptien que les Américains, qui ne sont pas seulement producteurs, mais aussi manufacturiers, se trouvent obligés de lui payer un tribut annuel, lequel, pour 1910, s'est traduit par une importation de 466.400 kantars. (Voir planche V.) Grâce à ses qualités spéciales, à la longueur, à la finesse et à la résistance de sa fibre, le coton égyptien est affecté à certains produits manufacturés auxquels, seul, il peut convenir. Son emploi est indispen- 
sable pour la fabrication des fleurs artificielles, des fils à coudre et à broder, pour la bonneterie, les satinettes, les vêtements confectionnés, les articles mercerisés mi-soie, les étoffes veloutées, les peluches et, en général, tous les articles en coton de qualité supérieure. Dans tous les centres manufacturiers où se fabriquent les articles fins, le coton égyptien prédomine. Jusqu'en 1909, il avait même joui d'un monopole au point de vue de son adaptation à un procédé industriel tendant à donner au coton l'aspect de la soie. Ce procédé, appelë mercerisation, du nom de son inventeur Mercer, a reçu, depuis lors, de nouveaux perfectionnements qui ont permis de l'appliquer aux belles qualités de l'américain. Cette nouvelle extension du procédé n'a cependant influé en rien sur les valeurs respectives des deux qualités, puisque l'égyptien continue à bénéficier d'une prime très importante par rapport à son rival.

Mais voici mieux encore: en 1909, date de l'extension du procédé Mercer au coton américain, la prime de l'égyptien n'avait été que de $530 / 0$; elle est remontée, l'année dernière, à $690 / 0$; ce qui prouve bien que la mercerisation de l'américain n'a pu lui faire regagner l'écart de prix qui le sépare de l'égyptien.

Il est vrai qu'il existe en Amérique quelques variétés de coton très fin, telles que la Sea Island, qui pourraient, sans contredit, remplacer le coton égyptien, mais leurs prix sont trop élevés et la quantité produite est absolument insuffisante, puisqu'elle ne représente que $0,500 / 0$ de la production mondiale. 



\section{Planche V}

\section{Coton EGyPTIEN EXPORTÉ en $1910: 6.009 .406$ kant.}

ANGLETERRE

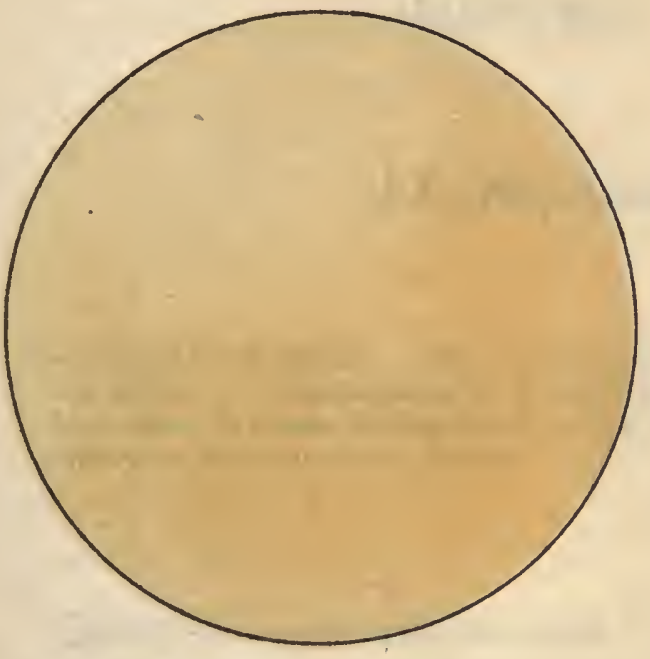

3.034.126 kantars

$\varepsilon A T S-U N / s$

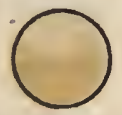

${ }^{8} 6.400 \mathrm{kan}^{3 \mathrm{P}^{5}}$

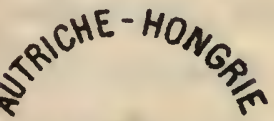

0

${ }^{2} 8.089 k 0^{50}$
FRANCF

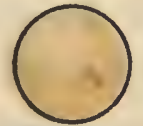

53.5.5 kank

SUISSE

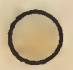

${ }^{3} 5.715 k 0^{x-0}$
PLLEMAGNS

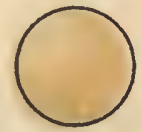

$554.569 \mathrm{kanta}^{\mathrm{rs}}$
RUSSIE

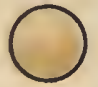

$3^{3} 5.721 \mathrm{kan}^{n 0^{5}}$

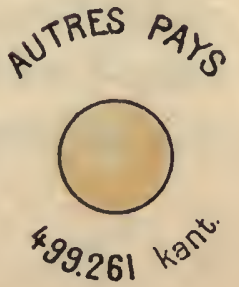

Pays importateurs de Coton égyptien. 


\section{$1-n|r|$}

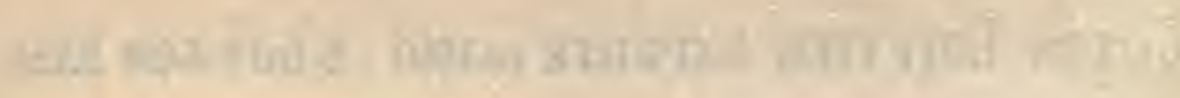

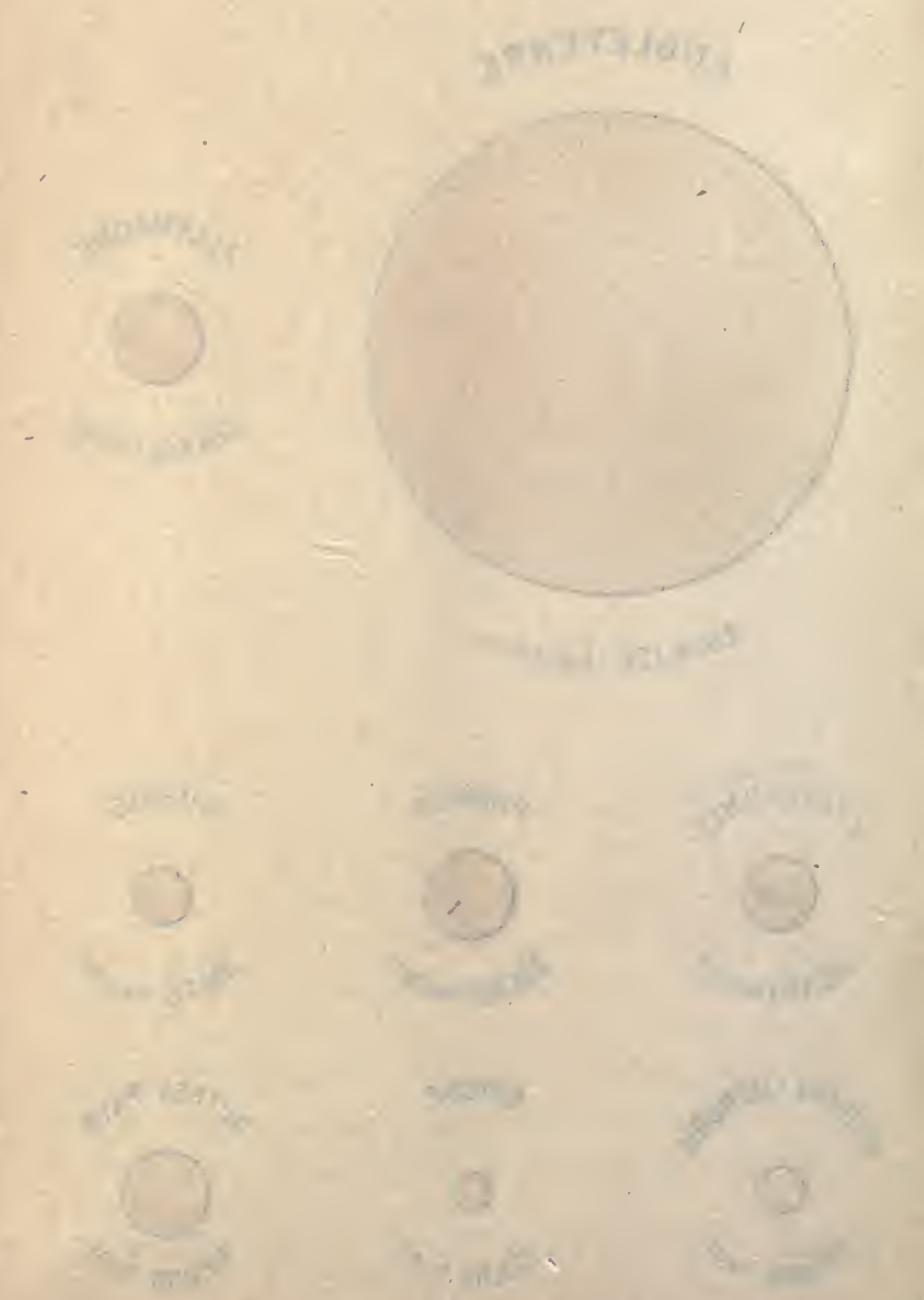

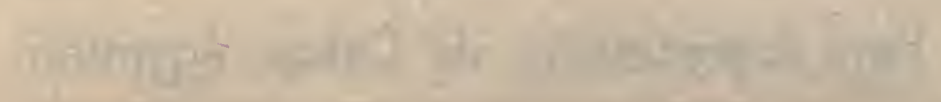




\section{CHAPITRE V}

\section{LE FELLAH}

Ses qualités et ses défauts. - Son amour de la terre. - Comment il place son argent. - Augmentation de la petite propriété. - Mesures prises pour élever le niveau intellectuel du fellah, améliorer son état moral et mettre en œuvre toute son énergie.

Que n'a-t-on pas écrit du fellah ? Les uns l'ont dépeint dans les ports, occupé à transporter du charbon à bord des navires et déployant, dans cette tâche, une activité d'autant plus surprenante pour l'étranger qu'elle s'exerce sous un ciel accablant; d'autres le montrent en plein champ, manœuvrant, sous le soleil de l'été, un appareil à élever l'eau et restant des heures et des heures attelé à cette besogne monotone autant qu'ingrate; d'autres enfin, prédisposés à l'admiration par les descriptions de ceux qui les avaient devancés, ont montré en lui l'image de l'homme de la glèbe, du travailleur sans trêve ni repos. Pourtant, lorsqu'on l'étudie plus attentivement, lorsque le commerce des affaires vous met en contact fréquent avec lui, lorsqu'enfin on s'est fait graduellement aux con- 
ditions sociales et climatériques du milieu, l'impression se modifie et le jugement se déplace.

Alors le fellah apparaît sous son véritable aspect avec ses qualités et ses défauts : vigueur, endurance, sobriété, mais aussi imprévoyance, manque d'esprit de suite, désordre, crédulité superstitieuse, apathie routinière. Commandé ou stimulé par une cause agissant sur son tempérament, il est, bien alors tel que l'ont montré tous les écrivains : travailleur acharné opposant à la fatigue et aux incommodités une résistance et une endurance extraordinaires. Mais aujourd'hui, le fellah est livré à lui-même ; libre, il dispose de son activité à son gré et, les stimulants lui faisant défaut, il est loin de dépenser au profit de la terre toute l'activité dont il est susceptible. Plus instruit, plus intéressé surtout, il pourrait tripler le rendement de son sol. Par intéressé, nous entendons l'homme qui calcule, prévoit, surveille les événements, suppute sans cesse ses gains et ses pertes, s'ingénie à grossir ses bénéfices, surveille d'un œil jaloux l'administration de ses biens. Tel nous apparait le paysan d'Europe, et tel n'est pas le fellah. Dans son fatalisme, ce dernier pousse le renoncement jusqu'à une résignation presque complète aux événements défavorables qui peuvent affecter ses intérêts. Maislà, où il se ressaisit 'et rachète son aveugle soumission aux arrêts de la fortune, c'est lorsqu'il s'agit de la possession de la terre.

Le fellah professe pour elle le culte de l'enfant pour sa mère qui le nourrit et le comble de caresses. Tous ses 
efforts sont employés à améliorer ou à étendre son champ. Resté, jusqu'à présent, l'homme de la nature, réfractaire au progrès économique, profondément traditionnaliste, s'il a de l'argent d'épargne, ce n'est pas à une banque qu'il le confiera, ce n'est pas en valeurs de Bourse qu'il le convertira; il l'emploiera soit à l'achat de nouvelles terres, soit à l'amélioration de celles qu'il a déjà. Manque-t-il à cet effet de l'argent nécessaire, il n'hésitera pas à emprunter ; il ne faut pas qu'il laisse passer l'occasion qui s'offre à lui, car la terre demeure l'objet de son ardente convoitise, et il n'est pas de sacrifices auxquels il ne soit disposé pour satisfaire sa passion.

Aussi, lorsque, pour une raison quelconque, une propriété est mise en vente, elle ne reste pas longtemps sans acheteur, et le nombre des compétiteurs est tel qu'elle change rarement de maître sans bénéficier.d'une plusvalue plus ou moins importante.

Certes, le paysan de tous les pays est un peu égyptien par son âpreté à acquérir le sol. Mais nul plus que le fellah n'y concentre sa vie, n'y borne tout son idéal. Lui seul en est encore à enfouir son argent quand il n'en trouve pas l'emploi dans la terre. Ne lui parlez pas d'autre placement, il n'en a cure.

Aussi est-on frappé de ce fait que les petits propriétaires de moins de cinq feddans possèdent presque le quart du sol, et qu'en moins de quatorze ans ils ont augmenté leurs propriétés de $37,180 / 0$, et cela grâce à leurs exceptionnelles qualités de travail, d'endurance et de sobriété. 
“Qui n’a pas voyagé le long du Nil, dit M. Paul Adam, " qui n'a pas traversé ces villages de limon sec et de " chaume, qui n'a pas visité ces fermes au mobilier som“ maire, qui n'a pas goûté la crêpe de froment et la salade " de graines mangées par ces familles vêtues de chemises " noires ou bleues, de voiles simples et de maigres tur" bans, celui-là ignorera toujours les prodiges de renon" cement possibles au caractère humain. "

Mais au tableau que nous venons de tracer, il y a une ombre. Le fellah serait le modèle achevé du parfait cultivateur si ses remarquables qualités n’étaient atténuées par l'ignorance, la routine et le défaut d'esprit de suite Une fois entré en possession de la terre qu'il a si ardemment convoitée, il s'occupera de la mettre en état, c'est-àdire qu'il y fera les travaux nécessités par les besoins de l'irrigation, du drainage et par les services de l'exploitation. Malheureusement, cela fait, sa sollicitude s'endormira. Il ne cherchera pas à tirer de la terre toutes les ressources qu'elle est en mesure de lui donner, ne dépensant à son profit qu'une parcelle de l'effort nécessaire et dont il est éminemment capable, ne consentant à aider la nature dans son travail de fécondation que tout juste assez pour satisfaire ses besoins immédiats. Cette négligencesemble un héritage des temps où tout le pays était au régime de l'inondation, régime qui, nous l'avons vu, permet de se passer de toute préparation du sol et de l'abandonner à l'action fertilisante de la nature.

Mais aujourd'hui le territoire soumis à ce régime est 
considérablement réduit. L'irrigation pérenne et, avec elle, le système d'assolement intensif se développent de plus en plus. Les cultures font suite aux cultures sans intervalle de repos pour la terre. Les matières fertilisantes apportées par le Nil ne suffisent pas, dans ces conditions, à lui restituer celles qui sont absorbées par la végétation continue. Or, non seulement cette restitution ne se fait pas partout, ni dans la mesure nécessaire, mais les labours et les quasilabours ne sont effectués que très imparfaitement, si même ils ne font, les uns et les autres, totalement défaut. Ainsi donc, et sauf pour le cotonnier, qui seul reçoit en général des soins plus attentifs, on peut dire que la terre n'est pas de la part du fellah l'objet de tous les soins convenables. Celui-ci s'est laissé persuader que la rente du sol devait être uniquement fournie par le cotonnier et que les autres cultures n'avaient d'autre raison que de couvrir par leur produit les frais d'exploitation.

La conséquence de cet état de choses ne pouvait que placer le pays dans la situation d'infériorité où il se trouve au point de vue de la production, exception faite pour celle du coton, où, comme nous l'avons vu, il occupe le premier rang. Ne semble-t-il pas cependant que ce rang devrait lui être acquis pour tous ses produits, étant donné qu'il est en possession d'un milieu réunissant au plus haut point toutes les conditions essentielles de prospérité agricole : sol alluvial enrichi tous les ans des apports fertilisants du Nil; climat régulier dont la température est particulièrement favorable aux cultures et à l'abri de 
tous les troubles atmosphériques, gelée, grêle, ouragans ; eau à volonté arrivant par canaux et distribuée avec toute la méthode nécessaire par une administration vigilante; main-d'œuvre d'une abondance et d'un bon marché uniques; engrais naturels formant des dépôts accumulés depuis des siècles; voies de navigation intérieure multiples, rendant les transports aussi économiques que possible; que sais-je encore? Enfin, un ensemble d'éléments qui, nulle part, ne se rencontrent, réunis ou isolés, au même degré de puissance. Remarquons aussi que la réunion de ces éléments, que ces réserves de forces enviables à tous égards ne sont rien cependant comparées à l'énergie dont la nature a doté le fellah, énergie qui, malheureusement, reste à l'état potentiel, mais dont il sait à l'occasion donner la mesure lorsqu'il se met au travail.

N'est-il pas déplorable que l'effet utile de toutes ces forces soit à peine appréciable relativement à leurs intensités respectives ? Que sont, en effet, les six ardebs de blé par feddan que l'on obtient des bonnes terres? D'ailleurs, pour l'ensemble du pays, la moyenne n'est que de quatre ardebs, alors qu'en Europe, particulièrement dans les pays du Nord, la moyenne est de beaucoup supérieure, comme le montre le tableau que nous consacrons plus loin à la population comparée.

Est-ce qu'avec les ressources merveilleuses dont il dis pose, le pays ne devrait pas venir en tête avec un rendement moyen de dix arbeds au moins? Est-ce que les terres particulièrement soignées en Égypte ne donnent 
pasjusqu'à 12 ardebs ? Est-ce que l'aptitude du sol, composé partout des mêmes éléments, n'est pas la même dans toute la vallée du Nil ? Pourquoi, aux ressources considérables de la production cotonnière - principal élément de la vie du pays dans ses rapports avec l'extérieur - ne viendraient pas s'ajouter celles des autres produits agricoles, qui, sans prétendreégaler les premières, permettraient du moins d'affranchir l'Égypte de sa dépendance vis-àvis de l'étranger pour les céréales ? C'est un aveu pénible à faire, mais l'Égypte, par suite de la densité considérable de sa population, importe, en moyenne, pour 40 millions de francs de farine par an, sans compter les sommes qu'elle consacre à l'achat d'autres produits alimentaires. Tout cela peut changer du tout au tout, à la volonté du fellah, le jour où son esprit aura modifié son orientation. L'effort, nous le savons, ne lui coûte presque rien, c'est à vouloir le dépenser davantage au profit de la terre qu'on désirerait le voir tendre. Le jour où ce désir sera devenu une réalité et en tenant compte, d'autre part, des ressources que réserve à l'Egypte l'exploitation du Canal de Suez, à l'expiration de la concession actuelle, ce pays pourra se flatter d'avoir la situation économique la plus brillante qu'il soit possible de posséder. Pour ceux qui suivent de près l'évolution qui est en train de s'accomplir, il semble que ce jour ne soit pas aussi éloigné que pourrait le faire supposer la tyrannie des traditions millénaires sous l'empire desquelles le fellah a toujours vécu. S'il est resté jusqu'à présent immuable dans ses habitudes, s'il s'est 
montré insouciant de ses véritables intérêts, c'est, d'un côté, faute d'enseignement et d'exemples, et, de l'autre, faute de stimulants actifs. Mais, comme on le verra plus loin, le moment semble venu où exemples, enseignement et stimulants vont s'offrir à lui.

Depuis la crise financière de 1907, un vent régénérateur a soufflé sur le pays. Le mouvement qu'il a imprimé et qui a pris naissance dans les grands centres n'a pas tardé à se propager sur toute l'étendue du territoire. Embrassant tous les domaines de l'activité, il semble surtout s'exercer avec plus d'énergie sur le terrain économique. Or, le terrain économique n'est autre que le terrain agricole, base unique de la richesse du pays. Après avoir longtemps résisté aux réclamations multipliées du public, le Gouvernement, prenant aujourd'hui la tête du mouvement, vient de créer un Département de l'Agriculture. Pour compléter cette œuvre, il a institué une Direction spéciale de l'Enseignement technique, agricole et commercial. Un excellent ouvrage sur l'agriculture égyptienne, dont nous avons déjà fait mention, vient d'être édité par ses soins.

Le public éclairé, dans un élan de générosité des plus louable, s'est imposé des sacrifices pour améliorer la situation morale du fellah, stimuler son intérêt, aider à son instruction. De nombreuses écoles agricoles se sont fondées dans les divers centres, tant par les soins de l'Administration seule qu'avec le concours de l'initiative privé?. Allant plus avant dans cette voie, le Pouvoir exécutif a rendu dernièrement un décret autorisant les Conseils 
provinciaux, dont il a en même temps étendu les pouvoirs, à percevoir une taxe additionnelle de $50 / 0$ à la Cote financière pour être employé exclusivement à la diffusion de l'instruction publique. Détail digne d'être noté, la nouvelle charge a été acceptée avec empressement, presque avec joie, eu égard à sa destination, tellement on est désireux de sortir de l'ornière séculaire dans laquelle on est resté jusqu'à présent. Aux nombreuses missions scolaires envoyées en Europe par le Gouvernement et par certaines Administrations universitaires, se joindront bientôt celles que les Conseils provinciaux se proposent d'entretenir, de leur côté, avec une partie du produit de la nouvelle taxe. Le but spécial de ces missions sera de former des agronomes et des techniciens qui, de retour au pays, seront engagés comme professeurs dans les établissements de nouvelle création.

De son côté, la Société khédiviale d'Agriculture, qui a un caractère quasi officiel, est entrée dans une voie plus active en procédant à la création de champs d'essais dont le nombre va naturellement s'augmenter, et en s'occupant, en outre, de l'élevage et de l'amélioration de la race bovine, question de la plus haute importance pour l'agriculture du pays, où, en raison de l'abondance et du bon marché de la main-d'œuvre, la machine ne jouera jamais qu'un rôle très secondaire. Enfin, l'élan est donné et bientôt le pays se trouvera doté de tous les moyens pouvant aider à la prospérité de l'agriculture.

Il est donc permis d'espérer que l'instruction, en général, 
et l'enseignement agricole, en particulier, pénétrant graduellement dans toutes les parties du pays, trouveront chez le fellah une intelligence apte à les recevoir et à se les assimiler; alors son esprit, refondu dans un nouveau moule, prendra l'orientation nécessaire pour ne plus laisser se perdre sans profit la puissante énergie dont la nature l'a doté. 


\section{GHAPITRE VI}

\section{TERRITOIRE ET POPULATION}

Etendue totale de la vallée du Nil. - Terres cultivées et incultes. Densité et augmentation constante de la population. - Composition de la population rurale et urbaine. - Répartition du sol. - Nombre élevé des petits propriétaires.

Superficie. - L'édition de 1910 de l'Annuaire statistique de l'Égypte nous fournit des données qui sont en désaccord avec celles de la précédente édition. Ces dernières étant plus conformes à la vérité et, d'ailleurs, en concordance avec les divers auteurs qui ont étudié la question, nous croyons devoir nous y tenir. Suivant elles, la superficie totale du territoire s'élève à 930.000 kilomètres carrés, dont 33.595 , soit la $27 \mathrm{e}$ partie de l'ensemble, représentent la vallée du Nil. Le reste est occupé par les deux déserts de l'Est et de l'Ouest et par la presqu'île du Sinaĩ. (Voir la carte, planche I.)

D'après les relevés du Ministère des Finances, la superficie possédée ayant acquitté la taxe foncière, en 1909, s'est élevée à 5.620 .000 feddans, équivalant à 2.360 .400 


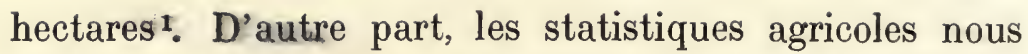
fournissent les données suivantes pour 1908-19092.

Terres cultivées. 5.373 .982 fed: 2.257 .072 hectares.

Terres incultes. $1.101 .712-462.719$ -

Totaux . $\overline{6.475 .694}$ fed. $\overline{2.719 .791}$ hectares.

Dans ces derniers chiffres ne sont pas comprises les terres appartenant à l'Administration des domaines de l'Etat égyptien, lesquelles accusaient, au 31 décembre 1908, une superficie de 155.103 feddans ( 65.143 hectares).

Enfin, si nous considérons la décomposition de l'éten. due totale de la vallée, nous trouvons les chiffres suivants : Terres cultivées, y compris celles de

l'Administration des Domaines. 23.222 kilom carrés. Terres en friches. . . . . . . 4.627

Nil, canaux, plantations de dattiers

et lacs . . . . . . . . . . $\frac{5.746}{33.595}$ kilom. carrés.

Population. - "La fertilité de son sol, l'exiguïté de son " territoire inextensible, la fécondité de la race qui l'oc" cupe, les obstacles opposés à l'émigration par la mer et "les déserts, tout contribue à faire de l'Égypte un pays " de population très dense."

Le tableau III ci-après, empruntéà l' Annuaire statistique de l'Égypte (1910), indique les chiffres des recensements

1. Annuaire statistique de l'Égypte (1910), p. 274.

2. Ibid., p. 238. 
de 1800, 1821, 1846 et, à la suite, le chiffre annuel de la population depuis 1880 . On y voit que le nombre total des habitants qui, à cette époque, était de 2.460 .200 , avait atteint, en 1907, date du dernier recensement, 11.287.359, accusant ainsi une augmentation totale de 8.827 .159 habitants et un accroissement annuel moyen de 83.275 habitants.

Dans les dix dernières années (1899-1908), l'augmentation moyenne annuelle a été de 142.879 habitants.

Par rapport à la superficie du territoire habité qui, on l'a vu, est de 33.595 kilomètres carrés, la population de 1907 représente donc 335 habitants par kilomètre carré, laissant loin derrière elle celle du plus peuplé des Etats européens, la Belgique, qui compte seulement 227 habitants par kilomètre carré. (Voir tableau $I V$.)

Nous devons faire observer que le chiffre de 11.287.359 habitants est celui du dernier recensement de 1907; d'après l'Annuaire statistique de l'Égypte de 1911, la population égyptienne est, pour l'année 1910, de 11.799.868 habitants; ce qui représente 351,23 habitants par kilomètre carré, au lieu de 335,98 indiqué ci-dessus. Nous avons voulu nous en tenir à ce dernier chiffre de 335,98 afin de baser nos calculs uniquement sur les derniers recensements aussi bien de l'Égypte que des autres Etats dont la population a également augmenté, mais dans une proportion beaucoup moindre.

" Nulle part ailleurs au monde, en dehors du Bengale, " on ne saurait trouver une population áussi dense étran- 
" gère au travail industriel. Cette densité est très variable, " et la façon dont les habitants sont répartis atteste " l'importance vitale du Nil pour l'Egypte. Dans l'Egypte " méridionale, où la surface cultivable forme de chaque " côté du Nil une marge très étroite, la population est " très dense. Mais, dans les parties de l'Égypte moins " resserrées, on constate une diminution de densité " d'autant plus forte que l'on s'éloigne plus ou moins du "fleuve ${ }^{1}$."

Examinons maintenant la composition de la population égyptienne.

D'après le recensement de 1907 , elle se répartissait ainsi :

\begin{tabular}{rr} 
Habitant les villes. . . . . & 1.930 .137 \\
Nomades.. . . . . . . . & 97.741 \\
Habitant la campagne. . & 9.259 .481 \\
Total . . . . . . & 11.287 .359 \\
\hline
\end{tabular}

Les habitants de la campagne représentaient donc, en 1907, les 82 0/0 de la population totale.

L'activité de cette population se répartit comme suit $^{2}$ :

$\begin{array}{lr}\text { Industrie. . . . . . . . } & 477.477 \\ \text { Commerce . . . . . . } & 161.210 \\ \text { Mines et carrières. . . . } & 4.112 \\ \text { Ouvriers agricoles . . . . } & 2.440 .030\end{array}$

1. The Census of Egypt (1907), p. 3.

2. Annuaire statistique de l'Égypte (1910), p. 25. 
Le nombre infime des ouvriers occupés dans les mines et les carrières montre bien qu'en dehors de l'agriculture le pays n'a pas ou n'exploite pas de richesses naturelles. Notons aussi que les industries dont il s'agit sont, en général, des métiers, la grande industrie proprement dite n'étant nullement représentée dans le pays.

Comme on le voit, la classe qui prédomine, et par le nombre et par la richesse, est celle des agriculteurs.

Voici, d'autre part, comment se partageaitla propriété du sol en $1909^{1}$ :

Nombre de propriétaires.

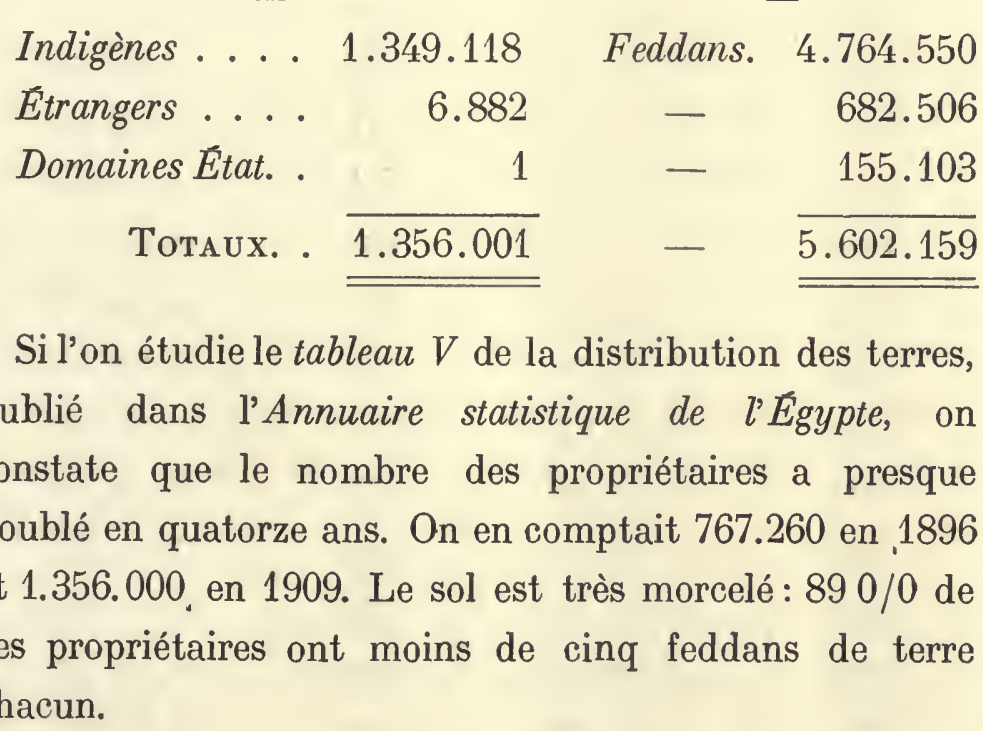

Superficie cultivée.

$x^{2}$




\section{TABLEAU III}

Population de l'Égypte de 1800 à $1910^{1}$

\begin{tabular}{|c|c|c|c|c|}
\hline ANNÉES & POPULATION & ANNEES & POPULATION & \\
\hline 1800 & 2.460 .200 & 1894 & 9.068 .722 & \\
\hline 1821 & 2.536 .400 & 1895 & 9.285 .398 & \\
\hline 1846 & 4.476 .440 & 1896 & 9.507 .251 & \\
\hline 1880 & 6.516 .040 & 1897 & 9.734 .405 & \\
\hline 1881 & 6.671 .726 & 1898 & 9.879 .562 & \\
\hline 1882 & 6.831 .131 & 1899 & 10.026 .883 & \\
\hline 1883 & 6.994 .345 & 1900 & 10.176 .402 & \\
\hline 1884 & 7.161 .459 & 1901 & 10.328 .150 & \\
\hline 1885 & 7.332 .556 & 1902 & 10.482 .161 & \\
\hline 1886 & 7.507 .761 & 1903 & 10.638 .469 & \\
\hline 1887 & 7.687 .142 & 1904 & 10. 797.108 & \\
\hline 1888 & 7.870 .809 & 1905 & 10.958 .112 & \\
\hline 1889 & 8.058 .864 & 1906 & 11.121 .517 & \\
\hline 1890 & 8.251 .412 & 1907 & 11.287 .359 & " \\
\hline 1891 & 8.448 .561 & 1908 & 11.455 .673 & \\
\hline 1892 & 8.650 .420 & 1909 & 11.626 .497 & \\
\hline 1893 & 8.857 .102 & 1910 & 11.799 .868 & \\
\hline
\end{tabular}

1. Annuaire statistique de l'Égypte (1911), p. 23 et 288. 


\section{TABLEAU IV}

Territoires et Populations

(Statistique comparée)

\begin{tabular}{|c|c|c|c|c|}
\hline \multirow{2}{*}{$\begin{array}{c}\text { DÉSIGNATION } \\
\text { DES } \\
\text { PAYS }\end{array}$} & \multirow{2}{*}{$\begin{array}{l}\text { SUPER- } \\
\text { FICIE (1) } \\
\text { EN } \\
\mathrm{Km}^{2}\end{array}$} & \multicolumn{2}{|c|}{ POPULATION (2) } & \multirow{2}{*}{$\begin{array}{l}\text { DEN- } \\
\text { SITE } \\
\text { PAR } \\
\mathrm{Km}^{2}\end{array}$} \\
\hline & & $\begin{array}{c}\text { D A T B } \\
\text { DES } \\
\text { RECESSYWNTS }\end{array}$ & $\begin{array}{l}\text { POPULATION } \\
\text { TOTALE }\end{array}$ & \\
\hline Allemagne ... & 540.647 & 1910 & 64.903 .423 & 120,04 \\
\hline Autriche ........ & 300.007 & 1910 & 28.567 .898 & 95,22 \\
\hline Hongrie ....... & 324.918 & 1910 & 20.850 .700 & 64,17 \\
\hline Belgique.... & 29.455 & 1900 & 6.693 .548 & 227,24 \\
\hline Danemark. . & 38.969 & 1906 & 2.605 .268 & 66,85 \\
\hline Égypte... & $33.595(3)$ & 1907 & 11.287 .359 & 335,98 \\
\hline Etats-Unis...... & $7.835 .995(4)$ & 1910 & 93.402 .151 & 11,91 \\
\hline France $\ldots . . \ldots \ldots$ & 529.557 & 1906 & 39.252 .245 & 74,12 \\
\hline $\begin{array}{r}\text { Grande }- \text { Bretagne } \\
\text { et Irlande.... }\end{array}$ & 313.691 & 1901 & 41.976 .827 & 133,81 \\
\hline Italie.......... & 286.648 & 1909 & 34.565 .000 & 120,58 \\
\hline Pays-Bas... & 32.599 & 1909 & 5.898 .429 & 180,93 \\
\hline $\begin{array}{l}\text { 1. Statistique ag } \\
\text { 2. Statesmans's } \\
\text { 3. Statistical Ye } \\
\text { 4. Annuaire sta }\end{array}$ & $\begin{array}{l}\text { ricole annuelle } \\
\text { Yearbook (1911) } \\
\text { arbook of Egypt } \\
\text { tistique de la F }\end{array}$ & $\begin{array}{l}(1909) . \\
(1909) . \\
\text { Trance }(1\end{array}$ & & \\
\hline
\end{tabular}




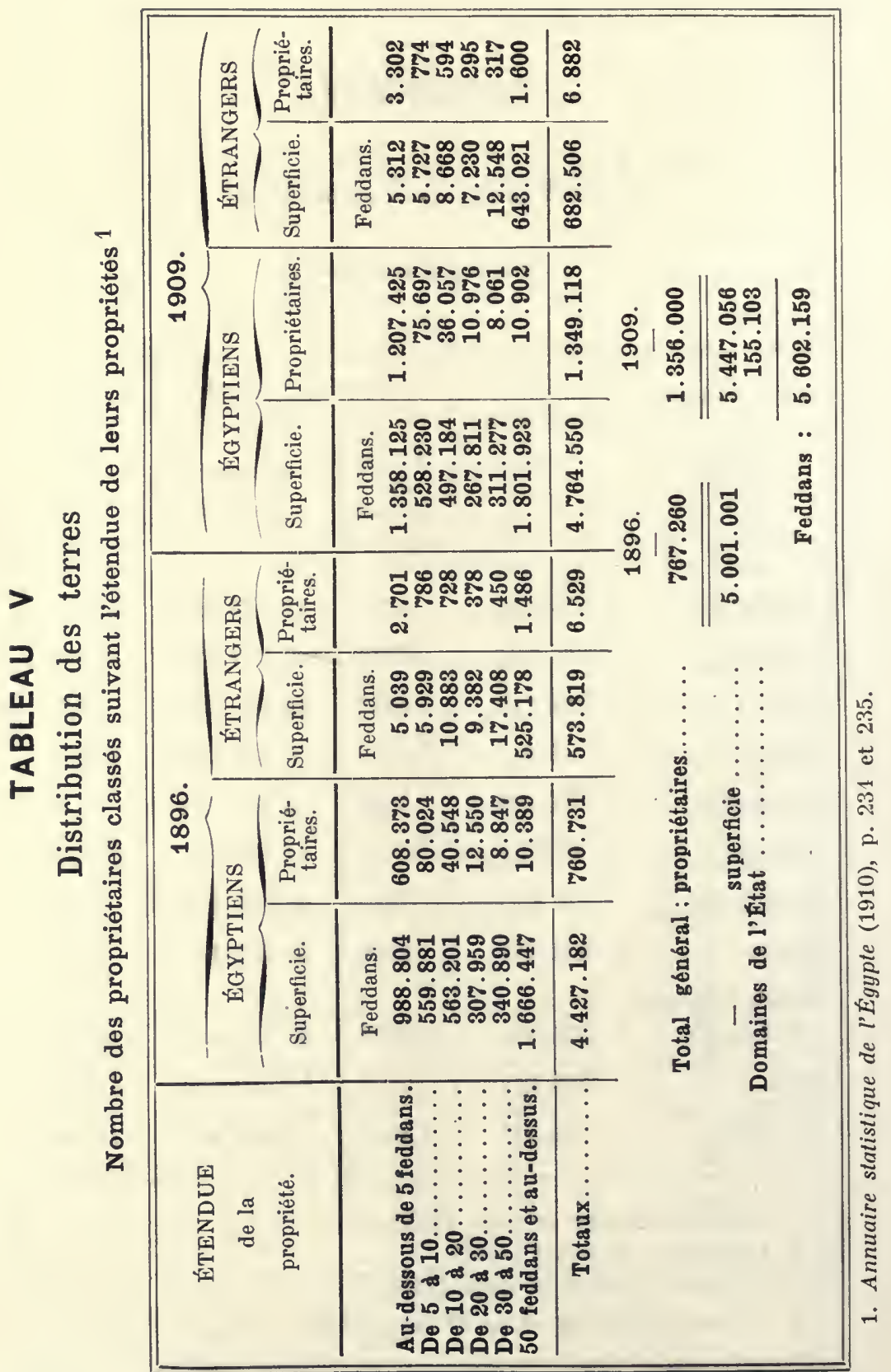




\section{CHAPITRE VII}

\section{ÉTAT POLITIQUE}

Suzeraineté de la Turquie. - Statut international. - Corps élus. Divisions administratives. - Bienfaits de l'occupation anglaise.

Après avoir été pendant longtemps simple province de l'Empire Ottoman, depuis la conquête de Sélim Ier, en 1517, jusqu'à la réunion de la conférence de Londres, en 1840, l'Egypte vit reconnaître par cette dernière et sanctionner par la Sublime Porte les droits à l'autonomie que lui avait acquis la haute valeur militaire et politique de l'illustre chef qui dirigeait ses destinées, Méhémet-Aly.

Cette autonomie, accordée au profit de la dynastie de Méhémet-Aly, fut confirmée et étendue par firmans successifs, puis définitivement consacrée par l'érection de l'Egypte en khédivat (vice-royauté) sous Ismaill-Pacha, de fastueuse mémoire. Depuis lors, les liens de l'Egypte avec sa suzeraine la Turquie n'ont plus consisté que dans les trois obligations suivantes : 10 Investiture des nouveaux khédives; $2^{\circ}$ payement d'un tribut annuel de 
150.000 bourses (17.140.207 francs); 30 interdiction de conclure des traités politiques et d'avoir des représentations officielles à l'étranger. Pour tout le reste : administration intérieure, émissions d'emprunts intérieurs ou extérieurs, conclusion de traités de commerce, etc., l'Egypte jouit d'une liberté absolue.

Avant de passer à l'examen de ses institutions actuelles, il convient de faire remarquer, avec tous ceux qui ont étudié la question au point de vue juridique, que la conférence de Londres de 1840, en donnant un nouveau statut à l'Egypte, a revêtu ce dernier du caractère d'acte international. Ce caractère n'a pas cessé, depuis lors, de s'affirmer et de se manifester dans les rapports prinpaux de l'Égypte avec sa suzeraine (firmans divers délivrés après assentiment des puissances représentées à Ia conférence, auxquelles se joignit postérieurement la France).

Depuis l'occupation anglaise, en 1882, l'Egypte est administrée intérieurement de la façon suivante:

Corps élus. - Ils sont au nombre de trois dont un avec voix consultative seulement: le Corps législatif, et deux avec voix délibérative restreinte à certaines questions : l'Assemblée générale des Notables et l'ensemble des Conseils provinciaux.

Administration proprement dite. - On divise ordinairement l'Egypte en deux régions, savoir: la HauteEgypte, au sud, et la Basse-Egypte, au nord du Caire. Au point de vue administratif, l'Egypte se divise en quatorze Moudiriehs et cinq Gouvernorats (Alexandrie, El Ariche, 
Le Caire, Sinaï et Canal). Les quatorze Moudiriehs se subdivisent en quatre-singt-quatre Markaz ou districts. La ville la plus importante et la capitale du pays, c'est Le Caire ayant une population de 654.476 habitants. Mais la ville principale des affaires, c'est la ville d'Alexandrie, qui a une population de 370.009 habitants.

L'importance de la ville du Caire dérive de ce qu'elle se trouve au point de jonction de la Haute à la BasseÉgypte. De tout temps, il a existé à cet endroit une grande ville. C'est là que se croise la route unissant le Nord au Sud avec celle qui réunissait autrefois l'Orient à l'Europe et à l'Afrique occidentale. La ville d'Alexandrie doit son importance commerciale à son port.

En dehors de ces deux grandes villes, l'Égypte compte 43 villes ayant plus de 10.000 habitants et 3.580 villages.

Le système administratif égyptien est essentiellement centralisateur.

Il semble inutile de faire le tableau complet des bienfaits que l'occupation anglaise a apportés à l'administration du pays. Il nous suffit de dire qu'en remplaçant l'ancien État politique par un régime d'ordre, de bonne administration financière et économique, de progrès continu, en substituant le régime de la loi au régime de l'arbitraire, en rassurant les intérêts et en encourageant les fécondes initiatives, en concevant et en mettant à exécution ce vaste ensemble de travaux publics, qui, à juste titre, fait l'admiration du monde, l'Angleterre a ouvert à l'Égypte une ère de prospérité jusqu' alors inconnue. 


\section{CHAPITRE VIII}

\section{FINANCES}

Revenus publics. - Augmentation continue des excédents de recettes.

Un! pays qui doit sa prospérité à la sagesse de son administration ne peut avoir de mauvaises finances; qui peut le plus peut le moins, la tâche la plus difficile consistant à faire passer un peuple de l'état précaire à l'état prospère. Le tableau VI, ci-contre, montre la progression des revenus publics de 1880 à 1909. On les voit monter de L. E. $8.998 .399(233.270 .226$ francs), en 1880, à L. E. 15.402.872 (399.296.746 francs) en 1909, accusant, entre ces deux années, un écart de L. E. 6.404 .473 (166.026.520 francs), soit une augmentation de 71 0/0 en faveur de 1909.

De même que les revenus, les dépenses ont augmenté; c'est qu'il a fallu en même temps doter le pays de tous les instruments économiques, organes de sa prospérité.

Malgré le développement de ces dépenses et grâce surtout à la présence de la Caisse de la Dette, qui, jusqu'à la Convention franco-anglaise de 1904, a exercé un con- 
trôle effectif sur les finances publiques, au point de vue des dépenses extraordinaires, les revenus généraux ont laissé des excédents annuels pendant toute la période qui a suivi celle de la réorganisation des finances, période commencée en 1889, et se continuant encore. Le tableau VII, emprunté comme le précédent à l'Annuaire statistique de l'Egypte (1910), nous fait connaitre les chiffres annuels des excédents pendant cette période.

De L. E. 218.427 (5.662.397 francs), en 1889, ces excédents se sont élevés progressivement d'année en année pour atteindre L. E. 3.102 .087 (80.417.031 francs), en 1904, année à partir de laquelle les pouvoirs de la Caisse de la Dette sur le contrôle des dépenses extraordinaires ont cessé (conséquence de l'accord franco-anglais de 1904).

Depuis lors, les excédents ont été en diminuant jusqu'en 1908, où ils sont tombés alors à L. E. 1.113.631 (28.869.241 francs). L'année suivante (1909), il y eut une petite reprise: l'excédent fut de L. E. 1.161.270 (30.104.212 francs).

Il faut dire enfin que, depuis la convention, les services publics ont beaucoup plus accentué leur développement que dans la période antérieure, ce qui explique l'absorption par les dépenses d'une part, chaque année plus grande, des excédents.

Au total, pour toute cette période de 1889 à 1910, les excédents ont été de L. E. 29.780 .033 (772.003.447 francs), ce qui correspond à une moyenne annuelle de L. E. 1.418.096 (36.762.047 francs). 


\section{$-66-$}

\section{TABLEAU VI}

\section{Revenus.du Gouvernement ${ }^{1}$}

Diminution de l'impot par rapport à la population

(EN LIỴRES ÉGYPTIENNES)

\begin{tabular}{|c|c|c|c|c|}
\hline ANNÉES & $\begin{array}{c}\text { CONTRIBUTIONS } \\
\text { et droits. }\end{array}$ & POPULATION & $\begin{array}{c}\text { TAXE } \\
\text { par } \\
\text { habitant }\end{array}$ & $\begin{array}{c}\text { ENSEMBLE } \\
\text { des } \\
\text { recettes ordinaires }\end{array}$ \\
\hline 1880 & $\begin{array}{l}\text { L. E. } \\
\text { Y. 294.500 }\end{array}$ & 6.516 .040 & $\begin{array}{l}\text { L. E. Mill. } \\
1,119\end{array}$ & $\begin{array}{l}\text { L.E. } \\
\text { 8.998.399 }\end{array}$ \\
\hline 1881 & 7.382 .499 & 6.671 .726 & 1,106 & 9.229 .965 \\
\hline 1882 & 7.172 .211 & 6.831 .131 & 1,050 & 8.852 .857 \\
\hline 1883 & 7.241 .710 & 6.994 .345 & 1,035 & 8.934 .675 \\
\hline 1884 & 7.520 .642 & 7.161 .459 & 1,050 & 9.403 .294 \\
\hline 1885 & 7.634 .710 & 7.332 .566 & 1,041 & 9.637 .173 \\
\hline 1886 & 7.834 .259 & 7.507 .761 & 1,043 & 9.574 .393 \\
\hline 1887 & 7.748 .785 & 7.687 .142 & 1,008 & 9.616 .358 \\
\hline 1888 & 7.892 .980 & 7.870 .809 & 1,003 & 9.661 .436 \\
\hline 1889 & 7.908 .706 & 8.058 .864 & 0,981 & 9.718 .958 \\
\hline 1890 & 8.286 .595 & 8.251 .412 & 1,004 & 10.236 .612 \\
\hline 1891 & 8.366 .374 & 8.448 .561 & 0,990 & 10.539 .460 \\
\hline 1892 & 8.068 .657 & 8.650 .420 & 0,933 & 10.297 .312 \\
\hline 1893 & 8.076 .660 & 8.857 .102 & 0,912 & 10.241 .866 \\
\hline 1894 & 7.903 .707 & 9.068 .722 & 0,871 & 10.161 .318 \\
\hline 1895 & 8.219 .862 & 9.285 .398 & 0,885 & 10.431 .265 \\
\hline 1896 & 8.344 .942 & 9.507 .251 & 0,878 & 10.693 .597 \\
\hline 1897 & 8.568 .352 & 9.734 .405 & 0,880 & 11.092 .564 \\
\hline 1898 & 8.489 .804 & 9.879 .562 & 0,859 & 11.131 .980 \\
\hline 1899 & 8.622 .346 & 10.026 .883 & 0,860 & 11.200 .303 \\
\hline 1900 & 8.772 .903 & 10.176 .402 & 0,862 & 11.447 .095 \\
\hline 1901 & 9.189 .621 & 10.328 .150 & 0,890 & 11.943 .924 \\
\hline 1902 & 9.214 .488 & 10.482 .161 & 0,879 & 11.933 .064 \\
\hline 1903 & 9.301 .592 & 10.638 .469 & 0,874 & 12.248 .108 \\
\hline 1904 & 10.105 .389 & 10.797 .108 & 0,936 & 13.690 .560 \\
\hline 1905 & 10.618 .396 & 10.958 .112 & 0,969 & 14.813 .346 \\
\hline 1906 & 10.891 .889 & 11.121 .517 & 0,979 & 15.337 .294 \\
\hline 1907 & 11.272 .022 & 11.287 .359 & 0,999 & $16.36 \% .818$ \\
\hline 1908 & 10.756 .137 & 11.455 .673 & 0,939 & 15.521 .775 \\
\hline 1909 & 10.783 .461 & 11.626 .497 & 0,928 & 15.402 .872 \\
\hline
\end{tabular}

1. Annuaire statistique de l'Égypte (1910), p. 266. 


\section{$-67-$ \\ TABLEAU. VI}

\section{Revenus du Gouvernement}

Diminution de l'impót par rapport à la population

(EN FRANCS)

\begin{tabular}{|c|c|c|c|c|}
\hline ANNÉES & $\begin{array}{c}\text { CONTRIBUTIONS } \\
\text { et droits }\end{array}$ & POPULATION & $\begin{array}{l}\text { TAXE } \\
\text { par } \\
\text { habitant }\end{array}$ & $\begin{array}{c}\text { ENSEMBLE } \\
\text { des } \\
\text { recettes ordinaires }\end{array}$ \\
\hline 1880 & $\begin{array}{c}\text { Francs. } \\
189.099 .157\end{array}$ & 6.516 .040 & $\begin{array}{l}\text { Francs. } \\
29\end{array}$ & $\begin{array}{c}\text { Francs. } \\
233.270 .226\end{array}$ \\
\hline 1881 & 191.380 .401 & 6.671 .726 & 28,67 & 239.273 .233 \\
\hline 1882 & 185.928 .995 & 6.831 .131 & 27,21 & 229.497 .265 \\
\hline 1883 & 187.730 .654 & 6.994 .345 & 26,83 & 231.618 .276 \\
\hline 1884 & 194.961 .555 & 7.161 .459 & 27,21 & 243.766 .532 \\
\hline 1885 & 197.918 .600 & 7.332 .566 & 26,98 & 249.829 .500 \\
\hline 1886 & 203.091 .613 & 7.507 .761 & 27,03 & 248.202 .022 \\
\hline 1887 & 200.875 .826 & 7.687 .142 & 26,13 & 249.289 .902 \\
\hline 1888 & 204.613 .869 & 7.870 .809 & 26 & 250.458 .483 \\
\hline 1889 & 205.021 .542 & 8.058 .864 & 25,43 & 251.949 .656 \\
\hline 1890 & 214.817 .757 & 8.251 .412 & 26,02 & 265.369 .073 \\
\hline 1891 & 216.885 .910 & 8.448 .561 & 25,66 & 273.219 .961 \\
\hline 1892 & 209.168 .036 & 8.650 .420 & 24,18 & 266.942 .631 \\
\hline 1893 & 209.375 .502 & 8.857 .102 & 23,64 & 265.505 .275 \\
\hline 1894 & 204.891 .950 & 9.068 .722 & 22,57 & 263.417 .187 \\
\hline 1895 & 213.087 .802 & 9.285 .398 & 22,94 & 270.415 .165 \\
\hline 1896 & 216.330 .317 & 9.507 .251 & 22,76 & 277.215 .735 \\
\hline 1897 & 222.121 .892 & 9.734 .405 & 22,81 & 287.558 .366 \\
\hline 1898 & 220.085 .651 & 9.879 .562 & 22,26 & 288.580 .168 \\
\hline 1899 & 223.521 .607 & 10.026 .883 & 22,29 & 290.351 .341 \\
\hline 1900 & 227.424 .575 & 10.176 .402 & 22,34 & 296.749 .060 \\
\hline 1901 & 238.227 .375 & 10.328 .150 & 23,07 & 309.628 .619 \\
\hline 1902 & 238.872 .015 & 10.482 .161 & 22,78 & 309.347 .090 \\
\hline 1903 & 241.130 .058 & 10.638 .469 & 22,65 & 317.514 .141 \\
\hline 1904 & 261.967 .310 & 10.797 .108 & 24,26 & 354.907 .582 \\
\hline 1905 & 275.266 .260 & 10.958 .112 & 25,11 & 384.014 .154 \\
\hline 1906 & 282.356 .163 & 11.121 .517 & 25,37 & 397.596 .733 \\
\hline 1907 & 292.210 .550 & 11.287 .359 & 25,89 & 424.311 .548 \\
\hline 1908 & 278.836 .992 & 11.455 .673 & 24,34 & 402.379 .131 \\
\hline 1909 & 279.545 .327 & 11.626 .497 & 24,05 & 399.296 .746 \\
\hline
\end{tabular}




\section{TABLEAU VII}

Excédents annuels des recettes du Gouvernement ${ }^{1}$

\begin{tabular}{|c|c|c|c|}
\hline ANNÉES & EXCÉDENTS & ANNEEES & SOMMES \\
\hline 1889 & $\begin{array}{l}\text { Livres Egyptiennes. } \\
218.427\end{array}$ & 1889 & $\begin{array}{l}\text { Francs. } \\
\text { 5.662.397, } 92\end{array}$ \\
\hline 1890 & 646.839 & 1890 & 16. $768.347,37$ \\
\hline 1891 & 932.862 & 1891 & $24.183 .071,93$ \\
\hline 1892 & 745.714 & 1892 & $19.331 .535,96$ \\
\hline 1893 & 886.880 & 1893 & $17.806 .351,20$ \\
\hline 1894 & 691.762 & 1894 & $17.932 .909,91$ \\
\hline 1895 & 1.002 .668 & 1895 & $25.992 .689,56$ \\
\hline 1896 & 1.088 .950 & 1896 & $28.229 .423,20$ \\
\hline 1897 & 1.383 .420 & 1897 & $35.863 .123,78$ \\
\hline 1898 & 1.331 .947 & 1898 & $34.528 .762,15$ \\
\hline 1899 & 1.270 .861 & 1899 & $32.945 .197,66$ \\
\hline 1900 & 1.551 .871 & 1900 & $40.229 .967,59$ \\
\hline 1901 & 2.020 .378 & 1901 & $52.375 .320,80$ \\
\hline 1902 & 1.892 .936 & 1902 & $49.071 .574,85$ \\
\hline 1903 & 1.986 .170 & 1903 & $51.488 .528,84$ \\
\hline 1904 & 3.102 .087 & 1904 & $80.417 .031,75$ \\
\hline 1905 & 2.688 .524 & 1905 & $69.696 .020,73$ \\
\hline 1906 & 2.175 .431 & 1906 & $56.394 .841,21$ \\
\hline 1907 & 2.087 .405 & 1907 & $54.112 .896,95$ \\
\hline 1908 & 1.113 .631 & 1908 & $28.869 .241,73$ \\
\hline 1909 & 1.161 .270 & 1909 & $30.104 .212,57$ \\
\hline & Total ... 29.780.033 & & Total. . 772.003.447,66 \\
\hline
\end{tabular}

1. Annuaire statistique de l'Égypte (1910), p. 266. 


\section{CHAPITRE IX}

\section{IMPÔTS}

Leur nature. - Impôt par tête d'habitant. - Sa diminution constante. Causes de cette diminution.

En Egypte, comme partout ailleurs, les impôts se répartissent en deux classes : les impôts directs et les impôts indirects. Seulement ceux de l'Égypte sont en nombre très restreint. Aussi le budget de l'Etat, surtout sur la base des moyennes qui servent à le préparer, est-t-il un des plus aisés à établir.

Les impôts directs sont au nombre de trois, dont un de répartition, l'impôt foncier, perçu sur la base de 28,55 0/0 de la valeur locative des terres, et deux de quotité, la taxe sur les dattiers fixée à P. T. 21/2 (0 fr. 648) par arbre, et l'impôtsur la propriété bâtie, porté dernièrement, pour la ville du Caire seulement, à $11,330 / 0$ de la valeur locative.

On peut dire que l'impôt foncier d'Égypte est un impôt à caractère particulièrement fixe de répartition. En effet, outre que l'établissement des contingents prin- 
cipaux remonte à une époque lointaine, on peut ajouter que ces contingents ne sont pas appelés à subir de modifications avant une nouvelle période de vingt à vingtcinq ans, si l'on s'en rapporte à un engagement pris en ce sens par le Gouvernement au moment où il fit procéder à la péréquation de l'impôt, opération commencée en 1899 et achevée en 1907.

Si son produit varie chaque année, c'est parce que le Gouvernement s'est réservé, par la même occasion, le double droit : 10 de taxer toutes les nouvelles terres acquises à la culture; $2^{\circ}$ de surélever les taxes frappant les propriétés de la Haute-Égypte ayant appartenu au régime des bassins, au fur et à mesure de leur conversion à l'irrigation pérenne.

Si nous passons aux impôts indirects, nous trouvons qu'ils sont au nombre de huit, comprenant notamment: les droits de douane, de ports et phares, judiciaires et d'enregistrement, une sorte de droit d'accise confondu et perçu avec le droit de douane sur les tabacs, tombacs et cigares, lesquels sont tous de provenance étrangère, la culture du tabac étant interdite en Égypte.

Notons, enfin, que l'Etat, propriétaire du réseau des chemins de fer d'intérêt général, en tire des revenus sans cesse grossissants du double fait de l'accroissement de la population et du développement du trafic, résultat de l'augmentation de la prospérité générale du pays. 
Pour 1909, les revenus des trois classes ont été respectivement:

$$
\begin{array}{rrrr}
\text { Contributions directes. . . . . . L. E. } & 5.447 .778 \\
\text { - } & \text { indirectes. . . . } & \text { - } & 5.335 .683
\end{array}
$$

Chemins de fer, postes et télé-

$$
\text { graphes, еtc........... - } \quad \frac{4.619 .411}{15.402 .872^{1}}
$$

Le total des contributions directes et indirectes seules s'est élevé, en 1909, à L. E. 10.783.461. Rapportant cette somme au nombre des habitants, qui, pour la même année, était de 11.626.497, la taxe par habitant s'établit à L. E. $0,928=24$ fr. 05 .

Il est à remarquer que, malgré l'accroissement considérable accusé, durant la période que nous examinons, par certaines sources de revenus telles queles droits de douane, les droits d'enregistrement, ceux des ports et phares, etc., accroissement caractéristique de fl'état de prospérité du pays, l'augmentation de la population, durant la même période, a été plus rapide encore. C'est ce que montre l'échelle descendante de la part de chaque habitant dans l'ensemble des contributions directes et des droits divers. La planche VI montre bien le sens de ce mouvement, qui s'est cependant redressé assez sensiblement à la suite de l'accord franco-anglais de 1904. L'effervescence qui s'en est suivie, et qui a eu pour 
épilogue la crise financière dont il sera question plus loin, a laissé, comme on le voit, des traces dans l'état des finances publiques de cette période.

Depuis 1907, les choses étant rentrées dans l'ordre, les douanes et l'enregistrement en particulier n'ont plus accusé de recette anormale, ce qui a abaissé, comme l'indique notre graphique, la quotité d'impôt par tête d'habitant. Le tableau VI et le graphique VI montrent que de 29 francs, en 1880, ce chiffre, descendu à 22 fr. 34, en 1900, s'est relevé, à partir de 1903, pour atteindre 25 fr. 89 , en 1907, et redescendre ensuite rapidement à 24 fr. 05, en 1909. Il a donc diminué de $17,060 / 0$ en près de trente ans.

Cette diminution provient de : 10 la suppression de certaines taxes sur les chevaux et voitures, les bateaux naviguant sur les canaux et les droits de péage; $2^{\circ}$ l'abaissement du droit de patente; $3^{\circ}$ certaines réductions opérées dans l'ensemble des rôles de l'impôt foncier qui ont été effectués en 1891,1893, 1894 et 1898, s'élevant à L. E. 564.100 (14.623.460 francs).

Tandis que les puissances européennes, obligées de faire face à des dépenses militaires de plus en plus écrasantes, voient s'accroître, chaque année, leurs charges fiscales, l'Égypte, qui n'a pas à se préoccuper de sa défense et n'entretient qu'une petite armée. (18.000 hommes), réalise chaque année des excédents de recette et augmente considérablement les réserves de son trésor. On s'explique, dès lors, la constante diminution de ses impôts. 
Planche VI

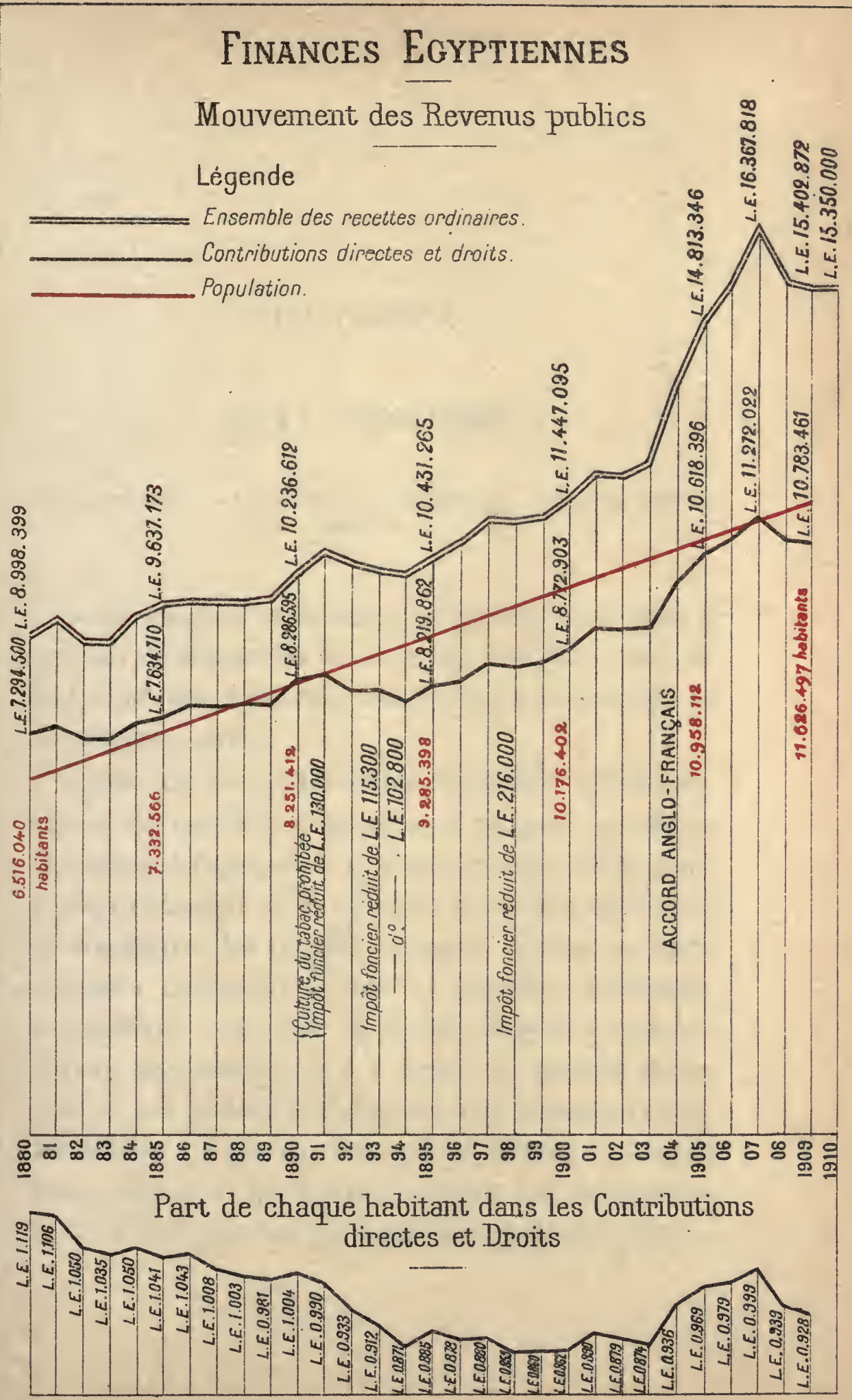



CHAPITRE X

\section{ÉTAT JUDICIAIRE}

Juridiction mixte. - La raison de son institution. - Son organisation. Législation.

De la situation économique et politique du pays il convient de rapprocher sa situation judiciaire. Cette situation est très solidement assise, grâce à l'institution de la juridiction mixte.

On sait que celle-ci fonctionne en Egypte depuis 1876. Elle a été instituée d'accord avec quatorze puissances étrangères, à l'époque où, la justice indigène étant encore à l'état rudimentaire, la nécessité s'était fait sentir, pour la sauvegarde des intérêts étrangers, d'avoir un corps judiciaire présentant toutes les garanties nécessaires. Aujourd'hui, il est vrai, la justice indigène a reçu une parfaite organisation, et il a même été question de demander aux puissances l'abandon de la législation mixte. La récente publication des articles secrets de l'accord franco-anglais de 1904 parut confirmer ces intentions ce qui n'était pas sans provoquer bien des inquiétudes - 
lorsque intervint, le 20 novembre 1911, un décret khédivial améliorant sensiblement ce système de législation en attribuant à la Cour d'appel mixte d'Alexandrie le pouvoir législatif, sous certaines conditions très strictes, et qui maintiennent intact le contrôle des puissances européennes tout en perfectionnant un régime judiciaire dont la rigidité ne s'adaptait plus aux besoins d'un pays sans cesse en progrès.

La juridiction mixte comprend une Cour d'appel à Alexandrie, trois Tribunaux de première instance au Caire, à Alexandrie et à Mansourah et une Délégation de justice sommaire à Port-Saïd. Les magistrats, pour tous ces tribunaux, sont au nombre de 63 , dont 40 étrangers. Ceux-ci, ayant qualité de fonctionnaires égyptiens, sont naturellement choisis et nommés par le Gouvernement égyptien, mais avec l'acquiescement officieux de leur gouvernement.

La législation spéciale, qui règle en matière civile et commerciale les rapports des étrangers entre eux ou avec les indigènes, assure, notamment aux créanciers, une sûreté et une rapidité de procédure que les pays les plus avancés pourraient envier à l'Égypte.

Nous croyons inutile d'entrer dans plus de détails sur ce sujet; ce que nous venons d'en dire nous paraît suffisant pour montrer qu'au point de vue judiciaire, l'Egypte offre aux intérêts étrangers engagés chez elle le maximum de sécurité. 


\section{ÉTAT ÉCONOMIQUE. - COMMERCE EXTÉRIEUR}

Balance du commerce extérieur. - Progression continue des importations et des exportations. - Majoration à apporter dans la valeur des exportations par suite des sous-estimations de la douane.

La balance du commerce extérieur de l'Égypte est facile à établir comparativement à celle des autres pays. Toutes les marchandises importées ou exportées acquittent, en effet, dans l'un ou l'autre cas, un droit ad valorem dont la fixation exige une estimation sérieuse faite d'après des procédés spéciaux impliquant, surtout à l'exporta. tion, des sous-évaluations très importantes.

Le tableau VIII ainsi que la planche VII, relatifs au commerce extérieur, font connaître, année par année, de 1886 à 1910, les montants respectifs des importations et des exportations. Pour en suivre utilement le dévelop. pement, nous avons, dans le tableau VIII, partagé cet intervalle en périodes de cinq ans, ce qui permet d'en saisir 
plus facilement la marche. On remarque tout de suite que les trois premières périodes, allant de 1886 à 1900, ne se signalent pas par une progression très rapide, la moyenne ayant, de l'une à l'autre de ces périodes, passé, à l'importation, de L. E. 38.825 .886 à 57.019 .667 et, à l'exportation, de L. E. 55.763.754 à 70.848.000, tandis qu'au contraire les deux dernières périodes ont accusé un mouvement ascensionnel considérable, ayant fourni, de 1906 à 1910, L. E. 121.015 .300 et L. E. 129.226 .838 respectivement à l'importation et à l'exportation.

Pour rendre le mouvement encore plus saisissant, nous établirons une comparaison entre la première et la dernière année de la série; nous trouvons ainsi : à l'importation L. E. 7.848.231, en 1886, contre L. E. 23.552.826, en 1910 ; et, à l'exportation, L. E. 10.198.573, en 1886 , contre 28.944.461, en 1910.

Si l'on considère l'ensemble du commerce extérieur (importations et exportations), on voit que celui-ci est passé de L. E. 18.046.804, en 1886, à L. E. 52.497.287, en 1910.

Si nous totalisons les chiffres de la série de 1886 à 1910, nous obtenons les sommes suivantes : L. E. 350.464.984, à l'importation, et L. E. 416.125.840, à l'exportation. Pour cette dernière, il y a lieu d'ajouter au total qui la concerne, transcrit des publications des douanes, le montant de la retenue que, d'accord avec le commerce d'exportation, cette administration fait subir à la valeur de la marchandise enregistrée dans ses offices. En restituant cette retenue, 
qui est de 10 0/0 de la valeur enregistrée, au total cidessus de L. E. 416.125.840, celui-ci se trouve augmenté de L. E. 41.612 .584 et porté à L. E. 457.738.424.

Déduisant de cette somme le montant correspondant des importations, qui s'est élevé, pour la même période, à L. E. 350.464.984, il reste L. E. 107.273.440 d'excédent à l'exportation, soit une moyenne annuelle de L. E. 4.290.937 (111.236.215 fr. 15). Mais cette moyenne ne représente pas exactement l'excédent réel de l'exportation sur l'importation; en effet, le coton, qui forme normalement plus de 80 0/0 de l'exportation, est tarifé sur la base des cours du Good fair brosn, qualité américaine dont le prix est toujours inférieur à celui du coton égyptien.

M. Roussin, dans un mémoire sur la Balance du Commerce qui a paru en appendice au rapport de lord Cromer, en 1906, sur l'Égypte et le Soudan, estime que l'évaluation de la douane est de $40 / 0$ inférieure au prix réel du coton égyptien.

De plus, il y a lieu de tenir compte du gain réalisé par l'Égypte sur la vente de son coton; on peut sans exagération fixer ce gain entre 5 et $60 / 0$ du prix des produits vendus; les chiffres attribués par la douane khédiviale à la valeur des exportations devraient dès lors être relevés encore de $10 \% / 0$, soit en tout une majoration de $200 / 0$; mais, dans notre tableau, nous n'avons voulu tenir compte que de la majoration de $100 / 0$ représentant la retenue pratiquée parla douane sur les mar. 
chandises exportées. Par conséquent, l'excédent annuel, dont nous avons parlé plus haut, devrait subir une majoration considérable.

Les chiffres que nous venons de donner sont assez éloquents et expriment suffisamment le degré de prospérité auquel est parvenu le pays.

Combien d'Etats pourraient-ils présenter un tableau aussi remarquable des progrès de leur commerce extérieur? 


\section{Planche VII}

\section{RÉSULTATS GÉNÉRAuX}

DU

\section{COMMERCE EXTÉRIEUR DEL'EGYPTE}

$\mathrm{DE}$

1884 a 1910

Légende

Importations

Exportations. (donnant seulement les $90 \%$ dela

valeur des marchandises, conformément à l'accoro'

intenvenu entre/administration des Douanes \& le

Commerce d'exportation.

Exportations ramerrées aumontanl réa! des
marchandises par l'addition des 10\% de retenue.

marchandises par l'addition des $10 \%$ de retenue.
manortations ramerrées aumontan réa! des

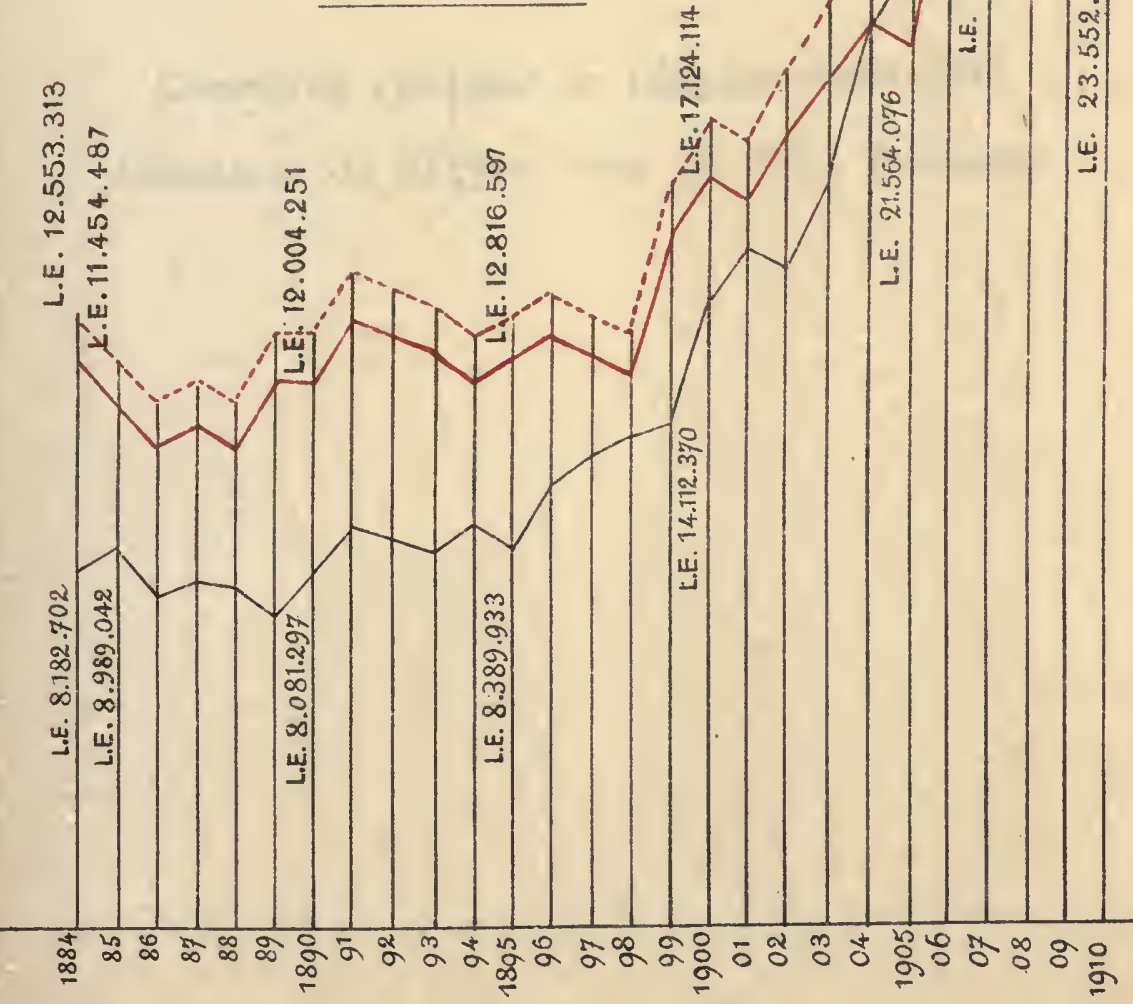





\section{TABLEAUX VIII et IX}

Commerce extérieur de l'Égypte (1886-1910).

Commerce de l'Égypte avec les Pays étrangers. 


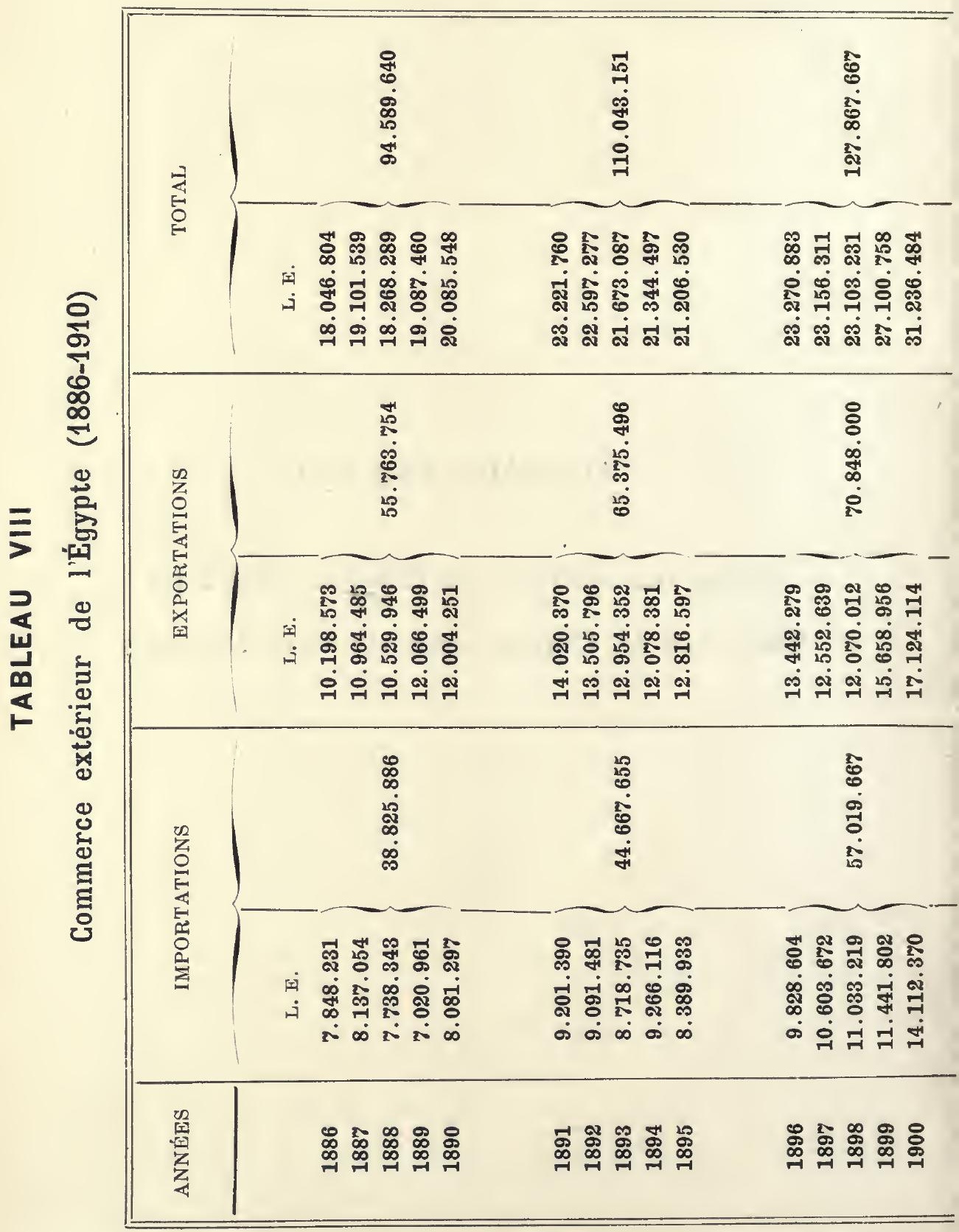




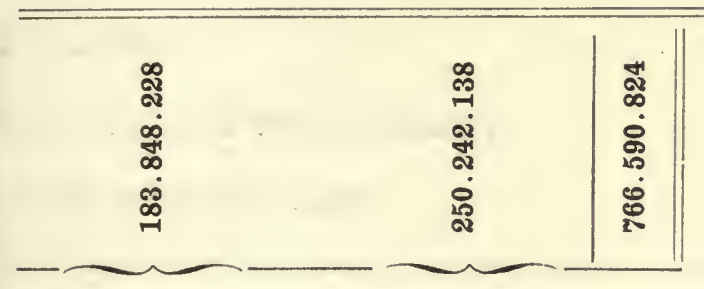

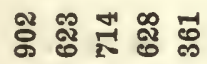

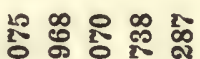

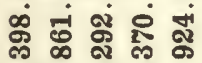

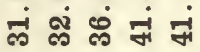

这宓客

我 F

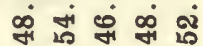
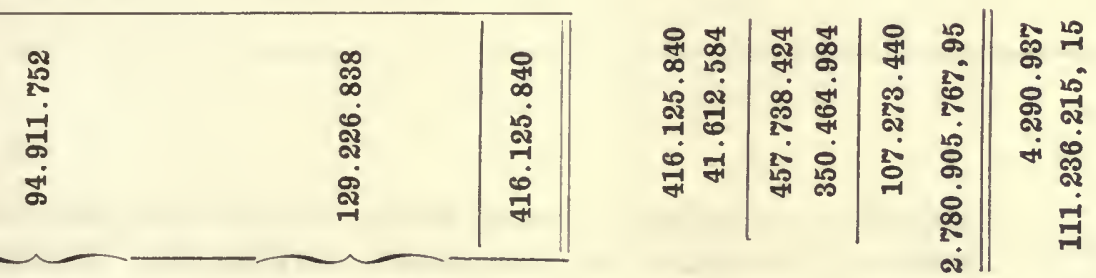

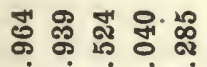

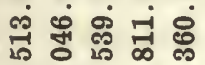

분

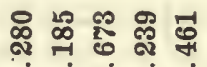

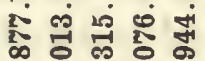

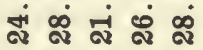

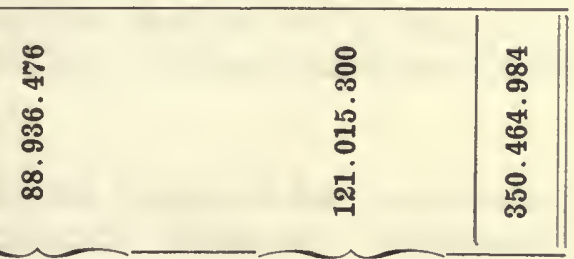

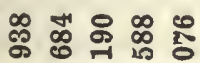

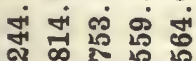

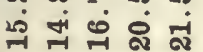

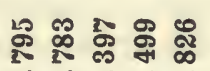

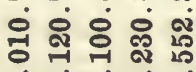

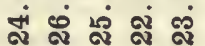

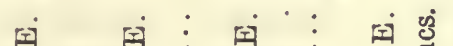

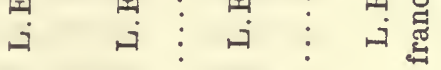

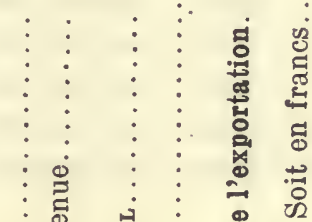

芭远

$\vdots$ :

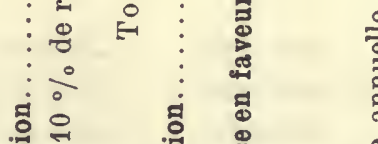

क्षि

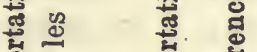

总哭

흠

竞।

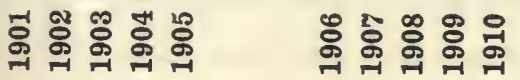


TABLEAU

Commerce de l'Égypte avec

(Part proportionnelle de

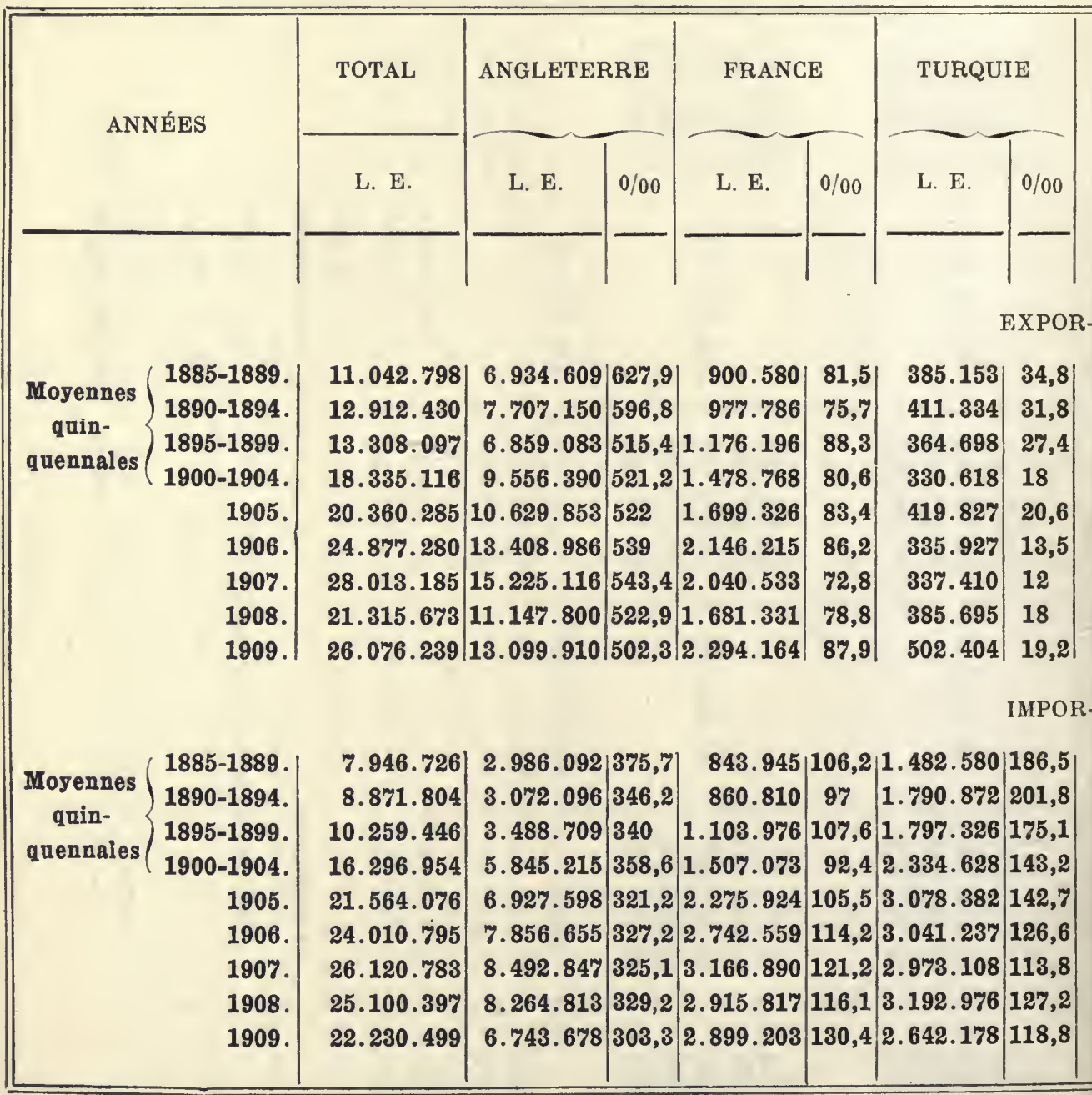

1. Numéraire non compris. [Ann. stat. de l'Egypte (1910), p. 190.] 


\section{les Pays étrangers ${ }^{1}$}

chaque pays pour mille)

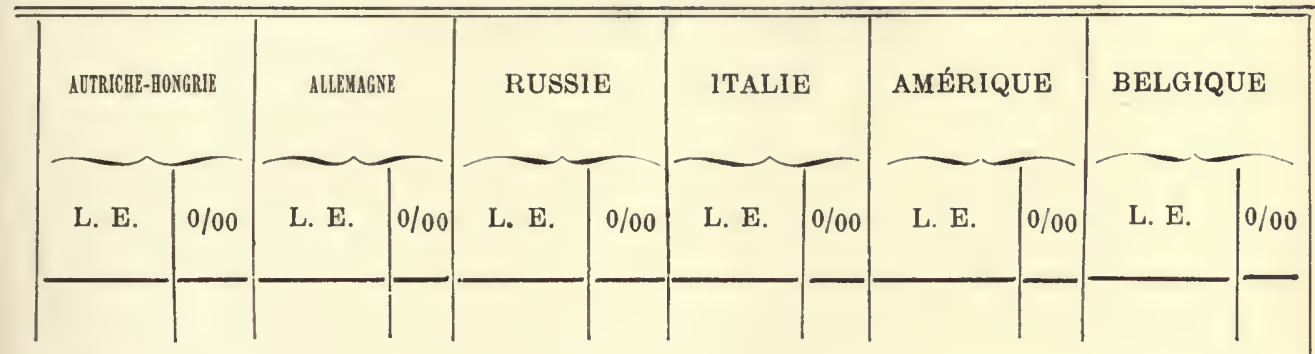

\section{TATIONS}

\begin{tabular}{|r|r|r|r|r|r|r|r|r|r|}
716.607 & 64,8 & 14.057 & 1,2 & 1.010 .041 & 91,4 & 754.284 & 68,3 & 20.535 & 1,8 \\
606.069 & 46,9 & 248.465 & 19,2 & 1.597 .679 & 123,7 & 662.620 & 51,3 & 172.813 & 13,3 \\
536.167 & 40,2 & 530.882 & 39,8 & 1.514 .912 & 113,8 & 412.041 & 30,9 & 922.694 & 69,3 \\
784.212 & 42,7 & 1.339 .866 & 73 & 1.404 .881 & 76,6 & 694.968 & 37,9 & 975.363 & 53,1 \\
991.177 & 48,6 & 1.737 .350 & 85,3 & 1.043 .096 & 51,2 & 629.006 & 30,8 & 1.257 .848 & 61,7 \\
1.259 .584 & 50,6 & 2.035 .054 & 81,8 & 1.399 .954 & 56,2 & 771.757 & 31 & 1.532 .180 & 61,5 \\
1.315 .397 & 46,9 & 2.252 .954 & 80,4 & 1.599 .580 & 57,1 & 791.044 & 28,2 & 2.101 .785 & 75 \\
1.030 .072 & 48,3 & 1.848 .932 & 86,7 & 1.377 .577 & 64,6 & 704.070 & 33 & 1.154 .832 & 54,1 \\
1.291 .848 & 49,5 & 2.481 .826 & 95,1 & 1.515 .614 & 58,1 & 736.694 & 28,2 & 1.913 .514 & 73,3 \\
\hline
\end{tabular}

41. 402| 3,7

$92.9697,1$

$42.7603,2$

$141.0467,6$

$111.7435,4$

$165.7816,6$

$90.2513,2$

$81.8203,8$

$85.8993,2$

\section{TATIONS}

\begin{tabular}{|c|c|c|c|c|c|c|c|c|c|c|c|}
\hline & 37.248 & 4,6 & 395.756 & 49,8 & 262.370 & 33 & 70.269 & 8,8 & 97.222 & 12,2 \\
\hline \multicolumn{2}{|c|}{\begin{tabular}{l|r|}
836.687 & 105,2 \\
y7y7.723 & 87,6
\end{tabular}} & 162.774 & 18,3 & 357.046 & 40,2 & 291.750 & 32,8 & 37.375 & 4,2 & 266.740 & 30 \\
\hline 715.202 & 69,7 & 292.838 & 28,5 & 402.358 & 39,2 & 422.773 & 41,2 & 162.375 & 15,8 & 493.480 & 48,1 \\
\hline 1.159 .109 & 71,1 & 671.977 & 41,2 & 626.025 & 38,4 & 866.363 & 53,1 & 265.101 & 16,2 & 547.554 & 33,5 \\
\hline 1.492 .566 & 69,2 & 948.612 & 43,9 & 741.349 & 34,3 & 1.133 .562 & 52,5 & 487.685 & 22,6 & 828.111 & 38,4 \\
\hline 1.718 .813 & 71,5 & 1.307 .675 & 54,4 & 527.944 & 21,9 & 1.210.221 & 50,4 & 609.604 & 25,3 & 1.229 .698 & 51,2 \\
\hline 2.059 .423 & 78,8 & 1.392 .381 & 53,3 & 676.868 & 25,9 & 1.361 .449 & 52,1 & 572.704 & 21,9 & 1.027 .590 & 39,3 \\
\hline 1.632 .273 & 65 & 1.118 .997 & 44,5 & 974.014 & 38,8 & 1.187 .786 & 47,3 & 558.677 & 22,2 & 725.747 & 28,9 \\
\hline 1.432 .966 & 64,4 & 1.129 .045 & 50,7 & 758.942 & 34,1 & 996.753 & 44,8 & 552.670 & 24,8 & 678.446 & 30,5 \\
\hline
\end{tabular}

La différence entre les \% \% de ce tableau et ceux de l'Annuiaire statistique de l'Égypte (p. 198 et 199) pravient de ce que nous avons tenu compte du commerce des tabacs qui, dans la statistique officielle a été séparé du commerce spécial. 



\title{
DEUXIÈME PARTIE
}

\author{
CHAPITRE XII
}

\section{LA CRISE ÉGYPTIENNE}

Ses causes psychologiques et économiques. - Spéculation effrénée sur les terrains ruraux et urbains. - Afflux énorme de capitaux étrangers depuis l'accord franco-anglais de 1904. - Abus de crédit. - Conséquences de la crise. - Les richesses naturelles du pays sont restées indemnes. - Les dernières faillites; opinion du Conseiller financier.

Parler de la crise égyptienne est devenu vraiment fastidieux, tant il aété noirci de papier à ce sujet; d'ailleurs, elle n'est plus pour le public qu'un vague et déjà lointain souvenir. Si l'on en parle quelquefois, c'est pour y faire remonter l'origine du mouvement d'évolution auquel nous avons fait allusion. Cependant, pour rester fidèle au programme que nous nous sommes tracé, de ne négliger 
l'examen d'aucune question susceptible d'éclairer le lecteur, nous nous résignons à la traiter de nouveau, mais en essayant d'apporter autant que possible des idées particulières dans son analyse.

Notons, en premier lieu, que cette crise relève bien plus de la psychologie que de l'économie politique. Il est vrai que l'une et l'autre y sont intervenues, mais il semble impossible d'en saisir les causes et d'en suivre les déve. loppements sans l'aide des instruments d'observation propres à la psychologie. En effet, la crise qui a sévi en Egypte ne rentre nullement dans la classe ordinaire des crises économiques. Il n'y eut ni surproduction, ni pénurie de produits, ni modification d'aucune sorte dans l'état des richesses du pays; telles elles étaient avant la crise, telles elles sont restées dans la période la plus aiguë, telles elles se retrouvent encore aujourd'hui, sauf, bien entendu, le développement naturel qu'elles ont dû prendre. Ce n'est pas l'industrie manufacturière, absente du pays, ce n'est pas l'industrie minière, encore à naître, qui, trompées dans leurs prévisions, ont fait pencher la balance d'un côté ou de l'autre. S'il y eut déséquilibre, ce fut dans l'état d'esprit de la population des centres, déséquilibre provoqué par une intense suggestion qui, parvenue graduellement à son paroxysme, s'empara de toutes les facultés cérébrales. Au règne de la volonté réfléchie se substitua peu à peu celui de l'impulsion irrésistible, et l'on eut alors le spectacle extraordinaire de toutes les classes de la population urbaine, indigène et étrangère, 
obéissant à la même excitation, manifestant les mêmes symptômes de folie.

" En Egypte, autant et plus qu'en aucun autre pays en " cours de développement économique, la partie de la "population que les affaires intéressent en qualité de " capitaliste ou d'intermédiaire est passible de ces em* ballements, soit dans un sens, soit dans l'autre. Une " âme collective extrêmement complexe, ondoyante et " diverse, unit ce bizarre groupement d'Européens déra" cinés, de Syriens, d'Hellènes, d'Arméniens, d'Israélites, " d'indigènes plus ou moins européanisés, formée d'in" clinations, de dispositions et d'aptitudes, les unes heu" reuses, tout au moins brillantes, les autres susceptibles " de devenir dangereuses sous l'action des circonstances: " imagination vive, remarquable facilité de conception, " et plus encore d'assimilation et d'expression; mais, " en revanche, vanité, goût de la dépense et de l'osten" tation, négligence mêlée d'impulsivité, dédain du béné" fice modeste et régulier, hantise du gros gain hasardeux, "imprévoyance manifestée surtout par l'insouciance " des engagements contractés, crédulité et défaut d'esprit " critique; enfin, ce qui est plus grave, absence aussi " complète que possible, chez beaucoup d'entre eux, de " sens moral. De cet ensemble de qualités attachantes " et de défauts parfois sympathiques est résulté un tem"pérament de joueur surexcité par l'optimisme qui se " dégage invinciblement, dans cette contrée bénie, du 
" spectacle d'un ciel toujours bleu, d'une nature éter" nellement souriante et prodigieusement féconde ; opti" misme d'ailleurs bien excusable quand on songe aux pro" grès immenses réalisés par l'Égypte en si peu d'années. "Que l'on joigne à cette tendance l'inexpérience auda" cieuse des plus habiles parmi ces hommes d'affaires " improvisés, lancés pour la plupart sans préparation " au beau milieu de ce monde financier découvert, au " début du XIX siècle, et dans lequel nos pères ne se sont " point acclimatés sans peine, et, tout compte fait, l'on " s'étonnera presque que la crise égyptienne actuelle, " cette première manifestation de la puberté économique " d'un pays récemment né à la vie moderne, n'ait pas été "plus violente ${ }^{3}$." -

Que s'était-il done passé ? Quelle était la raison de cet état de choses?

On sait que depuis la mainmise des Anglais sur la haute direction des affaires du pays, leurs principaux efforts se sont portés sur le développement de ses richesses naturelles. A cet effet, ils ont entrepris et mené à bonne fin l'exécution de travaux hydrauliques gigantesques qui ont doté le pays du remarquable système d'irrigation dont nous avons esquissé les grandes lignes. Par le développement parallèle des voies de transport terrestres et fluviales, l'exploitation agricole ayant été pourvue du

1. P. Arminjon, La Situation économique et financière de l'Égypte, p. 603. 
complément de ressources générales dont elle pouvait avoir besoin, l'Égypte se trouva dès lors dans la situation la plus enviable.

Tandis qu'autrefois la propriété n'était pas fournie régulièrement de l'eau nécessaire à son irrigation, et que, faute de drains, une partie en était sacrifiée pour recevoir les eaux de colature; tandis que le propriétaire, n'exploitant pas lui-même ses terres, ne pouvait, faute de moyens rapides de transport, les visiter qu'avec les plus grandes difficultés et, par suite, en contrôler effectivement l'administration; tandis que les produits de son domaine restaient longtemps sur place sans moyens de transport économiques pour les amener sur les marchés commerciaux; aujourd'hui, grâce aux travaux récents, une transformation eomplète s'est effectuée au profit et de la propriété et du propriétaire.

D'un autre côté, le développement de la richesse mondiale, la pénétration de la civilisation en de nouveaux milieux ont eu et ont encore pour conséquence une augmentation de la demande des matières premières, augmentation qui n'a pu être suivie parallèlement par la production. Au nombre de ces matières premières se trouve le coton, produit fondamental de l'agriculture égyptienne; plus que tout autre et en raison de sa grande nécessité, comme aussi, il faut le reconnaître, grâce à l'habile tactique de la puissante spéculation américaine, il a vu son prix bénéficier d'une plus-value considérable. Ces deux causes auraient dû, combinant leurs effets, 
déterminer un mouvement graduel de hausse dans le prix de la propriété foncière. Cependant cette hausse ne se produisit pas; il fallait le concours d'un troisième facteur, la stabilité politique, qui faisait encore défaut; l'occupation anglaise devait l'établir.

Mais cette occupation allait-elle durer ? La France ne finirait-elle pas par passer de la protestation passive à la politique active pour faire prévaloir ses droits qu'elle considérait comme lésés? N'allait-on pas retomber dans les bouleversements et l'anarchie du passé ? Telles étaient les raisons qui empêchaient les deux premiers facteurs d'exercer leur action commune sur la valeur de la terre.

La convention franco-anglaise de 1904 dissipa toutes ces appréhensions en donnant définitivement à l'Égypte cette stabilité politique sans laquelle nul effort ne saurait produire son plein et entier effet. Du jour où elle fut signée, la hausse des terres, jusque-là contenue, se manifesta grâce à l'afflux considérable de capitaux étrangers qui se produisit au même moment et au maintien des cours élevés du coton. En peu de temps, les prix se trouvèrent presque doublés. Cette augmentation était en elle-même parfaitement justifiée non seulement parce qu'elle correspondait étroitement aux améliorations de toutes sortes dont la terre avait bénéficié, mais parce que le taux de capitalisation qui servait de base à l'établissement du prix de la propriété était alors de beaucoup supérieur au taux actuel, lequel dépasse toujours $60 / 0$. Seulement cette hausse, venue brusque- 
ment, sans transition, devait produire l'accès de folie dont nous avons parlé et dont voici la genèse :

$\mathrm{D}$ u jour au lendemain, le propriétaire rural était devenu tout d'un coup deux fois plus riche qu'il ne l'était, sans toutefois que son revenu eût augmenté du fait de cet accroissement de sa fortune, et sa propriété se vendait facilement à un prix double de celui qu'il aurait pu en obtenir auparavant. Or il y avait aussi les terrains des villes; sans approfondir les raisons de la hausse, sans en rechercher l'action latente, on ne doutait point que la propriété urbaine, comme celle des champs, dût doubler de valeur. C'était toujours de la terre, et il n'y avait aucune raison de les différencier. Et puis, disait-on, sur quoi repose la valeur de la propriété urbaine ? Et qu'est-ce qui en fait le prix? D'une part, l'état de richesse du miliou; de l'autre, le nombre de ses habitants.

Riche, le milieu l'était, certes, puisque sa population, composée en grande partie de propriétaires ruraux, avait vu doubler sa fortune comme par un coup de baguette; très peuplé, il l'était aussi, puisque les divers recensements effectués jusque-là avaient révélé un accroissement considérable de la population. Ce futainsi que, peu à peu, on se fit cette douce illusion que la fortune du pays n'avait pas de limites et que la population ne devait pas cesser de s'accroître, celle du Caire notamment devant bientôt dépasser un million d'habitants. Pour ce million d'habitants, que de terrains ne fallait-il pas, surtout si, dans ce nombre, une foule de riches, à l'étroit dans leurs de. 
meures et acquis maintenant à une civilisation plus raffinée, entendaient se loger grandement avec tout le confort moderne. On supputait jusqu'aux résultats que devait procurer à l'Egypte, en général, et aux grands centres, en particulier, l'achèvement, qu'on disait très prochain, du chemin de fer du Cap au Caire.

Du fait de cet achèvement, Le Caire et Alexandrie n'auraient-ils pas bientôt à abriter une population double de celle qu'ils renfermaient aujourd'hui ? Pourrait-on jamais payer assez cher ces terrains, puisqu'il n'y avait là que l'escompte d'une valeur certaine réalisable dans un avenir très rapproché.

Et les calculs d'aller leur train, et les imaginations de les amplifier, et les esprits de s'exciter et de s'échauffer ! Pendant ce temps, les transactions sur les terrains à bâtir suivaient leur cours, se multipliant sans cesse et ne tardant pas à englober jusqu'aux terres cultivées ou désertiques de la grande banlieue que l'on faisait graduellement rentrer dans les périmètres des grands centres; les lots passaient de main en main, plusieurs fois même dans une seule journée, et voyaient leur prix hausser dans des proportions fantastiques.

Des sociétés immobilières se fondaient; puis des sociétés foncières, des sociétés urbaines et rurales, des sociétés boursières, industrielles, commerciales, se suivant les unes les autres à la course, tant et si rapidement que leur nombre dépassa bientôt deux cent cinquante.

Mais, dira-t-on, pour acheter, il faut avoir de l'argent : 
cela n'est vrai que jusqu'à un certain point, puisque, dans notre société moderne, il y a une chose qui tient lieu d'argent, c'est le crédit. En Egypte, le crédit était distribué à tout venant; chacun, à l'envi, se faisait ouvrir un compte.

Les Sociétés immobilières à leur tour surenchérissaient dans la distribution du crédit. Pour devenir leur acheteur, il suffisait d'effectuer le versement d'une fraction quelconque du prix du terrain et de contracter un engagement pour le règlement du reste. De leur côté, leurs acheteurs revendaient dans les mêmes conditions qui leur avaient été faites par les sociétés; tout le monde utilisait la même somme, qui ne faisait que changer de main. Ainsi avec une circulation relativement restreinte, arrivait-on à augmenter tellement le volume des transactions 'qu'elles devenaient de jour en jour plus précaires.

De leur côté, les agents de change, qui puisaient à volonté dans la caisse des banques, pour ne pas être en reste de générosité avec elles, leur consignaient des dossiers de titres où la variété des couleurs le disputait généralement à la nullité de la valeur. Beaucoup plus conciliants que les banques, ils allaient jusqu'à exécuter les ordres du premier venu sans la moindre garantie. De nombreux capitalistes étrangers, des touristes même, alléchés par les profits extraordinaires dont ils entendaient parler, se mêlèrent, eux aussi, à cette fête de la folie et lui apportèrent un très large concours.

Enfin, et comme il fallait le prévoir, la crise survint; 
elle fit de grands ravages et de nombreuses victimes, mais aussi, par un contre-coup des plus heureux, elle fut suivie d'une réaction éminemment salutaire. Nous avons déjà parlé des effets de cette réaction à laquelle nous continuons d'assister et dont, avec juste raison, on attend la transformation morale du pays. Cette transformation s'accomplit avec une rapidité remarquable, et le jour ne semble pas éloigné où, comme nous l'avons dit, le pays se trouvera, au point de vue économique, doté de tous les instruments de progrès.

Et le fellah, dira-t-on? Mais le fellah, que nous avons vu attaché à sa terre, comme les végétaux qu'il cultive, n'a pu naturellement prendre part à cette agitation qui s'est localisée essentiellement dans les villes. La terre rurale qu'il exploitait resta, elle aussi, étrangère à la spéculation et à la crise, et il est probable que, sans le resserrement du crédit qui se fit sentir pendant quelque temps et dont il eut à souffrir, il aurait ignoré que son pays avait traversé une crise.

Nous ne pouvons passer ici sous silence les retentissantes faillites, de la Bank of Egypt et de la Maison Zervudachi, qui eurent lieu en automne 1911. Elles ont provoqué bien des commentaires, la plupart défavorables au pays, il faut le reconnaitre. Pour mettre la question au point, il nous suffira de citer l'opinion du Conseiller financier de l'Egypte, dans sa note sur le Budget de 1912: 
"Ces faillites, écrit-il, sont dues à des causes bien anté" rieures à l'année en cours, et c'est à tort que l'on en " tirerait des conclusions défavorables à la situation éco" nomique de l'Egypte dans son ensemble...

"De fait, la faillite de la Bank of Egypt a été déter" minée par un système défectueux dans la gestion des " affaires datant de longtemps. On ne saurait sans danger " consentir avec des fonds empruntés à trois mois des "prêts recouvrables à des dates relativement éloignées... "Les autres faillites auxquelles il a été fait allusion ne " sont qu'un résultat, longtemps différé, il est vrai, du " mouvement de spéculation qui aboutit à la crise de "1907. Les lourds engagements qui avaient été pris " avant la crise, gagés par un actif déprécié ou devenu " momentanémentirréalisable, sont demeurés en suspens... "S'il doit résulter de ces événements une situation plus " claire et plus saine, le mal n'est pas sans avoir son bon " côté. Les sources essentielles de richesse et de prospérité " $d u$ pays n'ont pu être affectées, quel que soit le tort " causé aux affaires et au crédit de l'Égypte, par des pro" cédés tels que ceux qui viennent d'être révélés." 


\section{CHAPITRE XIII}

\section{MONOCULTURE}

Pourquoi on a parlé de monoculture. - Statistique comparative des superficies occupées par les différentes cultures; le coton vient en deuxième rang après le maïs; il n'entre dans l'ensemble des cultures que pour 20,83 0/0. - Différence existant entre un pays à vignobles, comme la France, si terriblement éprouvée par le phylloxera, et l'Égypte cotonnière.

Co mot dont la résonance a frappé si désagréablement les oreilles françaises, d'abord à propos de la garance et, en dernier lieu, à propos de la vigne, dont heureusement les désastres ont été réparés, a eu son écho en Egypte. C'est à cela sans doute qu'est due l'agitation qui s'est manifestée, dans certains milieux égyptiens, à propos du prétendu envahissement de la culture cotonnière. Il fut un temps où l'on n'entendait parler que de monoculture; on ne lisait que des diatribes contre la déplorable tendance $\mathrm{du}$ fellah à délaisser ses cultures habituelles au profit du cotonnier. Cette question de la monoculture, soulevée bien souvent à l'occasion de mauvaises campagnes, a été provoquée par la place prépondérante oc- 
cupée par le coton dans le commerce d'exportation et par l'extension de sa culture.

Si l'on n'a devant les yeux que les tableaux statistiques des Douanes, on est surpris d'y constater que presque tout le commerce d'exportation est accaparé par le coton, qui en détient les quatre cinquièmes (tableau $X$ page 104).

Cela tient, tout simplement, à ce que presque tous les autres produits sont consommés sur place, tandis que le coton est exporté en totalité, le pays ne possédant, en dehors des usines d'égrenage, aucune installation pour le travailler ${ }^{1}$.

Il est vrai encore que, depuis une quinzaine d'années, la culture du cotonnier s'est développée considérablement ${ }^{2}$, - ce qui se comprend, du reste, en raison du profit très élevé qu'en retire le pays, - mais sans pour cela faire tort aux autres cultures. Son extension a marché parallèlement à celle de la superficie totale cultivée qui s'est augmentée d'une quantité un peu inférieure, de terres autrefois en friche. C'est ce qu'établit le graphique de la planche VIII ci-après qui nous montre d'année en année, de 1893 à 1909, les accroissements respectifs de la culture cotonnière et de la superficie cultivée. On y voit qu'en 1909 les augmentations étaient de 1.320.659 feddans pour la superficie des cultures, et de 631.109 pour la culture cotonnière. Il faut bien se garder d'en conclure

1. Il y a bien deux fabriques de tissage, dont une à Alexandrie et l'autre au Caire, mais, pour des raisons spéciales, aucune d'elles n'a pu prospérer.

2. Voir tableau XI et planche VIII, pages 105 et 107. 
que les nouvelles terres, seules, ont fourni l'accroissement de la culture cotonnière; cet accroissement a été acquis partie sur ces terres et partie sur quelques-unes de la Moyenne-Egypte où s'est faite la conversion du régime des bassins à celui de l'irrigation pérenne.

Sous le premier de ces régimes, on ne pouvait entreprendre qu'une culture par an, et, le cotonnier restant encore sur pied au moment de l'inondation, il était impossible de le cultiver. Avec la conversion à l'irrigation pérenne, la culture en est devenue possible, et beaucoup de propriétaires de cette région en ont profité pour faire du coton, mais dans une bien moindre proportion que dans la Basse-Egypte. Quoi qu'il en soit, la conversion est aujourd'hui terminée, et l'on est en droit d'affirmer que, jusqu'à l'achèvement de la surélévation du réservoir d'Assouan, il ne se produira aucune nouvelle modification dans la répartition des cultures.

Examinons maintenant la superficie occupée par la culture cotonnière. Ce détail a déjà trouvé sa place dans la partie consacrée à l'exploitation du sol. Pour le rappeler, il vaut mieux le présenter dans un tableau d'ensemble (tableau $X I I$ et planche $I X$ ) où figurent les principales cultures du pays. De ce tableau, emprunté à l'Annuaire statistique de l'Egypte (1910), nous avons extrait les chiffres des deux saisons 1907-1908 et 1908-1909.

Sur le graphique $I X$, la comparaison est autrement frappante. La figure qui est en tête de la planche nous montre la répartition du sol, au point de vue des cultures qu'il 
reçoit et la place occupée par le cotonnier en particulier. On voit que celui-ci, pour la saison 1908-1909, ne vient qu'à la suite du maïs qui, lui, tient la tête avec ses 1.796.745 feddans représentant les $23,420 / 0$ de l'ensemble, tandis que le cotonnier ne représente que $20,830 / 0$ avec ses 1.597 .055 feddans. D'ailleurs, on remarquera que, pendant la saison précédente (1907-1908), la superficie occupée par le cotonnier avait atteint 1.640.415 feddans ; il y eut done, pour la saison suivante, un retour en arrière qui se traduit par une diminution de 43.360 feddans sur la superficie cultivée en 1907-1908 et qui se représente presque intégralement pour la saison 1909-1910.

On voit par ces chiffres que le pays est bien loin de l'état de monoculture, puisque le coton, au profit duquel on suppose à tort que le pays délaisse les autres cultures, occupe seulement le deuxième rang après le maïs et n'entre dans l'ensemble que pour 20,83 0/0.

Viennent ensuite le blé avec 1.249.264 feddans, le bersim avec 1.531.793 feddans, les fèves avec 566.688 feddans, l'orge avec 423.293 feddans, le riz avec 271.820 feddans, etc...

Par contre, au point de vue de la valeur commerciale, le coton occupe le premier rang avec L. E. 26.720 .880 sur L. E. 60.573.577 représentant la valeur brute moyenne de la récolte égyptienne; il est done loin de primer en valeur l'ensemble des autres produits agricoles.

Mais si, par la suite, la culture du coton venait à exclure toutes les autres, la situation économique de 
l'Egypte serait-elle réellement compromise? Pour répondre à cette question, il suffira de constater la différence existant entre la situation d'un pays à vignobles comme la France, si terriblement éprouvé par le phylloxera, et celle de l'Égypte cotonnière. Pour bien établir cette différence, il importe de rappeler que, l'établissement d'un vignoble exige une mise de fonds pouvant varier de 1.500 à 3.000 francs par hectare, soit L. E. $241 / 2$ à 49 par feddan.

Voyons maintenant quels sont les travaux d'aménagement qu'exige le sol pour la culture du coton.

Si l'on a affaire à une terre en friche, il faut qu' elle soit parfaitement nivelée pour être apte à recevoir l'eau par irrigation; il faut ensuite procéder à son dessalement, parce que tout le sol égyptien est plus ou moins imprégné de sel, surtout au voisinage de la mer ; ces deux opérations peuvent durer de quatre à cinq ans et coûter, suivant le relief du sol et la quantité de sel qu'il contient, de 20 à 50 livres par feddan, y compris les autres améliorations foncières.

Une fois qu'elles sont terminées, le sol a acquis toutes aptitudes pour recevoir la semence du coton, le faire pousser et fructifier à l'égal des autres terres en exploitation.

C'est donc à peu près une mise de fonds analogue à celle qui est nécessaire pour la plantation d'un_vignoble, avec cette différence cependant que, pour le cotonnier, les frais d'établissement sont presque entièrement absorbés par la mise en état du terrain: pour le vignoble, au contraire, 
la moitiéde ces frais ne profite pas au sol, puisqu'elle est représentée par des installations et du matériel complètement inutilisables en cas d'abandon de la culture de la signe.

D'ailleurs, pour la culture du cotonnier, la préparation du sol est exactement la même que pour la culture du blé, de l'orge, des fèves, du bersim, etc. Il n'y a donc lieu à aucune préparation particulière, à aucune installation, ni à l'acquisition d'aucun matériel. Notons encore que la vigne ne commence à produire sérieusement qu'au bout de quatre ou cinq ans, alors que le cotonnier donne sa récolte dans l'année même de sa plantation. Planté en mars ou avril, il produit son fruit, de septembre à novembre, en trois cueillettes; la dernière terminée, il dépérit et meurt. C'est donc une plante annuelle, comme toutes celles qui sont cultivées en Égypte, sauf la canne à sucre et l'indigo, qui, tous deux, occupent le sol pendant deux ou trois ans; l'une et l'autre culture, surtout la seconde, sont, d'ailleurs, de minime importance.

Après la mort du cotonnier, on arrache les pieds, dont le bois est vendu à raison de 2 fr. 50 la charge de 250 kilogrammes. Puis, suivant le système d'assolement adopté, on passe à d'autres cultures, ou bien on laisse reposer la terre pendant quelque temps avant de fla cultiver de nouveau, et, passé un an ou deux, on revient au cotonnier et ainsi de suite. Il n'y a donc aucune comparaison possible entre le cotonnier et toute autre plante dont la culture exige des aménagements spéciaux et a donné lieu, en d'autres pays, à des déceptions ou même à de véritables désastres. 


\section{TABLEAU $X$}

\section{Coton exporté ${ }^{1}$}

\begin{tabular}{|c|c|c|c|}
\hline ANNEES & $\begin{array}{l}\text { EXPORTA } \\
\text { TIONS } \\
\text { globales }\end{array}$ & $\begin{array}{c}\text { EXPORTA- } \\
\text { TIONS } \\
\text { de coton }\end{array}$ & $0 / 0$ \\
\hline 1 & L. E. & L. E. & \\
\hline (1885-1889 $\ldots$ & 11.042 .798 & 7.548 .161 & 68,35 \\
\hline 1890-1894 ..... & 12.912 .630 & 8.561 .246 & 66,30 \\
\hline (1895-1899 .. & 13.308 .097 & 9.682 .572 & 72,75 \\
\hline $1900-1904$ & 18.335 .116 & 14.227 .651 & 77,59 \\
\hline 1905 & 20.360 .285 & 15.806 .440 & 77,63 \\
\hline 1906 & 24.877 .280 & 20.528 .002 & 82,51 \\
\hline 1907 & 28.013 .185 & 23.597 .844 & 84,23 \\
\hline 1908 & 21.315 .673 & 17.091 .603 & 80,18 \\
\hline $1909 \ldots$ & 26.076 .239 & 21.477 .739 & 82,36 \\
\hline 1910 & 28.944 .461 & 24.241 .712 & 83,75 \\
\hline
\end{tabular}

1. Annuaire statistique de l'Égypte (1911), p. 226. 
Planche VIII

\section{AugMENTATION DE LA SUPERFICIE PLANTÉE EN COTON ET DE LA SUPERFICIE DES CULTURES}

$$
\text { DE 1893-94.A 1908-09 }
$$

Superficie des cultures

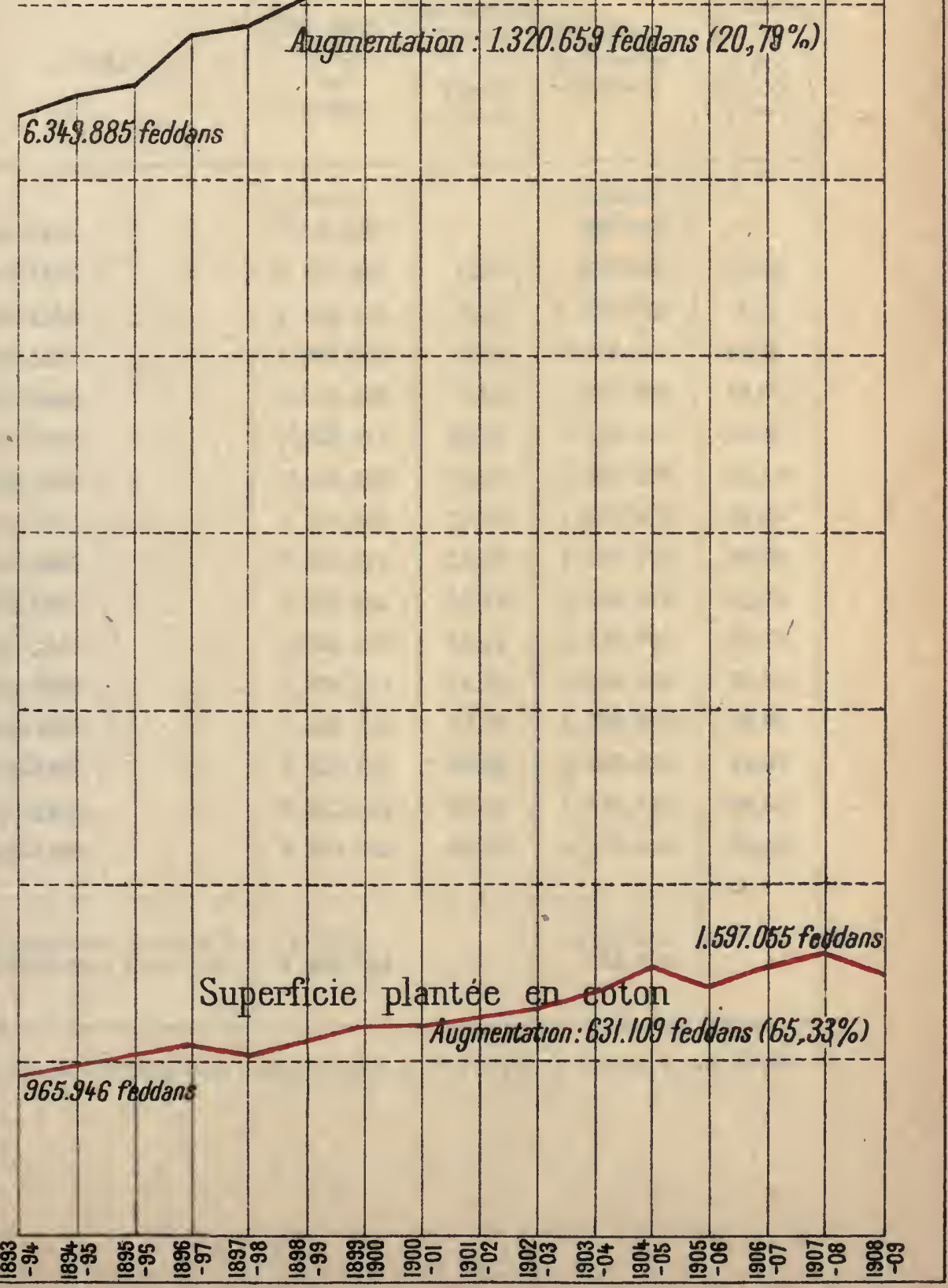




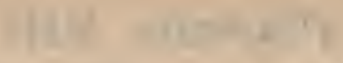

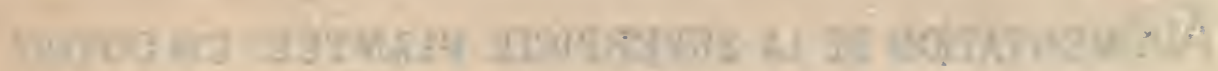

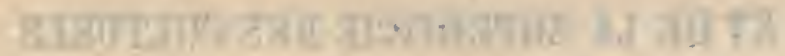

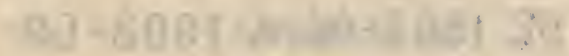
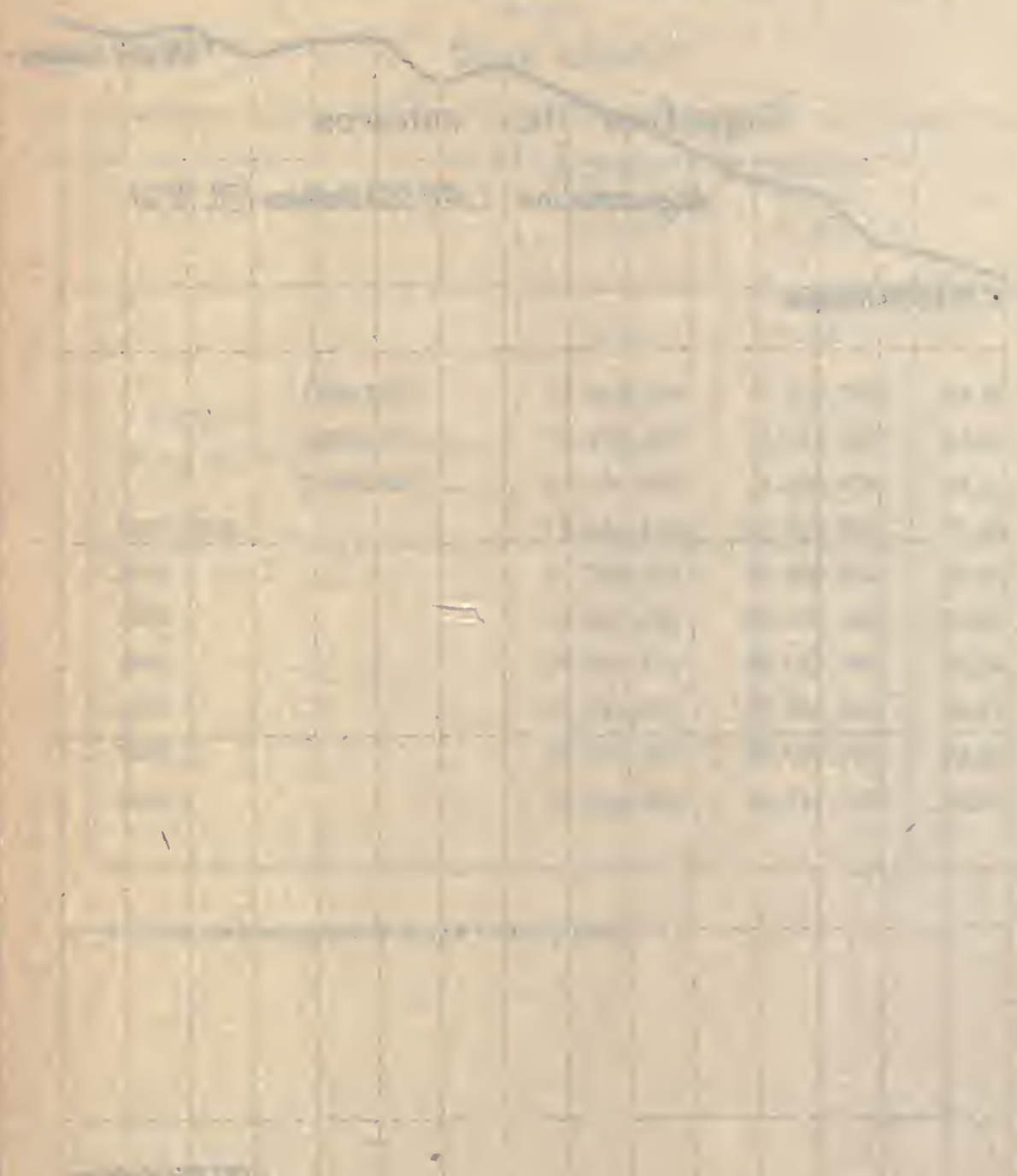

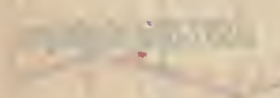

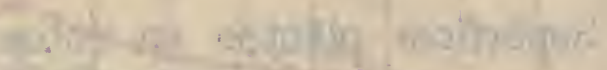

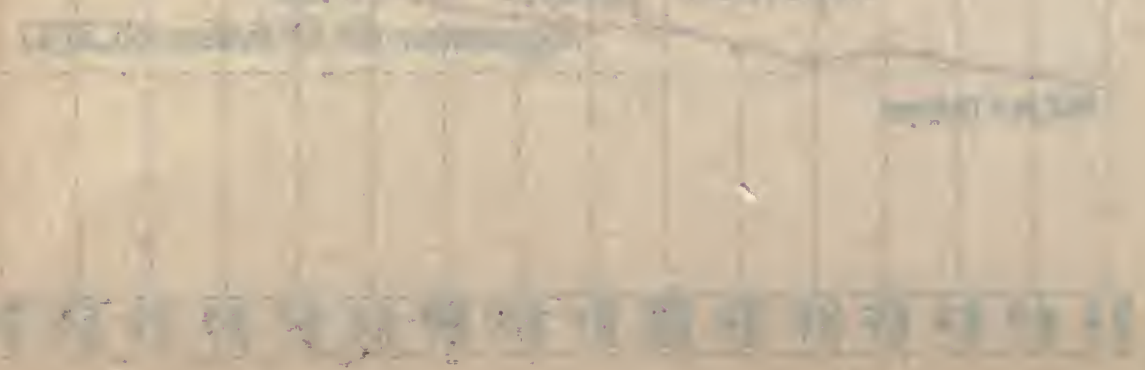




\section{TABLEAU XI}

Extensions comparées de la superficie totale des cultures et de la superficie de la culture cotonnière depuis 1893-94 à 1908-09 1

\begin{tabular}{|c|c|c|c|c|}
\hline ANNÉES & $\begin{array}{l}\text { SURFAGE } \\
\text { TOTALE } \\
\text { des } \\
\text { cultures }\end{array}$ & $\begin{array}{c}\text { AUGMEN- } \\
\text { TATION } \\
\% \text { par } \\
\text { rapport } \\
\text { à } 1893-94\end{array}$ & $\begin{array}{l}\text { SURFAGE } \\
\text { de la culture } \\
\text { cotonnière }\end{array}$ & $\begin{array}{l}\text { AUGMEN- } \\
\text { TATION } \\
\% \text { par } \\
\text { rapport } \\
\text { à } 1893-94\end{array}$ \\
\hline 1893-1894 & $\begin{array}{l}\text { Feddans. } \\
6.349 .885\end{array}$ & ") & $\begin{array}{l}\text { Feddans. } \\
965.946\end{array}$ & » \\
\hline 1894-1895 .. & 6.431 .808 & 1,29 & 997.735 & 3,29 \\
\hline $1895-1896 \ldots$ & 6.552 .172 & 3,18 & 1.050 .749 & $8,7 \mathrm{y}$ \\
\hline $1896-1897 \ldots$ & 6.764 .401 & 6,52 & 1.128 .151 & 16,79 \\
\hline $1897-1898 \ldots$ & 6.848 .396 & 7,85 & 1.121 .262 & 16,07 \\
\hline 1898-1899 .. & 7.032 .711 & 10,75 & 1.153 .307 & 19,39 \\
\hline $1899-1900 \ldots$ & 7.160 .804 & 12,77 & 1.230 .319 & 27,36 \\
\hline $1900-1901 \ldots \ldots \ldots \ldots$ & 7.291 .267 & 14,82 & 1.249 .884 & 29,39 \\
\hline 1901-1902 ... & Y.429.294 & 16,99 & 1.275 .677 & 32,06 \\
\hline 1902-1903 ... & 7.338 .685 & 15,57 & 1.332 .510 & 37,94 \\
\hline 1903-1904 ... & 7.583 .633 & 19,42 & 1.436 .709 & 48,73 \\
\hline 1904-1905 .......... & 7.563 .119 & 19,10 & 1.566 .602 & 62,18 \\
\hline $1905-1906 \ldots$ & 7.480 .546 & 17,80 & 1.506 .291 & 55,93 \\
\hline $1906-1907 \ldots \ldots \ldots$ & 7.662 .317 & 20,66 & 1.603 .224 & 65,97 \\
\hline $1907-1908 \ldots \ldots \ldots \ldots$ & 7.597 .859 & 19,65 & 1.640 .415 & 69,82 \\
\hline 1908-1909 ........ & 7.670 .544 & 20,79 & 1.597 .055 & 65,33 \\
\hline $\begin{array}{l}\text { Augmentation absolue de } \\
1893-1894 \text { à 1908-1909: }\end{array}$ & $\begin{array}{l}\text { Feddans. } \\
1.320 .659\end{array}$ & & $\begin{array}{r}\text { Feddans. } \\
631.109\end{array}$ & \\
\hline
\end{tabular}

1. Annuaire stalistique de l'Égyple (1909), p. 270 et 272, et (1910), p. 238 et 240. 


\section{TABLEAU XII}

Superficies occupées par les différentes cultures ${ }^{1}$

\begin{tabular}{|c|c|c|c|c|}
\hline & \multicolumn{2}{|c|}{$1907-1908}$. & \multicolumn{2}{|c|}{ 1908-1909. } \\
\hline & Feddans. & $0 / 0$ & Feddans. & $0 / 0$ \\
\hline Coton.. & 1.640 .415 & 21,59 & 1.597 .055 & 20,83 \\
\hline Mais . & 1.799.705 & 23,69 & 1.796 .745 & 23,42 \\
\hline Riz ... & 248.763 & 3,27 & 271.820 & 3,54 \\
\hline Blé......... & 1.168 .166 & 15,38 & 1.249 .264 & 16,28 \\
\hline Fèves.. & 541.085 & 7,12 & 566.688 & 7,39 \\
\hline Orge................ & 440.606 & 5,80 & 423.293 & 5,52 \\
\hline Canne à sucre...... & 38.562 & 0,51 & 43.982 & 0,57 \\
\hline Fourragères et autres.... & 1.693 .043 & 22,28 & 1.691 .363 & 22,05 \\
\hline Jardins.... & 27.514 & 0,36 & 30.334 & 0,40 \\
\hline Totaux............... & 7.597 .859 & $100 »$ & 7.670 .544 & $100 "$ \\
\hline
\end{tabular}

1. Annuaire statistique de l'Égypte (1910), p. 237. 
Planche IX

\section{Agriculture Egyptienne}

SAISON 1908-09

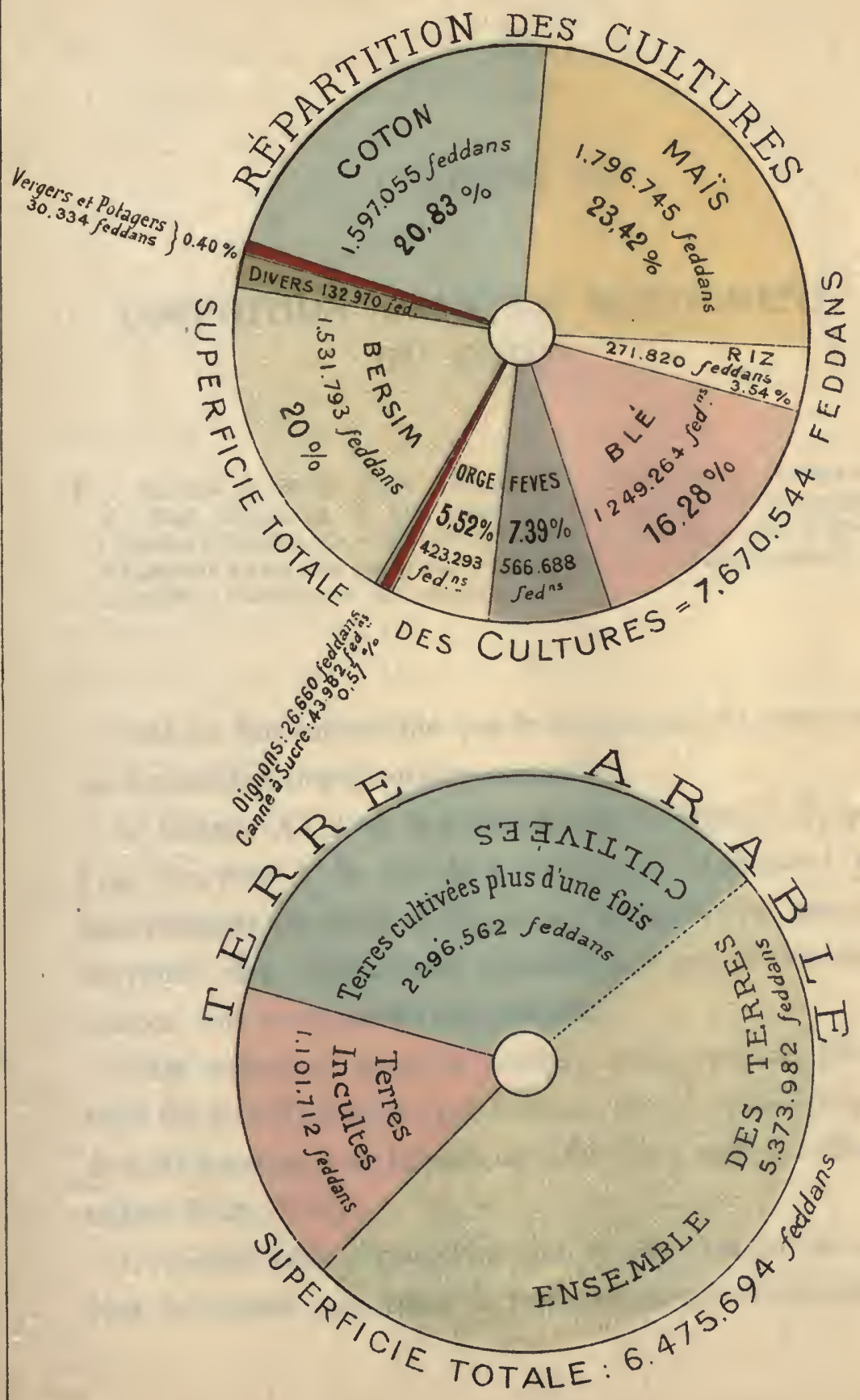


81. 6กละก:19

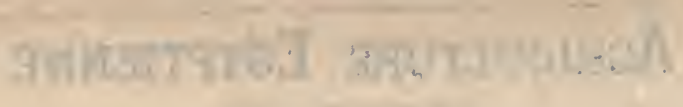

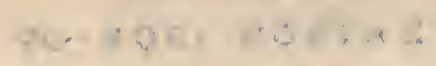

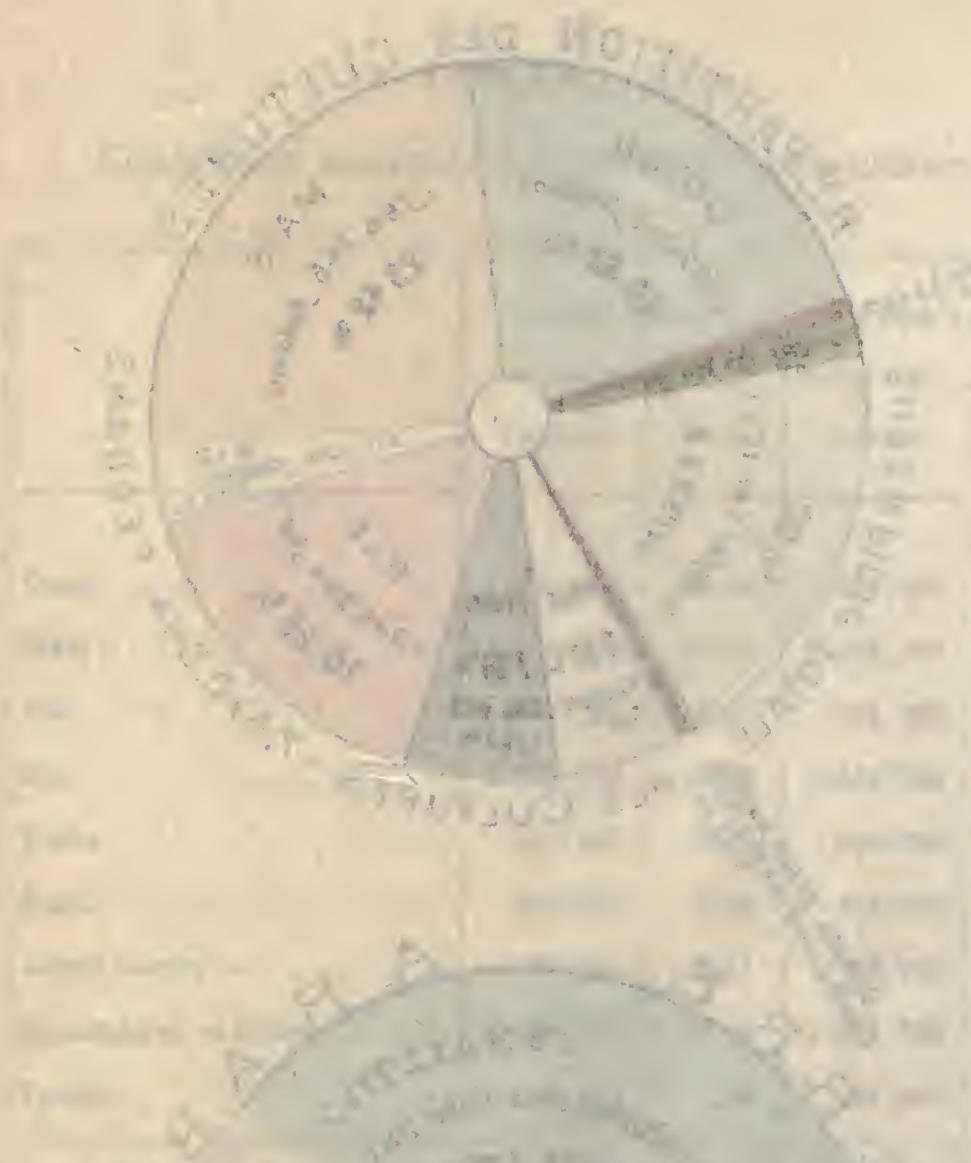

$\Delta y^{i}=2$

Ifris $5^{2}=$ 


\section{GHAPITRE XIV}

\section{DIMINUTION DANS LE RENDEMENT DU COTON}

Il a diminué de 20,30 \% $/ 0$ à l'hectare. - Commentaires erronés de M. Paul Deschanel et réfutation par la Chambre de Commerce française d'Alexandrie. - Causes principales de la diminution : l'excès d'humidité du sol ; les parasites. - Autres causes : dégénérescence de la graine; insuffisance des engrais.

C'est un fait indéniable que le rendement du coton est en diminution depuis quelques années.

Le tableau XIII et le graphique de la planche $X$, que l'on trouvera à la fin de ce chapitre, traduisent les mouvements de cette diminution. Ils montrent que la moyenne des rendements, calculée par période de cinq années, suit une marche décroissante.

Cette moyenne pour la période quinquennale 18971901 fut de 5,27 kantars par feddan; elle n'a plus été que de 4,20 kantars pour la période 1907-1911, soit une diminution de $20,300 / 0$.

L'opinion s'est vivement émue, et avec raison, de cet état de choses, car, selon la juste remarque d'une note 
du Service de l'arpentage rédigée pour le Service de la statistique, une diminution d'un kantar dans le rendement moyen du feddan représente, par rapport à l'ensemble de la récolte et aux prix moyens actuels, une perte annuelle de L. E. 6.000 .000 (155.541.000 francs).

Commentant cette diminution, M. Deschanel, dans son rapport sur le budget des affaires étrangères pour 1911, s'est fait, à la tribune du Parlement français, le complaisant écho des bruits alarmistes mis en circulation à ce sujet. L'honorable rapporteur a été induit en erreur par des chiffres qu'il convient de rectifier.

"Tandis qu'il y a quelques années, dit-il, le rendement " moyen des terres cultivées en coton était de 180 kilo" grammes au feddan, on n'a pu, en 1909, l'estimer à plus " de 90 kilogrammes au feddan, et cette estimation porte " sur des terres de culture exceptionnelles comme celles " des Domaines."

Outre que ces chiffres sont en retard d'une année, ils ont le tort, même en les appliquant à l'année 1909, d'être manifestement inexacts. C'est ce que démontre en ces termes le Bulletin de la Chambre de Commerce française d'Alexandrie, $\mathrm{n}^{\circ}$ 220, de février 1911 :

" Le rendement moyen de la période quinquennale ( 1906-1910 est bien de 180 kilogrammes de coton au " feddan (chiffre exact $183 \mathrm{~kg}$. 15), soit 463 kilogrammes “ à l'hectare; mais celui de l'année 1909 n'est pas de " 90 kilogrammes, comme le laisserait croire le rapport de . M. Deschanel, mais bien de 145 kilogrammes et 80/100 au 
" feddan, soit $347 \mathrm{~kg} .14$ à l'hectare. Disons tout de suite " qu'en 1910 ce chiffre est remonté à 495 kilogrammè à " l'hectare. En outre, il semble tout à fait injuste de com" parer des chiffres moyens résultant de plusieurs années " avec ceux d'une seule année choisie parmi celles qui ont " exceptionnellement donné des récoltes en déficit.

"Dans toute culture industrielle, vigne, tabac, pommes " de terre, betteraves, etc., il arrive occasionnellement " des années déficitaires, et le manquant de la récolte est " souvent beaucoup plus accentué qu'il ne l'a été en “ Egypte pour le coton. Il ne viendrait pourtant à l'idée " de personne de dire, par exemple, que la productivité " vinicole de la France est compromise parce que l'an“ née 1910 a donné des rendements très inférieurs à " la moyenne quinquennale.

" La seule constatation qui s'impose en matière de " culture de coton en Egypte est que la moyenne des ren" dements, calculée par périodes de cinq ans, suit une " marche décroissante. "

Constatant le superbe résultat de la récolte du coton en 1910, le Bulletin de la Chambre de Commerce française d'Alexandrie conclut :

" La récolte de coton de 1910 atteindra une valeur " que l'on peut, dès à présent, estimer à L. E. 30.000.000 " au moins, soit 780.000.000 de franes.

" De sorte que M. Deschanel proclame la faillite agri" cole de l'Egypte, au moment précis où la récolte " cotonnière s'élève à un chiffre qui n'avait jamais 
"été atteint, soit comme quantité, soit comme valeur."

Cependant, il n'en est pas moins vrai, comme nous venons de le constater, que, depuis quelques années, la moyenne des rendements dans la culture du coton est en diminution.

Quelles sont les causes de cette diminution?

Il faut d'abord en chercher la raison dans l'extension de la culture cotonnière sur les terres nouvellement défrichées.

“ Depuis 1890, dit le Bulletin de la Chambre de Com" merce d'Alexandrie (février 1911), l'amélioration du ré" gime des irrigations, la création de nouveaux barrages, la " consolidation des anciens ouvrages, l'établissement d'un " réseau de drainage très étendu ont permis de mettre en " valeur un domaine foncier extrêmement important.

" De plus, les prix du coton ont doublé, incitant ainsi " le cultivateur à étendre cette culture sur des terrains " médiocres, terrains dont le rendement n'aurait pas couvert " les frais de culture, aux prix anciens, tandis qu'il laisse " un bénéfice, aux prix actuels.

"Les terres nouvellement défrichées ne peuvent se " comparer, comme fertilité, aux terres dont l'exploi" tation remonte à des siècles. En Egypte, comme dans " tous les pays où le sol est de formation alluviale et ma" rine, la terre est d'autant plus fertile qu'elle est plus " anciennement cultivée; il est donc normal que les cen" taines de milliers d'hectares défrichés durant les derniers " vingt ans ne donnent en coton que des rendements rela" tivement faibles. 
"L'introduction de surfaces ainsi acquises dans le " calcul de la moyenne générale des rendements a "pour résultat normal de faire figurer un rendement " moyen plus faible à mesure que les défrichements " s'étendent.

"Les efforts du Ministère des Travaux Publics ayant " pour principal objet d'accroître la fourniture d'eau uti" lisable par la culture, il faut s'attendre à ce que les " défrichements de nouvelles terres marchent pari passu " avec l'augmentation de la quantité d'eau disponible. " Et, pendant des années encore, nous constaterons que la " moyenne générale à l'hectare du rendement cotonnier " sera décroissante, puisqu'elle inclura des quantités " toujours croissantes de terres nouvellement défrichées, " terres dont la fertilité ne s'accroît qu' avec le temps. "Il est donc normal que la récolte cotonnière en Egypte " s'accroisse chaque année en volume, bien que le ren" dement à l'hectare soit diminué : ceci résulte naturel" lement de l'extension considérable et constante de la " culture du coton sur des terres que l'on défriche au fur " et à mesure des progrès du régime des irrigations. Je "répète que les hauts prix atteints actuellement par le " coton accentuent encore le mouvement cultural. "

Nous n'avons rien à ajouter à cet exposé si clair et si convaincant. Toutefois, l'argument tiré de l'extension de la culture du cotonnier à des terrains nouvellement défrichés n'explique qu'en partie la diminution dans le rendement du coton; mais il ne donne pas toutes les causes 
de la diminution qui affecte les rendements des terres depuis longtemps mises en culture.

Ces causes principales sont:

L'excès d'humidité du sol et les parasites.

Excès d'humidité. - On ne peut méconnaître que les modifications profondes apportées au régime hydraulique ont accru l'humidité du sol égyptien. La surélévation des barrages et la création d'un vaste réseau de canaux, en permettant l'irrigation pérenne, source de richesses inappréciables pour le pays, a exhaussé en même temps le plan des eaux souterraines et provoqué des infiltrations excessives. La terre, ainsi gorgée d'eau, ne peut, faute de drains suffisants, se débarrasser du trop-plein de ce qu'on lui a fait absorber et, de son côté, l'évaporation n'arrive plus à dessécher les terrains dans la mesure convenable.

Dès 1889, sir William Wilcocks, dans son ouvrage Egyptian Irrigations, constatait déjà que "la hausse de l'eau $d u$ sous-sol constituait un grand danger pour le pays \%. Cette constatation est aujourd'hui expérimentalement vérifiée.

En effet, des expériences faites par l'administration des domaines de l'Etat sur ses propres terres permettent d'enregistrer les observations suivantes:

10 De toutes les plantes cultivées en Egypte, il n'y a que le cotonnier qui ait été affecté dans son rendement. Or, le cotonnier seul à des racines profondes qui doivent se rapprocher sensiblement de la nappe souterraine voisine du sol dans la période de la crue. Pendant cette période, les plantes alors sur pied sont, à part le cotonnier, 
le maïs, dont les racines fasciculées restent presque à la surface du sol, et le riz, qui, lui, s'accommode admirablement d'un excès d'eau.

$2^{\circ}$ Durant toute la période de croissance, le coton se présente dans les conditions normales. Il ne commence à accuser des signes de faiblesse que lorsqu'il est entré en fructification, soit à partir de la fin d'août ou du commencement de septembre. A cette époque, les racines ont atteint leur plein développement; de son côté, la nappe souterraine, favorisée, d'une part, par le mouvement ascendant de la crue, et, de l'autre, par l'action des eaux d'arrosage, se rapproche très sensiblement de la surface du sol.

D'après M. Barois, le niveau de la nappe souterraine s'élève, en octobre, jusqu'à un mètre au-dessous du sol dans la partie irriguée ${ }^{1}$. Le voisinage de la nappe doit certainement retarder l'infiltration des eaux d'arrosage, de sorte que le sol et le sous-sol, trop longtemps sursaturés, ne permettent plus aux racines la libre respiration qui leur est indispensable. Celles-ci, gênées dans cette partie de leur fonction, réagissent sur l'ensemble de la plante, qui manifeste alors des signes de faiblesse et même, en certains cas, de dépérissement.

$3^{\circ}$ Dans les années de basses crues, où le niveau de la nappe souterraine reste éloigné de la partie terminale des racines du cotonnier, la plante se comporte beaucoup mieux que dans les années de hautes crues. Dans ce cas, 
l'imperméabilité du sol est moins contrariée et l'infiltration des eaux d'arrosage s'opère assez rapidement pour ne pas laisser trop longtemps le sol en état de saturation. $4^{\circ}$ La période à partir de laquelle la diminution s'est manifestée a coïncidé avec l'augmentation de la retenue d'eau au barrage du Delta et, par suite, avec le relèvement du niveau de l'eau dans les canaux d'irrigation.

$5^{\circ} \mathrm{Il}$ y a lieu de faire observer que le rendement des céréales et légumineuses, qui sont cultivées et récoltées de novembre à mai, au moment où le Nil et les canaux sont à l'étiage, n'a souffert aucune diminution et que dans certaines régions la moyenne du rendement augmente d'une façon appréciable.

D'autres expériences, dues à $M$. Audebeau, l'ingénieur en chef des Domaines de l'Etat, établissent que des cotonniers ont donné leurs meilleurs rendements dans des fosses où leurs racines avaient pu atteindre la plus grande profondeur, et que les plants de cotonnier les plus chétifs et dont les rendements avaient été les plus faibles se trouvaient dans les terres où la tranche d'eau du fond était le plus rapprochée de la surface cultivée.

De tout ce qui précède, on peut conclure que la cause dominante de la diminution du rendement de la culture cotonnière réside dans la saturation du sol.

Ce mal s'aggraverait encore de ce que l'eau de la nappe souterraine qui remonte à la surface est chargée de sel, carle sol égyptien en contient à assez forte dose comme tout pays conquis sur la mer ou abandonné par elle. Au temps 
de l'irrigation par bassins, la nappe liquide déversée par le Nil inondait la plaine et, en se retirant, entraînait toute trace de sel ; aujourd'hui, ce lavage ne se fait qu'imparfaitement; le sel reste dans la terre et la stérilise.

En effet, les eaux dont le sol est imprégné disparaissent de deux manières ; une partie, s'écoulant par gravitation dans la terre, vient augmenter la nappe souterraine ou se vider dans les drains; l'autre partie, remontant à la surface par capillarité, s'évapore dans l'atmosphère. L'évaporation des eaux rouges ou eaux d'arrosage, fournies par les crues du Nil, est profitable à la terre, puisqu'elle renouvelle constamment la provision d'azote. Mais il n'en est pas de même des eaux composant la nappe souterraine; ces dernières sont chargées des résidus du lavage d'une grande masse de terres dont elles ont entrainé tout le sel alcalin et le sel marin; leur évaporation, formant à la surface du sol des dépôts salins, est aussi nocive que celle des eaux rouges est bienfaisante.

De ces explications, il résulte que le relèvement du plan des eaux souterraines, par les barrages d'Assouan, d'Assiout, du Delta et de Ziphteh, présente, par suite d'un drainage insuffisant, des inconvénients à un triple point de vue: d'abord, parce qu'il arrête la nitrification du sol et, par conséquent, son enrichissement en acide nitrique; ensuite, parce qu'il empoisonne les racines arrivées au contact de la nappe aquifère et empêche leur développement normal; enfin, parce qu'il détériore le sol en augmentant le dépôt des sels nuisibles à la surface. 
Cet excès d'humidité, aggravé encore par les arrosages trop copieux, souvent même intempestifs, auxquels procèdent les fellahs immédiatement après les distributions intermittentes et alternatives du liquide, appelées rotations, ne nuit pas seulement à la plante d'une façon directe, en provoquant la chute de ses feuilles, mais il contribue, en outre, à la pullulation des parasites dont souffre le cotonnier.

Parasites. - Les plus redoutables de ces parasites sont deux sortes de chenilles, — confondues généralement sous l'unique dénomination de vers $d u$ coton, - dont l'une s'attaque aux feuilles au printemps et l'autre aux capsules en automne.

L'excès d'humidité et les parasites, voilà donc les deux grands ennemis du cotonnier. A ce sujet, nous sommes parfaitement d'accord avec la Commission du coton qui a été instituée par le Gouvernement, le 20 décembre 1909, avec mission d'étudier les causes de la baisse du rendement cotonnier et les mesures à prendre pour relever la production.

Mais il est d'autres facteurs qui ont été envisagés par cette Commission, comme pouvant agir ensemble ou séparément sur la diminution du rendement. Ces facteurs, les voici :

$1^{\circ}$ L'appauvrissementdusol parlasubstitution, en beaucoup d'endroits, de l'assolement biennal à l'assolement triennal ; 
$2^{\circ}$ La dégénérescence de la graine;

$3^{\circ}$ L' insuffisance des engrais ;

$4^{\circ}$ Et des modifications qui seraient survenues dans les conditions météorologiques de l'Égypte.

Les rapports de la section de l'arpentage, chargée depuis deux ans, de la mesure des superficies occupées par le cotonnier, écartent le dernier de ces facteurs, démentant qu'il se soit produit aucun changement climatérique dans le pays. La Commission n'a pas, d'ailleurs, retenu cette prétendue cause de diminution.

Quant à l'assolement biennal, tout en estimant qu'il présente des inconvénients certains, elle ne pense pas qu'il semble " avoir donné lieu à un épuisement du sol tel qu'il " puisse expliquer la diminution des rendements, puisque " cette diminution s'est manifestée également sur les " terres où l'assolement triennal a toujours été suivi ", notamment dans des terres comme celles de l'administration des Domaines, où le phénomène de la diminution du rendement a été constaté avec la même proportionnalité que dans les terres avoisinantes, où la culture du coton est cependant plus fréquente.

En ce qui concerne la dégénérescence de la graine, la Commission reconnait qu'aucun fait précis ne permet de conclure à son existence; elle constate même que "au con" traire, la marche des rendements dans un certain nombre " de propriétés, jusqu'en 1908, semble contredire cette "opinion "; mais, ajoute-t-elle, "si aucune preuve n'a "été fournie de la dégénérescence de nos cotonniers, 
" par contre, la pratique agricole s'est rencontrée avec " des résultats d'étude pour affirmer l'impureté de nos " variétés actuelles ${ }^{1}$ ".

Il semble donc qu'il faille incriminer la mauvaise qualité des semences que le fellah se procure trop souvent au hasard en s'adressant à des fournisseurs qui lui livrent à bas prix des graines obtenues au moyen de l'hybridation de variétés perfectionnées avec l'Hindi, espèce de cotonnier à demi sauvage et d'un produit très inférieur. De là un croisement qui, d'après une circulaire de la Société khédiviale d'Agriculture, "prend de telles propor" tions qu'il est actuellement impossible de trouver un " échantillon de coton Afifi pur de tout mélange ".

On a accusé aussi l'insuffisance des engrais. Nous avons constaté ci-dessus que la diminution dans le rendement du coton s'était produite aussi bien dans les terres à assolement triennal que dans les terres à assolement biennal.

Est-ce à dire que le sol égyptien se soit appauvri ? Nullement. Comme nous l'avons dit plus haut, la diminution du rendement n'a été constatée que pour le coton; le rendement des céréales et légumineuses a accusé, au contraire, une sensible augmentation. La canne à sucre etle coton sont, il est vrai, des plantes éminemment épuisantes et les éléments nutritifs absorbés par celles-ci ne sont pas suffisamment compensés par ceux qui sont apportés par le Nil. On se demande, dès lors, comment les terres

1. Rapport général de la Commission du Coton, p. 16. 
égyptiennes n'ont pas été épuisées et quelle cause entretient la productivité de l'humus là où il ne reçoit pas d'engrais?

L'explication de ce phénomène a trouvé place dans notre chapitre premier, où sont exposées les conditions particulières qui, grâce au renouvellement incessant des forces productives du sol égyptien, en font la terre la plus fertile du monde.

Faut-il en conclure que les engrais sont inutiles? Non, certes. Les cultivateurs en apprécient si bien lés bons effets que la consommation en augmente sans cesse. Le fumier de ferme est en quantité fort insuffisante ; le fellah le remplace par la colombine recueillie dans les pigeonniers, la vase extraite des canaux, les boues de ville et surtout les monticules d'engrais terreux (coms ou sabackh) constitués par les détritus d'anciennes villes ou d'anciens villages; or, les ressources du pays en engrais vont en diminuant, car ces monticules sont presque épuisés et, en ces derniers temps, la peste bovine a décimé le bétail égyptien. Mais, comme le constate le rapport général de la Commission du Coton, l'importance des engrais chimiques importés n'a cessé de s'accroître. De 2.132 tonnes, valant L. E. 12.912, en 1902, elle a passé, en 1909, à 21.165 tonnes d'une valeur de L. E. 178.014. Elle a plus que décuplé en sept ans. Chaque année, la Société khédiviale d'Agriculture vend pour près de 100.000 livres d'engrais chimiques. Il y a là encore un indice des plus rassurant pour l'avenir agricole de l'Égypte. 
TABLEAU

Extension de la culture

Mouvements comparatifs du rendement au feddan, du prix

\begin{tabular}{|c|c|c|c|}
\hline $\begin{array}{l}\text { SAISONS } \\
\text { (A) }\end{array}$ & $\begin{array}{l}\text { SUPERFICIE } \\
\text { cultivée } \\
\text { (1) }\end{array}$ & $\begin{array}{l}\text { RÉCOLTE } \\
\text { (2) }\end{array}$ & PRIX DE L'UNITÉ \\
\hline $1896-1897$ & $\begin{array}{l}\text { Feddans. } \\
1.050 .749\end{array}$ & $\begin{array}{l}\text { Kantars. } \\
5.879 .479\end{array}$ & $\begin{array}{l}\text { P. T. } \\
190 \text { 15/40 (109 fr. } 84 \text { les } 100 \text { kilos). }\end{array}$ \\
\hline $1897-1898$ & 1.128 .151 & 6.543 .628 & $15828 / 40$ \\
\hline 1898-1899 & 1.121.262 & 5.589 .314 & 183 \\
\hline $1899-1900$ & 1.153 .307 & 6.510 .050 & $24811 / 40$ \\
\hline $1900-1901$ & 1.230 .319 & 5.427 .338 & $23822 / 40$ \\
\hline 1901-1902 & 1.249 .884 & 6.371 .643 & $22215 / 40$ \\
\hline $1902-1903$ & 1.275 .677 & 5.838 .090 & $31830 / 40$ \\
\hline $1903-1904$ & 1.332 .510 & 6.508 .947 & $31415 / 40$ \\
\hline $1904-1905$ & 1.436 .709 & 6.351 .878 & $273 \quad 23 / 40$ \\
\hline $1905-1906$ & 1.566 .602 & 5.989 .883 & $349 \quad 12 / 40$ \\
\hline 1906-1907 & 1.506 .291 & 6.949 .383 & $382 \quad 15 / 40$ \\
\hline $1907-1908$ & 1.603 .224 & 7.234 .669 & $31420 / 40$ \\
\hline 1908-1909 & 1.640 .415 & 6.751 .133 & 303 \\
\hline $1909-1910$ & 1.597 .055 & $4.911 .631(b)$ & $55124 / 40(b)$ \\
\hline $1910-1911$ & 1.603 .266 & $7.579 .355(b)$ & $44718 / 40(b)$ (258 fr. 16 les 100 kilos). \\
\hline
\end{tabular}

(A) Dans ce tableau, les années correspondent aux années commerciales commençant le $1^{\text {er }}$ septembre et se terminant le 31 août. Il faut remarquer que l'année commerciale commence au moment même où se termine l'année agricole. Ainsi le coton provenant des cultures de la saison agricole 1909-10 (1 ${ }^{\text {er }}$ septembre 1909-31 aout 1910), récolté en octobre-novembre 1910, figure à l'année commerciale 1910-11 (1 ${ }^{\text {er }}$ septembre 1910-31 août 1911) : c'est pourquoi dans ce tableau les chiffres ne concordent pas avec ceux-des tableaux où l'année agricole est seule considérée. 


\section{XIII}

\section{du Coton en Égypte}

du kantar et du revenu au feddan de 1896-97 à 1910-11.

\begin{tabular}{|c|c|c|c|c|}
\hline \multirow{2}{*}{$\begin{array}{c}\text { VALEUR } \\
\text { totale } \\
(3)\end{array}$} & \multicolumn{4}{|c|}{ PRODUCTION DU FEDDAN } \\
\hline & $\begin{array}{r}\text { RENDE } \\
\text { moy } \\
(2\end{array}$ & $\begin{array}{l}\text { MENT } \\
\text { en }\end{array}$ & & VALEUR \\
\hline $\begin{array}{l}\text { L. E. } \\
11.193 .058\end{array}$ & $\begin{array}{c}\text { Kant } \\
\mathbf{5 . 5 9}\end{array}$ & ars. & $\begin{array}{l}\text { L. E. } \\
10,641\end{array}$ & (656 fr. 78 l'hect.) \\
\hline 10.384 .737 & 5.80 & & 9,205 & \\
\hline 10.227 .533 & 4.91 & 5,27 & 8,984 & \\
\hline 16.163 .448 & 5.64 & & 14,002 & \\
\hline 12.947 .332 & 4.42 & & 10,544 & - \\
\hline 14.169 .867 & 5.10 & & 11,341 & \\
\hline 18.609 .683 & 4.58 & & 14,599 & - \\
\hline 20.462 .502 & 4.88 & 4,55 & 15,342 & \\
\hline 17.251 .283 & 4.39 & & 10,922 & \\
\hline 20.802 .971 & 3.80 & & 13,197 & \\
\hline 26.572 .703 & 4.61 & & 17,627 & \\
\hline 22.753 .034 & 4.51 & & 14,184 & \\
\hline 20.455 .932 & 4.12 & 4,20 & 12,484 & \\
\hline 27.093 .661 & 3.07 & & 16,934 & \\
\hline 33.915 .339 & 4.72 & & 21,120 & (1.303 fr. 57 l'hect.) \\
\hline
\end{tabular}

1. Annuaire statistique de l'Égypte (1910), p. 240.

2. Annuaire statistique de l'Égypte (1910), p. 260-61.

3. L'Égypte contemporaine, mars 1910, p. 258.

(b) Chiffres communiqués par la Chambre de Commerce française d'Alexandrie (lettre du 4 nov. 1911). 


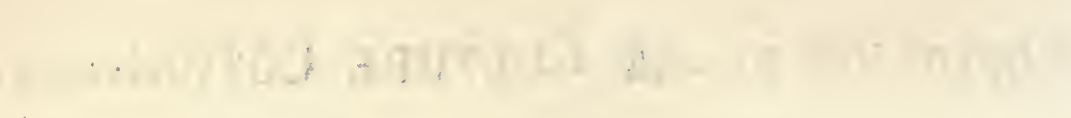

o.tinitis

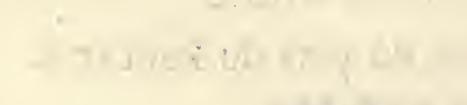

Why y w it. 
Planche $X$

\section{Exploitation de la Culture Cotonnière}

Mouvements comparatifs du rendement au fedảan, du prix du kantar \&

L.E. $21, \underline{120}$ du revenu au feddan de 1896-97à 1910-11

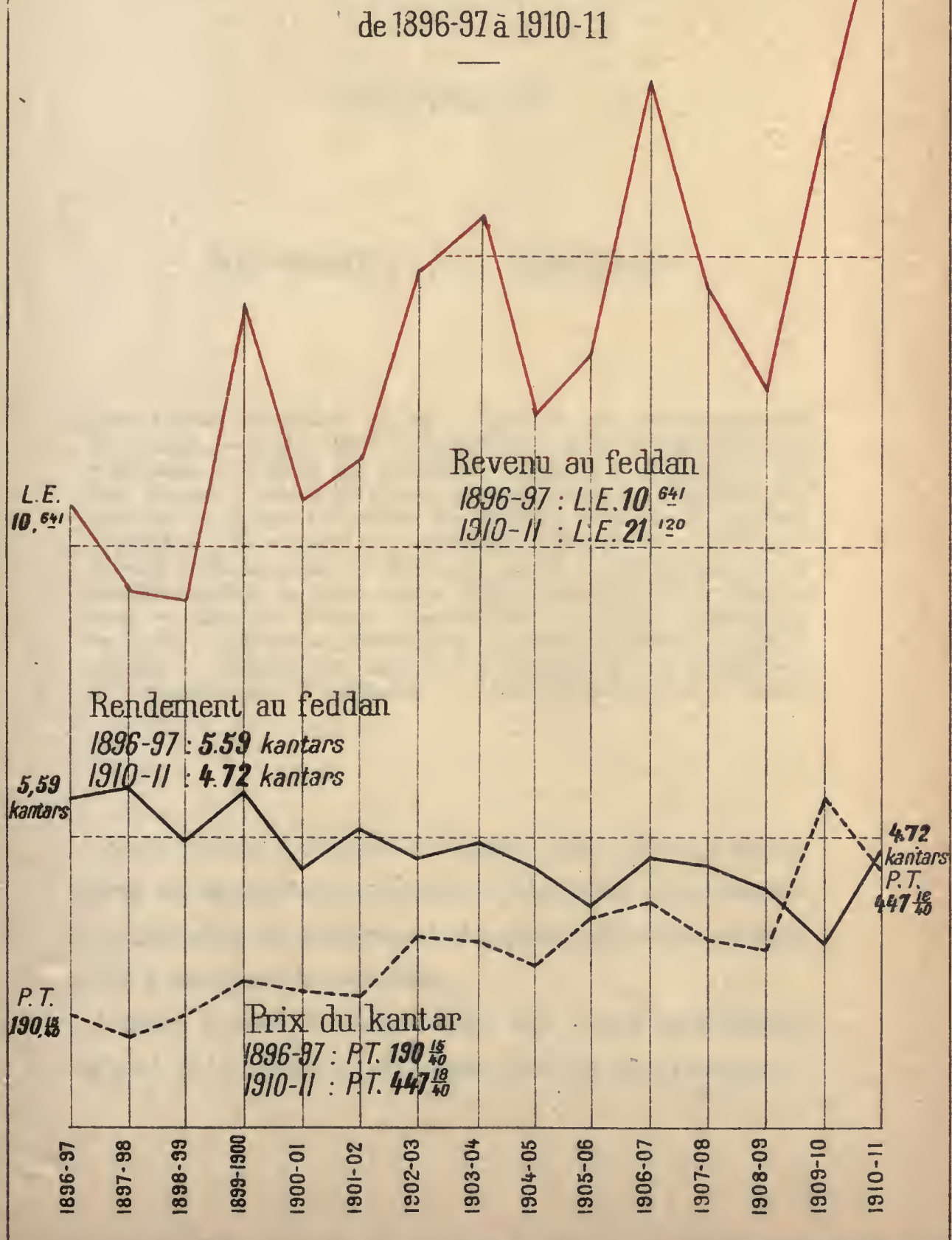

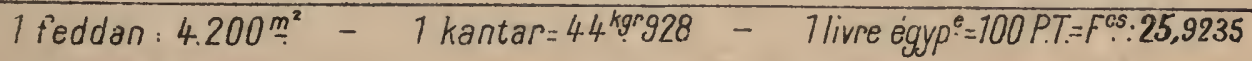




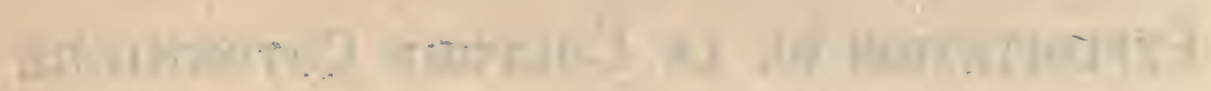
4x
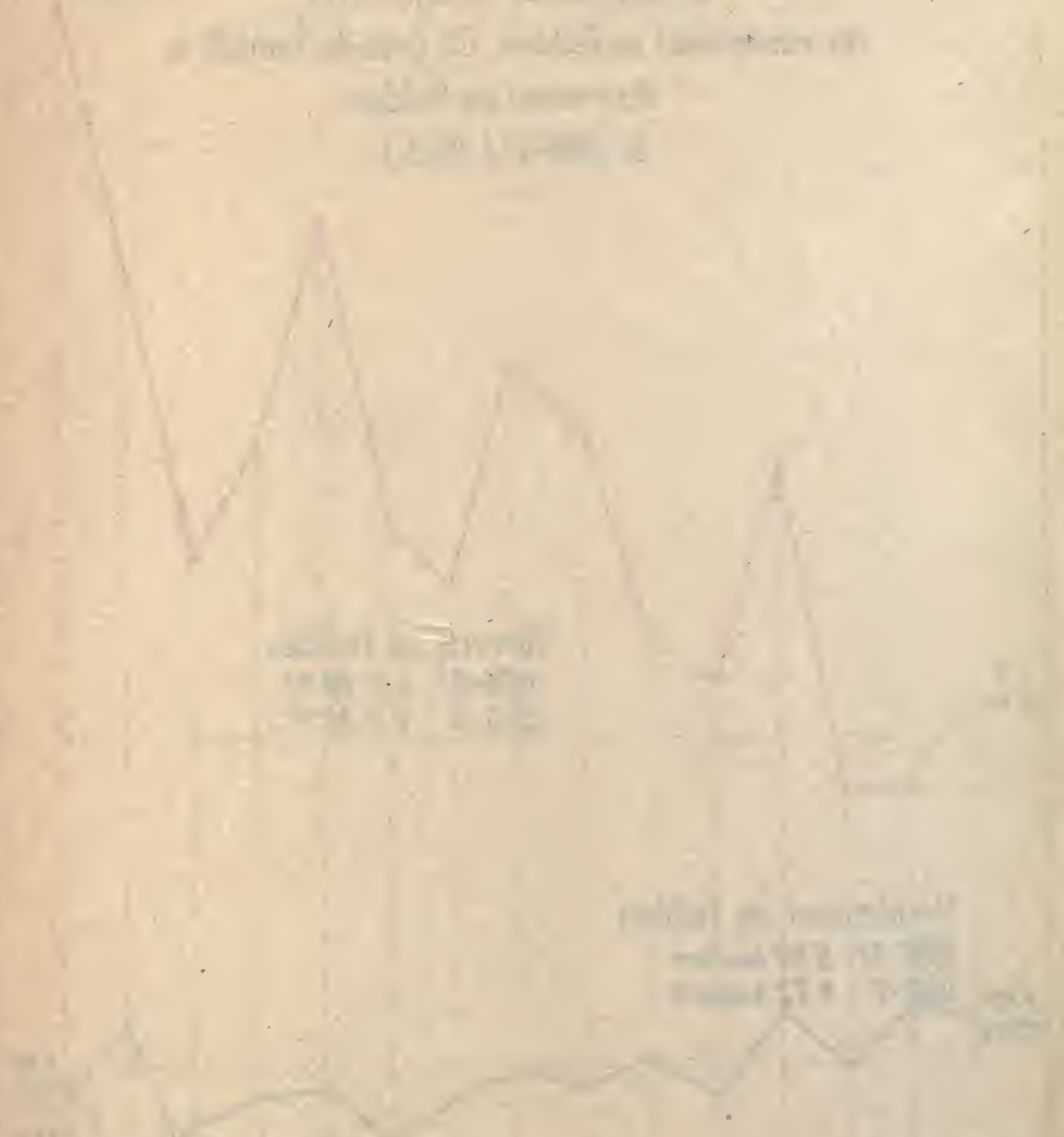

1

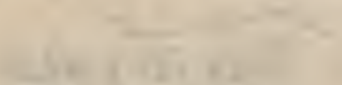

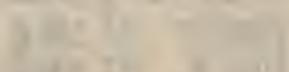

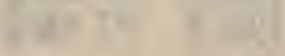

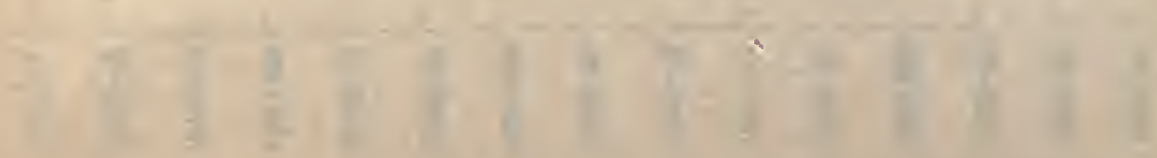




\section{G.HAPITRE XV}

\section{RÉFORMES ET REMÈDES}

Contre l'excès d'humidité du sol : extension et perfectionnement du drainage. - Contre l'abus des irrigations : meilleur emploi des eaux d'arrosage. - Contre les parasites : application méthodique des lois, décrets et arrêtés relatifs à leur destruction. - Résultats déjà obtenus. - Contre l'impureté des graines : sélection des graines; extirpation des variétés de cotonniers inférieures et recherche de variétés perfectionnées. - Réformes morales : amélioration de la condition sociale du fellah par la diffusion des éléments d'éducation. - Création d'écoles d'agriculture. - Station agronomique au Caire. - Fermes expérimentales. - Comité supérieur de l'Agriculture. - Associations agricoles de prévoyance, de production, de consommation, d'assistance. - Banques mutuelles de crédit.

Nous venons d'exposer les causes principales et secondaires auxquelles est attribuée la régression quantitative et qualitative du rendement du coton égyptien; il nous reste à examiner les remèdes.

Contre l'excès d'humidité du sol, cause primordiale du mal, la Commission du Coton émet les vœux suivants : 
Procéder le plus tôt possible à des expériences scientifiques dans diverses localités et sur des sols différents, en vue de déterminer le volume d'eau nécessaire pour les arrosages et le meilleur intervalle à observer entre eux.

En attendant que ces expériences aient fourni des données précises, il y aurait lieu :

a. De convaincre les cultivateurs de l'intérêt qu'ils ont à limiter l'eau d'irrigation à la quantité nécessaire au développement naturel de la plante;

b. D'établir les rotations d'été, dans les régions à coton, de façon à ne permettre qu'un arrosage tous les dix-huit jours dans les terres moyennes ;

c. Faire suivre immédiatement, à l'époque de la crue, le système des rotations d'été d'un système de rotations comportant des périodes, de durée égale autant que possible, de distribution de l'eau alternativement à haut et à bas niveau dans les canaux, système qui serait prolongé pendant l'hiver et le printemps ;

$d$. Prévenir les cultivateurs des dangers que présentent pour le cotonnier les arrosages excessifs donnés après les rotations d'été ;

e. Etendre et perfectionner le plus rapidement possible le système de drainage déjà existant.

C'est là, avant tout, affaire au Gouvernement, qui, du reste, s'en préoccupe très sérieusement; nous devons rendre justice à ses louables efforts; mais, s'il a donné à l'irrigation un si remarquable développement, il s'est 
beaucoup moins occupé de l'évacuation du précieux liquide. Le drainage est le complément de l'írrigation, puisqu'en desséchant le sol il le purge d'une grande partie de l'humidité ; or, il faut convenir que le système de drainage ne répond plus actuellement à tous les besoins parce qu'il n'a pas marché de pair avec l'irrigation. De là l'absolue nécessité de créer de nouveaux drains et d'améliorer ceux qui existent. Quant aux terres basses du Nord, il est clair que le drainage ne peut y être effectué qu'au moyen d'appareils élévatoires.

En tout cas, on voit que la question, tout en étant d'une importance capitale, peutêtre envisagée en toute tranquillité; sa solution est entre les mains du Gouvernement, et la vigilance de ce dernier à l'égard des intérêts économiques du pays est trop connue pour qu'il la laisse longtemps en suspens. Nous apprenons qu'il vient d'approuver les plans et devis relatifs au projet d'irrigation et de drainage de la région au nord du Delta. Un crédit de L. E. 300.000 a été immédiatement prélevé sur les fonds de la réserve générale pour faire face aux premières dépenses. Les travaux, qui doivent durer quatre ans environ, ont été commencés, le 23 mars dernier, à Ebehan, et le premier coup de pioche a été l'occasion d'une fête que présidait lord Kitchener assisté du ministre des Travaux publics et de tout le haut personnel de ce ministère.

C'est là un premier pas dans cette voie où le Gouvernement, sur l'initiative de lord Kitchener, s'est tracé un programme sérieux comprenant aussi bien la réfection 
et le curage des canaux existants que l'adoption d'un système complet de drains, dont le plan d'eau sera tenu aussi bas que possible par l'évacuation dans la mer ou dans les lacs, au moyen de pompes aspirantes.

Le projet comporte, particulièrement en ce qui concerne la province de Béhéra, le desséchement du lac Mariout et le creusement dans son lit d'un canal d'évacuation gigantesque, d'une profondeur d'un mètre.

Quant au drainage de la province de Gharbieh, de puissantes pompes, d'une capacité de 250 mètres cubes d'eau à l'heure, seront placées près du lac Borollos. Grâce à l'exécution de ces travaux, l'Égypte verra disparâttre le seul nuage qui aurait pu assombrir son avenir de fertilité et d'expansion économique.

Elle bénéficiera, en outre, dans un avenir prochain, de quatre avantages également importants :

$1^{\circ}$ L'approfondissement de la couche accessible aux racines par l'abaissement du plan des eaux souterraines, et, comme conséquence, la disparition de la cause principale de la diminution dans le rendement cotonnier ;

$2^{\circ}$ L'acquisition à la culture d'un million de feddans envahis, une partie de l'année, par les eaux de colature. Celles-ci, se répandant sur les terres qui entourent les lagunes à l'extrémité du Delta et se mêlant à leurs eaux, avaient fini par occuper avec elles une étendue considérable;

$3^{\circ}$ L'amélioration des terres voisines des précédentes, qui actuellement souffrent d'un excès d'humidité ;

$4^{\circ}$ Enfin une plus complète fertilisation du sol égyptien. 
en général par une plus grande aération de ses couches profondes.

Toutefois, le drainage n'est pas le seul point sur lequel doivent se concentrer les efforts du Gouvernement; il y a encore, nous l'avons déjà indiqué, le ver du coton.

Cette huitième plaie d'Égypte, dont la première manifestation se produisit en 1878, exerça des ravages particulièrement graves en 1886, 1891 et 1895. Le Gouvernement finit par comprendre que, pour lutter contre le fléau, une action énergique et bien coordonnée était indispensable. Deux lois, l'une de 1905, l'autre de 1906, et un arrêté en date de 1907 intervinrent, obligeant les propriétaires, les omdehs et cheikhs des villages, à dénoncer l'apparition des insectes, accordant le droit de réquisitionner moyennant salaire les garçons de dix à dix-huit ans pour détacher et brûler les feuilles de tout cotonnier où le ver aurait déposé ses œufs, "sous la surveillance des " autorités administratives et, en cas de besoin, par leurs " soins ». Un corps d'inspecteurs fut chargé d'assurer l'exécution de ces mesures, qui, de 1905 à 1907, furent appliquées avec un succès remarquable. Malheureusement, en 1908, le service d'inspection fut supprimé ; abandonnés à leur insouciance fataliste, les fellahs laissèrent les parasites se multiplier librement; le fléau, un instant contenu, reprit sa marche dévastatrice, et c'est à lui qu'est dû, en grande partie, le déficit des récoltes de 1908 et de 1909.

La leçon porta ses fruits et, l'an passé, la lutte fut organisée de nouveau et menée avec énergie. "Des me- 
" sures spéciales, écrit sir Eldon Gorst dans son dernier " rapport, furent adoptées en 1910 par le ministre de l'In" térieur pour combattre les vers du coton et de la cap" sule, qui avaient causé tant de dégâts à la récolte de " 1909. Cinq inspecteurs anglais spéciaux furent engagés " pour surveiller la lutte contre le ver du coton. Le Gou" vernement eut la bonne fortune de s'assurer les services " d'hommes ayant une grande connaissance et une grande " expérience de l'agriculture du pays, et trois d'entre eux " ont été depuis attachés à la direction du nouveau Dé" partement de l' agriculture. Vingt-cinq sous-inspecteurs, " dont vingt européens, ont été aussi engagés, et ils for" ment, avec trois cent soixante-six moaxins et soixante" dix clercs, le Comité spécial qui assiste les autorités " locales pour découvrir la présence du ver et assainir les " districts contaminés, au moyen de l'effeuillage. Le Co" mité de la Société khédiviale d'Agriculture apporte " également une aide importante. Les préparatifs de " campagne commencèrent en avril, un mois plus tôt " qu'en 1909, et elle fut menée jusqu'en septembre avec " une activité qui dénote le crédit qu'on y attachait. "Aucun effort ne fut épargné pour faire sortir la popu"lation de son attitude de fataliste indifférence à la" quelle elle se laisse aller lorsqu'il s'agit de lutter contre " ce fléau. A côté du noyau d'inspecteurs, beaucoup de " moudirs eux-mêmes aussi bien que les mamours fai"saient des tournées périodiques dans les provinces, " infusant l'énergie aux paysans. Le ministre et le con- 
" seiller visitèrent personnellement chaque moudirieh " du Delta. Parfois l'aide de la police fut requise pour " imposer de force le nettoyage des champs infestés. Les " instructions ministérielles et diverses notices à cet égard " circulèrent dans les villages, et l'on prêcha même dans " les mosquées la nécessité d'une action énergique. L'a" pathie et la négligence furent sévèrement traitées; " 13.570 personnes furent punies pour ne pas avoir si" gnalé l'apparition du ver, plus de neuf cents omdas et " cheikhs pour avoir négligé leur devoir, et six cent cin" quante-neuf travailleurs pour s'y être soustraits. Les " paysans commencèrent par vouloir se venger de la " pression qui s'exerçait sur eux, mais, au fur et à mesure " que la campagne avançait et qu'ils étaient à même d'en " apprécier les résultats, ils devinrent peu à peu éner" giques et désireux de coopérer avec les autorités. Les " inspecteurs, qui d'abord avaient trouvé une certaine " hostilité, furent ensuite reçus partoutà bras ouverts; et " la leçon ainsi donnée facilitera énormément les cam" pagnes futures. Les premières attaques du ver furent " annoncées dans la seconde semaine de mai ; elles de" vinrent plus sérieuses au milieu de juin et atteignirent " leur pleine violence dans les première et deuxième se" maines de juillet. A la fin de ce mois, grâce aux mesures " prises, les attaques avaient beaucoup diminué et, en "plusieurs districts, le ver avait disparu vers la fin " d'août. Au premier octobre, tout le pays en était débar" rassé. 643.000 feddans furent attaqués par le ver (dont 
( 6.000 seulement en Haute-Égypte) ; plusieurs le furent "plus d'une fois, d'autres plus souvent encore. Dans la " seconde semaine de juillet, le nombre moyen de feddans " signalés chaque jour comme attaqués en Basse-Égypte " était de 24.800, et le nombre moyen de personnes em"ployées chaque jour au nettoyage était de 106.500, " sans compter ceux occupés à la visite des cotonniers " encore indemnes et qui tous demandaient la surveil" lance constante de l'administration. Le ver du coton, " s'il est très abondant, dévore non seulement les feuilles " des cotonniers, mais aussi les capsules naissantes; ce" pendant, le principal dégât qu'il cause, c'est qu'en " affaiblissant et en retardant la croissance de la plante, " il expose cette dernière aux attaques du ver de la cap" sule, un fléau encore plus dangereux, qui ne fait une " importante apparition que tard dans la saison. En 1910, "grâce à ces deux faits que le ver du coton fut arrêté " de bonne heure et que la saison fut exceptionnelle" ment favorable, le ver de la capsule ne put attaquer "que les cueillettes tardives et de moindre valeur. Un " Gomité composé d'un inspecteur, treize sous-inspec" teurs et trente-six moawins fut constitué, le 1er dé" cembre 1910 jusqu'au 15 janvier dernier, pour com" battre le ver de la capsule par la mise en vigueur du " décret relatif à l'enlèvement des bois de cotonniers, " des chanvres et des bamias, qui forment, l'hiver, l'habi" tat et le terrain de culture de ce fléau. Le coût total de " cet ensemble de mesures a dépassé L. E. 20.000. Cette 
" année, la campagne contre le ver du coton et de la capsule " sera conduite de nouveau par le Ministère de l'Intérieur.

"Cependant le nouveau Département de l'Agriculture " recherchera le moyen de préserver complètement les " cultures et entreprendra des recherches sur les insecti. " cides pour continuer les expériences de ce genre faites " avant sa création. "

En ce qui concerne l'impureté des graines du coton, une sélection attentive et rigoureuse, jointe à l'extirpation des variétés inférieures, s'impose absolument.

A ce sujet, la Commission du Coton suggéra les solutions suivantes:

Les graines, choisies avec soin, seraient distribuées non plus au hasard des demandes, mais soit directement, soit par l'intermédiaire des maisons de commerce, à des cultivateurs qualifiés par leurs connaissances, la situation de leurs terrains et leurs moyens d'action, de façon à ce que la récolte, reprise par l'administration del'Agriculture, multiplie la quantité de graines pures mises à la disposition du public.

Il conviendrait aussi d'assurer, à l'aide d'un personnel spécial et de règlements bien conçus, l'arrachage des plantes étrangères à la variété voulue sur une surface choisie du territoire égyptien suffisamment étendue pour que sa production en graines représentât une proportion notable de la quantité requise par le public.

Sur ce terrain, d'ailleurs, les initiatives gouvernementales et privées, réunissant leurs efforts, semblent être 
arrivées déjà à des solutions satisfaisantes. Voici ce qu'en dit sir Eldon Gorst dans son rapport déjà cité :

“ L'importance qu'il y a à préserver la pureté des " meilleures variétés de cotonniers et à en produire " d'autres appropriées au pays est entièrement reconnue " par le nouveau département. On a décidé d'établir " une station où des expériences seront faites pour la " production de nouvelles variétés. Les efforts du Gou" vernement doivent être principalement dirigés à l'heure " actuelle vers l'amélioration des plants existants plutôt " que vers l'introduction de plants nouveaux. L'élimina" tion de l'Hindi occupe toute son attention, et l'arrachage " de cette plante dans les champs de sélection des graines " destinées à la distribution est étroitement surveillé. " Le contrôle des distributions de graines a déjà fonctionné, " et ses opérations, réduites momentanément à la pro" vince de Sharkieh, seront plus tard étendues aux autres " provinces. "

\section{$*^{* *}$}

Mais, à côté des causes matérielles de la diminution des rendements cotonniers, il en est une autre d'ordre purement moral : l'ignorance, l'insouciance, l'imprévoyance, l'esprit de routine du fellah.

Le sol de l'Égypte met à sa disposition des moyens de richesse que nul autre cultivateur au monde ne possède peut-être.

" En ce pays, dit avec raison le très distingué ingénieur 
" agronome M. Boustani, les magnifiques énergies de la " nature semblent soumises et captées entre les mains " de l'homme; le soleil y dispense sa chaleur perpétuelle, " et les eaux maitrisées et endiguées charrient partout " la vie et la fertilité. "

Le fellah, comme nous l'avons dit plus haut, ne sait pas et ne désire même pas tirer bon parti des merveilleuses ressources dont il dispose. Il vit au jour le jour, insouciant du lendemain, content du peu qu'il demande à la terre et qui suffit à ses modestes besoins, figé dans les traditions ancestrales et dans ses vieilles habitudes. A cela il n'y a qu'un remède : l'éducation.

" Le succès des divers projets administratifs, destinés “ à améliorer le sort des populations rurales, écrit lord "Cromer", a, dans une large mesure, pour condition la " diffusion dans le pays des éléments d'éducation, de " manière à rendre les habitants accessibles à des idées " autres que celles consacrées uniquement par la tradi" tion. La fondation de Banques et de Sociétés agricoles, " la vulgarisation des procédés de culture perfectionnés, " les plans d'amélioration des conditions sanitaires de la " vie rurale, tout cela, ainsi que les projets du même " genre, ne pourra jamais donner de résultats pleinement " satisfaisants tant que la population des campagnes " ne sera pas pénétrée de l’influence féconde d'une édu" cation sommaire." 
Cette éducation sommaire devrait revêtir évidemment un caractère pratique, tel que celui de fermes-écoles, dans lesquelles les élèves partageraient leur temps entre des travaux manuels rétribués et un enseignement théorique.

La Commission du Coton propose en outre de créer plusieurs écoles d'enseignement secondaire analogues à celles de Guiseh, et d'adjoindre à cette dernière école une section spéciale d'enseignement agricole supérieur destinée à préparer pour l'Égypte un corps d'agronomes.

Ces projets sont sérieusement et activement étudiés: "Plusieurs Conseils provinciaux ont déjà décidé d'établir " des fermes-écoles dans les districts ruraux, et le Dépar" tement de l'Agriculture va s'efforcer de coopérer avec " eux à cet égard. Les écoles ont pour but de former les " fils de fellahs et de petits propriétaires travaillant eux" mêmes pour les rendre plus aptes à leur future vie des " champs. Chaque école comprendra généralement une " ou deux salles de classe, une petite ferme-atelier, de " simples bâtiments de fermes et plus de cinq feddans de " terre dont tout le travail sera fait par les élèves eux" mêmes. L'instruction en classe sera limitée à des sujets " élémentaires et pour faire comprendre intelligem" ment le pourquoi et le comment des conditions et des " travaux agricoles. Pour fournir un corps enseignant " spécialement formé, cinq étudiants de l'École d'agri" culture, qui ont d'ailleurs quitté l'établissement en " juin dernier, après avoir terminé leurs études, ont 
"été retenus comme student-instructors (étudiants" intructeurs), et leur nombre sera augmenté en juin "prochain 1."

En France et en Belgique, indépendamment de nombreuses écoles d'agriculture, il y a, dans chaque département ou province et même dans certains arrondissements, un professeur chargé d'enseigner l'agriculture à l'école normale d'instituteurs et dans les écoles primaires supérieures; il va dans les villages faire des conférences, des démonstrations, des expériences de machines, d'outils, de méthodes ; il aide à la création de syndicats, de mutualités, donne des conseils, des indications, des encouragements. Pourquoi n'instituerait-on pas, en Egypte, des fonctionnaires investis d'attributions analogues?

"A leur défaut, dit fort justement M. Arminjon, " on ne voit pas qui pourrait instruire, conseiller et di" riger le fellah dans ces campagnes où il est abandonné " à lui-même et où personne ne se trouve pour assurer le "rôle joué en Europe par les grands "faisant valoir ", " les citadins propriétaires ruraux, l'instituteur ou " le curé. Petit pays au climat partout identique, au " sol uniforme sur tous les points, à la population “ rurale parfaitement homogène, l'Égypte se prête " mieux qu'aucune autre région à une action cen" tralisée par un système de mesures générales, et il est 
" généralement facile de bien connaitre ce qui s'y passe ${ }^{1}$. " Enfin, à côté de cet enseignement, la Commission du Coton suggère la création, au Caire, d'une Station agronomique chargée de travailler à la solution des questions actuellement non résolues. Les travaux de la Station agronomique pourraient être élargis et amplifiés par les stations d'essai placées dans les fermes-écoles. Le rapport de sir Eldon Gorst nous apprend que quatorze de ces fermes expérimentales ont déjà été créées.

La Commission insiste également d'une façon toute spéciale sur l'urgence et la nécessité absolue de créer un Service de l'Agriculture, chargé d'assurer les différentes mesures proposées en ce qui concerne le sol, l'eau, la graine, la plante et ses parasites, de diriger l'enseignement agricole et les recherches scientifiques à entreprendre ou à poursuivre.

La création de ce Département de l'Agriculture est maintenant un fait accompli, et il s'est mis résolument à l'œuvre.

" M. Gérald Dudgeon P. E. S., récemment inspecteur " d'agriculture dans l'Afrique Occidentale Anglaise, fut " nommé directeur général. L'expérience de $M$. Dudgeon " en culture cotonnière dans différentes parties du monde, " et ses travaux dans l'Inde et l'Afrique Occidentale sur " le fléau des insectes et leurs effets sur les cultures le " désignaient particulièrement pour cet emploi. Le " nouveau Département, qui a reprisl'ensemble du Comité 
" scientifique et d'inspection de la Société khédiviale d'A" griculture, est rattaché au Ministère des Travaux Publics, " mais il a des relations suivies avec ceux des Finances " et de l'Intérieur, le premier lui apportant son aide dans " la distribution de lagraine de coton, le second organisant " la campagne contre le ver du coton et de la capsule. Le "Département travaille maintenant régulièrement. Des " fermes expérimentales ont été créées et des conventions " passées pour la distribution de bonnes graines aux culti" vateurs trop pauvres. Des recherches pratiques vont " être entreprises sur quelques sujets, comme le fléau des " insectes et celui des maladies cryptogamiques, et les " recommandations nécessaires seront faites au moyen " de circulaires. La détérioration de l'espèce de coton "Mit-Afifi est à l'étude, et les opérations ultérieures " comprennent des analyses de sol et d'engrais et la pu"blication dans un journal de tout ce qui intéresse "l'agriculture."

Un Comité supérieur permanent de l'Agriculture serait, en outre, institué avec mission d'exercer un contrôle sur l'enseignement agricole et les recherches scientifiques du Service d'Agriculture.

Il est évident que de pareils organismes rendront les plus grands services.

Il conviendrait aussi de créer des Associations agricoles de prévoyance, de production, de consommation, d'assistance et de crédit, dont le fellah n'a pas la moindre idée. 
Introduites en Algérie, en Tunisie, et aussi dans l'Inde, ces institutions ont donné d'excellents résultats; elles permettraient aux fellahs de se grouper pour acheter au prix de gros, vendre sans intermédiaire leur coton et leurs céréales, acquérir à bien meilleur compte les instruments aratoires, les engrais, les semences, tous les objets nécessaires à l'exploitation, se procurer du crédit dans des conditions raisonnables au lieu d'avoir recours à l'usurier. On doit souhaiter que, d'ici peu, chaque district possède au moins un syndicat agricole.

Il faudrait enfin créer des Banques mutuelles de crédit, qui, placées sous le contrôle sévère du Gouvernement, pourraient en même temps servir de Caisses d'Épargne. Le musulman actuellement thésaurise et ne place pas son argent parce que le Coran le lui interdit; il faudrait l'amener à donner à son épargne un emploi iproductif. Le crédit est actuellement distribué au fellah par l'Agricultural Bank, Société de crédit rural, contrôlée et garantie par le Gouvernement. Elle consent aux cultivateurs solvables des prêts au taux de $80 / 0$, garantis par une hypothèque. La Banque a déjà prêté 8 millions de livres. Mais cet argent dépensé sans contrôle a été mal employé, ce qui n'aurait pas eu lieu dans une coopérative de crédit.

En résumé :

La diminution progressive des rendements de la culture cotonnière doit être attribuée:

A l'excès d'humidité du sol résultant de la disproportion entre l'abondance de l'eau et l'efficacité du drainage; 
Aux ravages de certains parasites;

A l'impureté de la graine cotonnière par suite de l'hybridation de variétés de choix avec des variétés de qualité inférieure;

Enfin, à l'ignorance, à l'insouciance et à l'esprit de routine du fellah.

Or, ces causes ne sont pas essentielles, permanentes, irréductibles, mais contingentes, accidentelles, susceptibles de disparaître, et nous avons constaté qu'elles ont été déjà beaucoup atténuées.

D'autre part, les remèdes, tels que nous les avons exposés, sont les suivants :

Contre l'excès d'humidité, l'extension et le perfectionnement du système de drainage actuellement existant; contre l'abus des irrigations, l'adoption d'un système de rotations plus rationnel pour l'emploi des eaux d'arrosage.

Contre les parasites, l'application méthodique des lois, décrets, arrêtés prescrivant les mesures nécessaires pour combattre le fléau, l'examen de procédés nouveaux de destruction des insectes et l'essai de tous ceux qui auraient paru dignes d'une prise en considération ;

Contre l'impureté des graines, un ensemble de mesures en vue d'une sélection attentive des semences, de l'extirpation des variétés de cotonniers reconnues inférieures et de la mise de graines de choix à la disposition du cultivateur.

Enfin, contre l'ignorance, l'imprévoyance, l'esprit de 
routine du fellah, la diffusion des éléments d'instruction par la création, à côté de grands établissements d'enseignement secondaire et supérieur, d'écoles d'instruction sommaire, de fermes-écoles, de stations d'essais agricoles et aussi, autant que possible, d'un corps d'instituteurs qui seraient chargés d'aller dans les villages faire des conférences et des démonstrations, d'éclairer, de conseiller, de diriger, d'encourager les paysans. Il conviendrait encore de tirer le fellah de son isolement, en lui procurant les puissants secours de syndicats agricoles, d'institutions mutuelles de prévoyance, d'assistance, de production, de consommation et de crédit.

Voilà exposée en quelques lignes la tâche qui s'impose au Gouvernement; elle est grande à coup sûr, mais elle n'est pas au-dessus de son dévouement aux intérêts dont il a la garde. Par ce qu'il a déjà fait et par ce qu'il se propose de faire encore, on peut prévoir qu'il ne négligera rien pour la mener à bonne fin; mais il faut espérer qu'il trouvera dans les initiatives privées le concours qu'il est en en droit d'attendre de ceux qui sont les premiers intéressés au succès d'une œuvre dont l'accomplissement doit grandement ajouter à la prospérité générale. 


\section{CHAPITRE XVI}

\section{LA STABILITÉ POLITIQUE}

L'Angleterre abandonnera-t-elle l'Égypte? Elle ne l'abandonnera pas de son plein gré, et son expulsion, soit par une révolution intérieure, soit par l'intervention d'une ou plusieurs puissances européennes, n'est pas à craindre. - Mais, si elle évacuait l'Egypte, l'Europe ne manquerait pas d'intervenir pour le maintien de ses garanties et la sauvegarde de ses intérêts. - La dette de l'Égypte envers l'Europe est trop élevée pour que l'Europe s'en désintéresse. - En cas d'indépendance, ou l'Égypte sera à la hauteur de sa tâche, ou elle retombera sous le contrôle des puissances européennes. - Rien ne sera changé. - Opinion de lord Cromer.

Nous devons d'abord examiner une question qui, pour être d'un ordre différent de celles qui précèdent, n'en est pas moins d'un grand intérêt pour notre sujet.

$\mathrm{Si}$, pour une raison quelconque, l'Angleterre abandonnait l'Égypte, qu'adviendrait-il des garanties de sécurité résultant de son occupation?

Cette objection suppose ou que l'Angleterre aurait abandonné l'Égypte de plein gré, ou qu'elle en aurait été expulsée, soit parle fait d'une révolution intérieure, soit par l'intervention d'une ou plusieurs puissances européennes. 
On nous permettra de ne pas nous arrêter un seul instant à l'éventualité d'un abandon volontaire. Comment admettre que les Anglais se retireraient bénévolement d'un des pays les plus riches du monde, dont la possession, tout en fortifiant singulièrement leur position dans la Méditerranée, leur a donné la clef de la route des Indes, et qui, du reste, à l'heure de l'accord franco-anglais de 1904, n'a pas été sans leur coûter quelques concessions. Leur diplomatie, on le sait, n'est pas coutumière de semblables actes de désintéressement, de pareils gestes de générosité.

Quant à l'hypothèse d'une expulsion par une révolution intérieure, il faudrait, pour l'envisager sérieusement, ignorer la mentalité du peuple égyptien et sa situation vis-à-vis de l'Angleterre.

Doux, naturellement respectueux de l'autorité, travailleur acharné, préoccupé d'agrandir et d'améliorer son champ, le fellah, qui, nous l'avons dit, forme l'immense majorité de la population, est loin d'avoir l'instinct et le tempérament révolutionnaires.

Sans doute, les succès remportés par les Japonais contre les Russes, la guerre du Transvaal, et surtout la campagne nationaliste menée par l'ardent patriote et grand tribun Mustafa Kamel Pacha ont pu, un instant, agiter plus ou moins profondément la masse populaire; d'autre part, en éveillant dans les jeunes cerveaux des sentiments exagérés de grandeur et d'indépendance, une première initiation scientifique a prédisposé une certaine 
élite intellectuelle à supporter impatiemment toute espèce de tutelle étrangère ; enfin, le caractère débonnaire de l'occupation anglaise a pu être interprété tout d'abord comme un indice de faiblesse.

Mais, aujourd'hui, ces causes d'agitation ont disparu. Les succès des Japonais, aussi bien que les difficultés de l'Angleterre au Transvaal, ont cessé de hanter les esprits ; le grand tribun égyptien n'est plus; arrivée au terme de ses études, la jeune génération a perdu ses ambitieuses illusions du début; elle a compris que le pays n'est pas mûr pour l'indépendance, qu'il est loin de pouvoir se passer d'une tutelle, et, chose plus curieuse encore, la politique anglaise a cessé de paraître débonnaire. A ce sujet, le dernier rapport du précédent Résident général en Egypte, sir Eldon Gorst, est des plus significatif, et l'envoi au Caire de lord Kitchener, un des hommes les plus énergiques que l'Angleterre possède, en fournit un témoignage plus significatif encore.

On peut donc affirmer que la population égyptienne, sauf quelques tempéraments qui tiennent à rester ou à paraître irréductibles, est aujourd'hui revenue à la tranquillité et au bon ordre. Elle en témoigne, d'ailleurs, par l'évolution morale qui s'opère en elle et tend toutes ses forces vers le progrès.

Mais si, d'aventure, elle s'avisait de se soulever, comment pourrait-elle lutter contre la formidable puissance britannique? Outre que le Gouvernement anglais dispose de forces considérables, il tient entre ses mains la vie 
même des paysans, puisqu'il est le dispensateur souverain de l'eau nécessaire à la vie du pays.

L'Angleterre ne pourrait donc être dépossédée que par l'intervention armée d'une ou plusieurs puissances européennes; mais, outre que toute intervention de ce genre en pays lointain se heurte à des difficultés sur lesquelles il n'est pas besoin d'insister, il faudrait d'abord que les Anglais eussent perdu la maîtrise de la mer.

Supposons, cependant, que, par suite, soit d'un abandon bénévole, soit d'une révolution intérieure, soit d'une intervention européenne, les Anglais aient évacué l'Égypte. Est-il permis d'admettre que les puissances sacrifieraient les nombreux et importants intérêts qu'elles ont dans la vallée du Nil, qu'elles permettraient l'abolition des garanties si jalousement maintenues, si attentivement sauvegardées depuis tant de siècles ? Non, à ce point de vue, rien ne saurait changer; trop d'intérêts se trouvent engagés dans le pays pour qu'aucune modification de nature à leur porter atteinte soit possible.

Il suffit pour s'en convaincre de considérer l'importance, au point de vue européen, de la situation géographique de l'Egypte, et, d'autre part, sa situation financière visà-vis de l'Europe. De tout temps, les puissances européennes ont compris l'importance politique que la terre des Pharaons tire de sa situation géographique. Grâce à cette situation, elle est comme le carrefour du vieux monde, le point de jonction entre l'Europe, l'Asie, l'Océanie et l'Afrique Orientale; elle est aussi la grande 
voie de pénétration dans tous les pays d'Extrême-Orient. $\mathrm{Au}$ point de vue stratégique, cette situation n'est pas moins importante.

Tout cela lui assure un rôle international que M. de Freycinet a défini excellemment en ces termes :

"Au centre de l'ancien continent, ayant vue à la fois " sur l'Europe, l'Asie et l'Afrique, dominant le bassin " oriental de la Méditerranée et la mer des Indes, base " d'opérations incomparable pour envahir la Syrie, me" nacer ou protéger le Sultan, donnant la maîtrise des " voies de terre et d'eau entre l'Europe et l'Extrême"Orient, aussi bien du canal de Suez que des chemins de " fer dirigés vers le golfe Persique, l'Égypte voit son rôle " international grandir tous les jours ${ }^{1}$."

Quant à la situation financière de l'Egypte vis-à-vis de l'Europe, elle se présente actuellement de la sorte:

La question du canal de Suez mise à part, l'Égypte se trouve en face d'une dette extérieure qui, au 31 décembre 1909, atteignait la somme de 95.240.740 livres, dont 89.232.420 en circulation et 6.008 .320 en titres détenus par la Caisse de la Dette et par le Gouvernement?

D'autre part, le montant des actions des Sociétés anonymes, pouvant être considéré comme actuellement détenu en Europe s'élèverait, d'après M. Papazian, auteur de l'Annuaire de la Finance égyptienne, à L. E. 21.675 .000 et celui des obligations à L. E. 41.062.400; soit au total :

1. L.a Question d'Égypte, p. 5.

2. Annuaire statistique de l'Égypte (1910), p. 30 ?. 
L. E. 62.737 .400 (donnant un revenu de L. E. 3.348.400). Ces deux sommes, dette de l'Etat et titres des Sociétés anonymes, réunies, portent la dette du pays à L. E. 157.978.140 (4.095.350.356 fr. 45).

Comme nous venons de l'indiquer, la presque totalité de cette somme a été tirée de l'étranger. L'Égyptien n'a presque pas de capitaux liquides à placer en titres; en eût-il, il préférerait les confier à la terre, qui, tout en lui offrant une sécurité sans égale, lui assure un revenu bien plus rémunérateur.

Mais si l'Égypte s'enrichit considérablement, si elle porte allègrement la charge de sa dette extérieure, cela ne veut pas dire qu'elle soit en état de se libérer. Sa richesse tout entière est dans son sol ; elle n'a pas de capitaux disponibles, toutes ses réserves étant immobilisées. Or cette dette, elle se verra obligée de l'augmenter dans une forte proportion pour exécuter de nouveaux et importants travaux, absolument indispensables, développer et perfectionner son outillage économique, mettre en valeur les terrains encore en friche et ceux actuellement recouverts par les lagunes, qui, réunis, occupent une superficie de près de 8.000 kilomètres carrés.

Dans cette augmentation, la part du Gouvernement ne sera pas moindre de 400 à 500 millions de francs, et il est présumable que celle du public dépassera le triple de cette somme.

Comme la majeure partie de la dette actuelle, la nouvelle, ainsi qu'il vient d'être exposé, sera consacrée à déve- 
lopper la richesse du pays, mais elle rendra l'Égypte plus étroitement tributaire des puissances étrangères. Il lui faudra donc beaucoup de temps pour se libérer de sa dette par le mécanisme toujours très lent de l'amortissement, d'autant plus que, concurremment avec les fonds d'emprunt, elle devra employer son épargne à l'amélioration du sol.

Restant ainsi débitrice de l'étranger, est-il possible qu'elle modifie son régime au détriment des intérêts, européens?

Evidemment non; il est inadmissible que les grandes puissances, pour qui la prospérité et la tranquillité de l'Égypte sont une nécessité rigoureuse et dont la situation a été définie, réglée, assurée, par des conventions, des traités internationaux, des accords précis et formels puissent assister impassibles à l'abolition de leurs prérogatives.

Admettons, cependant, que, dans un avenir plus ou moins éloigné, l'Égypte vienne à recouvrer son indépendance. De deux choses l'une : ou elle sera à la hauteur de sa tâche pour sauvegarder les intérêts de l'Europe et conservera son indépendance; ou elle tombera dans le désordre, et alors l'Europe interviendra, comme elle intervint déjà, en 1876, pour la réforme financière, et, en 1879, lors de la déposition du Khédive.

Dans les deux cas, il n'y aura rien de changé au point de vue de la sécurité des placements, et la prospérité égyptienne ne sera pas arrêtée dans son essor. 
C'est ce qu'indique fort nettement lord Cromer, dans son rapport de 1906, lorsque, après avoir constaté la progression continue de cette prospérité, il ajoute :

"Quelles sont les circonstances qui pourraient arrêter " cette progression? En premier lieu, on observera que " le retrait complet et soudain du contrôle européen ou " l'adoption précipitée d'institutions trop avancées pour " être en ce moment assimilées par les Égyptiens pour" raient, l'un et l'autre, amener des conséquences désas" treuses. Il surviendrait alors probablement une rechute " dans la mauvaise administration du passé. Je ne vois " pas cependant de raison pour que l'une ou l'autre de " ces deux éventualités arrive. Il est facile de prédire " l'avenir immédiat de l'Égypte, le régime actuel ne su" bira aucun changement radical.

" Je ne saurais entreprendre de prédire l'avenir éloi" gné du pays, mais il est permis d'affirmer, en consi" dération des grands intérêts engagés, tant européens qu'in" digènes, qu'on ne le laissera jamais choir de nouveau " dans son état antérieur. " 


\title{
TROISIÈME PARTIE
}

\author{
CHAPITRE XVII
}

\section{FORTUNE IMMOBILIÈRE DE L'ÉGYPTE}

Évaluation de la propriété rurale d'après l'impôt foncier, la valeur locative et le revenu des terres. - Évaluation de la propriété urbaine au moyen de la capitalisation du revenu des loyers, accusé par l'impôt. - Valeur totale de la fortune immobilière, déduction faite de l'impôt capitalisé et des wakfs (biens de mainmorte) publics. khédiviaux et privés.

Il nous reste une étape à parcourir pour terminer notre Etude, et ce n'est ni la moins importante, ni la moins intéressante pour les capitalistes français, puisque la majeure partie des capitaux français placés en Egypte sont engagés dans des placements hypothécaires. Nous voulons parler de la dette hypothécaire de l'Egypte, de son importance et de son rapport avec la fortune immobilière qui lui sert de gage.

La fortune immobilière de l'Egypte se compose de deux 
parties bien distinctes: la fortunerurale et la fortune urbaine. Essayons de déterminer la valeur de chacune d'elles.

\section{ÉVALUATION DE LA PROPRIÉTÉ RURALE}

Trois éléments se présentent à nous pour procéder à l'évaluation de la propriété rurale:

10 L'impôt foncier;

$2^{\circ}$ La valeur locative moyenne des terres;

$3^{\circ}$ Le revenu du sol.

Nous allons les employer successivement:

\section{$1^{\circ}$ Évaluation par l'impôt foncier}

Nous rappelons que les contingents principaux de l'impôt ont été fixés il y a très longtemps. Déjà IsmaïlPacha, à l'article 8 du décret du 2 mai 1876, instituant la Caisse de la Dette, s'exprimait ainsi : "Le Gouver" nement ne pourra, sans l'avis conforme des Commis" saires qui dirigent la Caisse de la Dette Publique, pris " à la majorité, porter, dans aucun des impôts affectés " à la Dette, des modifications qui pourraient avoir pour " résultat une diminution de la rente de cet impôt. "

Cette stipulation fut observée rigoureusement jusqu'à l'établissement de la taxe spéciale à l'entrée des tabacs, taxe qui eut pour conséquence l'interdiction de la culture de cette plante en Egypte. En dédommagement du sacri- 
fice imposé aux cultivateurs, le Gouvernement prit l'engagement d'employer une partie de l'excédent de recettes devant provenir de cette taxe d'entrée à certains dégrèvements de la propriété foncière. En exécution de cet engagement, des réductions d'impôts furent faites à quatre reprises successives, de 1891 à 1898; elles atteignirent, dans leur ensemble, la somme de L. E. 564.100.

D'autre part, les opérations de la péréquation de l'impôt, dont il a été déjà fait mention, n'ont apporté aucune modification à' l'ensemble ni, par suite, à la répartition générale. Le rôle de la Commission instituée à cet effet devait se borner : $1^{0}$ à supprimer la distinction entre les térres, établie jusque-là par le fisc, et qui en faisait deux classes séparées : les terres Ouchoury et les terres Kharadji inégalement taxées; $2^{\circ}$ à faire une répartition équitable de la cote de chaque contribuable en prenant pour base la valeur locative de la terre. Ces conditions posées, il s'agissait tout d'abord, pour la Commission, d'établir le rapport qui devait exister entre le montant total de l'impôt et celui du revenu du sol. Le premier étant connu, et ayant été fixé, pour 1894, à L. E. 4.611 .216 (sauf diminution de L. E. 102.800 consentie par le Gouvernement en faveur des contribuables), il ne restait plus qu'à déterminer l'autre. Les enquêtes auxquelles il fut procédé à cet effet permirent de fixer le revenu du sol, pour la même année, à L. E. 16.147.824.

Connaissant ces données, il était facile à la Commission d'en calculer le rapport. Ce rapport s'établit ainsi 
à 28,55 0/0, taux qui fut adopté comme assiette de l'impôt foncier. Sur cette base, et en ne perdant pas de vue que le contingent des villages ne devait pas subir de modification, la Commission divisa les terres en vingt-deux catégories et attribua, suivant les résultats du calcul, à la première catégorie une valeur locative de P. T. 575 (149 fr. 06) par feddan et, à la dernière, une valeur locative de P. T. 50 (12 fr. 96).

Nous donnons ces détails pour montrer que, si, dans l'évaluation de la propriété rurale, on prend pour base de calcul les chiffres absolus de l'impôt dans l'année en cours, on commet une grave erreur, ces chiffres ayant cessé depuis longtemps de correspondre à la valeur locatïve des terres. En effet, depuis 1895, de nombreux changements se sont produits dans le mode d'exploitation du sol.

En premier lieu, la conversion à l'irrigation pérenne de toutes les terres de la Moyenne-Egypte, depuis le barrage d'Assiout jusqu'au Caire, a eu pour effet d'accroître à la fois la proportion des terres cultivées en coton, passée, de 1895 à 1909, de 15, 51 0/0 à 20,83 0/0, et celle des terres cultivées plus d'une fois qui, en 1895, couvraient 1.557.352 feddans, pour un total de 5.640.226 feddans, soit les 27,60 0/0, tandis que, pour 1909, elles étaient de 2.296.562 feddans pour un ensemble de 6.475.694 feddans, ce qui en a fait remonter le rapport à $35,460 / 0$.

En second lieu, la sole du coton, qui était généralement de trois ans pour toute l'Égypte, a été presque partout 
abaissée à deux ans, ce qui a sensiblement influé sur l'augmentation de la proportion des terres cultivées en coton.

En troisième lieu, l'amélioration de l'exploitation caractérisée surtout par l'emploi des engrais chimiques, inconnus dans le pays avant 1900, alors qu'aujourd'hui, en dehors de ceux qui sont fabriqués sur place, il en est importé pour près de L. E. 300.000 par an, a eu pour effet d'augmenter sensiblement les rendements des produits du sol, exception faite du coton.

Enfin la hausse considérable, qui, depuis quelques années, s'est fait sentir sur le prix du coton, a non seulement contrebalancé l'effet de la diminution du rendement de la plante, mais déterminé une augmentation sensible du revenu de la terre. Pour la valeur de la récolte totale du coton, on voit que de L. E. 11.193.058 en 1896-1897, elle est arrivée à L. E. 33.915 .339 en 19101911 et que le rendement à l'hectare qui, en 1896-1897, était de 656 fr. 78 est passé, en 1910-1911, à 1.303 fr. 57, soit près du double. (Voir tableau XIII, p. 125.)

Ajoutons, en ce qui concerne la valeur de la propriété, et malgré les titres qu'elle avait acquis à la hausse antérieurement à l'accord franco-anglais de 1904, que ce fut seulement à partir de ce moment que cette hausse se produisit.

Pour nous résumer, nous pouvons dire, avec tous ceux qui connaissent tant soit peu le sol égyptien, que les 28,55 0/0 de l'assiette de l'impôt n'ont plus qu'un rap- 
port lointain avec le revenu du sol. Le tableau que nous consacrons plus loin à cette question montre, en effet, qu'aujourd'hui celui-ci dépasse de plus du double le chiffre quí a servi de base à l'établissement de l'assiette de l'impôt. Si donc nous voulons prendre le chiffre de l'impôt pour base d'évaluation de la propriété rurale, nous devons lui appliquer une majoration qui corresponde autant que possible à l'augmentation de son revenu ou, ce qui revient au même, à la plus-salue générale dont a fort justement bénéficié la terre depuis 1895. En aucune façon cette majoration ne saurait être inférieure à $750 / 0$ et, en l'adoptant, on peut se flatter de rester dans des limites modestes. Si nous prenons le dernier chiffre connu de l'impôt, celui de l'année 1909 1, qui s'est élevé à L. E. 5.059.231, et si nous lui appliquons la majoration de $750 / 0$ qui s'établit à L. E. 3.794.423, nous obtenons L. E. 8.853.654 représentant plus justement les $28,550 / 0$ de la valeur locative des terres.

Pour avoir cette valeur locative, nous procéderons de la sorte :

$$
\frac{100 \times 8.853 .654}{28,55}=31.011 .047
$$

Capitalisée à $60 / 0$, cette somme représente :

$$
\frac{31.011 .047 \times 100}{6}=516.850 .783
$$

1. Annuaire statistique de l'Égypte (1910), p. 270. 
Il en ressort que la valeur de la propriété rurale s'établissait, en 1909, à L. E. 516.850.783, soit : 13.398.594.504 francs.

Cette somme doit encore s'augmenter de la valeur des dattiers, complètement indépendante de la valeur des terres qui les portent.

Les dattiers sont soumis au paiement de la dîme fixée, une fois pour toutes, à P. T. 21/2 par arbre, ce qui leur donne un revenu moyen de P. T. 25 et une valeur moyenne de L. E. 4,167 en capitalisant à 6 0/0. Le coefficient par lequel il faut multiplier l'impôt pour en établir la valeur totale est 166,67 ou le produit de 10 (dîme) par 16,67 (denier) au taux de 6 0/0. D'après cela, l'impôt s'étant établi, pour 1909, à L. E. 139.543, la valeur corres pondante des arbres s'établit à L. E. 23.257.632¹

Cette somme, ajoutée au total trouvé plus haut de L. E. 516.850.783, donne pour total définitif L. E. 540.108 .415 .

\section{$2^{\circ}$ Évaluation de la propriétẻ rurale par la valeur locative}

Comme on le conçoit aisément, la valeur locative des terres est très variable; elle varie de L. E. 20 autour des grands centres, eu égard au grand débouché des fourragères, qui rapportent autant sinon plus que le coton, jusqu’à L. E. 2 dans les régions éloignées où la culture

1. D'après l'Annuaire statistique de l'Égypte (1910), le nombre des dattiers recensés en 1907 s'est élevé à 5.966 .010 , ce qui, pour la va eur totale cidessus de L. E. 23.257.632 déduite de l'impôt, fait ressortir la valeur de l'arbre à L. E. 3,898 . 
est encore à l'état rudimentaire. Dans cette diversité de prix, il faut tenir compte également du régime d'eau auquel les terres sont soumises; celles dépendant du régime des bassins ou de l'inondation ne donnent qu'une récolte par an, très abondante il est vrai, alors que les terres sillonnées par les canaux d'irrigation en donnent deux et même davantage, en même temps qu'elles sont les seules à produire le coton et la canne à sucre, cultures les plus rémunératrices. Cela posé, quelle serait la valeur locative moyenne de l'une et de l'autre de ces deux classes de terre? Si nous nous en rapportons aux taux actuels des locations, qui oscillent entre 8 et 10 livres pour les terres irriguées et entre 4 et 6 pour les terres à bassins, on ne peut attribuer moins de 7 livres aux terres irriguées et de $31 / 2$ aux terres à bassins, sauf déduction de l'impôt. Mais, en matière d'évaluation, il vaut mieux se montrer modeste et ne pas hésiter à pécher par défaut plutôt que par excès. Aussi croyons-nous devoir réduire les c̀iffres ci-dessus à L. E. $61 / 2$ et à 3 respectivement. Voici dès lors comment s'établissent les calculs :

Terres à bassins : 943609 feddans

à L. E. $3=$ L. E. 2.830 .827 .

Capitalisées à $60 / 0 \ldots \ldots \ldots \ldots$ L.E. $\quad 47.180 .450$

Faisant ressortir la valeur de l'unité

à L. E. $50^{1}$.

1. La valeur de l'unité pour chacune des catégories des terres à bassins et des terres irriguées doit subir une réduction représentant la capitalisation de l'impôt foncier au taux de $90 / 0$. Nous avons fait cette réduction à la fin du présent chapitre dans l'évaluation totale de la propriété immobilière. 
Report: 47.180 .450

Terres irriguées : 4.676 .391 feddans

à L. E. $61 / 2=$ L. E. 30.396 .542 .

Capitalisées à $60 / 0 \ldots \ldots \ldots \ldots$ L. E. 506.609 .033 Faisant ressortir la valeur de l'unité

à L. E. 108,333 .

$$
\text { Tотаl........ L. E. } \overline{\underline{553.789 .483}}
$$

Ce total, divisé par la superficie totale imposée en 1909, ramène la valeur moyenne du feddan à L. E. 98,539 .

\section{$3^{\circ}$ Évaluation de la propriété rurale par le revenu des terres}

C'est là la partie la plus délicate de notre travail. En effet, les seules statistiques que nous possédions sur la matière sont relatives à la superficie des cultures; il n'en existe pas sur la production. Nous avons essayé d'y suppléer par un travail personnel de recherches et d'enquêtes; la difficulté de la tâche et l'impossibilité d'obtenir une concordance acceptable dans les chiffres recueillis nous ont obligé à y renoncer. Nous eûmes alors l'heureuse inspiration de nous adresser à la nouvelle Direction de l'Agriculture, qui, avec un empressement dont nous ne saurions assez la remercier, nous a répondu par la lettre suivante : 


\section{Ministry of public Works \\ Department of Agriculture}

" Monsieur,

“En réponse à votre lettre du 24 courant, j'ai l'honneur de vous informer que mon Département s'efforce d'obtenir des états des rendements approximatifs des cultures pour cette année, mais ils ne sont pas encore complets. En attendant, j'ai le plaisir de vous communiquer les moyennes approximatives des rendements pour les cultures énumérées dans votre lettre, savoir :

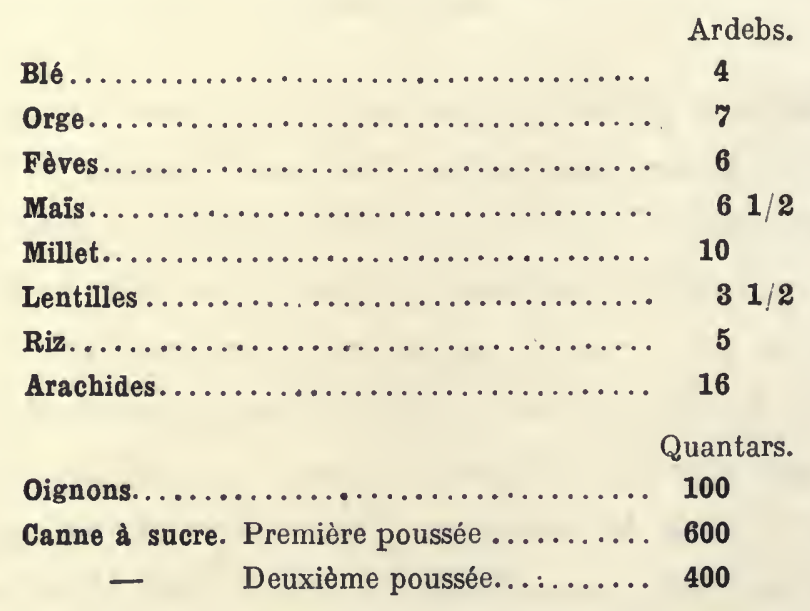

"Veuillez agréer, Monsieur, l'assurance de ma considération distinguée. »

Signé : Le Directeur général. 
Aux indications ci-dessus, nous avons nous-même ajouté les suivantes, qui nous ont semblé correspondre le plus possible à la réalité.

Bersim (espèce de trèfle), revenu net du feddan : L. E. 5 ;

Cultures diverses comprenant lentilles, pois chiches, sésames, arachides, indigo, etc., revenu du feddan : L. E. $3 / 12$;

Vergers et potagers, revenu du feddan : L. E. 15.

La récolte entière du coton étant exportée, il s'ensuit qu'on en connaitt le chiffre avec la plus grande exactitude. Pour cette culture, nous avons pris comme chiffre moyen du rendement 4,20 kantars, rendement moyen des cinq dernières années.

Quant aux frais correspondant aux différentes cultures, on peut en fixer les moyennes, en tenant compte de ce que les céréales, - sauf l'orge, cultivée en général dans les terres non encore améliorẽes de la Basse-Égypte; — étant produites en égales quantités dans les régions irriguées et dans celles des bassins où le sol ne reçoit aucune préparation, il en résulte que les frais moyens se trouvent considérablement réduits. D'ailleurs, pour ces cultures comme pour les autres, les frais moyens diffèrent sensiblement de ceux que nous avons donnés, au début de ce travail, pour une exploitation normale, en ce sens que ces derniers comprennent le prix des engrais; chacun sait cependant que l'emploi des engrais, déjà entré dans la pratique agricole, est loin de s'être généralisé. Il faut. 
enfin observer que, dans le tableau de l'exploitation ( $I$, pages 28 et 29), nous avons fait entrer le prix de revient de l'eau d'irrigation en la supposant élevée par machine, alors que, dans un grand nombre de terres, l'eau coule par gravitation, d'où économie assez sensible dansles frais.

Ces réserves faites, voici les frais moyens des diverses cultures parfeddan:

Piastres tarif.

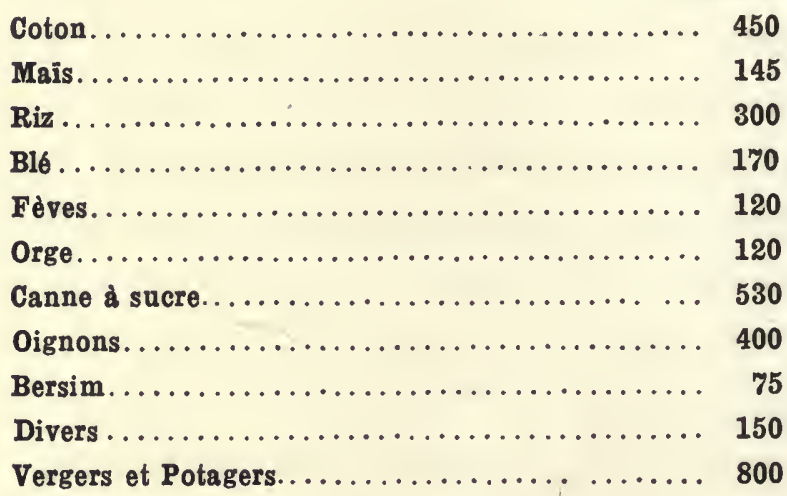

Les trois tableaux $X I V, X V$ et $X V I$ et la planche $X I$ qui suivent font connaitre les résultats unitaires et généraux des cultures, d'après les bases indiquées ci-desșus.

Les prix des produits étant sujets à variations au cours de l'année, nous avons adopté ceux des exportations ramenés à des moyennes annuelles d'après les valeurs enregistrées. Pour les pailles, nous avons établi nos moyennes sur les prix des six dernières années.

On voit, au bas de la dernière colonne du tableau $X V I$, que la valeur nette de l'ensemble des récoltes s'est élevée, d'après nos calculs, à L. E. 44.729.501, soit, 
comme nous l'avons déjà dit, à près de trois fois celle de 1894, qui a servide base à l'établissement du taux de l'impôt.

Il nous reste à déterminer la valeur de la propriété d'après le montant ainsi établi de ses revenus.

Revenu des terres net..... L. E. $\quad 44.729 .501$

Capitalisé à $70 / 0 \ldots \ldots \ldots$ L. E. 638.992 .871

Ce chiffre est sensiblement supérieur à celui que nous a donné la valeur locative des terres (L. E. 553.789.483). L'écart de 15,38 0/0 se conçoit sans peine, puisqu'il doit représenter la part de l'exploitant dans les revenus du sol.

Procédons maintenant à la récapitulation des résultats que nous ont donnés nos trois modes d'évaluation, afin d'en déduire une moyenne définitive pouvant être considérée comme représentant la valeur la plus approchée de la propriété rurale.

\section{Récapitulation.}

10 Résultat de l'évaluation par

l'impôt ......... L. E. $\quad 540.108 .415$

2o Par la valeur locative...... 5 553.789.483

3o Par le revenu du sol ....... $\quad 638.992 .871$

$$
\text { Total.... L. E. } \underline{\underline{1.732 .890 .769}}
$$

Ce qui nous donne une moyenne

$$
\text { de............ L. E. } \quad 577.630 .256
$$


De ce total nous pouvons tirer par une simple règle de trois la valeur moyenne du feddan pour chacune des deux classes de terres : terres irriguées et terres à bassins. Nous obtiendrons les résultats suivants :

10 Valeur des terres irriguées...... L. L. E. 528.418 .722 faisant ressortir le feddan à :

$$
\frac{528.418 .722}{4.676 .391}=\text { L. E. } 112,997
$$

$2^{\circ}$ Valeur des terres à bassins ..... . L. E. $\quad 49.211 .534$ faisant ressortir le feddan à :

$$
\frac{49.211 .534}{943.609}=\text { L. E. } 52,152 \text {; }
$$

$3^{\circ}$ Valeur moyenne du feddan pour les deux catégories réunies :

$$
\frac{577.630 .256}{5.620 .000}=\text { L. E. } 102,781 .
$$

Au total général de L.E. 577.630.256 il nous faut ajouter la valeur des terres incultes estimées L. E. 10 le feddan. La superficie de ces terres étant de 1.102.000 feddans, leur valeur est donc de L. E. 11.020.000, qui, ajoutées aux L. E. 577.630.256, forment un total de L. E. 588.650 .256 . 


\section{ÉVALUATION DE LA PROPRIÉTÉ URBAINE}

D'après un travail récent, la valeur de la propriété urbaine s'élèverait à 6.054 millions de francs; ce chiffre nous paraît fort exagéré.

D'après nos calculs, elle ne serait que de L. E. 77.813.750 (2.017.206.740 francs).

Soucieux de nous en tenir aux évaluations les plus modestes et considérant, d'autre part, que, depuis la crise, le prix des immeubles urbains a beaucoup diminué, nous croyons que la valeur la plus rationnelle serait celle dont la base se rapprocherait le plus du chiffre de l'impôt. Or nous savons, d'après l'Annuaire statistique de l'Égypte (1910), que l'impôt payé par la propriété bâtie a été, en 1909, de L. E. $249.004^{1}$.

Aux termes d'une disposition du décret du 13 mars 1884, réglementant l'impôt sur la propriété bâtie, cet impôt est égal au douzième de la valeur locative ${ }^{2}$. Nous aurons donc :

$$
\text { L. E. } 249.004 \times 12=2.988 .048 \text {. }
$$

En capitalisant ce revenu à $60 / 0$, on trouve :

$$
\frac{100 \times 2.988 .048}{6}=49.800 .800
$$

représentant la valeur des immeubles bâtis.

1. Page 270.

2. L'impôt sur la propriété bâtie a été tout récemment augmenté de $3 \%$ dans la ville du Caire, afin de pourvoir aux charges devant résulter del'établissement d'un réseau d'égouts en cours d'exécution. 
Il y a lieu cependant de tenir compte de ce que les déclarations des propriétaires, en général, sont inférieures au revenu des loyers, et que, dans leur ensemble et en raisonnant par analogie avec les faits parvenus à notre connaissance, elles doivent tout au plus représenter les $750 / 0$ de ces revenus. Il suit de là que, pour avoir la valeur réelle de la propriété bâtie, il faut majorer la somme ci-dessus d'au moins $250 / 0$; ce qui donne: L. E. 62.251.000 (soit 1.613.765.392 francs).

Ce chiffre ne représente pas encore la valeur exacte de la propriété urbaine, puisque celle-ci se compose aussi bien des immeubles bâtis que des terrains vagues auxquels s'ajoutentd'autrescatégories d'immeubles urbains exempts d'impôts comme ces terrains, savoir :

$1^{\circ}$ Les cabanes non productives de revenu;

$2^{\circ}$ Les maisons dont la valeur locative est inférieure à P.T. 500 (130 francs);

$3^{0}$ Tous les immeubles qui sont situés en dehors des villes et localités désignées par le décret comme devant payer l'impôt ;

$4^{0}$ Les nombreux enclos de terrains non bâtis qu'on trouve dans tous les quartiers et qui, pour ne pas payer l'impôt, n'en représentent pas moins une valeur considérable;

$5^{\circ}$ Les palais et les maisons habités par leurs propriétaires, lesquels ne paient qu'une taxe dérisoire.

En raison de ces importants facteurs, nous estimons 
qu'il convient de majorer de $250 / 0$ au moins la valeur déjà établie de la propriété urbaine.

Nous obtiendrons ainsi un total de L. E. 77.813.750, soit 2.017.206.740 francs, que l'on peut considérer comme la valeur minima de la propriété urbaine.

En résumé, la valeur globale de la propriété immobilière d'Égypte s'élève actuellement:
Pour la propriété urbaine à.. L. E. $\quad 77.813 .750$
Pour la propriété rurale à.. L. E. 588.650 .256
Total.......... L. E. 666.464 .006 


\section{BIENS WAKFS (Biens de mainmorte)}

Les Wakfs se partagent en trois classes : les Wakfs publics, les Wakfs khédiviaux et les Wakfs privés.

Les Wakfs publics sont des donations faites au profit de mosquées, d'écoles et d'œuvres pies. La plupart ont un passé ancien remontant aux souverains arabes ou turcs, surtout turcs, qui, après s'être chargé la conscience de beaucoup d'injustices à l'égard de leurs sujets, pensaient racheter leurs fautes en instituant une partie de leurs biens en Wakfs. Ces biens ont été, depuis une quarantaine d'années, placés sous la tutelle d'une administration spéciale dont le chef légal est le Khédive, lequel délègue son autorité à un directeur général. Chaque année, cette administration publie un budget qu'elle accompagne d'un long rapport de gestion. Pourl'année qui vient de s'écouler, les comptes publiés ont accusé un ensemble de revenus s'élevant à la somme de L. E. 502.904.

La seconde classe de Wakfs, les Wakfs khédiviaux, forme une administration à part, ayant un directeur général se rattachant plus directement à la personne du Khédive. Elle comprend les donations faites par les membres de la famille khédiviale ou par d'anciens serviteurs de cette famille, et les revenus en sont attribués soit à des œuvres pies (érections de mosquées ou autres monuments de caractère religieux ou humanitaire), soit à certains membres de la famille khédiviale, soit enfin à d'anciens serviteurs de cette famille. L'ensemble des Wakfs 
khédiviaux se compose de domaines ruraux ayant une superficie de 65.000 feddans et d'un certain nombre d'édifices urbains. Le revenu moyen annuel de cette administration s'élève à L. E. : 250.000 .

Pour les Wakfs privés, l'origine en est presque récente. La propriété du sol avait été, dès la plus haute antiquité, réservée à l'Etat, et, sous les différents régimes par lesquels avait passéle pays, les possesseurs nel'avaient occupé qu'à titre de tenanciers ou d'usufruitiers à vie. Ce n'est qu'à partir de 1854 qu'un décret de Saïd Pacha accorda la propriété pleine et entièredu sol à ses possesseurs. C'est donc à partir decette date que desWakfs privés purentse constituer.

Il y en eut fort peu dans les premières années et, si leur nombre a acquis une certaine importance, c'est surtout depuis quelque temps. Quoi qu'il en soit et quoiqu'on n'ait aucune donnée sur la valeur de ces biens, il n'y a pas à supposer qu'elle atteigne même celle des Wakfs khédiviaux. En l'estimant aux deux cinquièmes des Wakfs publics, on commettrait peut-être une exagération. Les Wakfs publics, ayant donné un revenu de L. E. 503.000, en 1910 , les $2 / 5$ de cette somme, L. E. 200.000 environ, représenteraientl'ensemble des revenus des Wakfs privés.

Faisons la récapitulation des revenus de chacune des trois classes de Wakfs :

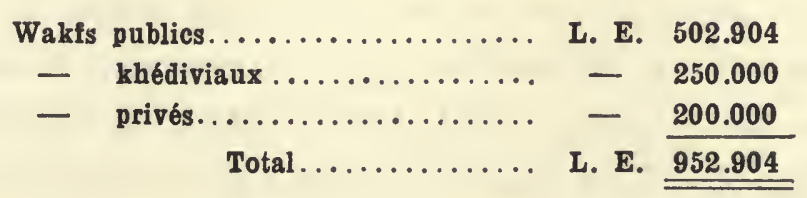


En ce qui concerne les revenus des biens Wakfs, une remarque s'impose, c'est que Ieur gestion ne ressemble en rien à celle des biens d'un particulier naturellement plus vigilant et plus soigneux qu'une administration. Si done, conformément à l'usage en matière de transactions immobilières, nous avons adopté le $60 / 0$ pour la capitalisation des revenus de la propriété privée, nous devons, en ce qui concerne les biens Wakfs, réduire ce taux à $30 / 0$.

Le denier de $30 / 0$ étant de 33,33, le produit de ce coefficient par L. E. 952.904 nous donne L. E. 31.763 .490 comme valeur des biens des trois classes de Wakfs, tant ruraux qu'urbains. Il ne nous reste plus qu'à défalquer cette somme de la valeur globale de la propriété immobilière rurale et urbaine, soit 666.464.006, ce qui laisse pour la valeur de la propriété libre L. E. 634.700 .516 (16.453.675.074 francs).

Ici une autre considération s'impose. Qu'est-ce que l'impôt foncier au point de vue économique? Ce n'est ni plus ni moins, comme on le sait, qu'une expropriation au profit de l'Etat d'une part indivise du sol, dont la valeur correspond au montant de l'impôt capitalisé. En effet lors qu'on achète une terre, on ne manque jamais d'en déterminer la valeur par le revenu, de faire la part de l'Etat, en déduisant de ce denier le montant de l'impôt auquel elle est assujettie et en capitalisant le solde au denier courant. Cette défalcation, qui accompagne toute mutation de propriété, n'est que la simple reconnaissance du droit de l'État dans la propriété du sol pour une part 
correspondant à la valeur, en capital, de l'impôt qui le frappe. Or, le domaine de l'Etat étant inaliénable, il s'ensuit qu'on ne peut le comprendre dans la partie libre susceptible d'hypothèques. Mais à quel taux capitaliser l'impôt pour cette défalcation? On doit le calculer au taux en usage à l'époque de son établissement et, comme cette époque, déjà lointaine, se signalait par la grande cherté de l'argent, le taux le moins élevé qui y eut cours fut celui de 90/0. L'impôt, s'étant élevé, en 1909 , à 5.447.778, représente au taux de $90 / 0$ un capital de L. E. 60.530.866. Déduisant cette somme de la valeur de la propriété libre, nous obtenons comme résultat final L. E. 574.169.650 (14.884.501.620 francs). 



\section{TABLEAU XIV}

\section{Production agricole d'après les superficies des cultures}

\section{Revenus unitaires des cultures}

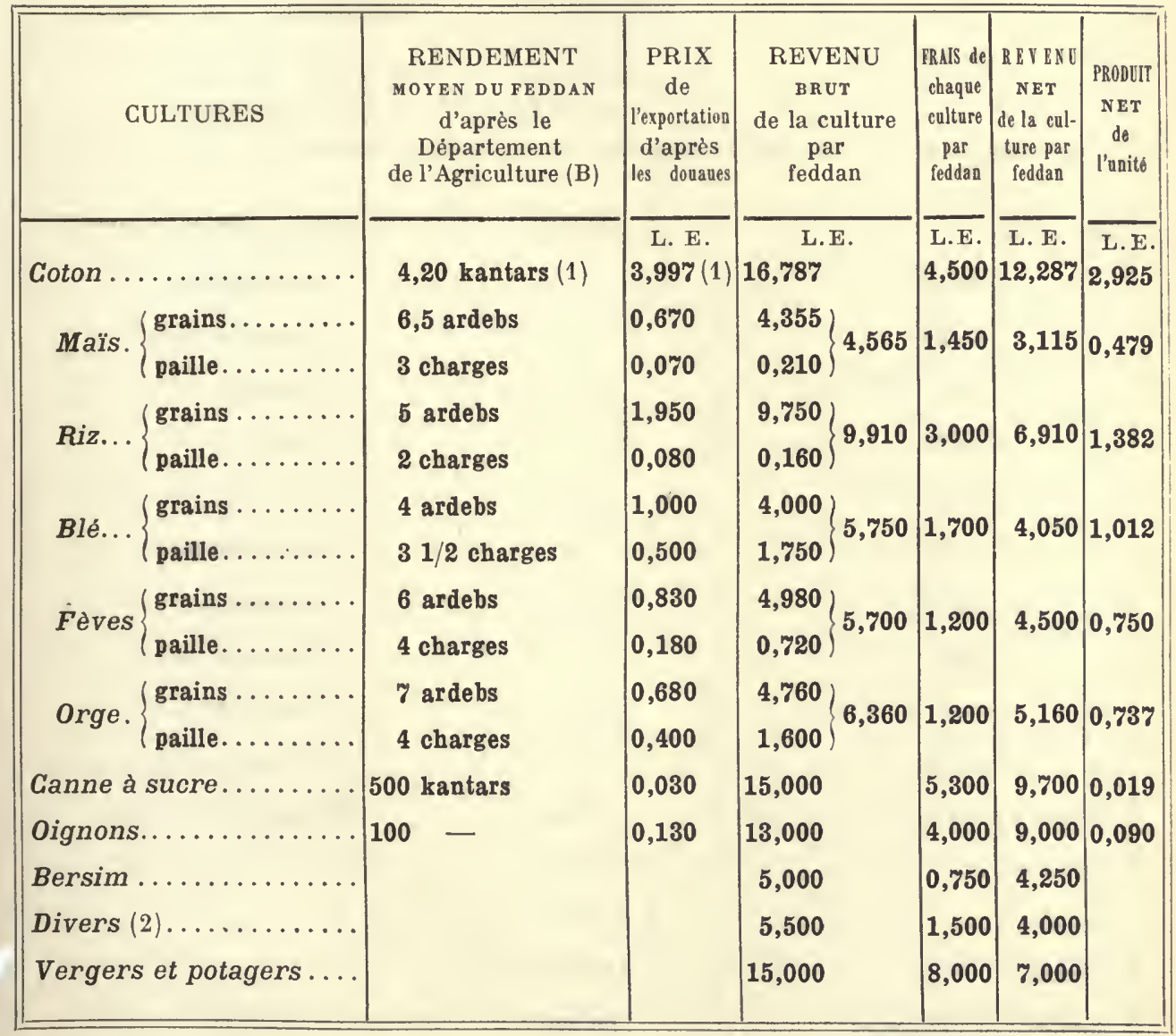

(B) Ces chiffres diffèrent de ceux du tableau $I$, car ils s'appliquent à toutes les terres, irriguées ou non, alors que les rendements du tableau $I$ sont exclusivement ceux des bonnes terres soumises au régime de l'irrigation pérenne.

1. Moyenne des cinq dernières années.

2. Lentilles, pois chiches, sésame, arachides, millet, indigo, lupin, fenugrec, chanvre, lin, henneh, me'ons et pastèques. 
TABLEAU

\section{Production agricole d'après}

Résultats généraux

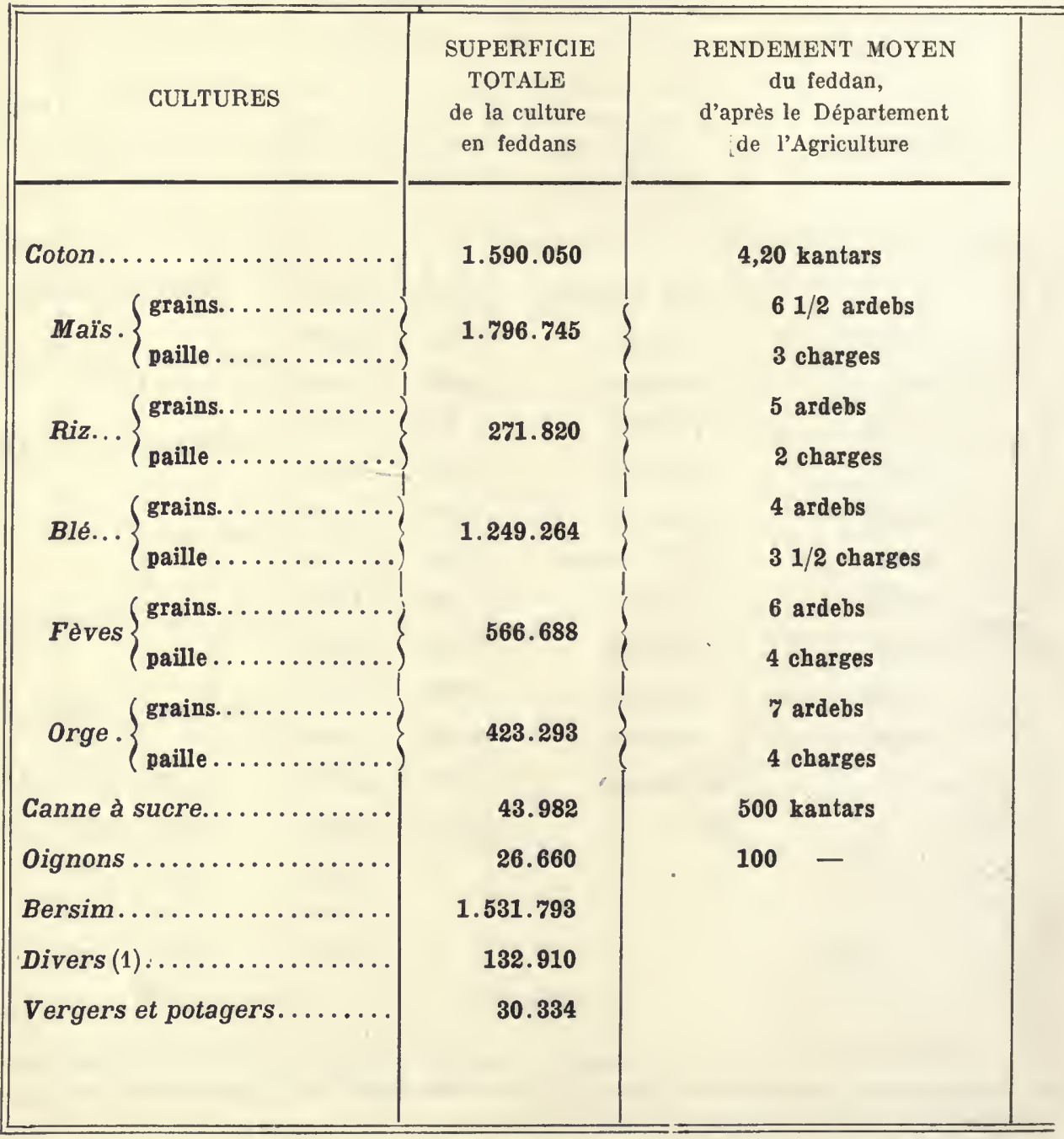

1. Lentilles, pois chiches, sésame, arachides, lupin, millet, indigo, fenugrec, chanvre, lin, henneh, melons et pastèques. 


\section{TABLEAU XVI}

\section{Résultats nets des cultures, tous frais déduits, sauf déduction de l'impôt (A)}

\begin{tabular}{|c|c|c|c|c|c|}
\hline CULTURES & $\begin{array}{c}\text { SUPERFIGIE } \\
\text { TOTALE } \\
\text { de la culture } \\
\text { en } \\
\text { feddans }\end{array}$ & $\begin{array}{c}\text { RENDEMENT } \\
\text { MoxEN parfeddan } \\
\text { d'après le } \\
\text { Département } \\
\text { de l'Agriculture }\end{array}$ & $\begin{array}{l}\text { RÉCOLTE } \\
\text { TOTALE }\end{array}$ & $\begin{array}{c}\text { Propult } \\
\text { NET } \\
\text { de } \\
\text { l'unité }\end{array}$ & $\begin{array}{l}\text { VALEUR } \\
\text { NETtE } \\
\text { dela } \\
\text { Récolte }\end{array}$ \\
\hline Coton........... & $1.590 .050(1)$ & 4,20 kantars $(1)$ & $6.685 .234 \mathrm{k} .(1)$ & $\begin{array}{l}\text { L. E. } \\
2,925\end{array}$ & $\begin{array}{c}\text { L. E. } \\
\text { 19.554.309 }\end{array}$ \\
\hline Maïs, grains et paille. & 1.796 .745 & $61 / 2$ ardebs & 11.678.843 ar. & 0,479 & 5.594 .165 \\
\hline $\boldsymbol{R i z} \ldots \ldots \ldots \ldots \ldots$ & 271.820 & $5 \quad-$ & $1.359 .100-$ & 1,382 & 1.878 .276 \\
\hline Blé............... & 1.249 .264 & $4 \quad-$ & $4.997 .056-$ & 1,012 & $5.05 \% .020$ \\
\hline Fèves............. & 566.688 & - & $3.400 .128-$ & 0,750 & 2.550 .096 \\
\hline 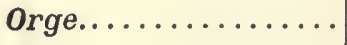 & 423.293 & $y \quad-$ & $2.963 .051-$ & 0,737 & 2.183 .768 \\
\hline Canne à sucre....... & 43.982 & 500 kantars & $21.991 .000 \mathrm{k}$. & 0,019 & 417.829 \\
\hline Oignons ........... & 26.660 & $100-$ & $2.666 .000-$ & 0,090 & 239.940 \\
\hline Bersim............ & 1.531 .793 & & & & 6.510 .120 \\
\hline Divers............. & 132.910 & & & & 531.640 \\
\hline \multirow[t]{4}{*}{ Vergers et potagers. } & 30.334 & & & & 212.338 \\
\hline & & 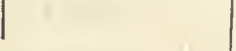 & Total ..... & ... & 44.729 .501 \\
\hline & & & $\begin{array}{l}\text { Valeur brute. } \\
\text { Valeur nette. }\end{array}$ & $\begin{array}{l}\text { L. E. } \\
-\end{array}$ & $\begin{array}{l}60.573 .577 \\
44.729 .501\end{array}$ \\
\hline & & & Différence... & L. E. & 15.844 .076 \\
\hline
\end{tabular}

(A) Chiffres de lasaison 1908-1909, sauf pour le coton, dont les chiffres représentent la moyenne des cinq dernières années.

(1) Moyenne des cinq dern:ères années. 


\section{Planche XI}

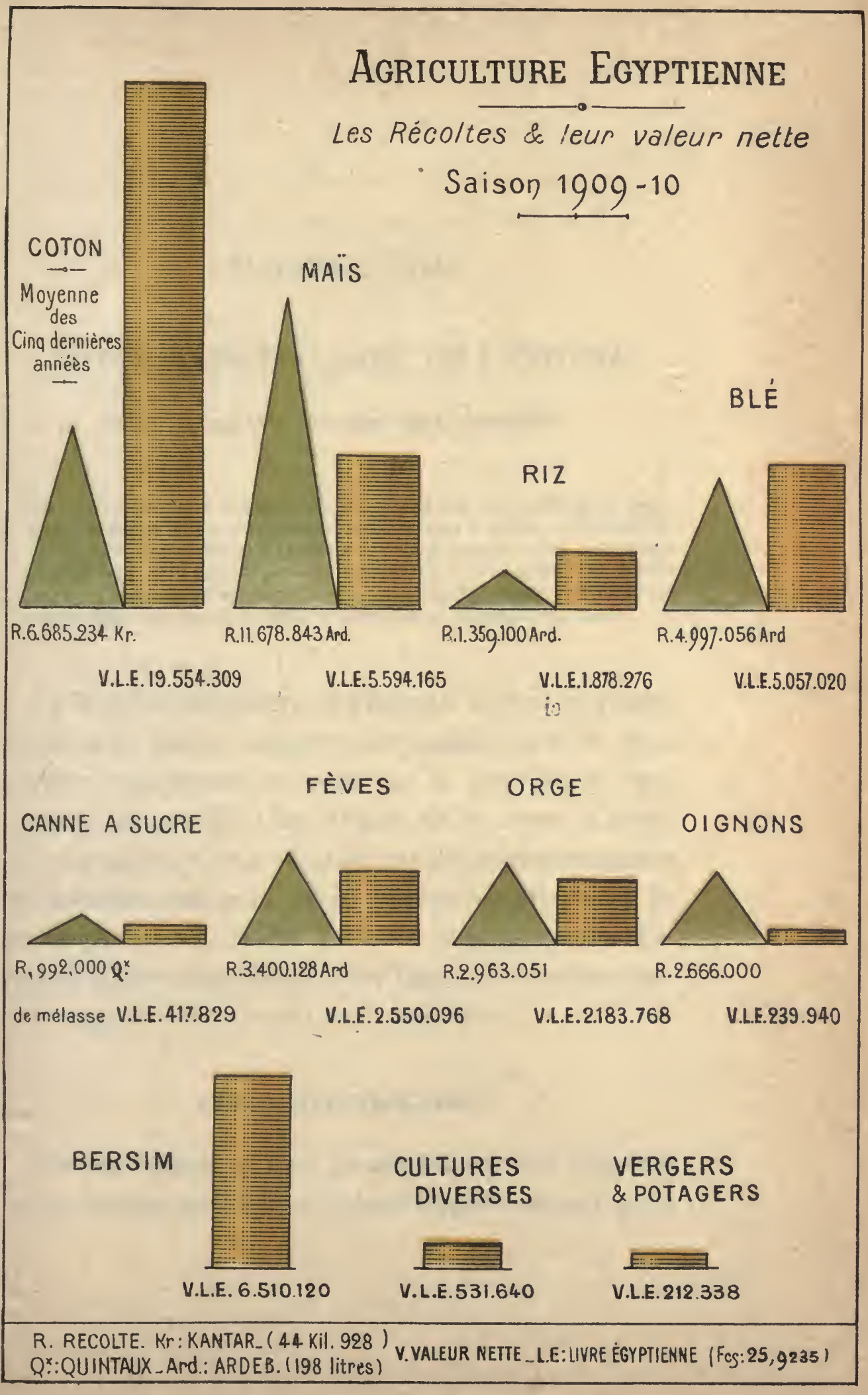


In $4 x^{-711} \mid=$

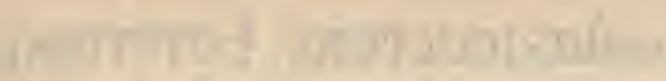

$$
7=+3 x+4
$$

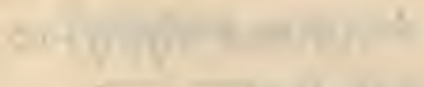

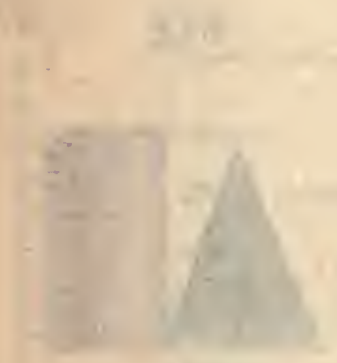

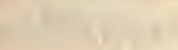

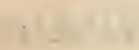

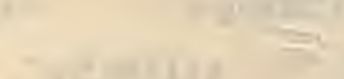

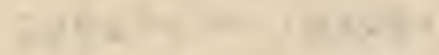

$t^{2}=0=0$

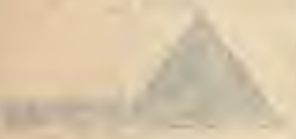

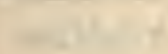

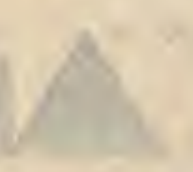

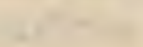

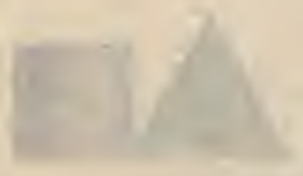

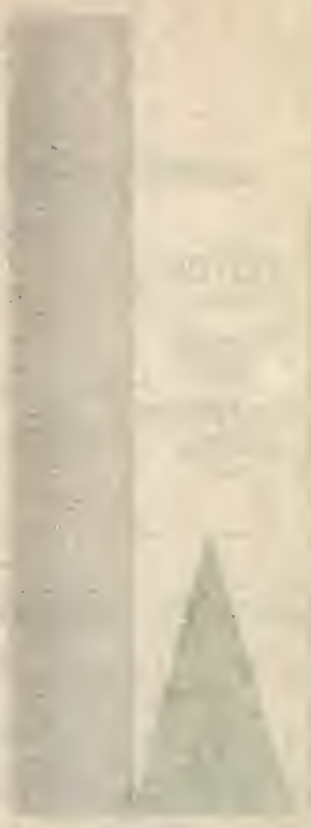

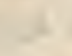

$=$
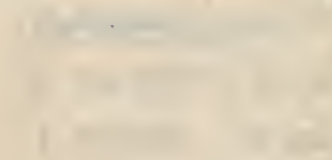

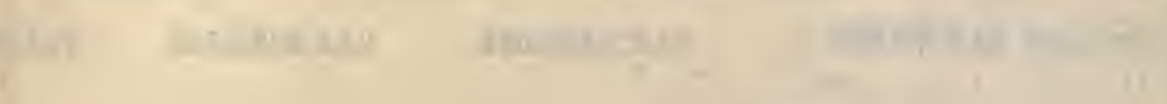
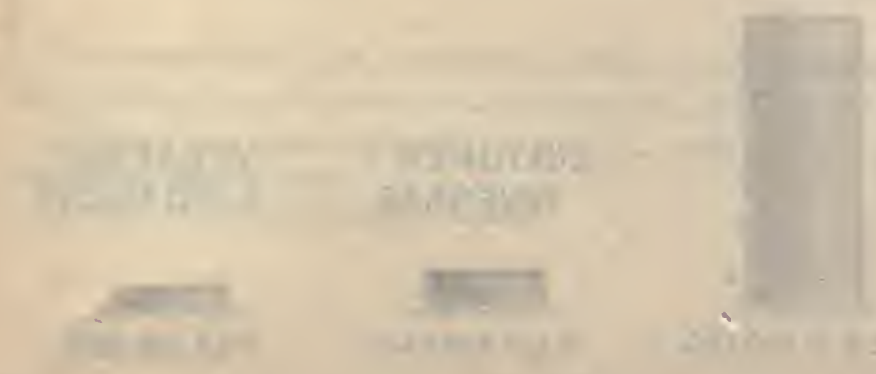

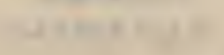

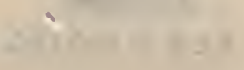




\title{
CHAPITRE XVIII
}

\section{DETTE HYPOTHÉCAIRE DE L'ÉGYPTE}

\author{
Son rapport avec la valeur de la propriété.
}

Prêts hypothécaires : engagements par prêts sur la propriété et engagements par privilège du vendeur sur les ventes à terme. - Évaluation de la dette hypothécaire égyptienne. - Son rapport avec la fortune immobilière de l'Égypte. - Sa comparaison avec celles des autres pays. - Raisons pour lesquelles l'écart entre la valeur de la fortune immobilière et celle de la dette hypothécaire s'augmentera encore.

La fortune immobilière de l'Egypte, dont nous venons de fixer la valeur, supporte des engagements de deux sortes : engagements par prêts sur la propriété et engagements par privilèges du vendeur sur les ventes à terme. Ces engagements sont effectués par différentes catégories de prêteurs, que nous allons successivement passer en revue et dont le chiffre d'affaires nous permettra d'évaluer la dette hypothécaire de l'Égypte et de déterminer son rapport avec la valeur de la propriété.

\section{PRÊTS HYPOTHÉCAIRES}

On peut classer en deux groupes les prêteurs hypothécaires opérant sur les immeubles d'Égypte, suivant qu'ils 
font connaitre ou non le résultat de leurs opérations.

Le premier groupe se compose des Sociétés par actions travaillant exclusivement dans le pays et qui, par leurs bilans annuels, nous renseignent sur les résultats de leur activité dans cette branche d'affaires. Dans ce groupe, figurent les banques hypothécaires proprement dites, les banques de commerce ou de spéculation, enfin les Sociétés soit foncières, soit industrielles, ayant employé une partie de leurs capitaux en prêts hypothécaires.

Quant au second groupe, il se compose de deux catégories de prêteurs :

$1^{\circ}$ Des Compagnies d'assurances étrangères qui placent une portion de leurs réserves en prêts hypothécaires avec ou sans combinaisons d'assurances;

$2^{\circ}$ Des particuliers, qui eux-mêmes se partagent en deux classes : les prêteurs étrangers et les prêteurs égyptiens.

Si nous nous livrons à cette décomposition, c'est qu'entrant avec ce groupe dans le domaine des conjectures, nous ne pouvons nous rapprocher de la vérité, qu'en procédant par divisions aussi nombreuses que peut le comporter le sujet. 


\section{PREMIER GROUPE}

\section{Sociétés faisant connaître leurs opérations}

Le tableau XVII ci-après, extrait des bilans des Sociétés engagées dans les placements hypothécaires, nous montre que l'ensemble de leurs placements s'élevait, en principal, arriérés d'annuités et annuités en cours, à L. E. 44.227.012, aux dates de clôture de leurs derniers bilans. Admettons que, depuis la clôture de ces bilans, les placements des Sociétés aient continué de suivre leur marche ascendante et, que, de ce fait, ils aient augmenté de la somme nécessaire pour porter le total ci-dessus à L. E. 45.000.000, nous pourrons ainsi inscrire, pour l'ensemble des prêts connus par les bilans, cette somme de L. E. 45.000 .000 .

\section{DEUXIÈME GROUPE}

\section{Prêteurs ne faisant pas connaître leurs opérations}

\section{Compagnies D'assurances}

Il n'y en a que trois, toutes anglaises, qui se soient intéressées aux affaires hypothécaires :

Ce sont la Gresham, la Standard Life et la Union Crown. Ces Compagnies, au début de leur participation aux affaires hypothécaires, avaient déployé une assez grande activité; depuis quelque temps, elles semblent 
avoir ralenti considérablement leurs opérations dans cette branche. Il est probable qu'elles auront épuisé la portion disponible de leurs réserves. Notons aussi que l'une d'elles, la Gresham, vient de construire un important immeuble de rapport qui a dû absorber une bonne part de ses réserves, étant donné surtout que le terrain, acquis au plus fort de l'effervescence qui a précédé la crise, a été payé par elle un prix très élevé. Dans ces conditions, il est raisonnable de ne pas évaluer les placements des Compagnies d'assurances à plus de L. E. 1.500.000.

\section{2o Prêteurs Particuliers}

\section{A. - Prêteurs étrangers}

Première catégorie : gros prêteurs, pour des sommes de L. E. 200.000 et au delà.

Ceux-ci ont généralement pour clients de gros personnages qui traitent avec eux à des taux plus réduits que ceux offerts par les Établissements d'Egypte. L'importance des prêts de cette classe explique leur très petit nombre. Nous ne pensons pas que leur chiffre atteigne L. E. 2.000.000, mais il ne doit pas en être éloigné.

Deuxième catégorie : prêteurs moyens, pour des sommes variant entre 1.000 et 4.000 livres, mais dont la moyenne peut être fixée à 1.500 livres.

D'après les renseignements très minutieux que nous avons puisés auprès des intermédiaires chargés de ces placements, le nombre des prêts effectués par leurs soins ne 
dépasserait pas 250. Le produit de ce nombre par 1.500 livres, valeur moyenne des prêts de cette classe, nous donne pour l'ensemble L. E. 375.000 .

\section{B. - Prêteurs égyptiens}

Première catégorie : les prêteurs de cette classe, coptes pour la plupart, exercent dans certaines parties de la Haute-Égypte trop éloignées des grands centres et où, en outre, le sol est à tel point morcelé que les Banques hypothécaires ne trouvent aucun intérêt à y engager leurs capitaux. Ce sont, en général, de très gros propriétaires qui ont pour clients des cultivateurs engagés dans leurs terres comme colons partiaires et qui tiennent un peu sous leur dépendance les omdehs, chefs de villages, investis de l'autorité officielle.

Cette double circonstance fait que leurs avances sont rarement garanties par des hypothèques, la situation de ces prêteurs leur permettant de rentrer dans leurs avances sans garanties réelles. Il s'ensuit que, dans ces régions, les prêts établis sur hypothèques sont en très petit nombre, et de minime importance, ne dépassant pas 100 livres en moyenne ; il n'y a donc pas lieu d'en estimer l'ensemble à plus de 250.000 livres.

Deuxième catégorie: les opérations de cette classe de prêteurs portent sur trois sortes de biens:

Ceux hypothéqués en premier rang dans les Banques et sur lesquels ils consentent des suppléments d'avance en deuxième rang. 
Ceux n'offrant pas toutes les garanties exigées par les Banques ;

Ceux, enfin, n'ayant pas obtenu des Banques l'offre d'un chiffre d'avance considéré comme suffisant par le demandeur.

Inutile d'ajouter que nous nous trouvons ici en plein domaine de l'usure et de l'inconnu ; nous n'avons donc aucune donnée particulière qui puisse nous servir de base sérieuse d'estimation.

Plusieurs considérations peuvent cependant nous guider :

10 Les capitaux disponibles appartenant en propre à l'épargne du pays sont de faible importance, fait nettement mis en relief par la dernière crise financière;

$2^{\circ}$ Les disponibilités de cette classe de prêteurs destinées à être investies en prêts hypothécaires n'atteignent pas un chiffre très élevé ;

$3^{0} \mathrm{Si}$ l'on estime à L. E. 750 la valeur moyenne des prêts de cette classe, on ne peut, en aucun cas, supposer que leur nombre dépasse trois mille; on est ainsi amené à prendre pour maximum dela valeur globale de ces prêts la somme de L. E. 2.500.000. Atteignent-ils ce chiffre? Restent-ils plus ou moins en deçà ? Voilà ce qu'il nous est impossible de savoir. Acceptons néanmoins le chiffre de L. E. 2.500.000 et procédons à la récapitulation :

10 Prêts connus par les Bilans et comprenant les sommes restant dues, les arriérés d'annuités et les annuités en 
cours..................... L. E. 45.000 .000

$2^{0}$ Prêts des Compagnies d'assu-

rances .................. -1.500 .000$

$3^{\circ}$ Gros prêts contractés à l'étranger. $\quad-\quad 2.000 .000$

$4^{0}$ Prêts moyens pour compte de

prêteurs étrangers........... - 375.000

$5^{0}$ Prêts des Égyptiens ( ${ }^{\mathrm{re}}$ catégorie). $\quad-\quad 250.000$

$6^{0}$ Prêts des Egyptiens ( $2^{\circ}$ catégorie). $\quad-\quad 2.500 .000$

Total........... L.E. $\overline{51.625 .000}$

\section{VENTES A TERME.}

Les derniers bilans des Sociétés immobilières que nous avons dépouillés nous ont permis d'établir le total des sommes qui leur sont dues sur le prix des terres de culture ou des terrains à bâtir vendus par elles à échéances successives. Le tableau XVIII ci-après, dans lequel nous avons condensé les indications des bilans, nous montre qu'à la clôture de ces derniers il restait dû par l'ensemble des acheteurs une somme de L. E. 2.024.313.

Comme, à la suite de la crise, cette branche d'affaires est restée presque inactive, il n'y a pas lieu de supposer que, depuis la clôture des bilans, il se soit produit quelque modification sensible dans la situation des Sociétés par rapport à leurs ventes à terme. Nous nous croyons donc fondé à conserver tel quel le total ci-dessus. Il ne nous reste plus qu'à l'ajouter à celui de la dette hypothécaire arrêtée plus haut à L. E. 51.625 .000 ; ce qui nous donne 
un total général de L. E. 53.649.313, soit en chiffres ronds L. E. 54.000.000, représentant très approximativement l'ensemble des engagements hypothécaires. (Voir ci-après planche $X I I$ ).

Comme, d'autre part, la fortune immobilière de l'Egypte s'élève, d'après nos calculs, à environ L. E. 574.169.650, le rapport entre la dette hypothécaire (L. E. 54.000.000) et la propriété immobilière ressort à $9,410 / 0$.

$\mathrm{Au}$ moment où nous mettons sous presse, nous recevons les derniers bilans de quelques sociétés hypothécaires. Ces bilans font ressortir une augmentation de leurs placements dont nous avons tenu compte en portant le total des opérations hypothécaires de L. E. 44. 222. 012 à L. E. 45.000 .000 .

Nous recevons également l'Annuaire statistique de l'Égypte pour 1911. Les impôts, sur lesquels nous nous sommes basé pour l'estimation de la propriété, se sont augmentés par suite de l'augmentation de la valeur de la propriété, résultant de la construction de nouveaux immeubles et de l'amélioration des terres actuellement cultivées ou de la mise en valeur de nouvelles terres. Ces impôts ont passé, de 1909-1910, de L. E. 5.059.231 à L. E. 5.118.887 pour les biens ruraux, et de L. E. 249.004 à L. E. 282.410 pour les biens urbains. Par suite, la valeur de la propriété rurale, que nous avons établie d'après les impôts à L. E. 540.108.415 (dattiers compris), devrait être actuellement de L. E. 545.924.034, et la valeur de la 
propriété urbaine devrait passer de L. E. 77.813 .750 à L. E. 88.253.125; soit, en tout, une augmentation de la propriété rurale et urbaine de L. E. 16.254.994 (frs. 421.386.753) équivalant à 2,56 0/0.

La dette hypothécaire est loin d'avoir augmenté dans de semblables proportions. Son rapport avec la propriété immobilière, que nous avons établi à $9,410 / 0$, doit encore être diminué; mais nous le maintenons à ce chiffre au risque d'être au-dessous de la vérité.

Si l'on compare cette dette avec celle des autres pays, elle apparaît bien peu considérable. Voici, en effet, les rapports existant entre la dette hypothécaire et la richesse immobilière de quelques Etats d'Europe et d'Amérique (planche $X I I I)$ :

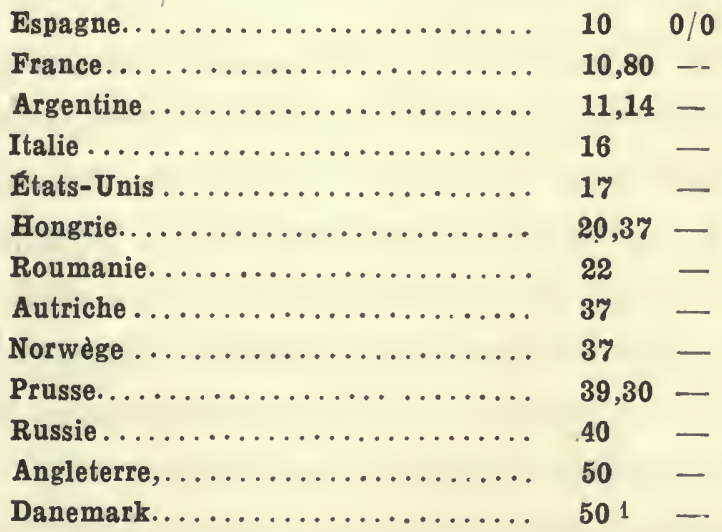

1. Ces chiffres ont été puisés : $1^{\circ}$ dans un rapport du Comité spécial élu par $1^{\prime}$ Institut international de Statistique tenu à Berlin en $1903 ; 2^{\circ}$ dans un article de M. de Folleville publié dans l'Économiste Français (24 janvier et 21 Février 1903); $3^{\circ}$ dans úne étude sur la Dette hypothécaire’et les Charges des immeubles en Hongrie, par Frédéric Fellener (1909); $4^{\circ}$ dans le Bulletin de l'Institut international d'Agriculture de Rome (Bureau des institutions économiques et sociales, aont 1911). 
En regard des charges qui pèsent si lourdement sur des pays dont le sol ne peut soutenir, au point de vue de la fertilité, aucune comparaison avec celui de l'Égypte, la dette hypothécaire de cette dernière apparaît bien modeste.

Cela est d'autant plus vrai que le rapport actuel entre cette dette et la fortune immobilière du pays est appelé à diminuer dans un avenir très prochain, lorsqu'aux terres actuellement en exploitation seront venues s'adjoindre celles qui sont encore soit en friche, soit à l'état de marécages.

Rappelons que les premières, dont la superficie s'élève à 1.102.000 feddans (hectares 462.840), n'attendent, pour être mises en valeur; que l'achèvement des travaux de surélévation du réservoir d'Assouan. Ces travaux, qui seront terminés dans deux ans, permettront d'emmagasiner 2.300 millions de mètres cubes d'eau au lieu d'un milliard actuellement. Une fois cette œuvre réalisée, il restera à procéder au desséehement des lagunes qui séparent le Delta de la Méditerranée et qui sont connues sous le nom de lacs Menzaleh, Borollos, Edkou et Mariout. Ces terres, couvertes par les lagunes, ont une superficie de 719.100 feddans (302.022 hectares).

Afin de les pourvoir de l'eau nécessaire à leur irrigation, plusieurs projets ont été présentés. Le dernier en date et qui paraît avoir obtenu le plus de faveur est dû à Sir W. Garstin, ex-sous-secrétaire d'Etat aux Travaux publics; ce dernier a proposé l'établissement d'un réservoir 
sous forme de canal dérivé du Nil Blanc entre le $9^{\circ}$ et le $10^{\circ}$ de latitude Nord (Voir planche $I I$, p. 7), soit à la jonction des trois grands affluents du fleuve, le Bahr-elZaraf, le Bahr-el-Ghazal et le Bahr-el-Djebel, canal devant avoir une capacité suffisante pour servir à l'irrigation du Soudan en même temps qu'à celle de la partie de la vallée d'Égypte occupée actuellement par les lagunes.

C'est donc 2 millions de feddans environ qui viendront s'ajouter à la superficie de la propriété rurale actuelle de l'Egypte.

Notre tableau II, page 30, de l'état de l'exploitation de la propriété rurale nous a donné pour valeur minimum du feddan L. E. 156,833, prix applicable aux bonnes terres. D'un autre côté, notre estimation de l'ensemble de la propriété rurale nous a conduit à attribuer au feddan une valeur moyenne de L. E. 102,781. L'écart entre ces deux chiffres s'explique par la différence de qualité des terres, dont les unes sont parvenues à l'extrême degré d'amélioration, tandis que les autres sont encore à des étapes diverses dans cette voie. Mettons cependantque, pour tenir compte de certains aléas auxquels l'exploitation peut être sujette, il faille diminuer le prix du feddan de bonne terre de $250 / 0$ environ; nous aurons alors, pour valeur moyenne du feddan de cette catégorie, L. E. 120, qui est justement son prix vénal actuel. Pour l'ensemble de la propriété, le jour où les grands travaux auront été exécutés, où les terres en friche et les terres marécageuses auront été mises en culture, leur valeur 
sera à peu près égale à celle des terres aujourd'hui cultivées, puisque toutes les terres, formées du limon du Nil, ont la même origine, la même constitution et la même nature.

Dès lors, au lieu que les terres déjà en valeur soient estimées, en moyenne, L. E. 102,781 le feddan, et que les terres incultes soient estimées seulement L. E. 10 le feddan, les deux catégories de ces terres pourront justifier largement le prix de L. E. 112,997 que nous a donné le calcul pour la classe des terres irriguées.

Nous aurons ainsi :

Terres déjà en valeur :

Fed. 5.620.000 à L. E. $112,997=635.043 .140$

Terres nouvelles:

Fed. 1.821 .100 à L. E. $112,997=205.778 .836$ Total :

Fed. 7.441.100 = L. E. 840.821 .976

Equivalant à : 21.797.070.019 franes.

Sans doute, pour amener les terres nouvelles au même état que celui des terres actuellement en exploitation, il faudra des dépenses considérables; mais, $\mathrm{si}_{\text {» }}$ de ce fait, la dette hypothécaire du pays s'augmente, la valeur de la propriété s'accroîtra elle-même dans une proportion bien plus importante encore. 


\section{TABLEAU XVII}

\section{Engagements hypothẻcaires}

Extraits des bilans des Sociétés par actions

Prêts hypothécaires

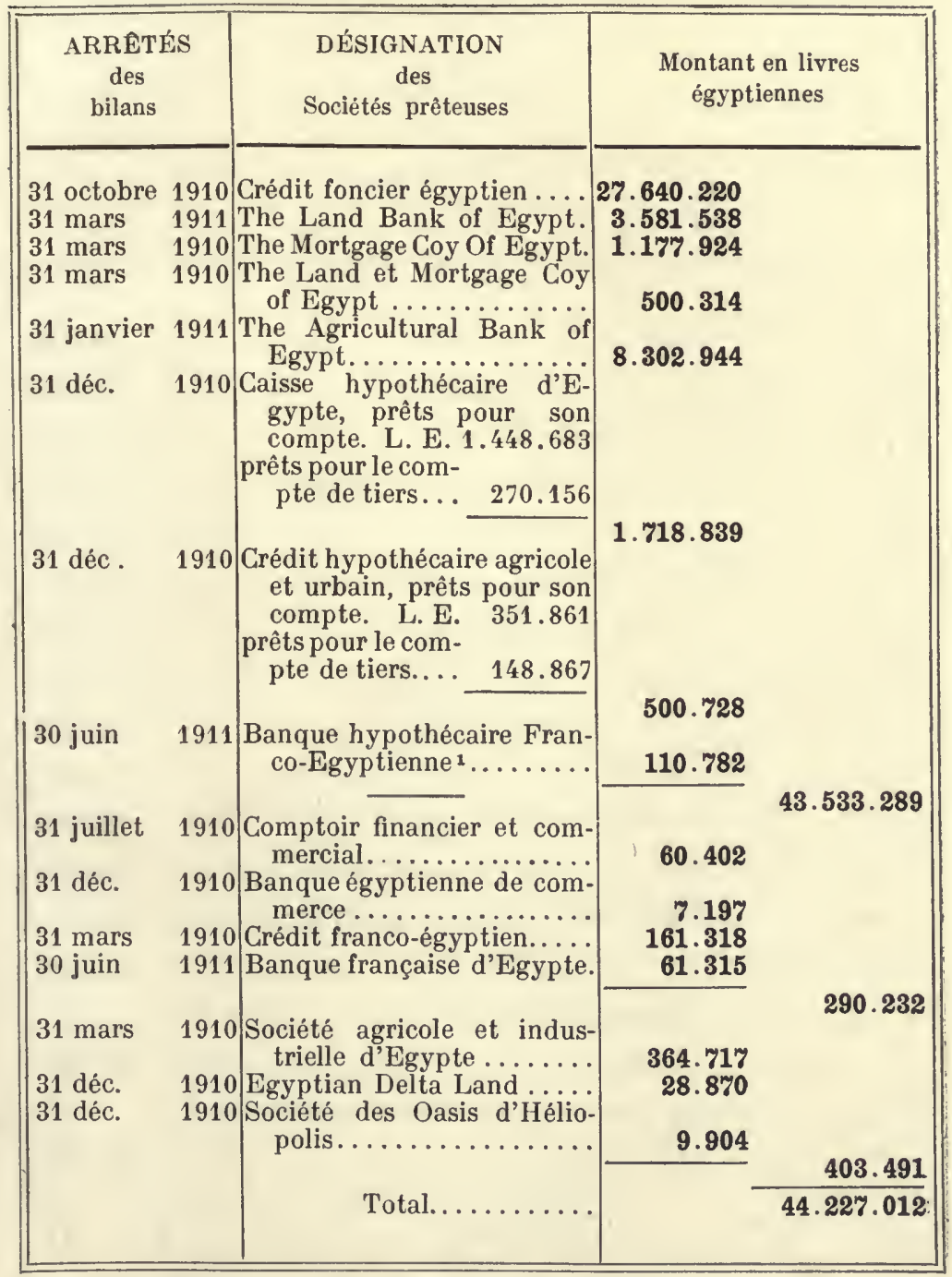

(1) La Banque hypothécaire Franco-Égyptienne a été fondée en 1910 au capital de 15.000 .000 de franes avec autorisation donnée au conseil d'administration de le porter à 50.000 .000 de francs. 
TABLEAU XVIII

\section{Engagements hypothécaires}

Extraits des bilans des Sociétés par actions

Ventes à termes

\begin{tabular}{|c|c|c|c|}
\hline \multicolumn{2}{|c|}{$\begin{array}{c}\text { ARRÊTÉs } \\
\text { des } \\
\text { bilans }\end{array}$} & $\begin{array}{l}\text { DÉSIGNATION } \\
\text { des } \\
\text { Sociétés vendeuses }\end{array}$ & $\begin{array}{l}\text { Montant } \\
\text { en } \\
\text { L. E. }\end{array}$ \\
\hline 31 déc. & 1910 & 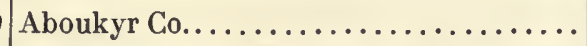 & 19.510 \\
\hline 31 déc. & 1909 & Cie Immobilière d'Égypte............ & 204.678 \\
\hline 31 mars & 1910 & 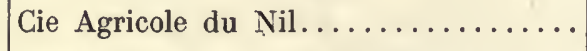 & 71.020 \\
\hline 31 octobre & 1910 & Sucreries et raffineries d'Égypte...... & 59.780 \\
\hline 31 déc. & 1910 & Egyptian Delta Land.......... & 299.963 \\
\hline 31 déc. & 1909 & 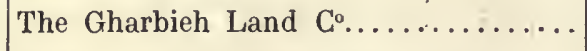 & 48.375 \\
\hline 31 déc. & 1910 & Béhéira Société Anonyme........... & 753.184 \\
\hline 31 janvier & 1911 & Agricultural Bank of Egypt........... & 17.933 \\
\hline 31 déc. & 1910 & Union foncière d'Égypte............ & 123.291 \\
\hline 31 déc. & 1910 & 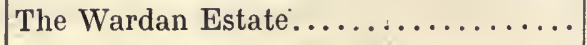 & 5.366 \\
\hline 31 déc. & 1910 & Société foncière d'Égypte........... & 86.308 \\
\hline 31 mars & 1910 & Société agricole et industrielle d'Égypte. & 99.868 \\
\hline 31 mars & 1910 & Société agricole de Kafr-el-Dawar..... & 27.736 \\
\hline 30 juin & 1910 & 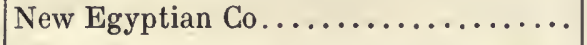 & 11.096 \\
\hline 31 déc. & 1909 & 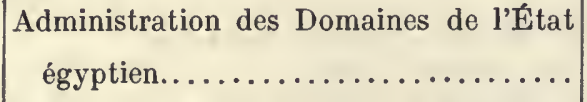 & 226.807 \\
\hline 31 déc. & 1910 & $\begin{array}{c}\text { The Cairo Electric Railway \& Heliopolis } \\
\text { Oases Co ..................... }\end{array}$ & 69.398 \\
\hline & & & 2.024 .313 \\
\hline
\end{tabular}




\section{Engagements Hypothécaires}

Extraits des Bilans des Sociétés par Actions

\section{PRÊTS HYPOTHÉCAIRES :LE. 44.227.012}

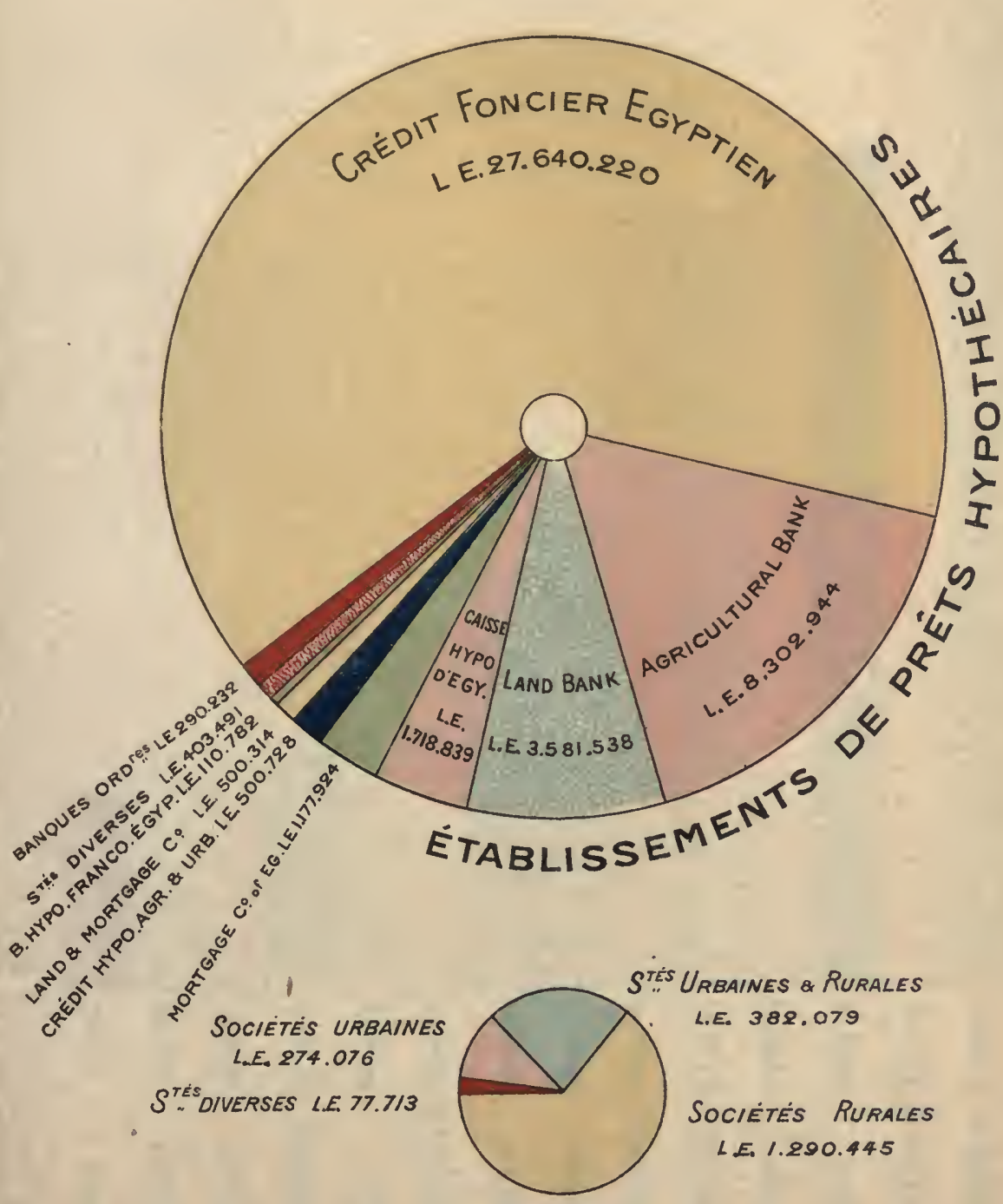

VENTES A TERME :L.E.2.024.313 


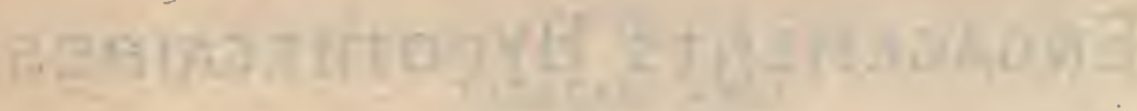

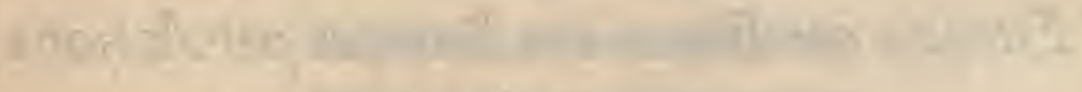

-.

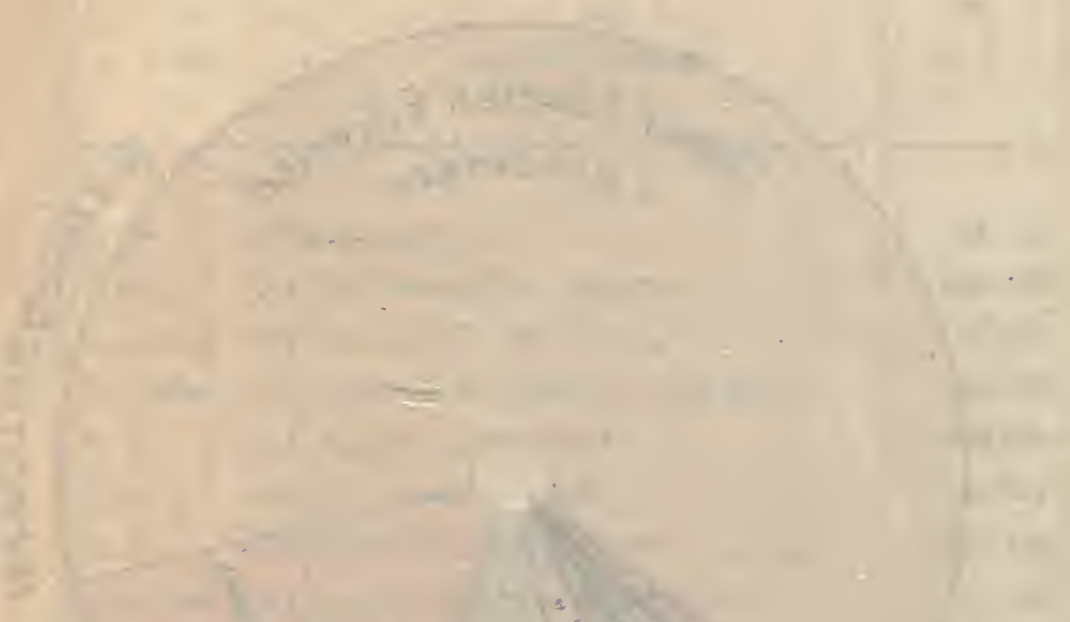

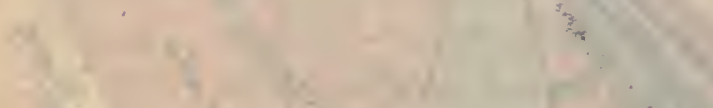
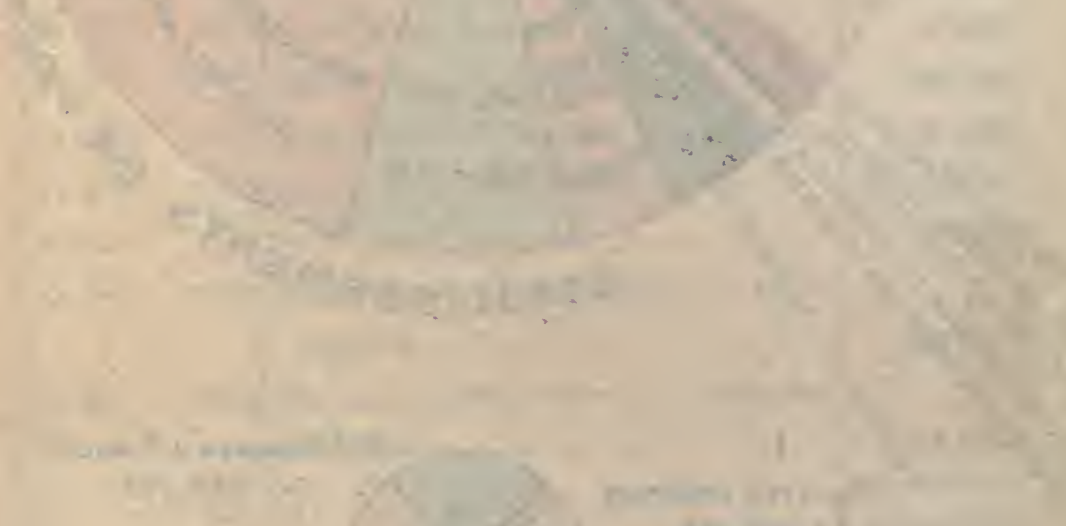

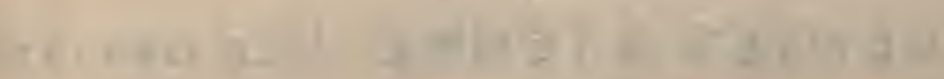




\section{DetTe HyPOTHÉCAIRE}

Rapport de la dette hypothécaire de quelques Etats à leur fortune immobilière .

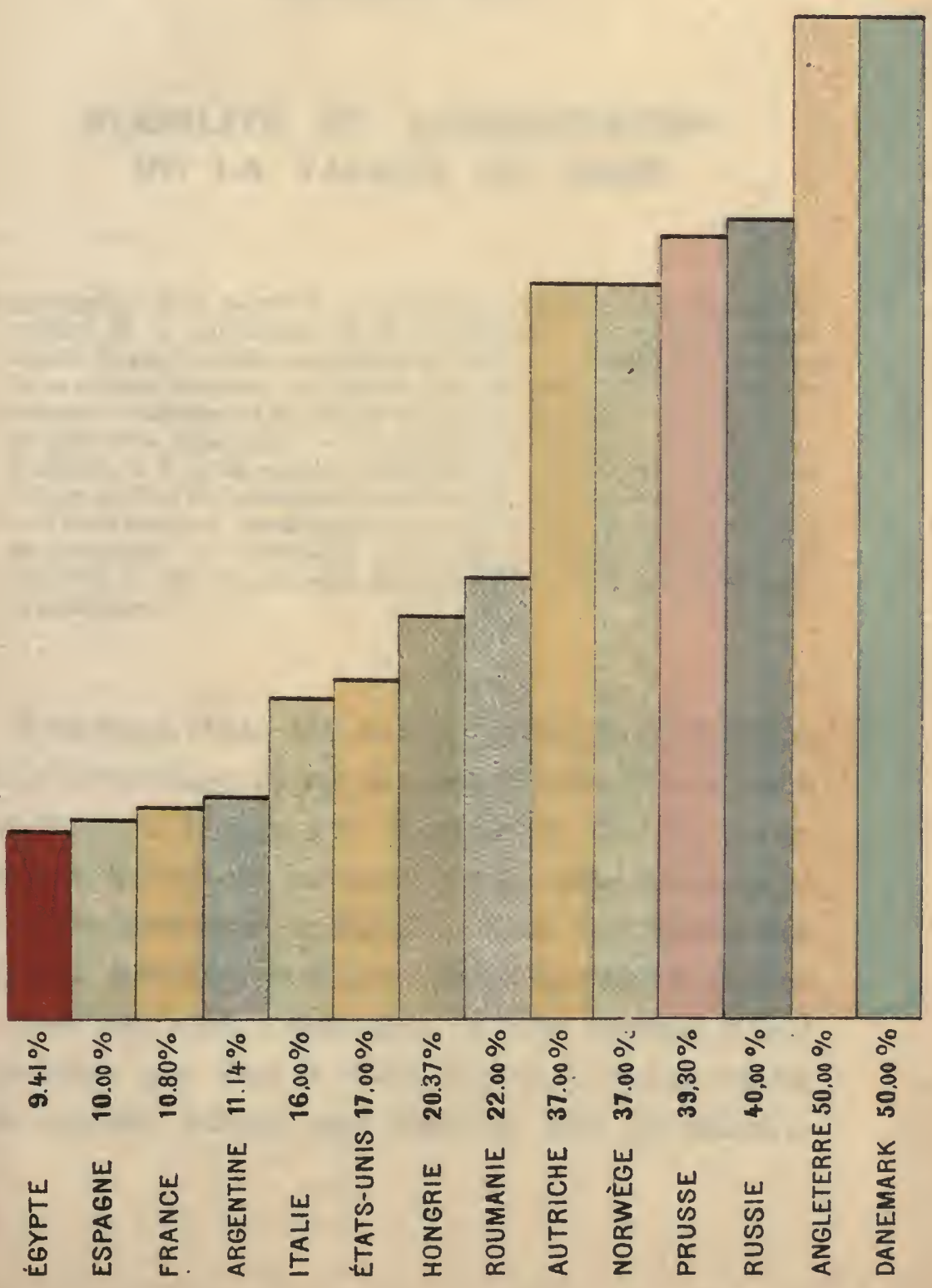




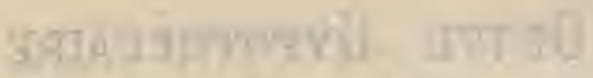

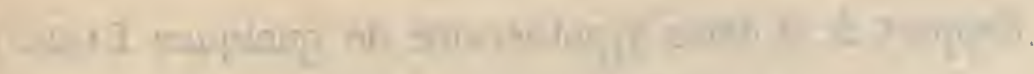

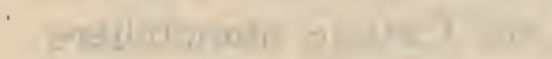

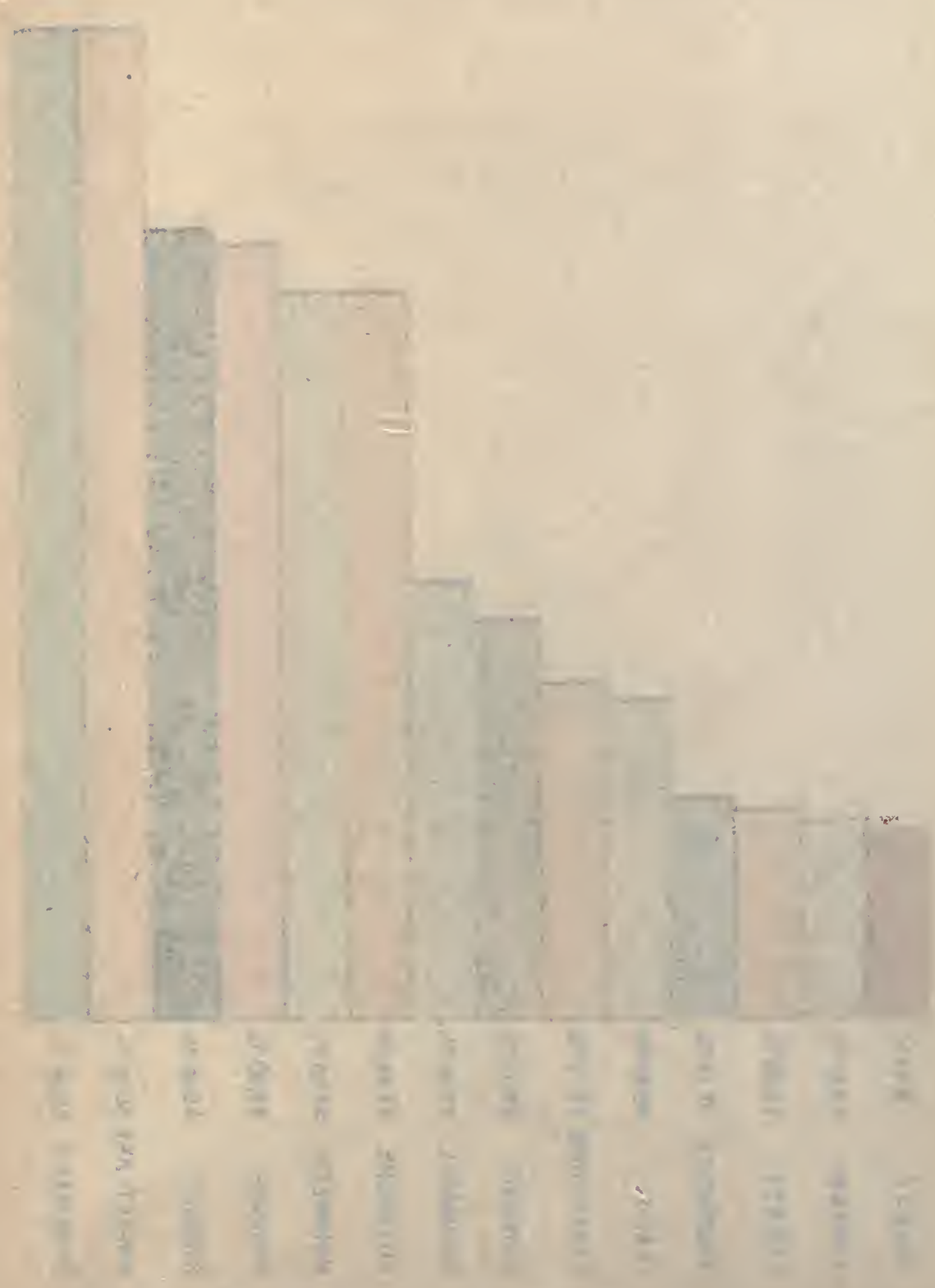




\section{CHAPITRE XIX}

\section{STABILITÉ ET AUGMENTATION DE LA VALEUR DU GAGE}

Augmentation de la valeur de la propriété, assurée par l'accroissement continu de la population, de la productivité du sol, de la valeur vénale de ses produits, notamment du coton. - Résultats à attendre de la culture intensive. - Raisons pour lesquelles il n'y a pas lieu de craindre l'avilissement du prix du coton, mais de prévoir, au contraire, sa plus-value constante. - La fortune de l'Egypte n'est pas liée, d'ailleurs, à la seule culture cotonnière. En cas d'abandon de cette culture, facilité de lui en substituer d'autres également rémunératrices.

- Valeur vénale et valeur locative de la terre avec ou sans la culture du cotonnier. - Conclusion en faveur de l'augmentation de la valeur de la terre et, par suite, de la stabilité et de la sécurité du gage hypothécaire.

Nous avons étudié plus haut les causes dela diminution dans le rendement moyen du coton et indiqué les mesures projetées ou déjà en voie d'application afin d'y porter remède. Examinons maintenant si les placements hypothécaires présentent, en Égypte, toutes les conditions de sécurité désirables tant pour l'avenir que pour le présent.

Pour bien saisir l'importance de cette question, il faut considérer que, dans la vallée du Nil, la presque totalité des capitaux français sont placés en prêts hypothécaires 
consentis pour de longues périodes, et que, dès lors, il importe au plus haut point de savoir si la propriété égyptienne est menacée dans l'avenir d'une diminution de valeur ou si, au contraire, elle est assurée d'une plus-value. Il n'est pas besoin de rappeler, à ce sujet, les ravages causés, dans les régions viticoles de la France, par le phylloxera, la dépréciation de la propriété qui en fut la conséquence, et les pertes que dut subir de ce fait le Crédit Foncier ${ }^{1}$.

Or il est bien évident que la valeur du gage est étroitement subordonnée à la valeur de la terre elle-même.

Trois facteurs principaux concourent, en Egypte, ̀̀ l'augmentation de la valeur de la propriété :

$1^{\circ}$ L'accroissement continu de la population sur un territoire dont la superficie cultivée ou cultivable est des plus limitées :

$2^{\circ}$ L'augmentation de la productivité du sol, conséquence nécessaire de l'accroissement de la population et de l'emploi de procédés de culture perfectionnés;

$3^{\circ}$ L'augmentation de la valeur vénale des produits agricoles de l'Égypte et notamment de son coton.

Dans notre chapitre VI, nous avons constaté que la population en Egypte a presque doublé depuis trente ans ; or, pour subvenir aux besoins sans cesse grandissants de cette population, il faut que le sol augmente continuellement sa production. On y parviendra grâce à la mise en

1. Dans notre chapitre XIII, nous avons montré qu'il n'y avait aucune parité à établir entre les pays de monoculture et l'Égypte et, plus particulièrement, entre la culture de la vigne et celle du cotonnier. 
exploitation de nouvelles terres et à la culture intensive, dont le résultat immédiat est d'augmenter la valeur de la terre en même temps que son revenu.

On comprend mieux, dès lors, la nécessité de la transformation que nous réclamons ailleurs dans le mode d'exploitation du sol.

En effet, quelles que soient, d'une part, l'importance des revenus de la culture cotonnière, même avec adjonction à cette culture des terres en friches ou en lagunes de l'autre, les facultés productives du sol et la sobriété proverbiale du fellah, il viendra nécessairement un moment où cet admirable équilibre sera rompu. Or nous savons l'attachement du fellah pour la terre, attachement si profond que sa personne semble se confondre avec elle; qui dit fellah dit terre égyptienne. Il lui faudra, pour continuer à vivre sur cette terre, mettre en œuvre la puissante énergie dont il dispose, tirer parti des nouveaux procédés de la science agricole pour multiplier à son gré les ressources que la terre lui procure et, parlà, s'identifier plus encore avec elle. Alors, on verra se réaliser la loi de Ricardo sur la rente, non seulement par l'effet direct de l'accroissement delapopulation, mais encore par l'action que cet accroissement exercera sur la productivité du sol, dont l'augmentation fera bénéficier le fonds d'une plusvalue correspondante.

Ici se pose tout naturellement cette question: Quels résultats l'Egypte est-elle en droit d'attendre de la culture intensive? Pour y répondre, nous avons dressé notre 
tableau XIX, où nous avons mis en parallèle les situations agricoles respectives des divers pays et les résultats obtenus.

Les données de ce tableau sont empruntées à différentes sources telles que le Bulletin de l'Institut international d'Agriculture de Rome (Essai d'inventaire d'après les documents publiés par les pays adhérents, Rome, 1910), le Statesman's Year Book(1911), la Statistique agricole annuelle (1909) (Ministère français de l'Agriculture), etc. ; et, pour éviter un encombrement de données qui auraient nui à sa clarté, nous n'avons fait figurer dans notre tableau que quelques pays choisis parmi les plus remarquables au point de vue agricole.

La planche $X I V$ montre le sol réparti en deux divisions principales: le territoire habité, - comprenant les terres arables, les prairies artificielles, les forêts, — les étendues d'eau et le sol improductif. Dans la terre arable, il ne faut compter, bien entendu, que les terres en culture ou en jachère.

On y voit qu'au point de vue du territoire habité le premier rang appartient aux Etats-Unis d'Amérique avec leurs 783.599.500 hectares, dont 114.663.034 de surface cultivée, tandis que le dernier est occupé par la Belgique avec 2.945.557 hectares, dont 1.767.216 en état de culture, représentant les quatre cinquièmes de la surface cultivée de l'Égypte.

Mais, si nous considérons la densité de la population et la production de la terre cultivée en céréales (Voir planche 
$X V)$, les situations changent. Pour la densité, c'est l'Egypte qui vient en tête, aussi bien pour la population totale que pour la population ouvrière ou agricole. Par contre, le rendement du blé à l'hectare place le Danemark au premier rang avec 27,81 quintaux (1904-1908), alors que le dernier rang est détenu par les Etats-Unis où, en raison de la rareté de la main-d'œuvre et de l'étendue du territoire, on ne peut se livrer à la culture. intensive.

L'Allemagne du Nord, de son côté, a également opéré des miracles, puisqu'en fort peu de temps, grâce à l'emploi de la méthode intensive, sa production, dont le rendement moyen arrivait à peine, avant 1870, à 9 ou 10 quintaux à l'hectare, a passé à 19,7 quintaux dans la période 19041908.

Or l'Egypte, si exceptionnellement favorisée au point de vue du sol, ne produit que 14,28 quintaux à l'hectare, c'est-à-dire moins que l'Allemagne du Nord et à peu près la moitié du rendement du Danemark.

Voilà de quoi faire réfléchir, surtout si l'on veut bien considérer que le sol danois, composé, comme celui de l'Allemagne du Nord, de terre blanche, est des plus pauvre.

S'il en est ainsi dans des pays où la nature s'est montrée particulièrement ingrate, que n'est-on pas en droit d'espérer de l'Égypte, où la nature s'est montrée prodigue à l'excès, la dotant d'un sol, d'un fleuve, d'un climat, d'une population agricole qui la placent à la tête des pays 
les plus favorisés? Et que ne pourra-t-on pas attendre de la terre égyptienne le jour où, grâce à l'usage de procédés de culture perfectionnés, ses cultivateurs, toujours de plus en plus nombreux, mettront en pleine exploitation ses incomparables richesses naturelles?

En ce qui concerne particulièrement la production cotonnière, des études dues aux personnes les plus compétentes, entre autres le rapport de la Commission du Coton, établissent surabondamment que les récoltes peuvent s'accroître dans une très large proportion. Il suffit d'ailleurs de comparer les récoltes obtenues par une bonne exploitation et celles produites par une exploitation négligée pour se rendre compte des résultats qu'on est en droit d'attendre d'une meilleure culture. Les écarts observés, notamment entre les rendements des terres bien drainées et ceux des terres drainées insuffisamment, fournissent déjà, à cet égard, d'utiles constatations.

Partant de ce point de vue, M. E. Catzeflis, le distingué ingénieur agronome, fait ces observations intéressantes :

"Nous considérons communément qu'un rendement au " feddan de 5 à 6 kantars de coton est très satisfaisant, " tandis quenous devrions tâcher d'arriverà desrendements " de 9 à 10 kantars. Dans certaines régions d'Europe, il y a " une trentaine d'années, on estimait comme très bonne " une récolte de 25 quintaux de blé à l'hectare; or voici "que, par la sélection des semences, le perfectionne" ment des modes de culture, l'emploi plus abondant « des engrais, on est arrivé à obtenir fréquemment 34 et 


\section{HECTARES}

TERRITO que ……..... $\begin{cases}\text { S.T. } & 2.945 .557 \\ \text { S.C. } & 1.767 .216\end{cases}$

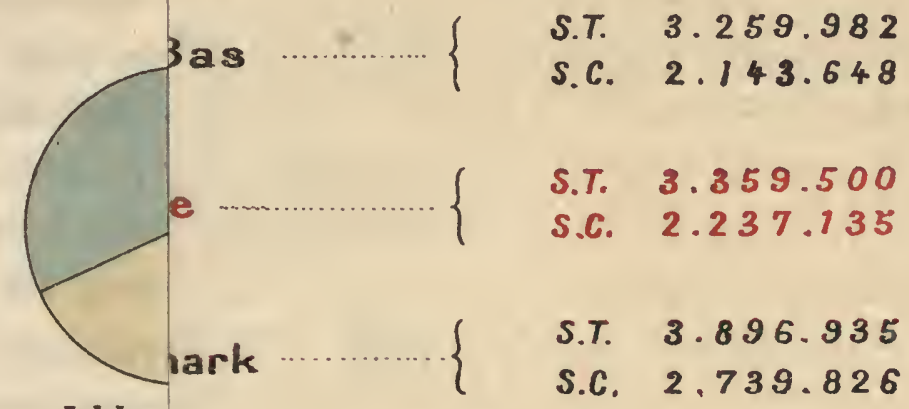

Alle

S.T. 54

S.C. 35

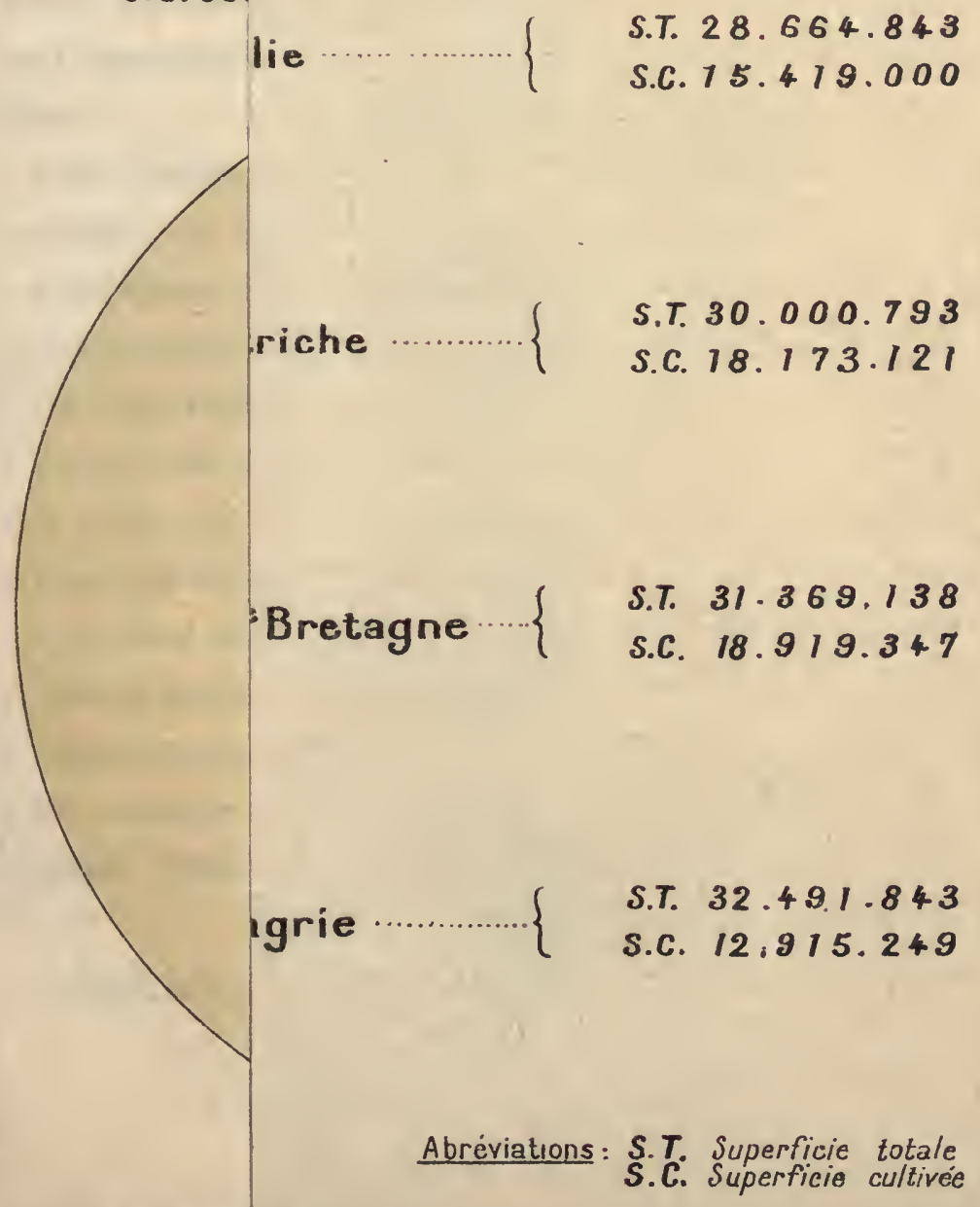




\section{SUPERFICIES COMPAREEES DES}

\section{TERRITOIRES HABITÉS ET DES TERRES CULTIVÉES}

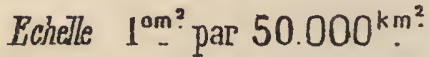

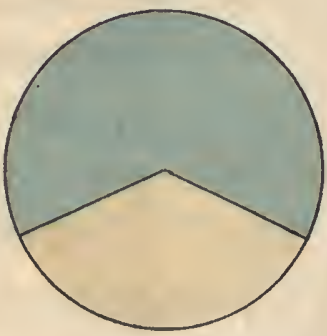

Allemagne

S.T. 54.064 .785 hectares

S.C. 35.055 .397 hectares

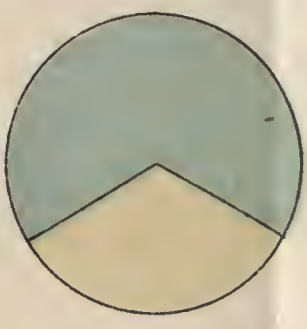

France

S.T.52.955.764 hectares S.C.36.564.472 - d. $^{\circ}-$

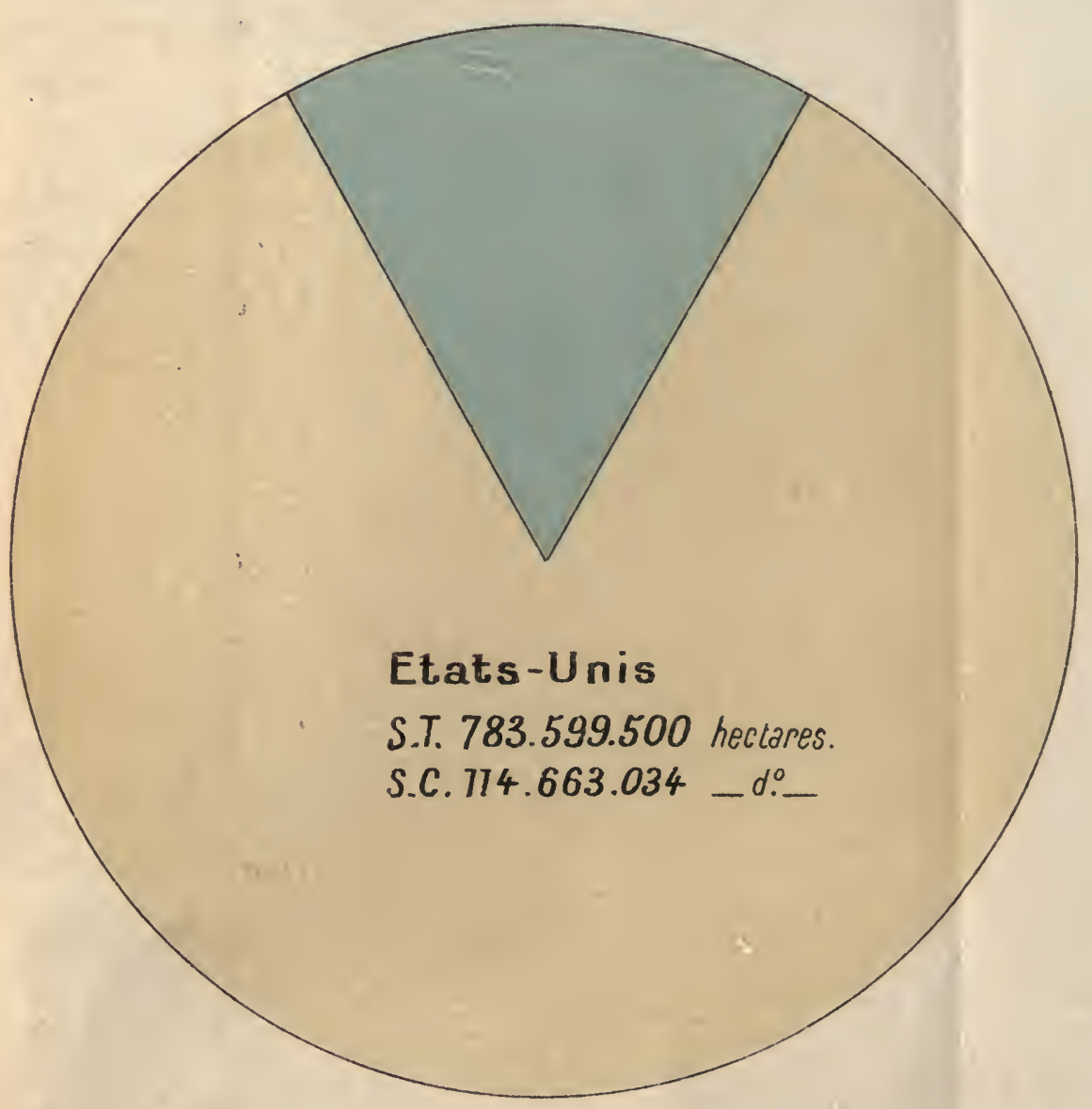


Belgique …….... $\begin{cases}\text { S.T. } & 2.945 .557 \\ \text { S.C. } & 1.767 .216\end{cases}$

Q Pays-Bas ……..... $\begin{cases}\text { S.T. } & 3.259 .982 \\ \text { S.C. } & 2.143 .648\end{cases}$

Degypte ………... $\begin{array}{ll}\text { S.T. } & 3.359 .500 \\ \text { S.C. } & 2.237 .135\end{array}$

Danemark …......... $\begin{array}{ll}\text { S.T. } & 3.896 .935 \\ \text { S.C. } & 2.739 .826\end{array}$

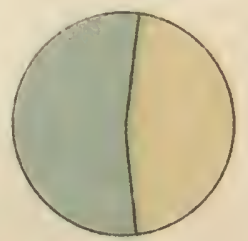

Italie

S.T. 28.664 .843 S.C. 75.419 .000

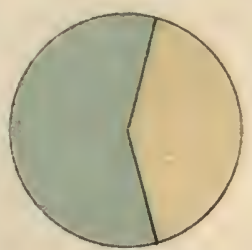

Autriche

S.T. 30.000 .793 S.C. 18.173 .121

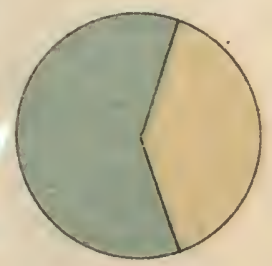

G de Bretagne $\cdots . . .\{$

S.T. 31.369 .138 s.C. $18.919 .3+7$

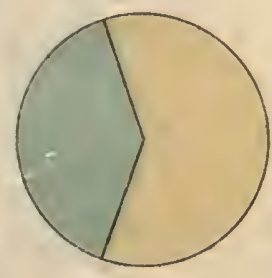

Hongrie

S.T. 32.49 .1 .843 S.C. 12.915 .249 


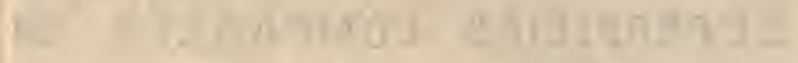

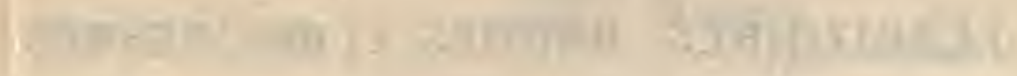
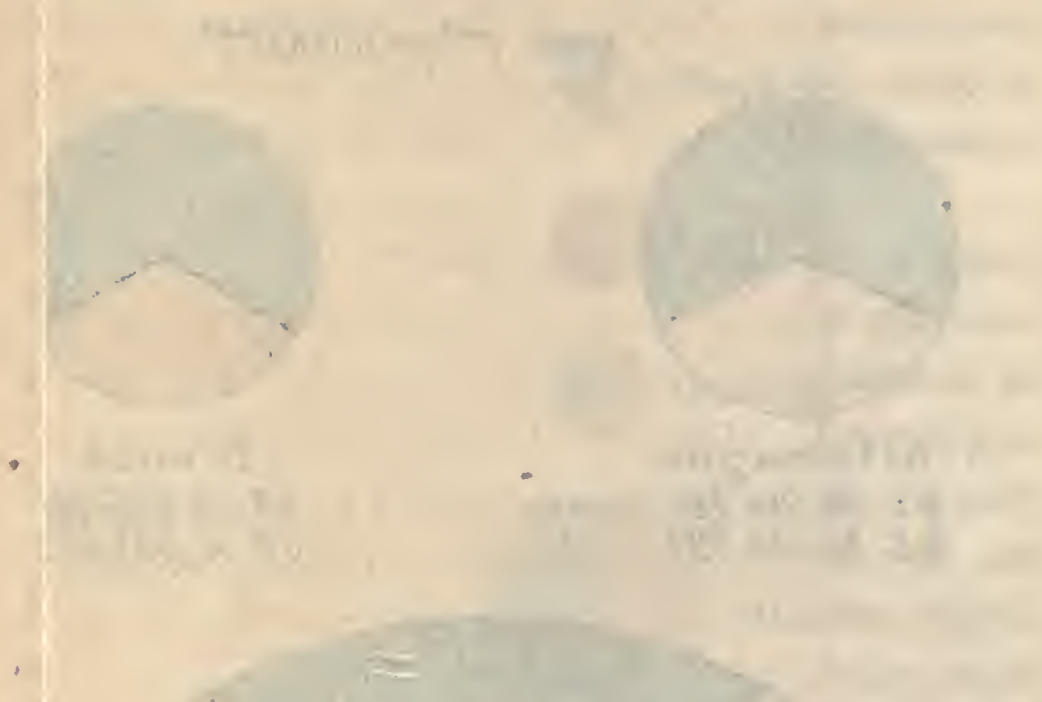
" 40 quintaux de blé à l'hectare; et ainsi en est-il de " beaucoup d'autres plantes. Pourquoi n'en serait-il pas " de même pour nos cultures de coton? D'ailleurs les " rendements de 9 à 10 kantars indiqués plus haut ont " été déjà obtenus en Égypte, dans certaines exploita" tions et sur des champs d'expérience ${ }^{1}$."

Sir W. Willcocks, la plus haute autorité en la matière, dans une importante communication faite à l'Institut égyptien, exprime, lui aussi, l'avis que, moyennant une judicieuse extension du régime des canaux et des drains et une meilleure utilisation des eaux, l'Égypte peut considérablement augmenter sa production cotonnière.

" En dotant les terres, dit-il, dans les parties élevées, de " canaux, et, dans les bas-fonds, de voies de drainage ; en " complétant les canaux par des fuites qui permettent " à la féconde eau rouge de la crue d'atteindre les champs " les plus éloignés, en maintenant le niveau de printemps, " dans le sud, assez bas par une irrigation adroite et, dans "le nord, par un drainage bien compris ; en précipitant " l'eau des réservoirs vers les friches du nord, en rendant " à la zone cotonnière du sud un été aussi chaud et sec " que les saisons le permettent; en utilisant la crue à son " heure naturelle et inévitable, nous ne pouvons manquer " de ramener les jours de la dernière décade du siècle "passé (1890-1900). Et, rattrapant l'ancien rende-

1. Bulletin de l'Union syndicale des Agriculleurs d'Égypte, décembre 1909. 
" ment de $51 / 2$ kantars par acre financière, avec une su" perficie cultivée en coton de 1.600 .000 acres dans la " Basse-Égypte, nous pouvons à coup sûr atteindre un ren" dement total de 9.000.000 de kantars en Basse-Égypte, " qui, grossi du contingent de 1.000 .000 de kantars de la "Haute-Egypte, porterait la récolte totale au chiffre de " 10.000.000 de kantars que j"ai prédit en 1902 1. "

Il est évident que l'augmentation continue de la population sur un territoire dont l'exiguïté ne saurait, nulle part ailleurs, se concilier avec la satisfaction des besoins toujours croissants des habitants, aura pour effet d'augmenter non seulement la main-d'œuvre agricole — et, par suite, de réduire ou tout au moins de maintenir aux taux actuels les salaires, c'est-à-dire les frais d'exploitation, mais encore la productivité et la valeur du sol. En matière de propriété, personne ne l'ignore, il est une loi immuable, précise comme un axiome de géométrie, en vertu de laquelle la valeur foncière, comme toutes les valeurs soumises aux fluctuations de l'offre et de la demande, progresse en raison de l'accroissement direct de la population.

A cette cause de la stabilité et de l'augmentation de la valeur de la terre, il en faut joindre une autre non moins importante : l'augmentation de la valeur des produits du sol égyptien et notamment de son coton.

Le coton, nous l'avons vu, s'il n'est pas le principal de ses produits proportionnellement à la surface cultivée et

1. Une Récolte de dix millions de kantars (Bulletin del'Union des Agriculleurs d'Égyple, décembre 1911, p. 312 et 313 ). 
à la production agricole, est le principal élément du commerce extérieur de l'Egypte. La terre égyptienne subira donc nécessairement, au point de vue de son revenu et, partant, de sa valeur vénale, l'influence de toute modification survenue dans le marché du coton, où le produit égyptien occupe une situation prépondérante par ses qualités, sinon par sa quantité.

Mais si, plus tard, la culture du cotonnier prenait, au détriment des autres cultures, une extension beaucoup plus considérable, devrait-on craindre l'avilissement du prix du coton, et, par suite, de la valeur de la terre ? II suffit d'examiner le tableau $X X$ et le graphique de la planche $X V I$, consacrés à la production et à la consommation mondiales du coton, pour comprendre que cette éventualité n'est pas à redouter, et cela pour deux raisons:

10 L'augmentation toujours croissante de cette consommation ;

$2^{\circ}$ Les qualités particulières du coton égyptien.

La consommation mondiale du coton augmente sans cesse. Sur le marché, la demande absorbe entièrement l'offre, et elle est loin de répondre aux besoins de la population du globe. Les manufacturiers vont même jusqu'à craindre que la production du coton ne puisse suivre les demandes de la consommation.

" L'année dernière, au Congrès des Filateurs de Coton, "M. Alexandre Kusnetzoff calculait que, sur les 1.600 " millions d'habitants du globe, il n'y en avait que " 500 millions vêtus complètement; 750 millions étaient 
TABLEAU

Territoires et Populations agricoles.

\begin{tabular}{|c|c|c|c|c|}
\hline \multirow{2}{*}{$\begin{array}{c}\text { DÉSIGNATION } \\
\text { DES } \\
\text { PAYS }\end{array}$} & \multicolumn{2}{|c|}{ SUPERFICIE (1) } & \multicolumn{2}{|r|}{ POPU } \\
\hline & TOTALE & CULTIVÉE & Dates & TOTALE \\
\hline Allemagne... ... & $\begin{array}{l}\text { En hectares. } \\
54.064 .785\end{array}$ & $\begin{array}{l}\text { En hectares. } \\
35.055 .397\end{array}$ & 1910 & 64.903 .423 \\
\hline Autriche............. & 30.000 .793 & 18.173 .121 & 1910 & 28.567 .898 \\
\hline Hongrie .............. & 32.491 .843 & 12.915 .249 & 1910 & 20.850 .700 \\
\hline Belgique............. & 2.945 .557 & 1.767 .216 & 1900 & 6.693 .548 \\
\hline Danemark . & 3.896 .935 & 2.739 .826 & 1906 & 2.605 .268 \\
\hline Egypte (4)........ & 3.359 .500 & 2.237 .135 & 1907 & 11.287 .359 \\
\hline Etats-Unis .... & 783.599 .500 & (a) 114.663 .034 & 1910 & 93.402 .151 \\
\hline France... & 52.955 .764 & 36.564 .472 & 1906 & 39.252 .245 \\
\hline Italie.............. & 28.664 .843 & 15.419 .000 & 1909 & 34.565 .000 \\
\hline $\begin{array}{l}\text { Grande-Bretagne et } \\
\text { Irlande } \ldots \ldots \ldots \ldots\end{array}$ & 31.369 .138 & 18.919 .347 & 1901 & 41.976 .827 \\
\hline Pays-Bas.............. & 3.259 .982 & 2.143 .648 & 1909 & 5.898 .429 \\
\hline
\end{tabular}

(1) Ministère de l'Agriculture, statistique agricole annuelle (1909): pour l'Égypte, d'après Statistical Year Book of Egypt (1909).

(4) The Statistical Year Book of Egypt (1909). Population agricole d'après The Census of Egypt (1907).

(a) Statistique générale de la France. Annuaire statistique (1909). 


\section{$\mathbf{X} \mid \mathbf{X}$}

\section{- Rendements du Blè à l'Hectare}

\begin{tabular}{|c|c|c|c|c|c|}
\hline LATION (2) & \multicolumn{2}{|c|}{ DENSITÉ } & \multirow{2}{*}{$\begin{array}{c}\text { Rapport } \% \\
\text { de la popul. } \\
\text { agr. à la } \\
\text { population } \\
\text { totale }\end{array}$} & \multicolumn{2}{|c|}{$\begin{array}{c}\text { RENDEMENT DU BLE } \\
\text { A L'HECTARE (3) }\end{array}$} \\
\hline AGRICOLE & $\begin{array}{l}\text { Générale } \\
\text { par } \mathrm{Km}^{2}\end{array}$ & $\begin{array}{c}\text { de la pop. agric. } \\
\text { par rapport à la } \\
\text { surface cultivée } \\
\text { par } \mathrm{Km}^{2}\end{array}$ & & DATES & $\begin{array}{l}\text { PRO- } \\
\text { DUITS }\end{array}$ \\
\hline 9.732 .472 & 120,04 & 27,76 & 14,99 & 1904-1908 & 19,7 \\
\hline 13.709 .204 & 95,22 & 75,43 & 47,98 & 1904-1908 & 13,24 \\
\hline 13.175 .083 & 64,17 & 102,01 & 63,18 & 1904-1908 & 11,95 \\
\hline 449.902 & 227,24 & 25,45 & 6,72 & $1903-1907$ & 23,62 \\
\hline 977.808 & 66,85 & 35,68 & 37,53 & 1904-1908 & 27,81 \\
\hline 9.259 .481 & 335,98 & 413,89 & 82,03 & $" \quad "$ & 14,28 \\
\hline 10.381 .765 & 11,91 & 9,05 & 11,11 & 1904-1908 & 9,74 \\
\hline 8.714.625 $(b)$ & 74,12 & 23,83 & 22,20 & $1903-1907$ & 14,24 \\
\hline 9.611 .003 & 120,58 & 62,33 & 27,80 & $" \quad n$ & ” \\
\hline 2.265 .868 & 133,81 & 11,97 & 5,39 & $1903-1907$ & 21,21 \\
\hline 3.688 .377 & 180,93 & 172,06 & 62,53 & 1904-1908 & 23,84 \\
\hline
\end{tabular}

(2) The Statesman's Year Book (1911).

(3) Institut international d'Agriculture, statistique des superficies cultivées, de la production végétale, etc. (Rome, 1910).

(b) Recensement général de la populalion (1906). 

É A L'HECTARE

\author{
REND.' DU BLE \\ (en Quintaux à l'Hectare)
}

DANEMARK

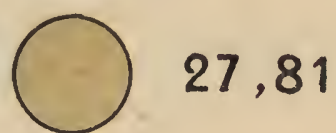

PAYS-BAS

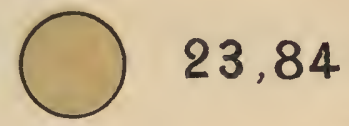

BELGIQUE

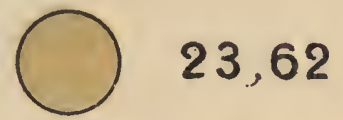

ANGLETERRE

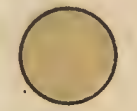

21,21

ALLEMAGNE

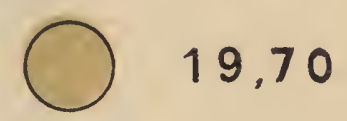

ÉGYPTE

14,28

FRANCE

○ 14,24

AUTRICHE

C 13,24

1

HONGRIE

○ 11,95

de terre cultivèe.

ÉTATS-UNIS

○ $\quad 9,74$ 


\section{Populations Comparées \& Rei}

\section{POPULATION}

ÉTATS-UNIS

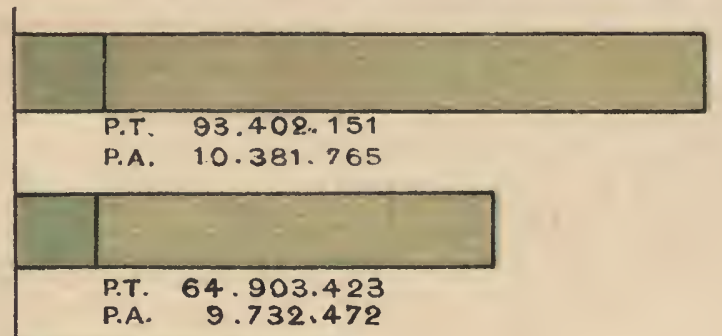

ANGLETERRE

FRANCE

ALLEMAGNE

P.A. $\quad 9.732 .472$

PAYS-BAS

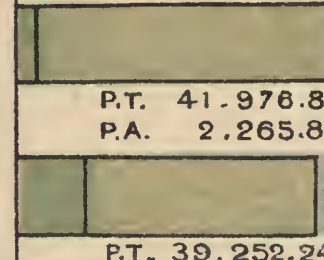

P.A. $\quad 8.714 .625$

ITALIE

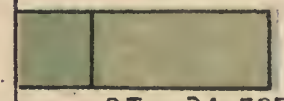

P.T. $\quad 34.565 .000$

P.A. $\quad 9.611 .003$

HONGRIE

AUTRICHE

AUTRICHE

HONGRIE

P.T: 28.567 .898

P.A. 13.709 .204

ITALIE
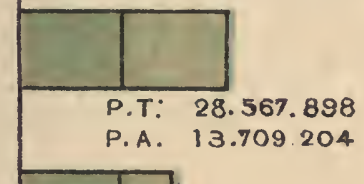

DANEMARK

P.T. 20.850.700

P.A. 13.175 .083

ÉGYPTE

BELGIQUE

P.T. 11.287.359

P.A. $\quad 8.259 .481$

ALLEMAGNE

BELGIQUE

FRANCE

P.T. $\quad 6.693 .548$

P.A. $\quad 449.902$

PAYS-BAS

P.T. $\quad 5.898 .429$

P.A. $\quad 3.688 .377$

DANEMARK

P.T. $\quad 2.605 .268$

P.A. $\quad 977.808$

$$
\text { LÉGENDE: } \begin{aligned}
& \text { P.T.=Population tolale } \\
& \text { P. A. } \_ \text {Population agricole }
\end{aligned}
$$




\section{JEMENTS DU BLÉ A L'HECTARE}

DENSITE

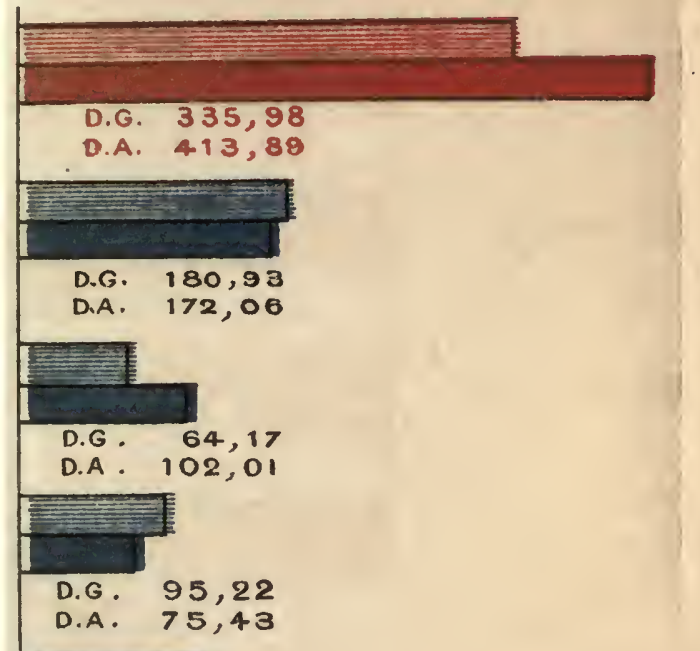

\section{\begin{tabular}{|l|}
\hline \\
\hline
\end{tabular}

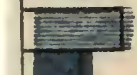 \\ D.G. 66,85 \\ D.A. $\quad 35,68$ \\ DA \\ D.G. 120,04 \\ D.A. $\quad 27,76$}

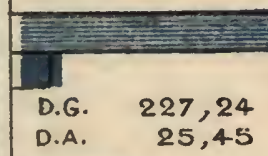

\section{플 \\ D.G, 74, 12 \\ D.A. 23,83}

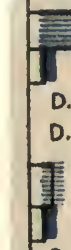

D.G. 133,81

D.A. 11,97

D.G. 11,81

D.A. 9,05

D.G.: Densité générale

D. A.z Densité de la population agricole par $\mathrm{K}^{\mathrm{m} ?}=$ de terre cultivée.
REND. DU BLÉ

(en Quintaux à l'Hectare)

DANEMARK

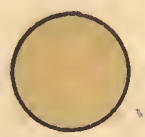

27,81

PAYS-BAS

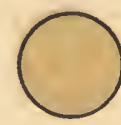

23,84

BELGIQUE

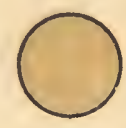

23,62

ANGLETERRE

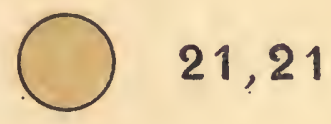

ALLEMAGNE

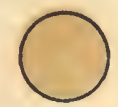

19,70

ÉGYPTE

14,28

FRANCE

14,24

AUTRICHE

13,24

HONGRIE

11,95

ÉTATS-UNIS

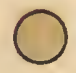

9,74 


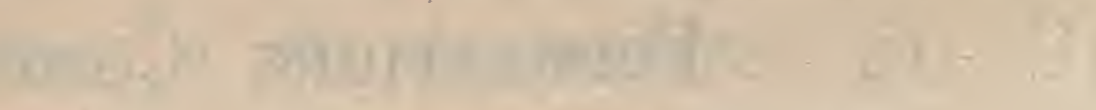

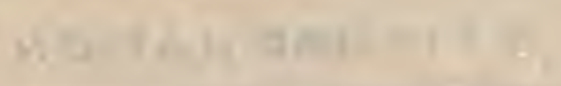

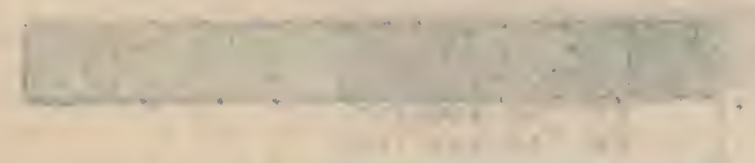

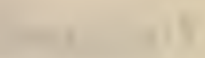

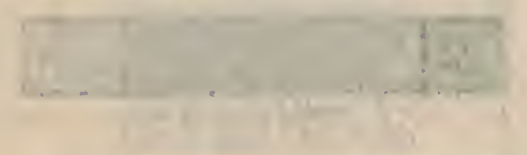

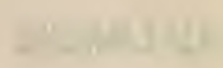

$+2$

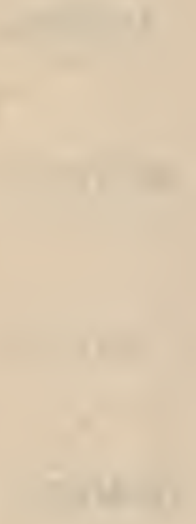

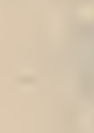
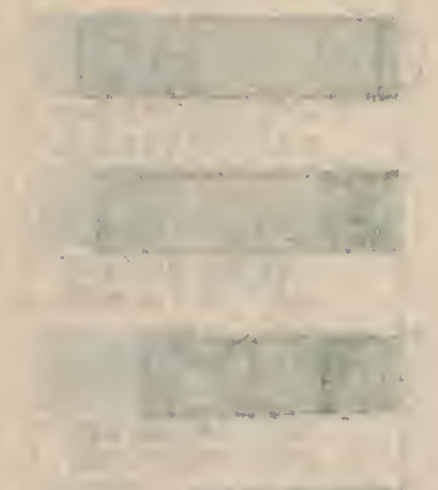

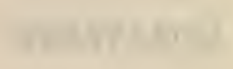
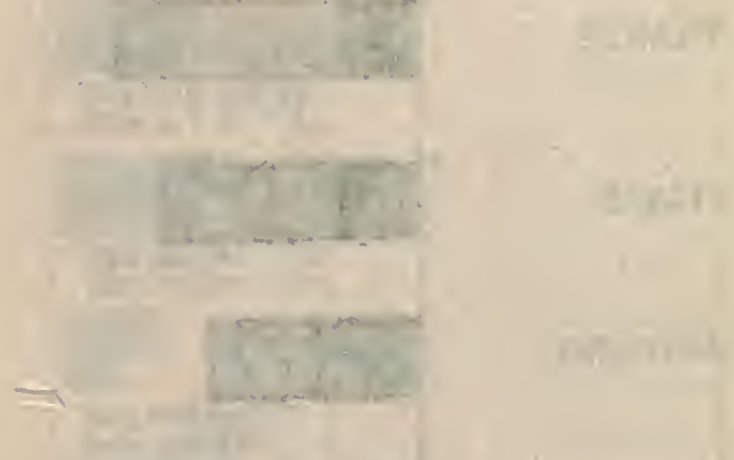

$$
\begin{aligned}
& -x+2 k 5 \\
& =2+x+4
\end{aligned}
$$




\section{TABLEAU $\mathbf{X X}$}

Production et Consommation mondiales du coton d'après John's Handbook et la Fédération internationale ${ }^{1}$

(En milliers de balles de 500 lbs.)

\begin{tabular}{|c|c|c|c|c|c|c|c|}
\hline \multirow[b]{2}{*}{ SAISONS. } & \multicolumn{6}{|c|}{ PRODUCTION. } & \multirow{2}{*}{ 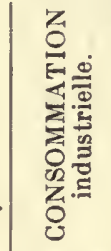 } \\
\hline & $\begin{array}{l}\text { ÉTATS- } \\
\text { UNIS. }\end{array}$ & INDES. & 国 & 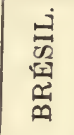 & 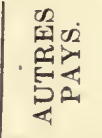 & TOTAL. & \\
\hline 1902-1903... & 10.758 & 3.085 & 1.115 & 264 & 1.541 & 16.763 & 13.476 \\
\hline 1903-1904 . . & 10.124 & 3.577 & $1.15^{17}$ & 181 & 1.557 & 16.596 & 13.268 \\
\hline 1904-1905. . . & 13.557 & 3.249 & 1.224 & 175 & 1.182 & 19.387 & 14.368 \\
\hline $1905-1906 \ldots$ & 11.320 & 3.838 & 1.159 & 263 & 1.307 & 17.887 & 15.200 \\
\hline 1906-1907. . & 13.550 & 4.158 & 1.345 & 249 & 1.495 & 20.797 & 15.743 \\
\hline $1907-1908 \ldots$ & 11.582 & 3.556 & 1.401 & 169 & 1.644 & 18.352 & 15.7799 \\
\hline 1908-1909... & 13.829 & 3.823 & 1.321 & 156 & 1.671 & 20.800 & 16.667 \\
\hline $1909-1910 \ldots$ & 10.651 & 4.186 & 985 & 108 & 1. 721 & 17.652 & 17.031 \\
\hline $\begin{array}{l}\text { Moyenne des } \\
8 \text { saisons.. }\end{array}$ & 11.921 & 3.684 & 1.213 & 195 & 1.514 & 18.529 & 15.191 \\
\hline Pourcentage. & 64,33 & 19,88 & 6,54 & 1,05 & 8,17 & & 81,98 \\
\hline
\end{tabular}

1. Pour la production, les poids des balles variant avec chaque provenance et les statistiques douanières et autres d'où ont été relevés les chiffres de chaque pays, portant les quantités des balles avec leurs poids locaux, il a fallu, pour arriver à la totalisation, ramener tous les poids à un type unique, celui de 500 livres anglaises équivalant à 226 kil. 5 . 



\section{Production \& Consommation mondiales du Coton}

Moyennes comparatives des Pays producteurs pour la période 1903-1910

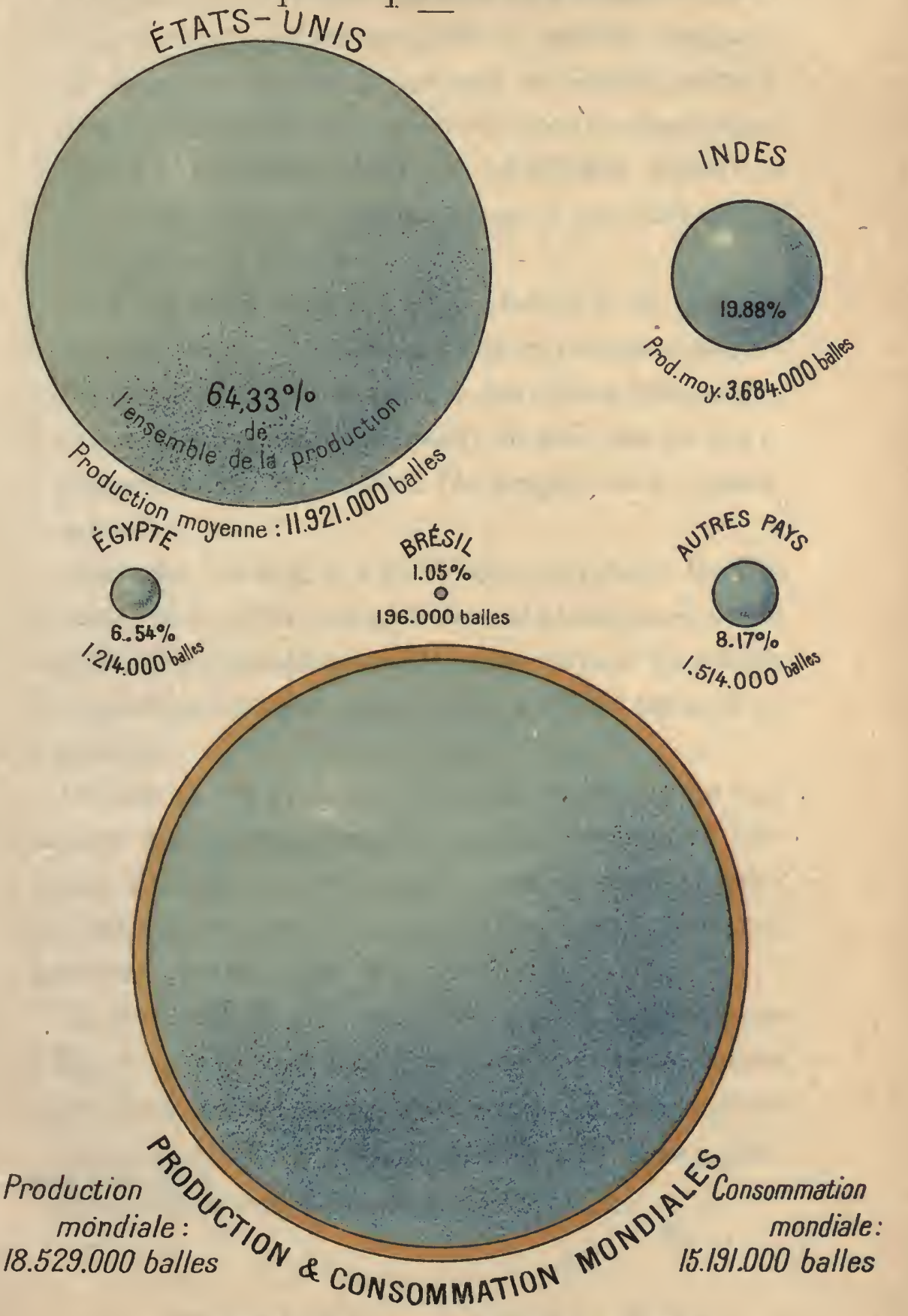

Rapport de la consommation à la production : $81,98 \%$ 


$$
8 x=2 \% \cdot 37
$$

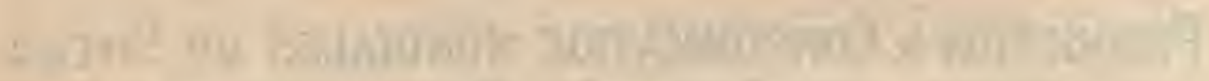
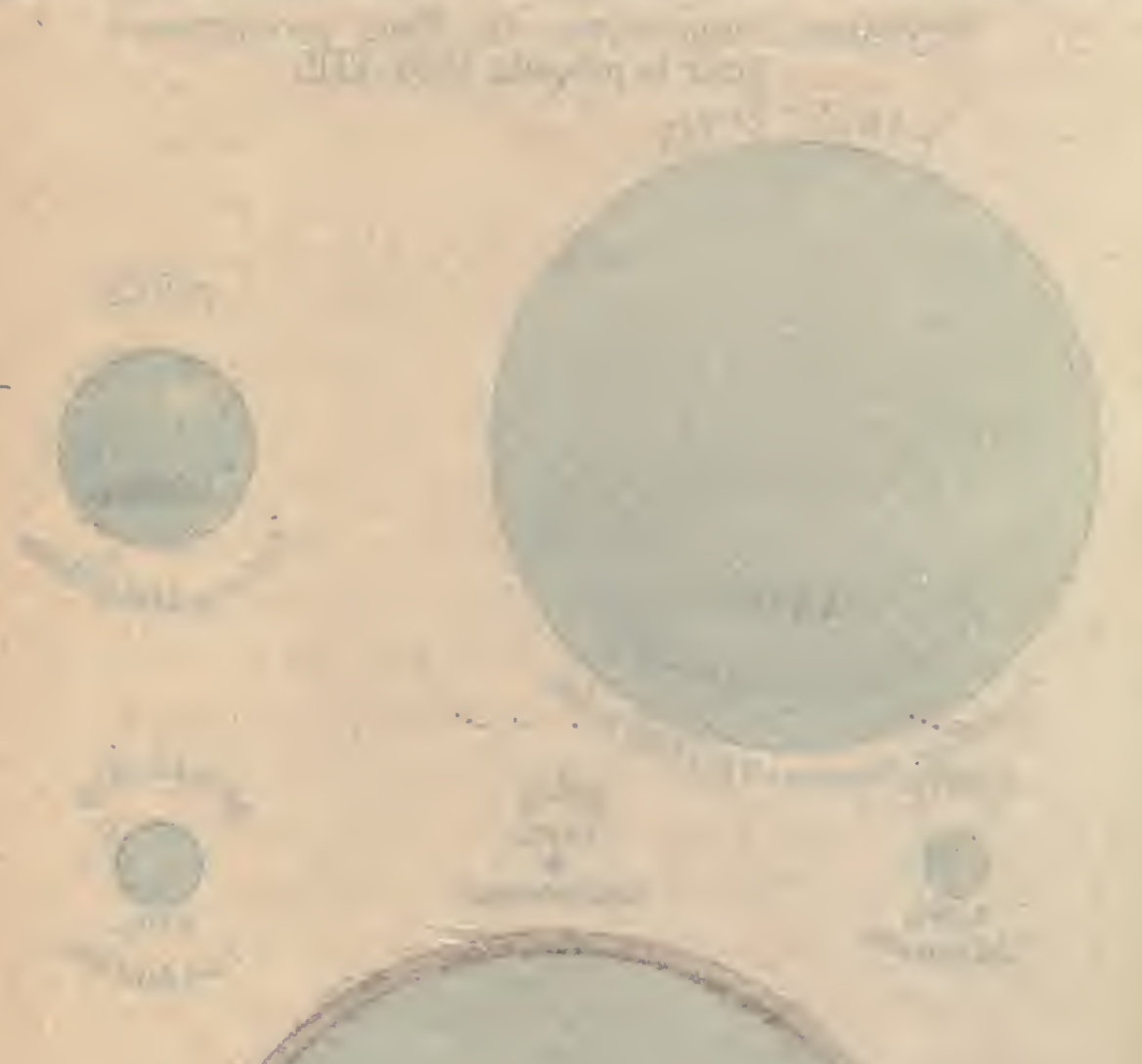

$=$

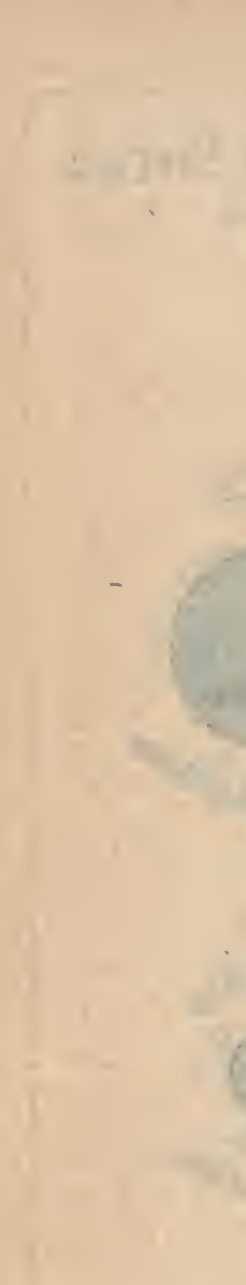


« vêtus en partie et le reste, soit plus de 300 millions, était " dans un état habituel de nudité. Il estimait que, pour " les vêtir tous tant bien que mal, il faudrait porter à " plus de 42.000.000 de balles de coton la production, "qui, en 1908-1909, était de 22.467 .000 balles " " "

Il y aurait donc une longue étape à parcourir avant qu'il y eût excès de l'offre.

Tout, du reste, tend à l'augmentation de la consommation du coton : l'accroissement de la fortune publique, " l'amélioration de la condition des classes laborieuses, " le besoin sans cesse grandissant du bien-être et de l'é" légance, enfin, et surtout, les progrès de la coloni" sation ${ }^{2}$ ".

Quel sera, dès lors, le sort du coton égyptien? Dans le chapitre où nous l'avons spécialement étudié, nous avons montré qu'il était spécialement recherché pour les articles de luxe et que son prix faisait prime de $690 / 0$ sur celui de l'américain.

Ce prix ne fera évidemment que s'accroître au fur et à mesure que la consommation mondiale s'accroîtra ellemême, à la seule condition que le coton égyptien conserve ses qualités, et nous avons vu que l'on faisait tout pour parvenir à les lui conserver.

La planche XVI nous montre le rang infime occupé par l'Egypte, par rapport aux Etats-Unis, dans la production mondiale. Le coton égyptien ne rentre que pour 6,54 0/0

1. A propos du danger de l'augmentation de l'or, par Y. Guyot (InformaLion, 17 mai 1911).

2. P. Arminjon, La Situation économique de l'Égypte, p. 214. 
dans l'ensemble de cette production. Or, quelle que soit l'extension qui puisse être donnée, dans la vallée du Nil, à la culture du cotonnier, il ne faut pas perdre de vue que cette extension sera toujours limitée par l'exigü̈té du sol cultivable auquel les déserts et la mer opposent des barrières infranchissables, sans parler des nécessités de l'assolement qui, elles aussi, limitent l'aire disponible de la culture cotonnière.

Est-ce à dire que la production de cette culture doive rester stationnaire? Assurément non; lorsque les terres actuellement stériles auront été mises en valeur, elle augmentera certainement d'une façon très appréciable, mais, en raison de l'exiguïté du sol cultivable, elle sera encore inférieure proportionnellement à la production totale du globe.

Ainsi, au point de vue cultural, il est impossible que le cotonnier d'Egypte voie se modifier sensiblement le rang qu'il occupe dans la production mondiale. Il y aurait lieu 'plutôt, à notre avis, d'envisager l'éventualité contraire, par suite non seulement de nouveaux facteurs de production, mais encore de l'extension de la culture du coton dans les deux pays qui en fournissent actuellement la majeure partie: nous voulons parler des Etats-Unis et des Indes, où le sol apte à cette culture peut s'étendre encore dans des proportions considérables.

La production cotonnière de l'Égypte devant rester, tout en s'augmentant, relativement restreinte en regard des besoins toujours croissants de la consommation et de la production. 
totales du globe, son prix est donc assuré d'une plus-value continue.

Ainsi, au point de vue purement économique, nous pouvons répéter que la valeur du coton suit le mouvement d'augmentation de la consommation mondiale. (Voir tableau XX et planches XVI et XVII.)

Enfin, au point de vue de la fabrication, nous savons déjà que les qualités particulières du coton égyptien, notamment la longueur et la résistance de sa fibre, lui assurent une place privilégiée qu'il sera impossible de Iui ravir.

Non seulement les pays qui l'emploient déjà augmentent, chaque année, leurs demandes, mais ses acheteurs se multiplient; parmi ces nouveaux venus, il faut citer l'Allemagne, qui absorbe 8 à $90 / 0$ de la production égyptienne, l'Amérique $(8,70 / 0)$, quelques autres pays d'Europe moins importants, et, enfin, chose très remarquable, l'Extrême-Orient, qui, en 1909; acheta pour L. E. 437.774 de coton égyptien.

De quelque côté qu'on envisage la question des prix, on voit que la situation de choix occupée par le coton d'Egypte repose sur des bases trop solides pour être susceptible de recevoir le moindre ébranlement.

Nous pouvons donc conclure qu'on n'a pas à craindre l'avilissement des prix du coton et, partant, de la valeur de la terre.

Supposons cependant que, pour une raison quelconque, une manœuvre de spéculation par exemple, la culture du 
cotonnier cesse d'être rémunératrice pendant une ou deux saisons et que, de ce fait, l'Égypte se voie dans la nécessité de l'abandonner jusqu'àl' assainissement delasituation commerciale; pourrait-elle le faire sans s'imposer de notables sacrifices? Assurément, puisque, encore une fois, la terre à cotonnier est la même terre qui, par rotation, reçoit le blé, l'orge, les fèves, etc.; puisque, en outre, l'exploitation du cotonnier, plante annuelle, n'exige ni installation, ni matériel particulier d'aucune sorte; puisque, enfin, au moment où, suivant le système d'assolement adopté, le tour du cotonnier arriverait, il n'y aurait qu'à lui substituer une autre semence.

En d'autres termes, il n'existe, au point de vue de l'exploitation des terres, aucune différence entre le cotonnier et toute autre culture du pays, hormis la canne à sucre.

Abandonnée, puis reprise, sa culture ne peut amener aucun trouble sérieux dans l'exploitation agricole; sauf une légère différence de rémunération, celle-ci continuerait comme par le passé.

D'ailleurs, nos tableaux $I$ et $I I$ de l'exploitation actuelle. nous ont déjà montré qu'avec les combinaisons culturales dans lesquelles le coton est absent, la rémunération ne diffère pas très sensiblement de celles dont le cotonnier fait la base. En prenant pour prix du kantar le chiffre de P. T. 300 adopté par l'usage en matière d'estimation, on y voit que si, avec le coton, le revenu net de l'hectare est, en moyenne, de 625 francs, avec les produits autres que le coton, ce revenu est de 682 fr. 65 pour la 


\section{Planche XVII}

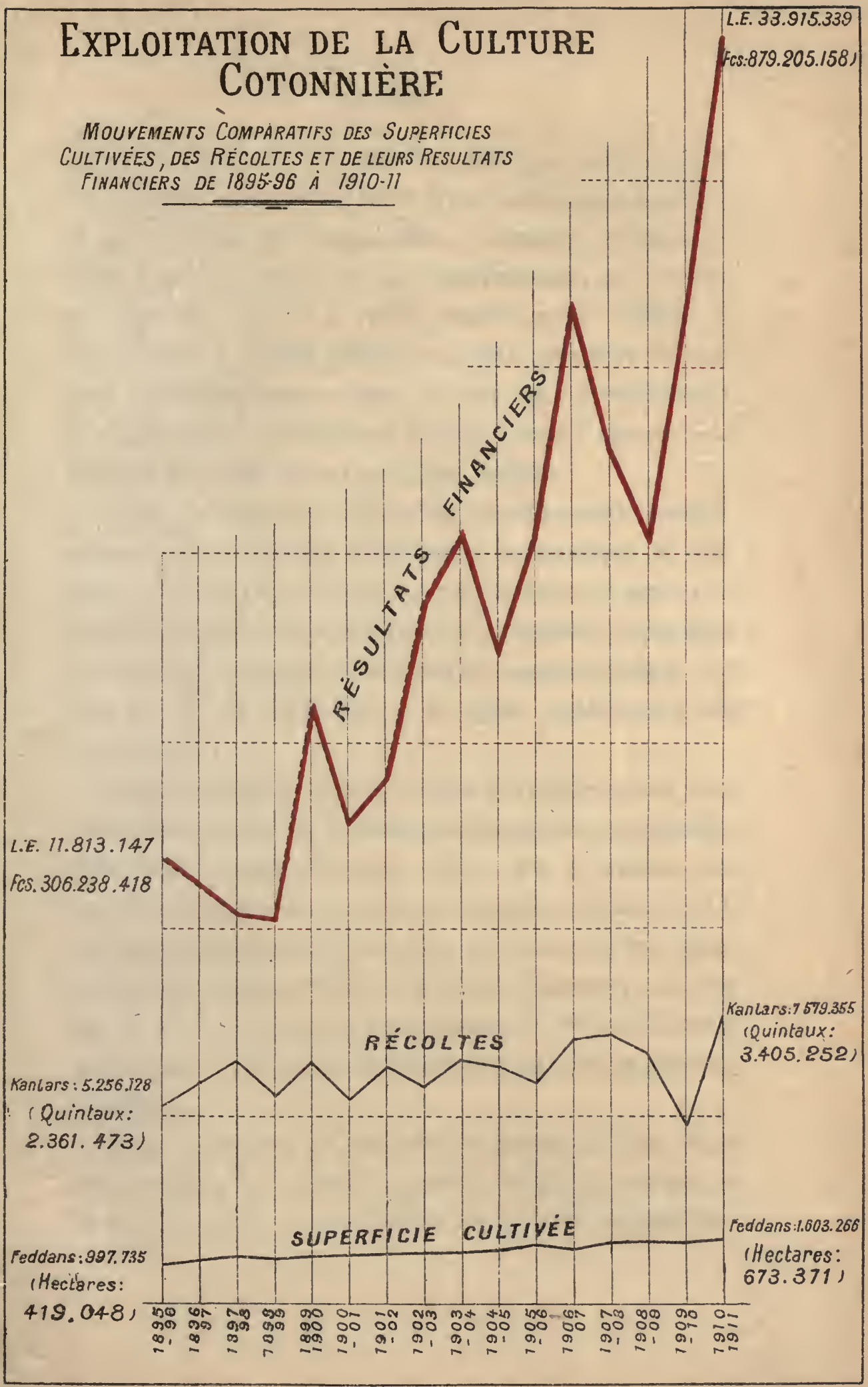



canne à sucre et de 580 fr. 80 pour les céréales.

De même, le prix de la terre, avec la culture cotonnière et sur la base des transactions courantes, s'établit à 9.258 francs l'hectare, et, par capitalisation du revenu, au taux de $60 / 0$, il peut varier entre 10.014 et 10.847 francs, tandis qu'avec un autre système de culture, où n'entre pas le coton, le prix est respectivement de 9.258 et de 11.377 francs pour la canne à sucre, et de 9.258 et de 9.680 francs pour les céréales.

Certes, la culture du coton est extrêmement rémunératrice; elle a modifié la situation économique de l'Égypte, et e'est par elle surtout que ce pays est arrivé au degré de prospérité qui le signale à l'attention ; cependant la fortune de l'Égypte n'est pas liée, comme on essaie très souvent de le persuader, à la seule exploitation du cotonnier.

Ce qui, du reste, montre que, pour nos chiffres, nous nous en sommes tenus à des données aussi modestes que possible, c'est leur comparaison avec ceux des locations. Les bonnes terres, dont il est question dans nos tableaux I et II, se louent communément à raison de 12 ou 14 livres égyptiennes par feddan (740 à 864 francs l'hectare); or, nos calculs nous ont donné un revenu net de 580 à 682 franes par hectare. Ils sont bien inférieurs, on le voit, au prix des locations.

Mais, en dehors des produits de grande culture, il en est d'autres qui peuvent ajouter beaucoup encore au revenu et, partant, à la valeur de la terre égyptienne : 
les légumes, les fruits, les menus produits de ferme. " S'il est une région, fait observer M. Arminjon, où la " culture des légumes et des fruits devrait prospérer et " faire l'objet d'une exportation abondante, c'est bien la " vallée du Nil. Cette culture y est, au contraire, si étran" gement négligée que l'Egypte, loin de satisfaire à ses " propres besoins, n'a pas payé à l'étranger, en 1909, moins " de L. E. 64.040 pour ces articles de consommation, " de L. E. 78.069 pour les pommes de terre, et de "L. E. 43.226 pour les conserves alimentaires végétales ${ }^{1}$. " De son côté, M. Léopold Jullien montre les précieuses ressources que le cultivateur égyptien peut trouver dans la production des fruits et des légumes :

"La culture arbustive, dit-il, peut être largement dé" veloppée : les provinces de Galioubieh et Menoufieh, le "Sud de la Gharbieh, l'Est Béhéra et l'Ouest Charkieh (1. et Dakahlieh offrent plus de 500.000 feddans où l'on " peut produire en grand l'orange, la mandarine, le citron, " la mangue, l'abricot, la pêche, le raisin, etc. Sur le (".reste du territoire, le bananier, le dattier, le figuier, le " néflier peuvent conquérir une large place. Tous ces fruits, «. convenablement traités, peuvent faire l'objet d'une " exportation intéressante vers les marchés européens. " La culture maraîchère est également susceptible d'une " très large extension; citons l'oignon, la tomate, la " pomme de terre. l'artichaut, le chou de Bruxelles, le me- 
«lon, le cornichon. Tous ces produits, convenablement for" cés, pourraient se vendre avantageusement en Europe ${ }^{1}$. "

L'exportation des légumes représente environ 1 ou $20 / 0$. de l'exportation totale, et celle des fruits est insignifiante.

Il semble, d'autre part, que, dans un pays si essentiellement agricole, où la propriété est si morcelée, les menus produits de ferme (beurre, volaille, œufs, lapins, etc.) devraient donner un revenu énorme. Il n'en est rien.

Cependant, l'exemple du Danemark est là pour démontrer qu'une exploitation agricole bien entendue et bien soutenue peut donner, avec des systèmes communs, des résultats satisfaisants à tous égards. Avec ses 2.739.826 hectares de terres cultivées et ses 977.808 ouvriers agricoles, ce petit pays tient non seulement le record du rendement du blé avec ses 27,81 quintaux à l'hectare (Voir le tableau XIX et les graphiques des planches XIV et $X V)$, mais encore il importe annuellement en Angleterre pour plus de $£ 18.000 .000$ de beurre, 'œufs et petit-salé. Dè ces trois chefs, ses exportations, en 1908, ont été de:

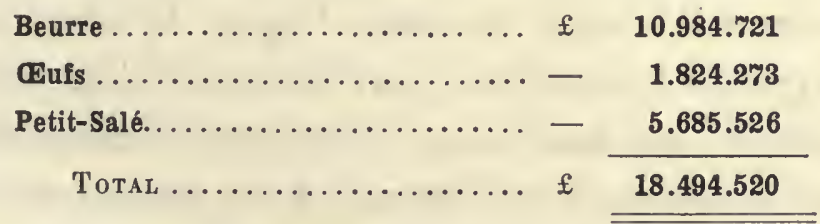

Or l'exportation égyptienne des produits de ce genre se réduit à celle des œufs, qui ne figure que pour L. E. 126.572 dans les chiffres du commerce de 1909,

1. L'Égypte sans le coton (Bulletin de l'Union des Agriculteurs d'Égyple mars 1912 , p. 55). 
et pour L. E. 111.581 dans les chiffres de 1910.

A quoi faut-il attribuer cet état d'infériorité ? Sans doute, pour la majeure part, à l'ignorance, à l'insouciance, à l'incurie du fellah et à l'absence, dans les campagnes, de toute organisation coopérative; mais, nous l'avons dit plus haut, le Gouvernement s'occupe de répandre l'instruction, de favoriser les institutions coopératives; on peut prévoir dès lors que, dans un avenir assez prochain, les fruits, les légumes, les menus produits de ferme viendront augmenter, dans une mesure considérable, les revenus du sol égyptien.

D'autres produits, au premier rang desquels on peut placer le tabac, dont la culture n'est pas aujourd'hui autorisée, pourront très sérieusement les augmenter encore. $\mathrm{Si}$, comme le constate M. Léopold Jullien, toutes les terres d'Egypte ne sont pas aptes à produire un tabac apprécié, il y a au moins 100.000 feddans de terres alluviales propres à donner un produit rémunérateur; et, parmi les autres. cultures, qui semblent devoir réussir, apparaissent la soja, le tournesol, le ricin, la ramie, l'agave, le safran, etc.

Le prêteur hypothécaire peut donc s'affranchir de toute inquiétude, car, dans le cas, absolument invraisemblable, où la culture du coton cesserait d'être rémunératrice, la terre, au point de vue de la valeur du gage, présenterait encore toutes les garanties désirables.

Des considérations exposées dans ce chapitre, aussi bien que dans les chapitres précédents, résultent les conclusions suivantes : 
10 La valeur de la terre égyptienne repose intrinsèquement sur des bases permanentes et inébranlables : nature particulière du sol, clémence et uniformité du climat, action fertilisante du Nil, densité de la population avec, pour conséquence, l'abondance et le bon marché de la main-d'œuvre.

$2^{\circ}$ Cette valeur s'augmentera encore grâce à l'accroissement continu de la population, au morcellement de plus en plus accentué de la propriété, aux grands travaux en cours d'exécution ou en projet (exhaussement de barrages déjà existants, et création de nouveaux barrages, canaux, routes, chemins de fer), à l'amélioration des terres actuellement cultivées, au perfectionnement des méthodes de culture qui, en bien des endroits, sont encore en enfance.

$3^{0}$ L'extension de la culture cotonnière, en Egypte, ne saurait entraîner l'avilissement du prix du coton égyptien, et, par suite, de la valeur de la terre.

$4^{0}$ Si le coton a été jusqu'à présent et promet d'être longtemps encore le facteur principal de la richesse du pays, il ne s'ensuit pas que la prospérité de l'Egypte soit nécessairement subordonnée à sa culture.

Dans l'hypothèse, d'ailleurs inadmissible, où, pour une cause quelconque, cette culture viendrait à disparaître momentanément ou définitivement, on pourrait lui substituer d'autres cultures également rémunératrices.

Done la valeur de la terre égyptienne, loin de diminuer, ne fera que s'augmenter, de telle sorte que le gage hypothécaire offrira toujours le maximum de stabilité et de sécurité. 


\section{CHAPITRE XX}

\section{EXPROPRIATION POUR DÉFAUT DE PAIEMENT}

En Égypte, les propriétés expropriées trouvent facilement des acquéreurs. - Insignifiance, dans les bilans des Sociétés hypothécaires, du chapitre réservé à l'actif immobilier laissé pour compte par suite d'expropriations.

Quand on a sous les yeux les bilans des diverses banques hypothécaires qui fonctionnent en Egypte, on est frappé de l'insignifiance du chapitre réservé à l'actif immobilier laissé pour compte par l'expropriation de débiteurs insolvables.

Comme partout ailleurs, il y a, en Égypte, des débiteurs qui contraignent leurs créanciers à les exproprier pour sauvegarder leurs avances; la seule différence - et elle est capitale - c'est que, dans ce pays, une propriété expropriée ne reste pas longtemps entre les mains de l'expropriateur.

Nous avons constaté plus haut l'attachement passionné du fellah au sol ; nous avons dit comment il emploie exclu- 
sivement son argent en achats de terres et en améliorations foncières générales et quel revenu exceptionnellement rémunérateur il en retire. Il est donc facile de comprendre que, lorsqu'un ou plusieurs lots de terrains sont mis en vente, ils trouvent aussitôt acquéreurs; on peut même ajouter qu'en raison des nombreuses compétitions il se produit le plus souvent des surenchères sensibles.

On conçoit, dès lors, que les Sociétés hypothécaires n'aient eu à faire figurer à l'actif de leurs bilans, par suite d'expropriation, que des immobilisations d'une très faible importance.

En dehors des raisons toutes particulières qui, en ce pays, concourent au maintien et à l'augmentation de la valeur des terres, c'est-à-dire de la valeur du gage, il ne faut pas perdre de vue ce point capital que les Sociétés hypothécaires n'avancent pas plus de 40 à 500,0 de la valeur des immeubles et que leurs risques diminuent d'année en année du fait des amortissements.

Si l'on considère que les Banques hypothécaires européennes, moins heureuses, ont été réduites à devenir propriétaires d'immeubles en nombre si considérable qu'elles ont dû créer, dans leurs Administrations, de dispendieux services uniquement préposés à la gérance de ces immeubles, le contraste entre les Etablissements fonciers d'Egypte et ceux d'Europe n'apparaît-il pas d'une manière saisissante?

En Égypte, comme nous l'avons vu, il n'y a pas à redou- 
ter une diminution de la valeur du sol. Il ne faut pas en conclure, néanmoins, que toutes les terres expropriées se vendent avec bénéfice : ce serait excessif et inexact. Si un prêteur prudent n'avance jamais plus de 50 à 60 0/0 de la valeur de la propriété, tous ne suivent pas cette règle et, lorsqu'il y a perte, on peut affirmer de la façon la plus formelle que l'affaire a été mal engagée dès le début et que l'on a dépassé les limites de la prudence même la plus élémentaire. 


\section{CONCLUSION}

Nous voici arrivé au terme de cette Étude. Quelles conclusions convient-il d'en dégager ?

La nature, nous l'avons vu, s'est plu à combler de ses dons cette terre d'Égypte dont la prodigieuse fertilité est, depuis des siècles, devenue légendaire. Par un phénomène dont nous avons examiné les causes, le sol égyptien, sous la double action d'une eau abondante et d'un climat sans égal, renouvelle sans cesse de lui-même, et pour ains dire automatiquement, les éléments de sa perpétuelle fécondité, et ce sol, cultivé par une race, à coup sûr ignorante, imprévoyante, livrée à l'esprit de routine, mais forte, sobre, endurante, laborieuse, passionnément attachée à la terre, donne jusqu'à deux ou trois récoltes annuelles et produit ce coton sans rival, source principale de la richesse du pays.

Mais, pour mettre sérieusement en ouvre ces puissants éléments de prospérité, il fallait un Gouvernement capable de faire régner partout l'ordre, la justice, la sécurité, de rétablir et de maintenir les finances publiques, d'inspirer confiance aux capitaux étrangers et aux vastes entreprises, de favoriser l'action de la nature par un ensemble de travaux publics, de faire enfin jaillir de ce sol 
privilégié les trésors enfermés dans ses entrailles. Ce Gouvernement, l'occupation anglaise est venue le donner à l'Égypte.

De quel développement est susceptible, aux mains des Anglais, la fortune du pays égyptien, nos statistiques sont là pour en donner une première indication et permettre de prévoir les résultats de l'avenir.

Si grande qu'elle soit à cette heure, elle est bien loin d'avoir atteint à son apogée. Les nouveaux travaux en cours d'exécution ou en projet étendront, dans de vastes proportions, le domaine des terres cultivables, tout en permettant aux propriétaires de transformer des terrains de peu de valeur en des terres de première qualité; le morcellement de la propriété, qui s'accentue chaque jour grâce à l'augmentation de la population, aura pour inévitable conséquence une exploitation plus attentive, plus soigneuse et plus intensive de la terre; le relèvement du niveau intellectuel du fellah, par la diffusion des éléments d'instruction, le disposera à l'emploi de méthodes de culture perfectionnées. Tout cela contribuera à augmenter, c'est-à-dire à doubler ou tripler la production agricole, et, par suite, à assurer au pays, dans un avenir prochain, une prospérité sans égale; cette prospérité sera favorisée encore par la diminution de plus en plus accentuée de la Dette de l'État, par l'absence de ces dépenses militaires 'et navales qui écrasent les nations européennes, par une situation politique qui met l'Égypte à l'abri des crises sociales, des guerres étrangères ou intérieures. 
Un instant, à des esprits mal renseignés ou superficiels la fortune de l'Égypte put, en ces dernières années, paraître quelque peu compromise, mais ce ne fut qu'une fausse apparence. La crise de 1907 a été, nous l'avons expliqué, une simple crise de spéculation qui ne pouvait atteindre et n'a pas atteint les couches profondes, les forces vives du pays. L'orage passé, on s'aperçut qu'il n'avait laissé de ruines que parmi les spéculateurs des grands centres et qu'en somme il avait assaini le terrain des affaires; depuis, l'Égypte poursuit tranquillement le cours de ses heureuses destinées.

Est-ce à dire qu'il n'y ait pas, aujourd'hui encore, quelques ombres au tableau de sa prospérité? Nous gardant d'un optimisme systématique, aussi bien que d'un pessimisme exagéré, nous avons constaté qu'en Égypte comme partout ailleurs il $\mathrm{y}$ avait des maux à conjurer ou à guérir, et que, à côté des progrès réalisés, il en restait beaucoup à accomplir; mais aussi nous avons montré que ces maux étaient guérissables, que ces progrès étaient en bonne voie d'accomplissement, et qu'on pouvait compter sur la ferme volonté des pouvoirs publics, — volonté déjà traduite par des actes nombreux, - pour assurer toutes les réformes nécessaires au plein développement de la prospérité nationale.

Résolu à faire avant tout œuvre de parfaite sincérité, nous n'avons voulu dissimuler aucune difficulté, ni laisser dans l'ombre aucune objection, nous attachant à mettre toutes choses au point, à dissiper toutes les ignorances, à 
détruire tous les préjugés touchant la situation politique et économique du pays.

Ce travail nous a été tout particulièrement inspiré par le souci des intérêts français, car c'est surtout l'épargne française qui alimente la richesse agricole de l'Égypte. Les capitalistes français, il faut qu'on le sache, sont les créanciers de la presque totalité de la dette hypothécaire égyptienne. Or, de l'examen des diverses questions traitées par nous, il ressort, avec la dernière évidence, la confirmation de ce fait que, si les placements hypothécaires sont, en général, les plus sûrs, l'Egypte est de tous les pays du monde celui qui, pour ces opérations, offre la plus grande somme de garanties.

La fertilité proverbiale de son sol, son admirable situation géographique, politique et économique, l'uniformité et la douceur de son climat, l'importance et la valeur de ses produits agricoles, l'extrême faveur dont jouit son coton sur tous les marchés, le caractère de ses habitants, l'exiguïté de son territoire cultivable par rapport à l'accroissement constant de sa population, tout concourt à faire de l'Égypte un champ d'opérations unique pour les placements hypothécaires. 


\section{TABLE DES PLANCHES}

I. - Garte générale de l'Égypte............... 3

II. - Garte $d u$ Nil......................... 7

III. - Agriculture égyptienne. État d'exploitation des

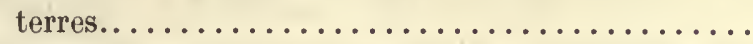

IV. - Agriculture égyptienne. Résultats de l'exploitation des terres par périodes de deux ans. Revenus comparatifs du sol suivant les cultures exploitées dans la période considérée................

V. - Goton égyptien exporté en 1910 (pays importateurs de coton égyptien).................

VI. - Finances égyptiennes. Mouvement des revenus

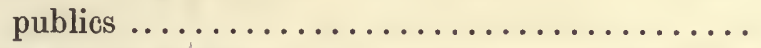

VII. - Résultats généraux du commerce extérieur de l'Égypte de 1884 à $1910 \ldots \ldots \ldots \ldots$. . . . . . .

VIII. - Augmentation de la superficie plantée en coton et de la superficie des cultures de 1893-1894 à $1908-1909 . \ldots \ldots \ldots \ldots \ldots \ldots \ldots \ldots . . . \ldots \ldots$

IX. - Agriculture égyptienne (saison 1908-1909). — Répartition des cultures et des terres.............. 109

X. - Exploitation de la culture cotonnière. Mouvements comparatifs du rendement du feddan, du prix du kantar et du revenu au feddan de 1896-1897 à 1910-1911 ..........................

XI. - Agriculture égyptienne. Les récoltes et leur valeur nette (saison 1909-1910)................

XII. - Engagements hypothécaires. Extraits des bilans des Sociétés par actions. Prêts hypothécaires et ventes à terme..................... 
XIII. - Dette hypothécaire. Rapport de la dette hypothécaire de quelques États à leur fortune immobilière............................... 199

XIV. - Superficies comparées des territoires habités et des terres cultivées...................... 207

$\mathrm{XV}$. - Populations comparées et rendement du blé à l'hectare........................... 215

-XVI. - Production et consommation mondiales du coton. Moyennes comparatives des pays producteurs pour la période $1903-1910 \ldots \ldots \ldots \ldots \ldots$..........

XVII. - Exploitation de la culture cotonnière. Mouvements comparatifs des superficies cultivées, des récoltes et de leurs résultats financiers de 1895-1896 à 1910-1911............................ 


\section{TABLE DES MATIERES}

Introduction . . . . . . . . . . . . . . . . . . .

\section{CHAPITRE PREMIER}

Définition géographique et économique de l'Égypte. - Le Nil, ses origines, sa formation. - La crue ; ses causes. - Régime hydrographique du Nil. - Formation de la vallée du Nil. - Constitution du sol; sa fécondité. - Travavx hydrauliques.........

\section{CHAPITRE II}

\section{climat.}

Conditions climatériques. - Les saisons; leur régularité. - La température; ses moyennes. - Le Khamsin. - Les trois facteurs

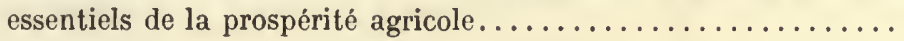

\section{CHAPITRE III}

\section{Produits du sol.}

Les saisons agricoles. - Terres soumises au régime de l'irrigation pérenne. - Etat de leur exploitation et résultats de cette exploitation par termes de deux ans. - Combinaisons culturales ;

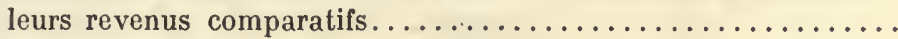

\section{CHAPITRE IV}

\section{Le Coton.}

Son introduction en Égypte (1820). - Son acclimatation. - Il est le premier produit du genre. - Rendements comparés de l'Égypte et de l'Amérique. - Qualités spéciales du coton égyptien; sa prime sur le coton américain. - Ses emplois. - Son con-

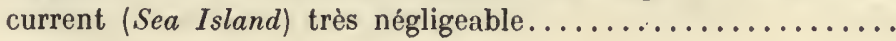




\section{CHAPITRE V}

\section{Le Fellah.}

Ses qualités et ses défauts. - Son amour de la terre. - Comment il place son argent. - Augmentation de la petite propriété. Mesures prises pour élever le niveau intellectuel du Fellah, améliorer son état moral et mettre en œuvre toute son énergie....

\section{CHAPITRE VI}

\section{Territoire et Population.}

Étendue totale de la vallée du Nil. - Terres cultivées et incultes. - Densité et augmentation constante de la population. - Composition de la population rurale et urbaine. - Répartition du sol. - Nombre élevé des petits propriétaires.............

\section{CHAPITRE VII \\ État Politique.}

Suzeraineté de la Turquie. — Statut international. — Corps élus. - Divisions administratives. - Bienfaits de l'occupation

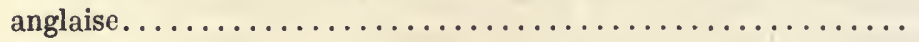

\section{CHAPITRE VIII}

\section{Finances.}

Revenus publics. - Augmentation continue des excédents de

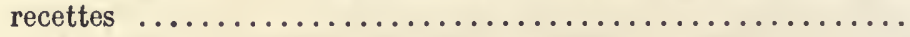

\section{CHAPITRE IX}

\section{Impôts.}

Leur nature. - Impôt par tête d'habitant. - Sa diminution constante. - Causes de cette diminution...............

\section{CHAPITRE $\mathrm{X}$}

\section{Etat judiciaire.}

Juridiction mixte. - La raison de son institution. - Son orga-

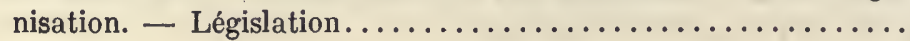




\section{CHAPITRE XI}

\section{État économique. - Commerce extérieur.}

Balance du commerce extérieur. - Progression continue des importations et des exportations. - Majoration à apporter dans la valeur des exportations par suite des sous-estimations de

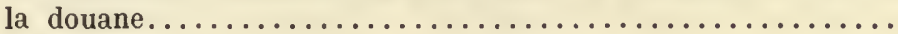

\section{CHAPITRE XII}

\section{La Crise égyptienne.}

Ses causes psychologiques et économiques. - Spéculation effrénée sur les terrains ruraux et urbains. - Afflux énorme des capitaux étrangers depuis l'accord franco-anglais de 1904.- Abus de crédit. - Conséquences de la crise. - Les richesses naturelles du pays sont restées indemnes. - Les dernières faillites; opinion du Conseiller financier..........................

\section{CHAPITRE XIII}

\section{Monoculture.}

Pourquoi on a parlé de monoculture. - Statistique comparative des superficies occupées par les différentes cultures; le coton vient en deuxième rang après le maïs et n'entre dans l'ensemble des cultures que pour 20,83 0/0. - Différence existant entre les pays à vignobles, comme la France, si terriblement éprouvée

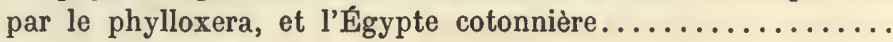

\section{CHAPITRE XIV}

\section{Diminution dans le rendement du coton.}

Il a diminué de 20,30 0/0 à l'hectare. - Commentaires erronés de M. Paul Deschanel et réfutation par la Chambre de Commerce française d'Alexandrie. - Causes principales de la diminution : l'excès d'humidité du sol; les parasites. - Autres causes : dégénérescence de la graine; insuffisance des engrais......... 


\section{CHAPITRE XV}

\section{Réformes et Remèdes.}

Contre l'humidité du sol : extension et perfectionnement du drainage. - Contre l'abus des irrigations : meilleur emploi des eaux d'arrosage. - Contre les parasites : application méthodique des lois, décrets et arrêtés relatifs à leur destruction. Résultats déjà obtenus. - Contre l'impureté des graines : sélection des graines; extirpation des variétés de cotonniers inférieures et recherche de variétés perfectionnées. - Réformes morales : amélioration de la condition sociale du fellah par la diffusion des éléments d'éducation. - Création d'écoles d'agriculture. - Station agronomique au Caire. - Fermes expérimentales. - Comité supérieur de l'Agriculture. - Associations agricoles de prévoyance, de production, de consommation, d'assistance. - Banques mutuelles de crédit..............

\section{CHAPITRE XVI}

\section{La Stabilité politique.}

L'Angleterre abandonnera-t-elle l'Égypte? - Elle ne l'abandonnera pas de son plein gré, et son expulsion, soit par une révolution intérieure, soit par l'intervention d'une ou plusieurs puissances européennes, n'est pas à craindre. - Mais, si elle évacuait l'Égypte, l'Europe ne manquerait pas d'intervenir pour le maintien de ses garanties et la sauvegarde de ses intérêts. - La dette de l'Égypte envers l'Europe est trop élevée pour que l'Europe s'en désintéresse. - En cas d'indépendance, ou l'Égypte sera à la hauteur de sa tâche, ou elle retombera sous le contrôle des puissances européennes. - Rien ne

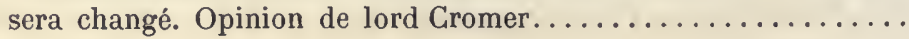

\section{CHAPITRE XVII}

\section{Fortune immobilière de l'Egypte.}

Évaluation de la propriété rurale d'après l'impôt foncier, la valeur locative et le revenu des terres. - Évaluation de la propriété urbaine au moyen de la capitalisation du revenu des loyers, accusé par l'impôt. - Valeur totale de la fortune immobilière, déduction faite de l'impôt capitalisé et des wakfs (biens de main-

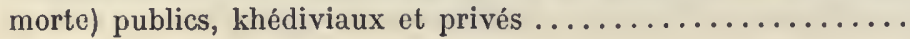




\section{$-245-$ \\ CHAPITRE XVIII \\ Dette hypothécaire de l'Égypte. Son rapport avec la valeur de la propriété.}

Prêts hypothécaires : engagements par prêts sur la propriété et engagements par privilège du vendeur sur les ventes à terme. - Évaluation de la dette hypothécaire égyptienne. - Son rapport avec la fortune immobilière de l'Egypte. - Sa comparaison avec celles des autres pays. - Raisons pour lesquelles l'écart entre la valeur de la fortune immobilière et celle de la dette hypothécaire s'augmentera encore...............

\section{GHAPITRE XIX}

\section{Stabilité et augmentation de la valeur du gage.}

Augmentation de la valeur de la propriété, assurée par l'accroissement continu de la population, de la productivité du sol, de la valeur vénale de ses produits, notaimment du coton. Résultats à attendre de la culture intensive. - Raisons pour lesquelles il n'y a pas lieu de craindre l'avilissement du prix du coton mais de prévoir, au contraire, sa plus-value constante. - La fortune de l'Égypte n'est pas liée, d'ailleurs, à la seule culture cotonnière. En cas d'abandon de cette culture, facilité de lui en substituer d'autres également rémunératrices. Valeur vénale et valeur locative de la terre avec ou sans la culture du cotonnier. - Conclusion en faveur de l'augmentation de la valeur de la terre et, par suite, de la stabilité et de la sécurité

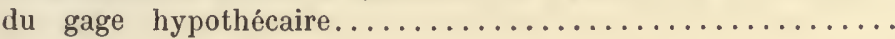

\section{CHAPITRE XX}

\section{Expropriation pour défaut de paiement.}

En Égypte, les propriétés expropriées trouvent facilement des acquéreurs. - Insignifiance, dans les bilans des Sociétés hypothécaires, du chapitre réservé à l'actif immobilier laissé pour compte par suite d'expropriations.............. 232

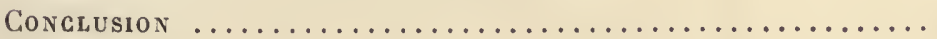

Vue Puḱdoye, - Grav.-Imprimeur, 101, rue des Boulets. Pakis (Xle), 


?.

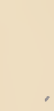

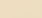



